\title{
A FEMINIST CRITIQUE OF CLINICAL PSYCHOLOGY TRAINING PROGRAMMES IN AOTEAROA NEW ZEALAND
}

Heather Anne Barnett

A thesis submitted to Victoria University of Wellington in fulfilment of the requirement of the degree of Doctor of Philosophy in Women's Studies

Victoria Univesity of Wellington

2004 
Dedicated to Tui

and

my nieces, Kas and Bonnie 


\section{Abstract}

This thesis provides a feminist critique of clinical psychology training programmes in Aotearoa New Zealand. Taking a feminist standpoint epistemological position I argue that most clinical psychology training programmes do not adequately incorporate analyses of gender, or convey an understanding of the connection between women's sociopolitical positioning and psychological health. The central focus of the thesis is to examine the way analyses of gender and other relations of power are included in clinical psychology curricula. The curriculum is important because it reflects and reproduces dominant psychological knowledge and impacts on the way clinical psychology is practiced.

To examine these issues, questionnaires were administered to fifty clinical psychology students and twelve academic clinical psychology staff in six Aotearoa New Zealand universities. Some of these participants also completed a further interview. Additional interviews were undertaken with eleven feminist clinical psychologists. Taking a feminist methodological position, my research involved systematic thematic analysis using a constant comparative approach, as well as the use of quantitative analysis. The research findings, in conjunction with attention to the broader ontological, epistemological, theoretical and methodological foundations of the clinical psychology curriculum, highlight the ways in which psychology's dominant discourses minimise the effects of gendered structural relations and continue to marginalise women's experiences, realities and material lives. As such, an underlying argument of this thesis is that clinical psychology participates in the reproduction of gender inequities, and may perpetuate rather than alleviate the 'psychological' difficulties women experience. The thesis concludes by offering ideas for the future development of clinical psychology training which takes a critical-realist approach to the construction of knowledge, offers multi-level epistemological analyses grounded in the diverse experiences of women and other marginalised groups, and locates gender and other analyses of power as central to the clinical curriculum. 


\section{Acknowledgements}

To my parents, Nancy and Allan, who passed away during the course of this research thank you for your constant love and inspiration, for being different, for always believing in me and for your continued presence in my life.

Special thanks to the clinical psychology directors, staff and students who participated in this research - thank you for your time, frankness and generosity, and the chance to make a difference.

To the feminist clinical psychologists - thank you for contributing to an ongoing dialogue, for your generosity and time, and reminding me why the research is important.

To Dr Jenny Neale who supervised my work for the duration of this thesis - thank you for being a constant anchor, for endless reading and feedback, for your patience, perseverance and commitment, for providing a great place to work, for your faith in the process and not least, your eternal optimism.

To Associate-Professor Kay Morris-Matthews whose arrival as Head of Women's Studies was timely - thank you for your astuteness, encouragement and understanding, for thorough feedback, sound advice and the mammoth task at the end - and most importantly - for still being here.

To Phillida Bunkle who was Head of Women's Studies when I first enrolled - thank you for believing in the project, for instilling courage, for your cleverness, insights and reflections, for your commitment to women's health and being unafraid to challenge the establishment.

To Dr Nicola Gavey, Senior Lecturer in Psychology, University of Auckland, who I met part way through the research - thank you for your warmth, support and encouragement, and for your expertise and feedback.

To Lesley Hall who provided interim supervision when Phillida left for Parliament. Thank you for your input and for your generosity and willingness to share information when I first started the PhD.

To Linda Lee who transcribed many interviews and assisted with the final format thank you for your expertise, patience, generosity and thoughtfulness.

To Janey Bedggood - thank you for your sustained support and for being a great person to have in the department during the early days of the research.

To Pine Southon - thank you for all the ways you were wonderful, for your aroha and spiritual sustenance.

To Dr Annie Potts - thank you for your enthusiasm for the research, for generous support and feedback on some early writing. 
To Shirley Roberson - thank you for feedback, and interesting and critical discussions about psychology.

To Anaria Tangahou and Dr Judith Galtry - thank you for your loyalty, for speaking out, for lively discussions and great humour.

To Justin Cargill - thank you for accommodating many library requests, for thinking outside the square and having great wit. Also, thanks to the people behind the scenes who promptly and efficiently processed numerous interloans.

To VUW Disability Support Services - Specia l thanks to Joanna Clover, Vanessa Shoulton, Daphne Lawless and especially, Rowan Brookes for patience and perseverance.

I am grateful to the VUW Student Hardship Service, and in particular, Maria Goncalves-Rorke for sensitivity and understanding.

Thank you to the VUW Faculty of Humanities and Social Sciences Grants Committee for providing a financial contribution to the research.

To Melanie Heron, Megan Pearce, Lisa Focus and Kahu Karaitiana - thank you for being such great people, for going the extra mile and for your immense generosity.

Three special people patiently and generously helped me through a long period of illness. Many thanks to Dr Jill Shepherd, Shelley Goldsmith and Deepa Ranchod. Very special thanks Deepa for your cleverness, optimism, and generosity, and for taking an holistic approach to healing.

Many people gave time, energy and support at various stages of the process - my appreciation to Avril Bell, Margaret Earle, Lindsay Eaton, Athena Gavriel, Celia James, Ann Walker, Rosie Walsh, Tim Best, Graeme Leslie, Eddie Coker, Bob Tristram. Special thanks to Josie Roberts; and Liz Thompson and Warwick Hadwin.

Special thanks to the school whanau, especially Liz Patara and Sue Clements.

To my dear friend and kin, Mary Garner, and 'the Rotorua team'- thank you for your generosity, nurturance and unstinting support.

To Kath, Pete and $\mathrm{Col}$ - our diversity is a richness we can learn from. Thanks Kath for new beginnings, Pete for wonderful memories, and Col for your love, loyalty and support throughout.

To Dr Vicki Culling and Lesley Patterson - The PhD Group - from whom I learnt so much. Thank you for your support across many domains of my life, for your enthusiasm and encouragement, for inspiring discussions, sound feedback and for being such great scholars, while also having your feet planted firmly on the ground. Vicki, thankyou for shared beginnings as we read our way through feminist theories and interdisciplinary epistemological frameworks. Lesley, my heartfelt thanks for your immense generosity, commitment, thoughtfulness and constant support throughout the final year. 
To my extended family - Frances Anderson, Lesley Ayland, Robyn Bailey, Ann Fleming, Tighe Instone, Wendy Kelly, Dr Tess Moeke-Maxwell, Annie Muirgen, Di Sidwell, Jane Siene and not least, Elizabeth Smith - thank you for the many ways you supported and nurtured Effie and I through this long journey. Thank you especially for your thoughtfulness during times of grief and for your patience while I was ill. Your generosity, humour and above all, your love, made it possible. Special thanks to those of you who shared ideas, read pieces of work and gave great feedback. Particular thanks to those of you who provided Effie with a home away from home - I couldn't have done it without you. Some of you did all of these things, at short notice and under difficult circumstances - thank you.

Finally, and most importantly, Effie - thank you for being a constant joy, for your sensitivity, patience and lovingness, and your delightful sense of humour. 


\section{Table of Contents}

ABSTRACT

ACKNOWLEDGEMENTS iv

TABLE OF CONTENTS vii

INTRODUCTION

Positioning the Research $\quad 5$

Motivation for the Research $\quad 7$

The Structure and Context of Clinical Psychology Training Programmes $\quad 8$

PGDipClinPsych Structure $\quad 9$

Clinical Programme Staffing $\quad 12$

$\begin{array}{lr}\text { Clinical Programme Entry Criteria } & 12\end{array}$

Assessment and Examination $\quad 13$

Accreditation and Governance 13

Terminology Used in the Thesis $\quad 15$

Clinical Psychology Training Programmes $\quad 15$

$\begin{array}{lr}\text { Clinical Practice and Psychological Practice } & 15\end{array}$

Describing Women's Experiences $\quad 16$

Psychological Health 16

$\begin{array}{lr}\text { Thesis Structure } & 17\end{array}$

CHAPTER ONE

Psychology, Feminism, and Knowledge $\quad 22$

Positivism and the Construction of Knowledge in Psychology 23

The Political and Regulatory Nature of Positivist Psychology - An Example 26

Science, The Media and the Construction of Knowledge 27

The Impact of Positivist Science on the Construction of Knowledge about Women 27

$\begin{array}{ll}\text { Positivist Science and Individualism } & 28\end{array}$

Positivism, Individualism and Clinical Psychology 30

Clinical Language and the Diagnostic and Statistical Manual of Mental Disorders 32

The Scientist-Practitioner Model of Clinical Psychology

Critiques of the Scientist-Practitioner Model $\quad 36$

A Critical-Practitioner Proposal $\quad 39$

$\begin{array}{lr}\text { Conclusion } & 39\end{array}$

CHAPTER TWO 41

The Dominance of Cognitive-Behaviour Theory and Therapy in Clinical Psychology 41 The Nature and Pervasiveness of Cognitive Behavioural Therapy 43

$\begin{array}{lr}\text { Critiques of Cognitive Behaviour Therapy } & 48\end{array}$

$\begin{array}{ll}\text { Epistemological Issues } & 49\end{array}$

$\begin{array}{ll}\text { Cognitive-Behaviour Therapy and Individualism } & 50\end{array}$

The Primacy of Cognitions and Behaviours $\quad 52$

The Process of Therapy $\quad 53$

Marginalising Women's Gendered Social Position $\quad 54$

$\begin{array}{ll}\text { Eclectic Approaches to Clinical Psychology } & 57\end{array}$

Conclusion $\quad 58$

$\begin{array}{lr}\text { CHAPTER THREE } & 59\end{array}$

$\begin{array}{lr}\text { Feminist Psychologies } & 59\end{array}$

$\begin{array}{ll}\text { Contemporary Feminist Psychologies } & 60\end{array}$

$\begin{array}{ll}\text { Difference and Diversity } & 63\end{array}$

The Local Context

The Treaty, Bicultural Developments, Māori Knowledges and Critiques of Psychology 67

Development of Feminist Psychologies in Aotearoa New Zealand 73 
Feminist Critiques of Clinical Psychology

'Clinical Psychology Training: Training in Oppression?'

Responses to Williams and Watson's (1991b) Survey 80

Recent Feminist Criticisms of Clinical Psychology 81

Conclusion 84

$\begin{array}{ll}\text { CHAPTER FOUR } & 86\end{array}$

$\begin{array}{lr}\text { Feminist Standpoint Epistemology } & \mathbf{8 6}\end{array}$

$\begin{array}{lr}\text { Key Features of Feminist Standpoint } & 88\end{array}$

$\begin{array}{lr}\text { Experience } & 89\end{array}$

Difference $\quad 92$

$\begin{array}{ll}\text { Realism-Relativism } & 94\end{array}$

Utilising Nancy Hartsock's Version of Feminist Standpoint Epistemology 95

Macro Power and the Collective Subject 96

Hartsock's Notion of Privileged Knowledge $\quad 98$

$\begin{array}{lr}\text { Criticisms of Feminist Standpoint } & 99\end{array}$

$\begin{array}{lr}\text { Realism } & 99\end{array}$

Privileged Knowledge $\quad 100$

$\begin{array}{ll}\text { Essentialist Notions of 'Woman' and Categories of Difference } & 101\end{array}$

$\begin{array}{ll}\text { Jane Ussher's Material-Discursive-Intrapsychic Approach } & 102\end{array}$

Taking a Feminist Standpoint and Critical-Realist Position 103

$\begin{array}{ll}\text { Conclusion } & 104\end{array}$

$\begin{array}{ll}\text { CHAPTER FIVE } & \mathbf{1 0 6}\end{array}$

$\begin{array}{lr}\text { Feminist Methodologies } & 106\end{array}$

$\begin{array}{ll}\text { Feminist Research Practice } & 106\end{array}$

$\begin{array}{ll}\text { Contemporary Feminist Debates About Research } & 108\end{array}$

$\begin{array}{ll}\text { Beyond the Qualitative/Quantitative Dichotomy } & 108\end{array}$

$\begin{array}{ll}\text { Interviewing } & 112 \\ \end{array}$

Interviewing Anti-Feminist Participants and Interviewing 'Up' 113

Issues of Reciprocity 116

$\begin{array}{ll}\text { Ethics } & 118\end{array}$

$\begin{array}{lr}\text { The Treaty of Waitangi } & 124\end{array}$

Pakeha Research with Māori Participants $\quad 125$

Ethical Approval 126

$\begin{array}{lr}\text { Informed Consent } & 126\end{array}$

$\begin{array}{ll}\text { Conclusion } & 127\end{array}$

$\begin{array}{lr}\text { CHAPTER SIX } & 128\end{array}$

$\begin{array}{lr}\text { The Research Process } & 128\end{array}$

$\begin{array}{lr}\text { Participants } & 130\end{array}$

$\begin{array}{ll}\text { Access to Students } & 131\end{array}$

$\begin{array}{ll}\text { Access to Clinical Psychology Staff } & 133\end{array}$

Access to Feminist Clinical Psychologists 133

$\begin{array}{ll}\text { Questionnaires } & 134\end{array}$

$\begin{array}{ll}\text { Questionnaire construction and revision } & 134\end{array}$

$\begin{array}{ll}\text { Questionnaire pilot } & 135\end{array}$

$\begin{array}{ll}\text { Questionnaire administration - Students } & 136\end{array}$

$\begin{array}{ll}\text { Questionnaire administration - Staff } & 137\end{array}$

$\begin{array}{ll}\text { Pseudonym Allocation } & 137\end{array}$

$\begin{array}{lr}\text { Interviews } & 138\end{array}$

$\begin{array}{ll}\text { Interviews - Students and staff } & 138\end{array}$

$\begin{array}{lr}\text { Interviews - Feminist Clinical Psychologists } & 140\end{array}$

$\begin{array}{lr}\text { Transcripts } & 140\end{array}$

$\begin{array}{lr}\text { Transcripts - All Participants } & 140\end{array}$

$\begin{array}{ll}\text { Reflexivity } & 141\end{array}$

Trustworthiness of the Research $\quad 142$

Data Analysis $\quad 142$

$\begin{array}{ll}\text { Conclusion } & 145\end{array}$ 
$\begin{array}{ll}\text { Meanings of Gender and the Inclusion of Gender Education } & 147\end{array}$

$\begin{array}{ll}\text { Demographic Information } & 148\end{array}$

$\begin{array}{lr}\text { Student Participant Group } & 149\end{array}$

$\begin{array}{ll}\text { University Staff Participant Group } & 152\end{array}$

Feminist Clinical Psychologists Participant Group 153

$\begin{array}{ll}\text { Meanings of Gender } & 154\end{array}$

$\begin{array}{ll}\text { Summary } & 160\end{array}$

$\begin{array}{ll}\text { The Inclusion of Gender Education } & 160\end{array}$

$\begin{array}{ll}\text { The Nature and Scope of Gender Education } & 161\end{array}$

Whether Any Education About Gender Issues was Included $\quad 162$

$\begin{array}{ll}\text { Time Allocation } & 162\end{array}$

How Gender Content is Included $\quad 163$

$\begin{array}{ll}\text { Examples of Education about Gender } & 166\end{array}$

$\begin{array}{ll}\text { Content Primarily Relevant to Women } & 168\end{array}$

Power Differences Between the Groups 'Men' and 'Women' 170

$\begin{array}{ll}\text { Conclusion } & 172\end{array}$

\section{CHAPTER EIGHT}

$\begin{array}{lr}\text { Gender Diversity Education } & 174\end{array}$

The Inclusion of Gender Education Relating to Diversity 175

$\begin{array}{ll}\text { Conclusion } & 186\end{array}$

$\begin{array}{lr}\text { CHAPTER NINE } & 188\end{array}$

$\begin{array}{lr}\text { Analyses of Power - Example One: The Treaty of Waitangi } & 188\end{array}$

The Treaty of Waitangi, Māori Knowledges and Bicultural Practices in Psychology 189

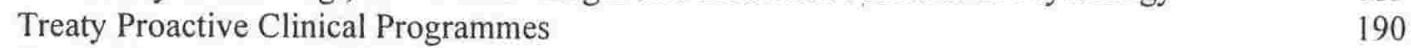

$\begin{array}{ll}\text { Treaty Non-Proactive Clinical Programmes } & 197\end{array}$

$\begin{array}{ll}\text { Conclusion } & 201\end{array}$

$\begin{array}{lr}\text { CHAPTER TEN } & 203\end{array}$

Analyses of Power - Example Two: Men's Violence Against Women 203

Education Relating to Male Violence $\quad 204$

Student and Staff Participants' Understanding of Power in Relation to Male Violence 211

$\begin{array}{ll}\text { Contributors to Male Violence } & 214\end{array}$

$\begin{array}{ll}\text { Difficulties Leaving Violent Relationships } & 217\end{array}$

$\begin{array}{ll}\text { Application of Knowledge About Male Violence and Exploitation } & 218\end{array}$

$\begin{array}{ll}\text { Conclusion } & 218\end{array}$

\section{CHAPTER ELEVEN}

Women and Psychological Health: Barriers to the Inclusion of Gender Education 220

Women's Sociopolitical Position and Psychological Health 220

Adequacy of Education About Women's Position and Psychological Health 225

$\begin{array}{ll}\text { Summary: Women's Sociopolitical Position } & 227\end{array}$

Appraisals of the Importance of Education about Gender $\quad 228$

$\begin{array}{ll}\text { The Adequacy of Education about Gender } & 229\end{array}$

Summary: Adequacy of Education about Gender $\quad 234$

Barriers to the Inclusion of Gender Education 235

Summary: Barriers to the Inclusion of Education About Gender 244

Conclusion $\quad 245$

\section{CHAPTER TWELVE $\quad 247$}

$\begin{array}{ll}\text { The Theoretical Orientation of Clinical Psychology Training } & 247\end{array}$

The Dominance of Cognitive-Behaviour Therapy 248

Rationale for the Dominance of Cognitive Behaviour Therapy 249

Criticisms of the Dominance of Cognitive Behaviour Therapy 250

$\begin{array}{ll}\text { An Eclectic Approach to Clinical Training } & 257\end{array}$

Feminist Clinical Psychologists' Endorsement of Eclectic Models of Training 259

The Inclusion of Feminist Knowledges and Perspectives in Clinical Training 261

$\begin{array}{ll}\text { Conclusion } & 268\end{array}$ 
Future Directions for the Development of Clinical Psychology Training 274 Jane Ussher's Material-Discursive-Intrapsychic Model 275

$\begin{array}{ll}\text { Frameworks for Doing Psychology Critically } & 276\end{array}$

$\begin{array}{ll}\text { Treaty of Waitangi Frameworks } & 278\end{array}$

$\begin{array}{lr}\text { Strategies for Feminist Curriculum Development } & 279\end{array}$

Williams and Watson's Workshop - Recommendations for Change $\quad 281$

$\begin{array}{ll}\text { Institutional Change } & 284\end{array}$

Limitations of my Research/Suggestions for Future Research 285

$\begin{array}{ll}\text { Conclusion } & 289\end{array}$

$\begin{array}{lr}\text { BIBLIOGRAPHY } & 290\end{array}$

$\begin{array}{lr}\text { APPENDIX A } & 323\end{array}$

$\begin{array}{lr}\text { APPENDIX B } & 325\end{array}$

$\begin{array}{ll}\text { APPENDIX C } & 327\end{array}$

$\begin{array}{ll}\text { APPENDIX D } & 342\end{array}$

$\begin{array}{lr}\text { APPENDIX E } & 348\end{array}$

$\begin{array}{lr}\text { APPENDIX F } & 350\end{array}$ 


\section{Introduction}

Clinical psychology commonly defines itself as 'the science of the mind and human behaviour' and is integrally concerned with the 'scientific' pursuit of knowledge. The epistemological basis of clinical psychology rests on the premise that knowledge or 'truth' exists independently from the knower and can be 'discovered' using objective research methodologies. Clinical psychology is also grounded in an individualist philosophical tradition that produces knowledge about people as if such knowledge is separate from the sociopolitical context. It also assumes that scientific knowledge is universal. Furthermore, clinical psychology's historical connection with psychiatry has meant that 'psychological' knowledge is infused with the concepts and language of a medical model (Albee, 2000). Although clinical psychology as a profession has, to some extent, shifted away from medical theoretical frameworks, it continues to endorse a positivist science philosophy and the taxonomic systems of a psychiatric paradigm (Hare-Mustin and Marecek, 1997; Ussher, 1991, 1992). In addition, the increasing medicalisation and corporatisation of mental health care has impinged on clinical psychologists' autonomy in terms of forcing adherence to a medical model and psychiatric diagnoses (Albee, 2000; Hare-Mustin and Marecek, 1997). In this regard, Albee (2000: 2) argues that "by aligning itself with the conservative view of causation, clinical psychology has joined the forces that perpetuate social injustice'. Although many individual clinical psychologists may no longer regard people's distress as biological or genetic, or as an 'illness' or 'disease', mainstream clinical psychology continues to perpetuate an individualist, medical/organic understanding of human distress that takes only marginal account of the role of structural relations and the sociopolitical context in shaping peoples experience (Albee, 2000; Hare-Mustin and Marecek, 1997). ${ }^{2}$

\footnotetext{
' See for example, promotional material provided at the 'Psychology Conference', August 29 September 2, 1998. The New Zealand Psychological Society, New Zealand College of Clinical Psychologists and School of Psychology, Victoria University of Wellington.

${ }^{2}$ It is also noted that in some quarters of clinical psychology there is renewed interest in biological theories and moves toward medical prescribing powers (Hare-Mustin and Marecek, 1997).
} 
This positivist science dominant approach to knowledge and 'reality' offers a limited understanding of human life, reflecting the interests and values of dominant cultural groups. Many clinical psychologists take a reflexive approach to their work, and are critical of clinical psychology's rigid adherence to a positivist science framework, but the general discourse of clinical psychology remains strongly positivist. Jane Ussher (1992: 62), a feminist critical psychologist, notes the way science is 'practised, the theories it has reified, and the individuals it has empowered, may not serve in the interests of women or other disempowered groups'.

Feminist and other critical psychologists have challenged clinical psychology and the wider discipline of psychology for ignoring the way power relations and the sociopolitical context shape people's lives, 'realities' and material worlds. ${ }^{3}$ In addition, psychology has been charged with failing to acknowledge its own institutional power in constructing everyday meaning and knowledge about women's lives (Burman, 1996a, 1996b; Hare-Mustin and Marecek, 1997). Erica Burman (1996a: 2) highlights 'the gendered agendas that structure the shape of the discipline and are performed by its academic, clinical, educational and research practices'. Feminists have argued that clinical psychology not only ignores women's experiences, but often produces distorted accounts of women's lives and realities (Hare-Mustin and Marecek, 1997; Ussher and Nicolson, 1992). Critics suggest that by ignoring the gendered nature of social life and other power relations, clinical psychology contributes to, and maintains, inequitable social arrangements that dis/advantage particular social groups.

Thus, while clinical psychology claims to improve health and wellbeing, its individualism and methodological naturalism ${ }^{4}$ can lead to a denial of the relationship between gendered structural relations and women's health. That is, clinical

\footnotetext{
${ }^{3}$ While the focus in this thesis is on clinical psychology, many of the arguments and much of the literature that informs this thesis are derived from critiques of the wider discipline of psychology. Because clinical psychology remains strongly aligned with the positivism and empirical traditions of mainstream psychology, and is one of the more conservative branches of mainstream psychology, criticisms of the latter are also applicable to the former.

${ }^{4}$ This term is used by Ussher (2000b: 209) to refer to an emphasis on the homogenous use of hypothetico-deductive methodologies, and on standardized, validated measures of both dependent and independent variables - that is, mental health problems and their causes - through an emphasis on objectivity, reliability, and research replicability'.
} 
psychology's insistence on locating individuals as the source of psychological difficulties, as well as the site for change, can work against women's interests and cause women harm.

Internationally, feminist psychologists have examined the absence of gender analyses and feminist knowledges in clinical psychology training (Bekker, 1991; Ussher and Nicolson, 1992; Williams and Watson, 1991b). In Aotearoa New Zealand, Māori writers have addressed the monocultural and colonising nature of clinical psychology's theories, methodologies and practices (Paterson, 1993; Lawson-Te Aho, 1994; MoekePickering, Paewai, Turangi-Joseph and Herbert, 1996; Nathan, 1999). Indigenous writers and women of colour internationally have addressed similar issues in relation to clinical psychology (LaFromboise, Choney, James and Running Wolf, 2002; MoekeMaxwell, 2003; Moreton-Robinson, 2000; Trimble, 1991; Vazquez, 1991), including feminist psychology (Espin and Gawalek, 1992; Greene and Sanchez-Hucles, 1997). In addition, there have been occasional publications relating to students' experiences of clinical psychology training (O'Donovan, Dyck and Bain, 2001; Pilgrim and Treacher, 1992; Vickers, 1991) and feminist students have discussed the more general arena of graduate psychology (Baker's Dozen, 1997). However, there appears to be an absence of formal or systematic research that focuses on the way gender is conceptualised and included in clinical psychology training programmes in Aotearoa New Zealand.

In this thesis I argue that the dominant discourse of clinical psychology, and the epistemological and theoretical approaches taken in most clinical psychology training programmes, continues to marginalise gender and analyses of power, and the interrelationship between structural relations and sociopolitical context, and psychological health.

The research examines the way concepts of gender are included in clinical psychology training programmes at six universities in Aotearoa New Zealand, focusing on curriculum content and education that occurs within the university context. ${ }^{5}$ While

\footnotetext{
${ }^{5}$ At the time this research was undertaken (1996-1997) there were only six clinical psychology training programmes. These were located at the universities of Auckland, Waikato, Massey, Victoria, Canterbury and Otago.
} 
taking gender as a focus, I acknowledge that gender is always mediated by other dimensions of power such as class, 'race', ethnicity, sexual orientation, (dis)ability, and age. I also recognise that women's experiences are diverse, and that for many women, dimensions of power such as race or class are more pressing sites of inequality and injustice (Brown, 1994; Cram, 2001a). More recently, I have come across critical work advancing conceptual frameworks for integrating multiple sites of inequality (Jenkins and Pihama, 2001; Madden and Hyde, 1998; Weber, 1998). However, my focus on gender in this thesis was a means to manage the research and contribute to debate on the way clinical psychology training represents women and understands the psychological effects of gender inequalities and inequities. The research also addresses relations of power in terms of the Treaty of Waitangi and diversity of experience, identity and sociocultural context for different groups of women. While recognising the broader context in which knowledge is produced, I identify clinical psychology training programmes as a key site of power in the construction and legitimation of 'psychological' knowledge, which has a direct bearing on all women's lives.

The title of the thesis reflects the objective of providing a feminist critique of clinical psychology training in a local context. While recognising that feminist psychology has moved away from critiques of positivist psychology to the re/conceptualisation of psychological knowledge and practice, I consider it important to sustain ongoing challenges to clinical psychology as a branch of dominant psychology that continues to occupy a significant and powerful position in the wider terrain of psychological knowledge and practice. The thesis also offers ideas for the future development of clinical training, recommending how clinical psychology training might better represent, respond to and serve women.

In this thesis I take a feminist standpoint position to analyse the way clinical psychology constructs and conveys meanings about women, gender and other relations of power. My approach emphasises reflexive research practice and the active use of the research process, as well as its outcomes, as a means to effect political change. I regarded the research process itself as a political strategy for raising awareness of issues of power by prompting debate amongst clinical psychology academics and students. 
The research utilised both quantitative and qualitative research methods as a means to gauge the ideas of a large group of participants involved in clinical psychology training, while also enabling in-depth analysis of issues that may have been masked if only quantitative data were gathered. This approach served the purpose of generating numerical information, or the 'hard data' frequently requested by mainstream clinical psychologists to justify a particular stance, but had the added benefit of contextualizing and exploring the substance of the participants' perspectives in more detail. A qualitative approach also permitted exploration of feminist clinical psychologists' ideas about how feminist theoretical perspectives can inform the practice of clinical psychology. The combination of quantitative and qualitative methods was regarded as an appropriate means of appealing to a mainstream clinical psychology audience, where there remains skepticism as to the validity of qualitative and other interpretative analyses. ${ }^{6}$ Thus, using quantitative and qualitative approaches, the research involved the administration of postal questionnaires to clinical psychology teaching staff and students enrolled in clinical psychology training programmes in the period 1996-1997. Subsequently, a subgroup of staff and student participants agreed to take part in interviews. I also interviewed feminist clinical psychologists.

\section{Positioning the Research}

The research was initially informed and developed around feminist critiques of psychology and a broad body of explicitly feminist psychology (for example HareMustin and Marecek, 1990; Ussher, 1991; Ussher and Nicolson, 1992; Wilkinson, 1986; Williams and Watson, 1991b). However, the thesis is also positioned within a diverse array of critical feminist work that takes a social constructionist approach. I use the term social construction in its broadest sense to include diverse epistemological standpoints. This work recognises the historical and cultural situatedness of knowledge, and the way knowledge is mediated by social practices (Burman, 1996a, 1996b; Hare-Mustin and Marecek, 1997; Stoppard, 1999, 2000; Ussher, 2000b).

\footnotetext{
${ }^{6}$ Debates concerning the use of quantitative and qualitative approaches in the context of feminist research are discussed in Chapter Five.
} 
Critical realism (Bhaskar, 1989) has also shaped my ideas during the writing of the thesis. A critical-realist position recognises the existence of 'reality' in terms of people's experience of distress, as well as physical, environmental and structural factors (Ussher, 2000b). While acknowledging materiality, this position also recognises that these 'representations are characterized and mediated by culture, language, and political interests rooted in factors such as race, gender, or social class' (Ussher, 2000b: 221). Thus, while acknowledging the discursive and contextual nature of knowledge, a critical-realist position also recognises the strategic usefulness and political expedience of empirical research and feminist standpoint theory. In addition, this position implicitly recognises the legitimacy of subjectivity and people's experience as an important and 'expert' source of knowledge.

The thesis is also located within a diverse field of critical psychology, which, while encompassing feminist writing, also includes a range of work by other critical writers (for example Fee, 2000; Fox and Prilleltensky, 1997; Ibàñez and İñiquez, 1997; Prilleltensky and Nelson, 2002; Sloan, 2000). In recognition of the bicultural context of Aotearoa New Zealand and indigenous issues internationally, I have also drawn upon ideas from a burgeoning field of indigenous psychology and kaupapa Māori research ${ }^{7}$ (for example Cram, 1993; Durie, 2001; Nairn and the NSCBI, 1997; Nikora, 1993, 2001; L. Smith, 1998; Stewart, 1995). I use these broad bodies of literature, feminist psychologies, critical psychologies and indigenous psychologies, in conjunction with the research 'findings' to develop ideas for shaping the future of clinical psychology training.

Within this thesis there is some tension between the epistemological underpinnings of the empirical approach taken at the outset of the research and my subsequent engagement with critical-realist ideas. Decisions around the epistemological orientation of the research reflect my knowledge at the outset of the research, my own training in clinical psychology, as well as the desire to take a pragmatic political position. My

\footnotetext{
7 Kaupapa Māori means 'Māori ways' (Cram, 2001: 404). Kaupapa Māori theory means 'the validity and legitimacy of Māori is taken for granted; the survival and renewal of Mãori language and culture is imperative; the struggle for autonomy over our own cultural wellbeing, and over our own lives is vital to Māori survival' (G. H. Smith, 1990 cited in Cram, 2001: 404).
} 
attention to the structural and material in its broadest sense reflects a resistance to clinical psychology's focus on the individual and intrapsychic, echoing a dominant strand of feminist psychology in the early 1990s. Although I do not entirely negate the intrapsychic, my aim was to embrace an understanding of the way structural relations shape everyday meanings, contribute to the construction of psychological knowledge, and thereby constitute women's realities. More recently I have come across work by feminist psychologists that takes a multi-level analysis comprising the material and discursive (for example Stoppard, 2000), or the material, discursive and intrapsychic (Ussher, 2000b). These models provide comprehensive analytical frameworks for understanding and reconceptualising the 'psychological', and have particular significance for the future development of clinical psychology.

The thesis reflects shifting knowledges and identifications and does not seek to be definitive. Rather, it offers a snapshot of the place of gender in clinical psychology training in this country and proposes ways forward.

\section{Motivation for the Research}

This thesis has its genesis in my experiences of clinical psychology training in Aotearoa New Zealand in the mid 1980s when there was heightened radical feminist and lesbian feminist political action, with which I became increasingly involved. During this period there was a surge in awareness around issues to do with rape, sexual violence and sexual abuse, male violence against women, pornography and the more broadly defined area of women's health. Māori sovereignty, ${ }^{8}$ and Pakeha ${ }^{9}$ pro-Treaty initiatives related to the Treaty of Waitangi and antiracism were also prominent.

\footnotetext{
${ }^{8}$ As embodied in the work of Awatere (1984).

${ }^{9}$ In common usage the term Pakeha refers to 'non-Māori New Zealanders of European ethnic origin (in effect, descendants of the Treaty signatories)' (Lapsley, Gavey and Cram, 2001: 278). The less commonly used term, tauiwi, refers to 'settlers, including recent immigrants, who came after Mäori, the indigenous people' (Lapsley, Gavey and Cram, 2001: 278).
} 
This political environment was grounded in identity politics and the experiences of marginalised groups. It was influential in developing my understanding of power and shifting the way I thought about the lives of women and other marginalised groups. It also contributed to an increasing dissonance with the dominant ideology of clinical psychology and disillusionment with the training I was undertaking. In addition, discussions with other women highlighted the lack of congruity between women's diverse experiences and material realities, and the psychological frameworks promoted by clinical psychology. The issue of gender thus became increasingly pertinent as I began to understand how clinical psychology's theoretical frameworks failed to include an analysis of gender or other issues of power.

I eventually left clinical psychology training and subsequently worked in communitybased initiatives, and later in the public sector, where I worked on research and policy issues relating to women and gender. My knowledge and interest in the relationship between clinical psychology and feminism developed as I began reading feminist critiques of psychology and feminist ideas about the construction of knowledge and women's 'madness' (Hare-Mustin and Marecek, 1990; Ussher, 1991; Ussher and Nicolson, 1992). I subsequently entered Women's Studies where I was introduced to feminist theories and epistemologies, and the broader domain of interdisciplinary thought. More recently I have begun exploring the broad landscape of critical psychology. While moving in this direction I have been constantly reminded of the importance of bringing about change in clinical psychology. Thus, this thesis is testimony to a belief that clinical psychology can and must embrace gender and other dimensions of power and move toward more broadly defined notions of psychological knowledge and practice in which values, and issues of justice and equity are central.

\section{The Structure and Context of Clinical Psychology Training Programmes}

Clinical psychology training is primarily undertaken as a postgraduate degree qualification commonly known as the Postgraduate Diploma in Clinical Psychology, PGDipClinPsych. ${ }^{10}$ This is a professional qualification usually required for clinical

\footnotetext{
${ }^{10}$ Or some derivative thereof, such as the DipCIPs at the University of Otago.
} 
psychologists to become Registered Psychologists, and was the most common means of training at the time this research was undertaken. ${ }^{11}$

\section{PGDipClinPsych Structure}

Most clinical psychology training programmes are based on a scientist-practitioner model. ${ }^{12}$ Indeed, the scientist-practitioner model is used to distinguish clinical psychologists from other 'helping professions'. ${ }^{13}$ The programmes typically involve a three year period of post-graduate training. The clinical diploma is divided into three key components comprising postgraduate clinical course papers, practical placements and a final year internship. ${ }^{14}$ A Masters degree by thesis, or Doctoral Degree in Psychology, may also be undertaken concurrently with the PGDipClinPsych. Each programme has its own system for the provision of placements and internships. Placements are offered across a range of settings and client groups including for instance the Department of Corrections, Child and Family Services, community mental health services, rehabilitation and psychiatric services, drug and alcohol services, university counselling services, and Child, Youth and Family Services (CYFS). An important factor in securing internships is the availability of appropriately qualified and

1 The PGDipClinPsych is the most commonly endorsed form of training for clinical psychologists although other routes to registration do exist. Registration comes under the jurisdiction of the New Zealand Psychologists Board.

${ }^{12}$ Employment vacancies for clinical psychologists frequently specify that applicants are oriented to a scientist-practitioner (and cognitive-behavioural) model. For example a 2003 advertisement for a Lecturer in Clinical Psychology, Department of Psychology, University of Waikato [Ref 210403] stated that 'You will define yourself within the scientist-practitioner model of training, with a cognitive-behavioural orientation' http://psychology.waikato.ac.nz/staffprofile.cfm?ID=25. Likewise, an advertisement for a Director of Clinical Psychology at Victoria University in 1999 stated: "the PGDipClinPsych at Victoria is taught within the scientist-practitioner framework and from a cognitive-behavioural theoretical perspective' (Director of Clinical programme, Faculty of Science, Victoria University, Wellington. The Evening Post, 25 September, 1999).

${ }^{13}$ For instance the Clinical Psychology Programme at Massey University states that the scientistpractitioner model is adopted for a number of reasons: 'In the helping profession, there are some others who possess assessment and intervention skills which are at the core of most clinical psychology practice. However, it is often only the clinical psychologist who approaches this work more comprehensively and from a scientist-practitioner perspective' (http://www.massey.ac.nz/-psyweb/grad/clintr.htm 27/08/03).

${ }^{14}$ The term internship is used in most programmes. However some programmes use the term 'final year placements'. 
experienced supervisors, and their preparedness to take on students. Some programmes have a funding relationship with the Department of Corrections that ensures programmes have permanent internships available. ${ }^{15}$ In some areas District Health Boards make internship positions available. Māori agencies are also sometimes available for Mãori students. However, issues concerning the over-utilisation of Māori staff and workplaces that are both in high demand and poorly resourced, sometimes preclude this option. ${ }^{16}$ At the time of this research, students who were concurrently undertaking doctoral degrees with the PGDipClinPsych usually deferred their internship until the doctorate was complete.

Recently there have been moves to bring the PGDipClinPsych into line with clinical training in Britain, North America and Canada by making it a four year doctoral level degree (Bushnell, 1995). ${ }^{17}$ A 1995 survey of students suggests some resistance to extending training by another year, although almost half the participants were in favour of the current qualification being renamed a Doctorate of Clinical Psychology (Brassington, 1996). All universities offer traditional academic doctoral degrees in psychology which may be taken concurrently with the PGDipClinPsych, and Auckland University offers a professional Doctorate in Clinical Psychology (or PsyD) qualification.

Clinical programmes fall under the authority and administration of individual psychology departments or schools of psychology and are most commonly part of a faculty or division of science. Decisions regarding the clinical curriculum are the responsibility of programme directors and clinical lecturers. Each programme has its own area/s of specialisation or expertise that reflects the specialist knowledge, skills and research orientation of the staff teaching in the programme. Similarly, the theoretical orientation of clinical programmes reflects staff interests and specialties. Academic psychology is increasingly aligned with the sciences, possibly reflecting the associated

\footnotetext{
${ }^{15}$ For example, Victoria University.

${ }^{16}$ Personal communication, Averil Herbert, University of Waikato, 1998.

${ }^{17}$ In these countries, a four year equivalent of the New Zealand Diploma in Clinical Psychology is called a Doctorate of Clinical Psychology (Brassington, 1996: 32).
} 
status and funding of sciences at universities in this country. The New Zealand Psychological Society (NZPsS), which is the primary professional organisation for psychologists, also promotes psychology as a science. Likewise, the NZPsS's Institute for Clinical Psychology endorses a scientific research orientation.

Clinical programmes have links with local practicing clinical psychologists who are used in an advisory capacity and as placement or intern supervisors. Some programmes have links with associated places of learning such as that between the Otago clinical programme and the School of Medicine at Otago University. In some areas, clinical programmes utilise the expertise of kaumatua, ${ }^{18}$ Māori staff within the university, Māori mental health professionals in the community and kaupapa Māori psychology researchers. ${ }^{19}$ Some programmes have a relationship with local iwi ${ }^{20}$ and hapu. ${ }^{21} 22$ Some draw on the specialist knowledge of feminist clinical psychologists in their communities $^{23}$ and representatives from community groups such as Women's Refuge or Rape Crisis are sometimes invited as guest lecturers. However, the involvement of these diverse groups and sources of knowledge is reliant on the commitment of clinical staff and can change with changing staff. ${ }^{24}$

\footnotetext{
18 'Elder' (Ryan, 1997: 100).

${ }^{19}$ For example researchers from the Māori and Psychology Research Unit (MPRU) at Waikato University (L.W. Nikora and I. Evans. A Mãori and Psychology Research Unit. Paper presented at the Te Oru Rangahau Conference, Massey University Palmerston North July 7-9 $9^{\text {th }}, 1998$ http://130 .217.157.10/mpru/pubs/confpapers/nikora-evans.htm (06-02-03).

${ }^{20}$ Iwi means 'tribe' (Ryan, 1997: 76).

${ }^{21}$ Hapu means 'sub-tribe' (Ryan, 1997: 48).

${ }^{22}$ For example, at the time this research was undertaken, the clinical programme at Waikato University had strong links with Tainui iwi. This was largely attributable to the proactive role of the Māori lecturer employed at that time. Relationships with local Māori communities vary between clinical programmes and are largely dependent on the commitment of clinical staff and the resourcing of clinical programmes.

${ }^{23}$ For example, the University of Auckland.

${ }^{24}$ For example, the recent employment of a Kaupapa Māori Teaching Clinician has resulted in the initiation of change in course content at the clinical programme at Victoria University (personal communication, Wendy Kelly, 2003).
} 
The number and qualifications of staff who teach clinical psychology varies between universities. Most programmes have staff at professor/associate professor, senior lecturer and lecturer levels of the academic scale. They also have clinical practitioners or clinician teachers. Directors are at the level of professor or senior lecturer. Staff teaching in clinical psychology programmes are Registered Psychologists and the majority have the New Zealand Diploma in Clinical Psychology or its international equivalent. Directors and most lecturers hold a doctoral degree and have considerable research, publishing and clinical practice experience. Some are also involved with local community initiatives. ${ }^{25}$ Most clinical programme staff are members of the NZPsS and/or the New Zealand College of Clinical Psychologists (NZCCP) the latter of which is a practitioner-oriented professional organisation. While vacancies for academic staff in clinical programmes usually include a statement regarding honouring the Treaty of Waitangi, and encourage applications from Māori, Pacific Nation peoples, ethnic minorities and people with disabilities, there are few, if any, academic staff in senior positions from these groups.

\section{Clinical Programme Entry Criteria}

University regulations governing entry to clinical psychology training vary. In exceptional circumstances, entry may be granted without conforming to prescribed university regulations, however, most programmes require a Bachelors degree with Honours or a minimum B-plus average. ${ }^{26}$ Clinical programmes usually restrict entry to between six and ten students per year. A high applicant rate means competition for entry is intense. ${ }^{27}$ Most programmes aim to increase the proportion of Māori students who

\footnotetext{
${ }^{25}$ For example clinical staff from Canterbury University provide consultancy services to the Kia Marama Sex Offender Treatment Programme at Rolleston Prison, Christchurch.

${ }^{26}$ Honours must be first class, first division $(1: 1)$ or second class, first division $(2: 1)$.

${ }^{27}$ For instance in 2002 Victoria University had around sixty applicants for the PGDipClinPsych (personal communication, Wendy Kelly, 2003).
} 
apply for clinical training. Some programmes also operate affirmative action policies targeting Māori and Pacific Nation peoples. National Department of Corrections Bursaries are also available to encourage Māori and Pacific students to undertake clinical training.

Assessment and Examination

The first year of training is internally assessed and is based on students' course work. In the second year assessment comprises course work, supervision reports and an oral exam. The third year primarily involves a series of written case reports based on assessments and interventions undertaken as part of the student's internship, supervision reports and the final oral exam, which extends over a few days. The final exam process involves students undertaking a 'real-life' interview and assessment, and subsequently writing a psychological report. Paper cases are also given to the student who must provide a systematic general approach to the cases described.

The examination structure and process is designed to ensure that students are competent in a range of skills and have substantive knowledge pertinent to clinical practice. Thus, students may be examined on any topic relevant to clinical practice. The exam involves external examiners to ensure a consistent and comparable level of competency throughout the country.

\section{Accreditation and Governance}

Clinical psychology training currently has no national accreditation system but programme educators from throughout the country have recently established a group called the National Association of Clinical Psychology Training Programmes. Members intend meeting twice yearly, providing an information sharing mechanism for clinical trainers. It is likely that the Association will eventually develop national accreditation criteria for clinical psychology training. 
The NZPsS has a number of positions within its executive that impact on the training of psychologists. The Director of Training and Standards is responsible for "ensuring the maintenance of standards in psychology; and facilitating and monitoring activities relating to the education and training of psychologists and their professional development' (New Zealand Psychological Society, 1998). Other executive positions, including those relating to bicultural, scientific and professional affairs, also inform clinical psychology training.

Clinical psychologists/graduates are required to register with the Psychologists Board and to obtain an annual practicing certificate in order to practice as registered psychologists. $^{28}$ Registration Board regulations and statutory obligations governing psychologists are based on the Psychologists Amendment Act (1999). ${ }^{29}$ Registe red Psychologists are also bound by The Code of Ethics for Psychologists Working in Aotearoa/New Zealand (2002). ${ }^{30}$ Psychologists working in the health sector will soon be bound by the Health Professionals Competency Assurance Bill, currently being heard by the Health Select Committee. Clinical psychologists are also expected to be familiar with a range of legislation such as the Mental Health (Compulsory Assessment and Treatment) Act (1992) and the Amendment Act (1999), Children, Young Persons and their Families Act (1989), The Guardianship Act (1968) and the Guardianship Amendment Act (1991), the Domestic Violence Act (1995) and the Accident Rehabilitation and Compensation Insurance Act (ACC) (1998).

\footnotetext{
${ }^{28}$ Registration is the equivalent of 'licensed' or 'chartered' in other countries such as Australia, Britain, Canada and the United States of America.

${ }^{29}$ At the time this research was undertaken the Psychologists Act (1981) was in effect. In accordance with the Psychologists Act (1981) applicants for registration must declare any criminal convictions leading to imprisonment of six months or more. When applying to enter clinical programmes applicants are typically asked to declare whether they have any criminal convictions, or have been involved in situations that 'might interfere with your practicing clinical psychology in an unethical manner' (Application Form, clause 8, PGDipPsych(Clin) Programme, The University of Waikato, 1999). However, police checks are not standard practice. This means that it is difficult to identify those subject to Protection Orders or NonTrespass Orders, or to track police reports of child sexual abuse, the use of child pornography, or relationship violence, or to identify cases of harassment brought before the Human Rights Commission or the Race Relations Office.

${ }^{30}$ At the time the research was undertaken The New Zealand Psychological Society Code of Ethics (1986) was in effect and made no specific mention of the Treaty of Waitangi. However, the revised Code of Ethics for Psychologists Working in Aotearoa/New Zealand (2002) makes explicit mention of the spirit and intent of the Treaty of Waitangi (Code of Ethics Review Group, 2002).
} 


\section{Terminology Used in the Thesis}

Throughout the thesis I attempt to use terms and language that embody feminist theories and concepts relating to knowledge, reality and experience, rather than the patriarchally defined concepts and values that dominate mainstream clinical psychology. However, I may use traditional forms of language, reflecting the deeply ingrained ideology of the dominant discipline. Further, there are instances where I purposefully use the language of clinical psychology to illustrate a point or to reflect language commonly used in psychological research and literature. I explain some of the key terms here and others in the context of the thesis.

\section{Clinical Psychology Training Programmes}

I refer to Clinical Psychology Training Programmes and the training which occurs in the context of the Postgraduate Diploma in Clinical Psychology (PGDipClinPsych) in various ways throughout the thesis. These include: 'the programme', 'clinical programme', 'clinical psychology training', 'clinical training' and 'training'.

Clinical Practice and Psychological Practice

I generally use the term 'clinical practice' when referring to the specific aspect of clinical psychology relating to individual, couple or family 'assessment', 'treatment' or 'intervention'.

The term 'psychological practice' is used in a more general sense to include the diverse work clinical psychologists may undertake such as therapy/intervention, education/training, research, scholarship, consultation, policy and political action. I also use the term 'psychological practice' to embody the theories and models of psychology as well as 'the full gambit of technical, professional and everyday practices that psychology informs' (Burman, 1996a: 1). The notion of psychological practice therefore encompasses: 
the way psychology colludes in the maintenance of structural inequalities, psychologists' role as gatekeepers of physical, institutional and knowledge boundaries, and, more insidiously, the ways psychological ideas inform everyday knowledge and our ways of experiencing our lives (Burman, 1996b: 3).

\section{Describing Women's Experiences}

Women's experiences have been described by clinical psychologists in terms of the symptoms of an ever increasing range of diagnostic disorders (Hare-Mustin and Marecek, 1997; Marecek, 2001). Typically, such diagnoses are based on the Diagnostic and Statistical Manual of Mental Disorders (DSM) (American Psychiatric Association, 1994) or the International Statistical Classification of Diseases and Related Health Problems (ICD) (World Health Organisation, 1994) (Hare-Mustin and Marecek, 1997; Stoppard, 2000). Feminists have widely critiqued the psychological construction of women's experiences as pathological (Hare-Mustin and Marecek, 1997; Marecek, 2001; Nicolson, 1995, 1998; Stoppard, 2000; Ussher, 1991, 1992, 2000b). They have described women's experiences as distress, despair, anger, rage, emotional pain, trauma, and sadness, amongst others as an outcome of the historical, cultural, sociopolitical and discursive context within which women's experiences are constituted.

In this thesis I use various words to capture this diversity of experience. While my aim is to move away from individualistic and pathologised notions of the "psychological', available discourses and language make it difficult to adequately capture the meaning intended, hence my use of terms such as 'psychological difficulties' or 'psychological problems'.

\section{Psychological Health}

Throughout this thesis I use the term psychological health to communicate the broad spectrum of experience and being embodied by the interrelated aspects of the physical, spiritual, sensory, intuitive, cultural, sociopolitical, economic, environmental and historical worlds within which health or wellbeing is constituted. 
While the term psychological is less than ideal in capturing this diverse experience of being, it identifies the particular area of health that the thesis focuses on. I use the term in preference to more individualist, reductionist and decontextualised conceptualisations of 'psychological health' reflected in language commonly used in clinical psychology, such as 'mental illness' or 'psychological disorder'. I also use the term psychological health in preference to 'mental health' to move away from conventional notions and models of 'illness' inherent in the mental health arena.

\section{Thesis Structure}

In Chapter One, Positivism, Feminism and Knowledge, I review critiques of the positivist science foundations of clinical psychology. These critiques show how psychology's dominant epistemological and methodological frameworks construct certain kinds of knowledge. Critics demonstrate how the positivist science dominance of clinical psychology reproduces knowledge reflecting the individualist and masculinist ideology of psychology's philosophical tradition. This chapter highlights ways clinical psychology tends to ignore relations of power that are integral to an understanding of human life and experience, and consequently often works to the detriment of women and other marginalised groups.

The theoretical orientation of clinical psychology is outlined in Chapter Two where I explore cognitive-behaviour therapy (CBT) and outline the contours and pervasiveness of this approach within clinical psychology. I then discuss a range of critiques of CBT and explore the how this model affects the way knowledge is constructed and applied. I give particular attention to the gendered and decontextual nature of CBT, and how it can reproduce the very power inequities that constitute peoples' experience of psychological pain. The chapter concludes by noting the difference between 'treatment' and techniques, as opposed to therapy and healing, and the concomitant importance of eclectic, holistic and multi-level analytical approaches to clinical training discussed in the following chapter. 
Chapter Three presents a review of literature encapsulating the rich and diverse body of work characteristic of feminist psychologies. I address meanings associated with the notion of feminist psychology and note the diverse array of epistemologies, methodologies, theories and topics in this broad body of work. I also address contemporary issues in feminist psychology, highlighting the importance of structural relations which shape women's diverse material worlds, experiences and realities. I discuss aspects of feminist psychology in Aotearoa New Zealand in the context of the Treaty of Waitangi, Māori /indigenous psychologies and the work of Pacific writers. I subsequently chart historical developments in feminist psychology in this country and comment on contemporary trends. Returning to the international context, I present feminist critiques of clinical psychology drawing attention to the ways clinical psychology fails to theorise gender and power, thus perpetuating the oppression of women and other marginalised groups. I outline the inclusion of sexual inequality education in clinical psychology training in Britain in the early 1990s and conclude the chapter by returning to recent developments in feminist psychology which have been influential in shaping the increasingly legitimated field of critical psychology. This chapter locates my thesis argument within the feminist psychologies literature and makes explicit my philosophical and political stance.

In Chapter Four I discuss the epistemological position of feminist standpoint that informs this thesis. Feminist standpoint takes women's experiences as an authoritative source of knowledge and explicitly recognises women's material realities in the conceptualisation of women's "psychological" difficulties and the construction of psychological knowledge. While acknowledging criticisms of feminist standpoint, I draw on Nancy Hartsock's (1997a) use of this approach to make explicit the relationship between experience, power and knowledge, and to recognise that "truth" and "reality" are socially produced constructs. This chapter also explores the notion of critical realism and the ways feminist standpoint can be used within this philosophical approach to offer a more comprehensive and meaningful analysis of people's experiences.

In Chapter Five, Feminist Methodologies, I address the social, political and ethical foundations of knowledge production. The chapter includes debates central to the broad 
terrain of feminist psychologies today and a comprehensive discussion of research ethics, reflecting the importance of these issues in discussions of feminist research. In accordance with the broad parameters of feminist methodologies discussed in this chapter, the thesis offers a counter hegemonic position that challenges the positivist epistemological basis of clinical psychology.

Chapter Six, The Research Process, presents an outline of my research which involved the use of a multi-method approach, combining quantitative and qualitative methods, and the inclusion of diverse participant groups. A discussion of ethical considerations follows, with particular attention to the Treaty of Waitangi and issues relating to the protection of participants' identities. I then define the three participant groups and how I accessed participants. The development and administration of student and staff research questionnaires, procedures relating to interviews with the different participant groups, and transcript review processes are then described. I also briefly report on how the research addressed issues of reflexivity and transparency, and the trustworthiness of the research, and outline processes of data analysis.

Chapters Seven to Twelve present an analysis of the research findings. In Chapter Seven, Meanings of Gender and the Inclusion of Gender Education, I report demographic information about the three participant groups. I subsequently examine student and staff participants' ideas about meanings of gender and the nature and scope of gender education in clinical psychology training programmes.

In Chapter Eight, Gender Diversity Education, I explore student and staff participants' views and understanding of gender in the context of other power relations. In particular I examine student and staff participants' perceptions about the inclusion of diversity education relating to different groups of women.

Chapter Nine and Ten present two examples of analyses of power. Chapter Nine, Example One: The Treaty of Waitangi and Chapter Ten, Example Two: Men's Violence Against Women examine participants' ideas about power relations and the way aspects of power are understood within clinical training. This draws primarily on participants' responses to two key issues: the way clinical programmes incorporate the Treaty of 
Waitangi, Māori knowledges and worldviews and bicultural approaches to training; and the inclusion of analyses of power relating to male violence, as well as participants understanding of this issue.

In Chapter Eleven, Women and Psychological Health: Barriers to the Inclusion of Gender Content, I examine participants' views on a feminist analysis of health and the relationship between women's sociopolitical context and well-being. I also examine participants' appraisals of the importance of gender education and adequacy of the inclusion of gender education to clinical psychology training. This chapter is based on staff, student and feminist clinical psychologists' perceptions of potential barriers.

I present an examination of the theoretical focus of clinical training in Aotearoa New Zealand in Chapter Twelve. This includes identifying the dominant theoretical approach to clinical training and examining student, staff and feminist clinical psychologists' views on the prevalence of cognitive-behaviour therapy. This is followed by a brief description of one clinical programme that takes an eclectic theoretical approach. I subsequently discuss feminist clinical psychologists' endorsement of an eclectic model of training. The chapter concludes by examining the inclusion of feminist perspectives in clinical programmes.

The final chapter, Concluding Comments and Future Directions, reflects on the research findings, drawing on ideas put forward by critics cited throughout the thesis and presenting theoretical and analytical frameworks for the future development of clinical psychology training. While the research findings derive from an analysis of clinical psychology training in Aotearoa New Zealand, the ideas put forward in this chapter are likely to be applicable to clinical training in international contexts. 
Feminist psychology is explicitly informed by the political objectives of the feminist movement: centrally, to end the oppression of women...[it] is - and always has been - critical of mainstream psychology, and the harms it has inflicted on women (Wilkinson, 1997b: 178-179).

[W]ithin feminist psychology personal passions and collective politics fundamentally ground our critical scholarship. The mystified space yawning between "objectivity" and "politics" is exposed as an illusion, justifying and laminating existing forms of social privilege in the name of objectivity...feminist psychology rests upon the assumption that deep and sustained power asymmetries construct our conceptions and relations of gender, race, class, disability, and sexuality' (Fine, 1992: VII).

People come into therapy because they no longer sleep or cannot remember when they ever slept well; because terror strikes in their hearts when they leave home or enter a crowded room; because their dreams are filled with images that frighten or confuse them; because they cannot stop crying or are too numb to feel. They come because a quarter of their hour is absent; because they experience a profound distance from themselves, their feelings their capacity for action. They come because a relationship is strangling on itself; because a family is fraying at the seams; because illness has robbed them of what once gave pleasure and value to life. For some, the pain feels almost physical, palpable, sometimes so much so that death feels more attractive than an endless future with such distress' (Brown, 1994: 124). 


\section{Chapter One}

\section{Psychology, Feminism, and Knowledge}

Clinical psychology is located within a psychological tradition entrenched in positivism and scientific epistemology. Feminist and other critical psychologists have variously addressed the positivist-realist philosophical foundations of psychology, arguing that knowledge is constructed in accordance with scientific precepts and the patriarchal values, beliefs and assumptions of those in power (for example Burman, 1990b, 1996a, 1996b, 1997; Hare-Mustin and Marecek, 1990, 1997; Kantrowitz and Ballou, 1992; Kitzinger, 1997; Nicolson, 1995, 1998; Stoppard, 1999, 2000; Ussher, 1990, 1991, 1992, 2000b; Ussher and Nicolson, 1992; Wilkinson, 1986, 1996, 1997a, 1997c). Such critiques question the underlying assumptions of positivism, and a scientific discourse that presents mainstream psychological knowledge as authoritative and all powerful. Underpinning these criticisms of psychology is a "white" male dominant organisational structure that maintains gender inequities and the dominance of masculinist knowledge (Nicolson, 1992). Because mainstream clinical psychology remains one of the stalwarts of psychology's positivist science tradition, many of the criticisms of dominant psychology made in this chapter, and in the thesis more generally, are applicable to the more specific body of work encompassed by clinical psychology.

In this chapter, I review critiques of the positivist science dominance of mainstream psychology. I note the regulatory nature of positivist psychology and the increasing impact of the media on the relationship between science and knowledge. In particular, I focus on feminist critiques of the epistemological basis of psychology as a positivist science in which individualism and empirical research methodologies are central. I then discuss ways in which clinical psychology uses clinical language and relies on medically derived diagnostic systems that contribute to an allure of the 'scientific'. I subsequently review literature examining the dominance of a scientist dominant, scientist-practitioner model of clinical psychology training, and the implications of this model for the practice of clinical psychology. Finally, I briefly draw attention to a 
critical-practitioner proposal which offers ways forward for a more reflexive and holistic model of clinical psychology training.

\section{Positivism and the Construction of Knowledge in Psychology}

The epistemological basis of psychology rests upon positivist notions of knowledge and reality in which it is assumed that universal 'truths' can be discovered through scientific empirical research (John, 1998; Larner, 2001; Parker, 1997; Stoppard, 1999, 2000; Ussher, 1990, 1992, 2000b; Wilkinson, 1996; 1997c). While writers from diverse theoretical orientations have long critiqued the positivist foundations of psychology, the meaning of positivism has become increasingly vague. In this thesis, the term positivism is used to refer to the epistemological basis of psychology, which relies on 'methodological naturalism' and 'realist logic'31 (Ussher, 2000b: 209). Jane Ussher (2000b: 209) argues that the "fundamental premise of a scientific-realist perspective is that objects have real existence independent of any perceiver, knowledge system, or practice'. Janet Stoppard (1999: 80) uses the term 'positivism' to refer to methodological approaches "dominated by reliance on the experimental, hypotheticodeductive method' and characterised by 'an emphasis on "objective" procedures and precise measurement of "variables"... [typically involving] the use of quantitative methods'.

Critiques of the positivist assumptions upon which psychology is based centre upon the ways in which psychological knowledge is produced within a vacuum of scientific inquiry. Many argue that positivist conceptions of knowledge and reality are positioned as singular and stable phenomena, regarded as externally located and independent of the values and beliefs of the 'scientist' or inquirer (John, 1998; Larner, 2001; Nicolson, 1995; Parker, 1997; Stoppard, 1999, 2000; Unger, 1996; Ussher, 2000b). Such writers challenge the way positivism is premised upon the unitary subject and assumes that

\footnotetext{
${ }^{3.1}$ Ussher refers to 'realist logic' as 'knowledge [which] is only possible as the result of observation, and the only things that can be observed are those which are accessible to the senses. Causality is understood in terms of antecedent conditions and general laws governing phenomena; facts and theories, moreover, are clearly separated from values, with only the former being the legitimate focus of scientific interest' (Ussher, 2000b: 209).
} 
scientific inquiry is objective, apolitical and value-free (Burman, 1990b, 1996b, 1997; Larner, 2001; Nicolson, 1995, 1997; Parker, 1997; Prilleltensky and Fox, 1997; Riger, 1992; Stoppard, 1999, 2000; Unger, 1996; Ussher, 1991, 1992, 2000b; Wilkinson, 1996, $1997 b, 1997 \mathrm{c})$. In this sense, critiques of positivism reflect wider concerns about the modernist epistemologies that dominate mainstream clinical/psychology, and move towards postmodern accounts of 'knowledge', 'truth' and 'reality'. Put simply, modernism rests upon universal assumptions of the bounded and decontextualised individual (Hare-Mustin and Marecek, 1997). Knowledge is thought to exist independently from the individual or knower, and can be 'found' using the methods of scientific inquiry (Hare-Mustin and Marecek, 1997). Postmodernism however, is fundamentally concerned with the relationship between power, knowledge, language and the self, and asserts that all 'knowledge' is historically embedded (Fee, 2000; HareMustin and Marecek, 1997; Nicolson, 1995). Metanarratives and totalising theories (for example the taxonomy informing the Diagnostic and Statistical Manual of Mental Disorders) are rejected in favour of accounts of 'reality' problematising knowledge as socially and historically situated (Fee, 2000; Hare-Mustin and Marecek, 1997; Nicolson, 1995). Importantly, the boundaries of modernism and postmodernism are not discrete. Rather there is an epistemological continuum, as evidenced in the work of writers cited throughout this thesis.

Feminist writers have addressed the way positivism is premised upon masculine philosophical notions of reason and rationality which are constructed as normative and applied in a universal manner (Burman, 1990b, 1996, 1997; Hare-Mustin and Marecek, 1990, 1997; Kantrowitz and Ballou, 1992; Stoppard, 1999, 2000; Unger and Crawford, 1996; Ussher, 1992, 2000b; Wilkinson, 1996). They argue that positivism is imbued with masculine ideology, reflecting male assumptions about human experience and the nature of 'reality' (Hare-Mustin and Marecek, 1990, 1997; Stoppard, 1999, 2000; Ussher, 1991, 1992, 2000b; Wilkinson, 1996, 1997b, 1997c).

Writers have particularly questioned the positivist methodological foundations of psychology on the basis that this approach was designed for use in the natural sciences (Baydala, 2001; John, 1998; Larner, 2001; Ussher, 1991, 1992). For example, Ussher (1992: 43) asks: "is human thought or action really analogous to plate tectonics, the 
behaviour of microbes or DNA?' Assumptions implicit in this question are addressed by other writers who argue that psychology is characterised by a monolithic form of inquiry and analysis, reflecting hypothetico-deductive experimental methodologies in which quantitative research and statistical analyses dominate (Henwood and Pidgeon, 1995; Kidder and Fine, 1997; Larner, 2001; Stoppard, 1999; 2000; Ussher, 1991, 1992, 2000b).

It is argued that the positivist assumptions of psychology mean that research undertaken in the name of science is limited to the measurable and manageable (John, 1998; Larner, 2001; Stoppard, 1999; 2000; Ussher, 1991, 1992; 2000b). As Ussher (2000b: 210) states, only phenomena that can be "observed and measured using reliable, standardized techniques... [can] be "known" within a positivist paradigm". This means that the questions asked and topics addressed within the context of psychological research, are constrained by the values and beliefs of those undertaking the research. A common theme in the critical literature is that the theoretical assumptions upon which psychological research is based are narrowly defined, reductionist, decontextualised and deterministic (Burman, 1996b; Henwood and Pidgeon, 1995; Nicolson, 1995; 1997; Parker, 1997; Stoppard, 1999; 2000; Ussher, 1991, 1992, 2000b). This means that this narrow epistemological framework is used to construct 'common' or everyday meanings about human life, and constitutes the basis for defining normative ways of thinking, feeling, behaving, and experiencing the world (Burman, 1996b; Hare-Mustin and Marecek, 1997; John, 1998; Larner, 2001; Pilgrim and Treacher, 1992).

A range of commentators argue that knowledge constructed in accordance with the principles of positivist science reflects the cultural ideologies of those in power (Burman, 1996b; Hare-Mustin and Marecek, 1997; Henriques, Hollway, Urwin, Venn and Walkerdine, 1984; John, 1998; Kantrowitz and Ballou, 1992; Kitzinger, 1990a; Parker, 1997; Riger, 1992; Stoppard, 1999, 2000; Ussher, 2000b). Indeed, they illustrate how psychology's use of the 'scientific' in legitimating meaning is deployed to affirm (or negate) certain kinds of knowledge (Baydala, 2001; Hare-Mustin and Marecek, 1997; John, 1998; Kitzinger, 1990a; Larner, 2001; Stoppard, 1999). In the critical literature, attention is directed at psychology's failure to recognise that all knowledge is 
discursively produced, and historically, socially, culturally, and politically situated (Burman, 1996b; John, 1998; Nicolson, 1995; Parker, 1997; Ussher, 2000b).

Many writers draw upon the work of Michel Foucault (1980) in arguing that power and knowledge are inextricably linked (Burman, 1996b; Hare-Mustin and Marecek, 1997; Nicolson, 1995; Parker, 1997; Pilgrim and Treacher, 1992). They illustrate how control over the production of knowledge is confined to a dominant minority (John, 1998; Kitzinger, 1990a; Nicolson, 1992; Parker, 1997; Pilgrim and Treacher, 1992; Wilkinson, 1997a). Much of the critical literature directs attention to the way positivist science serves as a discourse of control (Burman, 1996b; Hare-Mustin and Marecek, 1997; John, 1998; Kitzinger, 1990a; Pilgrim and Treacher, 1992). They argue that psychology operates as a regulatory regime and technology of surveillance which constructs and monitors acceptable ways of 'knowing' and 'being' (Hare-Mustin and Marecek, 1997; Nicolson, 1995; Parker, 1997; Pilgrim and Treacher, 1992).

The Political and Regulatory Nature of Positivist Psychology - An Example

Celia Kitzinger (1990a) discusses changes in the Diagnostic and Statistical Manual of Mental Disorders (DSM) regarding the classification of homosexuality to show how psychology controls dominant meanings, regulates behaviour, and is inherently political. Kitzinger (1990a) examines the way 'homosexuality' was removed from the DSM as a result of political activism, wider social change and direct protest to the American Psychiatric Association, despite a body of published 'scientific' research in which a pathological view of homosexuality was asserted. Kitzinger (1990b) cites a body of 'scientific' research which has since been established to affirm the more recent position. Kitzinger's example highlights the fallacy that psychology and the DSM are premised upon the scientific, rather than current social, cultural and political values. The argument here is that dominant psychology has yet to recognise the inseparability of science and politics, and the role of power in determining what counts as knowledge. 
Science, The Media and the Construction of Knowledge

The interplay between science and the media is increasingly examined in discussions of the position of psychology as a culturally sanctioned and legitimated producer of knowledge. Writers have shown how the development of electronic media is pivotal in the process of constructing and disseminating 'knowledge' (Hare-Mustin and Marecek, 1997; Nicolson, 1995; Walkerdine, 1997). They argue that because knowledge has become synonymous with science, only that which is regarded as scientifically authoritative is granted media legitimacy. Feminist writers in particular have demonstrated how science and the media operate to locate gendered subjectivity as normative (Hare-Mustin and Marecek, 1997; Nicolson, 1995; Walkerdine, 1997). As such writers point out, the relationship between science and the media is increasingly regarded as central to the construction of gendered meaning, the prescription of normativity and definitions of 'pathology'. In this way science and the media have become powerful instruments in psychology's apparatus of social regulation and control (Nicolson, 1995; Walkerdine, 1997).

\section{The Impact of Positivist Science on the Construction of Knowledge about Women}

Many feminist and critical psychologists argue that the scientifically derived research characteristic of dominant psychology has little in common with the complexities and contradictions of human experience (Baydala, 2001; Larner, 2001; Parker, 1997; Stoppard, 1999, 2000; Ussher, 1991, 1992, 2000b). In particular, they show how psychological research and the 'knowledge' it produces about women bears little resemblance to the realities and conditions of women's lives (Stoppard, 1999, 2000; Ussher, 2000b; Wilkinson, 1996).

Many writers are critical of the way psychology constructs knowledge about women in accordance with the patriarchal assumptions and values of 'white', male North American academics (Burman, 1996b; Hare-Mustin and Marecek, 1997; Kantrowitz and Ballou, 1992; Pilgrim and Treacher, 1992; Stoppard, 1999; Ussher, 1991, 1992). For example, assessment and treatment approaches commonly used in clinical 
psychology reflect the norms of this dominant elite who value independence, individual identity and achievement, competition and material wealth (Hare-Mustin and Marecek, 1997). For many non-dominant cultural groups, including many groups of women, these values are not regarded as important, healthy or likely to contribute to well-being. Similarly, many of the 'strategies' clinical psychology promotes in coping with stress, such as taking time out, having a massage, going to a movie, and joining a gym, are not options for people living with economic hardship and/or those with disabilities (Bostock, 1997; Hare-Mustin and Marecek, 1997). In addition, the time and economic costs associated with accessing or physically getting to therapy are prohibitive for many groups of people, particularly women lone parents (Bostock, 1997; Holland, 1992). Equally, the development of conceptual frameworks for 'depression' and other psychological health problems in clinical psychology have ignored gendered and other structural relations of power, the oppressive conditions often associated with marriage and/or motherhood, and the devalued status of femininity, as well as the multiple demands on women to be providers and caregivers (Nicolson, 1998; Stoppard, 2000; Ussher, 2000b). Thus, the kinds of knowledge psychology produces about women are also limited by psychology's negation of historical, social, cultural and political contexts (Henwood and Pidgeon, 1995; Nicolson, 1995, 1998; Stoppard, 2000).

Feminist writers also demonstrate how the process of knowledge construction affects the kinds of therapies promoted for use with women (Stoppard, 1999, 2000; Ussher, 2000b). Namely, that the lack of congruity between women's experiences and psychology's understanding of those experiences has important ramifications for what psychology thinks it 'knows' about women, and ultimately what can be 'known' about women within the bounds of a positivist science framework (Stoppard, 1999, 2000; Wilkinson, 1996, 1997b, 1997c; Ussher, 1991, 1992, 2000b; Nicolson, 1995; Prilleltensky and Fox, 1997).

\section{Positivist Science and Individualism}

One of the characteristics of psychology's positivist science orientation is the focus on the individual. Critics argue that within this epistemological and theoretical framework 
'problems' are constructed and located at a personal rather than sociopolitical level (Adcock and Newbigging, 1990; Burman, 1996b; Fox and Prilleltensky, 1997; Nicolson, 1992, 1995, 1997; Unger, 1996, 1998; Ussher, 1991, 1992, 2000b; Wilkinson, 1996, 1997a, 1997c). This literature highlights the way in which such constructions lack analyses of power. It suggests that while attending to the individual, the centrality of power and social context, both of which are integral to people's experiences and realities, are minimised or negated (see also Fine and Gordon, 1991; Stoppard, 1999, 2000). It is argued that by decontextualising and depoliticising the 'problems' or difficulties people experience, psychology obscures the centrality of gender, race, ethnicity, culture, class, age, sexuality, ability and other social dimensions in constructing meaning, and in contributing to psychological difficulties (Adcock and Newbigging, 1990; Fine and Gordon, 1991; Stoppard, 1999, 2000; Ussher, 1991, 1992, 2000b). Paula Nicolson goes further to note:

There is evidence that psychological science, by not problematizing power and context, has actively contributed to the subordination of women through reinforcing misogynist mythology under the label 'science' (1995: 123).

A prominent theme in the critical literature is that while psychology is presented as objective and value-free, and makes 'truth' claims on the basis of its positivist science foundations, it obscures an inherently discriminatory set of practices that have adverse consequences for women and other marginalised groups. Indeed, feminist writers have long highlighted psychology's role in the (mis)construction of knowledge and meanings about woman, and in the pathologisation of women (Burman, 1996b; Hare-Mustin and Marecek, 1997; Nicolson, 1995; Stoppard, 1999, 2000; Ussher, 1990, 1991, 1992, 2000b; Wilkinson, 1996). Such critics argue that by constructing the individual as problematic, psychology reinforces a theoretical milieu in which individual people are located as the source of 'problem' and site of change. Positioning individuals in this way means the interventions and solutions to 'problems' are also individualistically prescribed. Ultimately this exacerbates the subordinate position of women and other marginalised groups, and is deleterious to health (Adcock and Newbigging, 1990; Burman, 1996b; Stoppard, 1999, 2000; Ussher, 2000b, Wilkinson, 1997b). As Isaac Prilleltensky and Dennis Fox (1997: 12) state: 
Encouraging women, people of color, the poor, and the working class to define their problems as individual ensures that they work to change themselves rather than society. The result is reduced effort to alter the status quo, a state of affairs that benefits the privileged.

It is in this way, critics argue, that mainstream psychology is seen as central to an apparatus of social regulation and control (Hare-Mustin and Marecek, 1997; Prilleltensky and Fox, 1997).

\section{Positivism, Individualism and Clinical Psychology}

Critiques of the positivist science foundations of psychology have primarily examined psychology in its broad sense however, some have specifically addressed the limitations of this framework as it relates to clinical psychology. They argue that clinical psychology is entrenched in modernist ideology and epitomises the positivist science of its wider disciplinary body (Baydala, 2001; Boyle, 1997; Ussher, 1992). ${ }^{32}$ Indeed, some say that clinical psychology is a particularly conventional branch of psychology which posits an epistemological framework in which people are understood in reductionist and pathological terms (Boyle, 1997; Hare-Mustin and Marecek, 1997; Nathan, 1999; Ussher, 1990, 1991, 1992, 2000b). In particular, this critical literature illustrates how clinical psychology is renown for its role in the problematisation of individuals (Adcock and Newbigging, 1990; Boyle, 1997; Hare-Mustin and Maracek, 1997; Nathan, 1999; Prilleltensky and Nelson, 1997; Ussher, 1991, 1992). Some critics suggest that while clinical psychology focuses on reductionist concepts of thought and behaviour, it negates the centrality of subjectivity. Nicolson (1995: 124) discusses the insistence in psychology on the 'behaviour' of the subject rather than the subject per se. She argues that this focus removes integral contextual factors that constitute subjectivity and give meaning to specific behaviours. Such contextual issues are explored in Chapter Two in relation to critiques of cognitive-behaviour therapy (CBT).

\footnotetext{
${ }^{32}$ Although this thesis is concerned with critiques of mainstream clinical psychology, there is recognition of the plurality, and critical thought and practice, amongst different subgroups of clinical psychologists, such as those who take feminist, kaupapa Maori, narrative and/or poststructural approaches.
} 
As with psychology more generally, a number of scholars maintain that by appealing to the scientific, clinical psychology conceals the epistemological foundations of its profession which are premised upon male assumptions, perceptions and experiences of human life (Adcock and Newbigging, 1990: Boyle, 1997; Hare-Mustin and Marecek, 1997; Pilgrim and Treacher, 1992; Stoppard, 1999; Ussher, 1991, 1992, 2000b; Ussher and Nicolson, 1992). Much of the critical literature suggests that while clinical psychology denies the role of the social and political, and psychologists' personal values and beliefs in the construction of psychological knowledge, it colludes in the oppression of people positioned outside dominant culture (Adcock and Newbigging, 1990; Baydala, 2001; John, 1998; Nathan, 1999). Effectively, this means that only the stories of the dominant culture are told, while others remain silenced or distorted (Adcock and Newbigging, 1990; Baydala, 2001; John, 1998; Nathan, 1999; Prilleltensky and Fox, 1997).

Another area examined has been the political role of clinical psychology in perpetuating theories and ways of knowing. It is maintained that by invoking the 'scientific', clinical psychology denies that its theories reflect dominant culture ideologies (Adcock and Newbigging, 1990; Baydala, 2001; John, 1998; Pilgrim and Treacher, 1992; Ussher, 2000b). This insistence on the scientific status of clinical psychology obscures the implicit interests and motivations of individual psychologists who consolidate research consistent with prescribed and professionally legitimated theories (Baydala, 2001; John, 1998; Larner, 2001; Pilgrim and Treacher, 1992).

While many authors cited in this review have identified problems and limitations with psychology's narrow positivist science foundations, they also illustrate how epistemological and methodological approaches that transgress the narrow parameters of dominant psychology are viewed disparagingly or dismissed by the discipline (Baydala, 2001; Larner, 2001; Parker, 1997; Stoppard, 1999, 2000; Ussher, 2000a, 2000b; Wilkinson, 1997a). In many instances it is demonstrated how unconventional (such as qualitative, inductive, and interpretative) research is obstructed through an array of regulatory mechanisms (Burman et al, 1996; Larner, 2001; Parker, 1997; Ussher, 2000b). This means that feminist and other critical epistemological approaches 
remain the exception rather than the rule in psychology and, if approved, must be continually justified (Ussher, 2000a, 2000b).

Many commentators have addressed the alliance between clinical psychology and positivist science, and the way this relationship has been used to construct the profession as a legitimate and superior field of academic inquiry. They show how clinical psychology has invoked the rhetoric of scientific discourse to establish and maintain its professional position, while simultaneously professing the 'scientific efficacy' of its research to justify its status (Baydala, 2001; John, 1998; Larner, 2001; Pilgrim and Treacher, 1992; Ussher, 1992). By claiming scientific status, clinical psychologists have been able to establish a secure and professionally superior position in the mental health field (Baydala, 2001; John, 1998; Pilgrim and Treacher, 1992; Ussher, 1992).

\section{Clinical Language and the Diagnostic and Statistical Manual of Mental Disorders}

The scientific discourse of clinical psychology is infused with clinical terminology derived from a medical tradition closely aligned with psychiatry (Pilgrim and Treacher, 1992). Despite attempts to delineate itself from psychiatry, clinical psychology continues to use quasi-medical terminology and its own plethora of jargon (Adcock and Newbigging, 1990; Pilgrim and Treacher, 1992). The infusion of medical and clinical language contributes to an allure of the scientific and contributes to the positioning of clinical psychology as a powerful and authoritative producer of knowledge. These strategies protect and monitor the borders of clinical psychology (Pilgrim and Treacher, 1992; Ussher, 1991, 1992, 2000b). In this way, the language of clinical psychology is part of an apparatus that positions clinical psychologists as experts, marks them as authority figures and attributes them with unequivocal power (Adcock and Newbigging, 1990). Not surprisingly, this practice contributes to a psychology that is often regarded as inaccessible and alienating, and which impedes transparency and the potential for external scrutiny (Adcock and Newbigging, 1990; Pilgrim and Treacher, 1992; Ussher, 1991, 1992, 2000b). 
In accordance with the epistemological and theoretical orientation of clinical psychology, terminology used by the profession reflects its individualism and the location of problems within individuals (Adcock and Newbigging, 1990; Pilgrim and Treacher, 1992). This is particularly notable in contemporary clinical psychology in which a CBT model is dominant. For example, the problems people experience, and indeed people themselves, are conceptualised in terms of disorders, dysfunctions, deficiencies, distortions and irrationalities (Stoppard, 2000). The use of reductionist and mechanistic concepts of this kind contributes to the problematisation of individuals and invokes notions of personal responsibility and blame (Adcock and Newbigging, 1990; Pilgrim and Treacher, 1992; Ussher, 2000b). These issues are further explored in Chapter Two where I discuss the theoretical dominance of CBT in contemporary clinical psychology.

In psychological research and practice, terminology consistent with a pseudo-medical model is also common. For example, terms such as mental illness, mental disorders, conditions and psychopathology are frequently used and people are commonly referred to as patients (sick) or cases (objects) (for example J.S. Beck, 1995; Blackburn and Davidson, 1995; Bloch, 1996).

Just as the discourse and language of clinical psychology reflect its positivist science foundations, its utilisation of a taxonomic system such as the Diagnostic and Statistical Manual of Mental Disorders (DSM IV) (American Psychiatric Association, 1994) ensures the profession is regarded as a 'real' science akin to medicine. The DSM is central to the dominant discourse of clinical psychology and reflects the medicalisation of psychological health (Hare-Mustin and Marecek, 1997; Kitzinger and Perkins, 1993; Larner, 2001). It also constitutes an authoritative instrument in the (mental) health arena where DSM classifications are increasingly required to source government funding (Hare-Mustin and Marecek, 1997; Larner, 2001; Ussher, 2000b; Wilkinson, 1997a).

While the DSM is integral to the scientific status of clinical psychology, there is much debate concerning the reliability and validity of the DSM, and a rejection of classifications particularly maligning of women (Hare-Mustin and Marecek, 1997; Ussher, 1991, 1992, 2000b; Wilkinson, 1997a). The DSM is regarded by feminist 
psychologists as an inherently masculinist classificatory system in which women are defined and interpreted according to male concepts of reason, rationality and normativity (Hare-Mustin and Marecek, 1997; Ussher, 2000b). Its role in labelling people operates to pathologise and subjugate women, and instead of alleviating women's experience of distress is likely to enhance it (Adcock and Newbigging, 1990; Hare-Mustin and Marecek, 1997; Ussher, 2000b).

The scientific basis of the DSM is widely refuted. It is now well documented that the DSM is inherently biased, susceptible to clinicians' values, and shaped by economic and political variables (Caplan, 1991, 1995; Hare-Mustin and Marecek, 1997; Kitzinger, 1990a; Ussher, 1991, 1992, 2000b). In their discussion of the DSM, Rachel HareMustin and Jeanne Marecek (1997) address the substantive increase in DSM classifications in recent years, as well as a notable shift in the DSM's alliance with the medical model. They argue that moves toward medicalisation are associated with increasingly conservative politics, individualism, and a mental health economy that mandates diagnostic classifications in return for funding. Further, the widespread utilisation of the DSM contributes to a disciplinary regime that has the effect of regulating an increasing range of individual behaviour. Due to these practices, HareMustin and Marecek (1997: 109) conclude that:

Ultimately, the decision to regard any set of behaviors or experiences as a psychological disorder - rather than a medical disorder, an eccentricity, a criminal act, or a response to an oppressive and intolerable environment - is not and cannot be a scientific one. It is a political and moral decision, a judgement grounded in cultural perspectives as to which behaviors are acceptable or not acceptable.

Despite varying degrees of utilisation of the DSM and distancing by some psychologists, clinical psychology continues to conceptualise and articulate individuals in terms of 'disorders' or 'problematic' thoughts and behaviours. Even in the most nonmedicalised and non-legalistic settings, the issues and distress people experience are constructed as personal disorders, dysfunctions or deficiencies of the individual (HareMustin and Marecek, 1997).

The training of clinical psychologists and undergraduate courses in 'abnormal' psychology constructs psychological knowledge around these concepts utilising texts 
and mainstream academic journals that consolidate this position (Hare-Mustin and Marecek, 1997). Students of clinical psychology must be well versed in their knowledge of the DSM, even if only to justify arguing against the use of certain classifications and diagnostic labels.

\section{The Scientist-Practitioner Model of Clinical Psychology}

Since its official recognition at the Boulder (USA) conference in 1949, the scientistpractitioner model has been the predominant paradigm for clinical psychology training (Baker and Benjamin, 2000; O'Gorman, 2001). ${ }^{33}$ This model of professional psychology training is used in New Zealand (Knight, 1990), Australia, Britain, Canada and the United States of America (USA) (O'Gorman, 2001). Research undertaken in the USA suggests that the scientist-practitioner model is still supported amongst the majority of directors of postgraduate psychology programmes (O'Sullivan and Quevillon, 1992).

Based on a positivist science philosophy, the scientist-practitioner model was defined in 1990 at the National (USA) Conference on Scientist-Practitioner Education and Training for the Professional Practice of Psychologists:

The scientist-practitioner model of education and training in psychology is an integrative approach to science and practice wherein each must continually inform the other. This model represents more than a summation of both parts. Scientist-practitioner psychologists embody a research orientation in their practice and a practice relevance in their research (Belar and Perry, cited in O'Gorman, 2001: 164).

While an integrative model of training is embodied in this definition, and appears to have been the original intention of the Boulder conferees (Baker and Benjamin, 2000) the scientist-practitioner model most commonly deployed is strongly scientist in focus (Addis, 2000; John, 1998; Larner, 2001; Pilgrim and Treacher, 1992). Further, despite the rejection of this model during the Vail Conference (USA) 1973 and calls for the adoption of a practice inclusive model of professional psychology training to reflect

\footnotetext{
${ }^{33}$ For discussion of the history of the scientist-practitioner model of clinical psychology training see Pilgrim and Treacher (1992). Also see articles in American Psychologist, 2000, 55: 2.
} 
more accurately the stated intent of the original scientist-practitioner model, this approach has not gained prominence (Stricker, 2000). Indeed, in the 1980's the scientist dominant model was reasserted as the model of clinical psychology training (Corballis, 1990).

\section{Critiques of the Scientist-Practitioner Model}

Debates about the scientist-practitioner model of clinical psychology are widespread and form part of an ongoing dialogue in the profession. Psychologists from diverse theoretical positions have questioned the 'scientist' dominance of this approach and drawn attention to the limitations of the model (for example Andrews, 2001; John, 1998; Larner, 2001; Pilgrim and Treacher, 1992; O'Donovan, Dyck and Bain, 2001; Ryba, Pine, Mentis and Bowler, 1999). Feminist psychologists in particular have long challenged the philosophical foundations of the scientist-practitioner model and argued that it is based on an inherently gendered system of knowledge (Hare-Mustin and Marecek, 1997; Ussher, 1992). Māori, Pacific and other psychologists in Aotearoa New Zealand have also addressed the western positivist science philosophy upon which this model is based (Abbott and Durie, 1987, Hirini and Nairn, 1996; Lawson-Te Aho, 1993, Moeke-Pickering, Paewai, Turangi-Joseph and Herbert, 1996; Ministry of Health Manatū Hauora, 1997; Nathan, 1999; Nikora, 1993; Paterson, 1993; Stewart, 1995; Tamasese, 1993; Waldegrave, 1993). Feminists have also drawn attention to the academic psychology's bias in favour of positivist science dominant research within an organisational structure where white privileged men dominate positions of institutional power, thus reproducing a Eurocentric, masculinist ideological position (Bell and Gordon, 1999; Cumming and Hyslop, 1998; Denmark, 1998; Levy, 2002; Nathan, 1999; Nicolson, 1992, 1995; Ussher, 2000a; Wilkinson, 1997c).

While the scientist-practitioner model is promoted as the model of clinical psychology training, its limitations are increasingly under scrutiny (Andrews, 2001; Atkins and Christensen, 2001; O'Donovan and Dyck, 2001; Pilgrim and Treacher, 1992). Critics have addressed the way the model enshrines positivism, promotes a scientist dominant discourse and accords authority to scientific knowledge (John, 1998; Larner, 2001; 
Pilgrim and Treacher, 1992). Indeed, many of the arguments against a scientistpractitioner model draw on ideas expressed earlier in this chapter, which expose the limitations of clinical psychology's positivist science epistemological and methodological orientation. It is argued that the scientist-practitioner model, in conjunction with psychology's philosophical foundations and organisational structure, limit the kinds of knowledge deemed valid and normative (John, 1998; Larner, 2001; Soldz and McCullough, 2000). Ian John suggests that "the scientist-practitioner model serves the political hegemony of psychologists as the guardians of epistemological truth' (John, 1998 cited in Richards, 2001: 101).

What is being suggested here is that the alliance between clinical psychology and the scientist dominant model is used to maintain clinical psychology as a legitimate focus of academic inquiry, and as a credible profession (Hare-Mustin and Marecek, 1997; Pilgrim and Treacher, 1992; Ussher, 1991, 1992). Writers have discussed the way this positioning is strategically deployed to locate clinical psychology as a distinct and relatively incontestable commodity in the infrastructure and marketplace of mental health (Pilgrim and Treacher, 1992). For example, John (1998: 24) argues that references to the 'scientist-practitioner' reflect the privileging of a discourse in which "the psychologist" [is metaphorically likened] to an idealised, heroicised, but historically outmoded, picture of the "scientist"'. He notes that reference to this model is increasingly used as 'a justificatory discourse' that imbues psychologists from diverse branches of psychology with scientific authority (John, 1998: 25). Indeed, commentators claim that psychologists' legitimacy rests on claims to science, scientific research and scientific 'evidence' (John, 1998; Larner, 2001).

While clinical psychology promotes the scientist-practitioner model as a scientific, evidence-based practice approach to postgraduate training, it downplays the importance of the practice context, the therapeutic relationship, the diversity of individual clients, and the style and interpersonal skills of psychologists (Andrews, 2001; Horvarth, 2001; Larner, 2001; Pilgrim and Treacher, 1992; Soldz and McCullough, 2000). Those that challenge the dominance of this model point to the fact that it relies on controlled experimental or clinical trial research, the findings of which are then generalised to diverse people and diverse contexts in the uncontrolled world (Larner, 2001; Pilgrim 
and Treacher, 1992; Soldz and McCullough, 2000). Many suggest that people's experiences are complex and multifaceted, deriving from a shifting, dynamic world that has little in common with the conditions of dominant positivist science research.

The promotion of a scientist-practitioner model therefore means a lack of engagement with the experiences of the people clinical psychology claims to assist (Pilgrim and Treacher, 1992). Psychology's insistence on positivist science research as a means of determining therapeutic efficacy means only that which the scientist regards as important is granted legitimacy (Andrews, 2001; Larner, 2001). Most typically this involves focusing on a particular theoretical approach, intervention or technique (Andrews, 2001; Larner, 2001).

This approach ignores a whole range of phenomenon related to the dynamics of practice and people's sociopolitical context (Adcock and Newbigging, 1990; Andrews, 2001; Larner, 2001; Pilgrim and Treacher, 1992). Equally, the diversity of clients and practice settings necessitates multiple approaches to therapy that are not well accommodated within a positivist science framework (Andrews, 2001; Horvarth, 2001; John, 1998; Larner, 2001). As Pilgrim and Treacher (1992: 195) state:

The scientist-practitioner model dominant in clinical psychology, predicated as it is on positivism, tends towards technocratic solutions to existential problems. It assumes the non problematic status of 'facts' and the justified power of their possessors. The lack of value engagement and reflexivity of this approach ... does not augur well for an accountable form of professional practice.

A vast body of work is dedicated to issues concerning the therapeutic relationship, and psychologists' interpersonal style and skills (Andrews, 2001; Horvarth, 2001; Soldz and McCullough, 2000). The interplay of client characteristics and practice approaches are also increasingly addressed. Attention is also directed at the lack of legitimacy of practice based knowledge and clinical 'wisdom', knowledge that most practitioners hold in high regard (Larner, 2001; Orlinsky, Botermans and Ronnestad, 2001; Soldz and McCullough, 2000). 


\section{A Critical-Practitioner Proposal}

More recently critical-practitioner models of professional psychology have been posited (Larner, 2001; Prilleltensky and Nelson, 2002). Such paradigms embrace integrative, flexible and people oriented approaches. Within these models there is cognisance of the diversity and multiplicity of human life and the complexity of difficulties people may experience. There is recognition of the dynamics and importance of the therapeutic relationship, and acknowledgement of the centrality of psychologists' personal attributes and skills (see for example, Larner, 2001). Larner (2001: 36) describes this model as:

A critical psychology that addresses the cultural, spiritual, emotional, subjective, physical, and discursive foundations of psychological life [and] invites psychologists to consider qualitative, collaborative, meaning-focused, and person-sensitive methodologies in scientific therapy and its research.

By embracing a psychology in which 'best practice' is that which combines multiple knowledges derived from the reciprocal interweaving of practice and diverse forms of research, clinical psychology would be better positioned to construct knowledge that reflects the diversity of peoples' lives and meet the needs of those who use its services. This approach would allow greater responsiveness to the limitations feminist and other psychologists have addressed in relation to the positivist science dominance of clinical psychology and the scientist-practitioner model of clinical psychology training.

\section{Conclusion}

While clinical psychology endorses a positivist science epistemological and methodological position in which individualism is central, as well as a scientist dominant model of training, it decontextualises sociopolitical problems and tends to marginalise women, and excludes or minimises issues of gender and other relations of power. It also fails to recognise the harmful consequences of this model for women and other marginalised groups (Stoppard, 1999, 2000; Ussher, 1991, 1992, 2000b). The adoption of a non-critical and non-reflective position and failure to recognise its power in the production of knowledge, combined with the continued use of a diagnostic system 
which pathologises women, means clinical psychology tends to function as a source of regulation and oppression (Hare-Mustin and Marecek, 1997; Kitzinger, 1990a; Nicolson, 1995; Pilgrim and Treacher, 1992). At all levels - clinical practice, academic teaching, supervision, research, staff training, consultancy, policy development, and management - clinical psychology limits the (pro)vision of a psychology which is holistic and reflexive, engages plurality and multiplicity, centralises subjectivity, and in which sociopolitical context is integral to understanding human experience. While these issues are highlighted in critiques of the positivist science dominance of psychology and use of the scientist-practitioner model, they are also implicit in the current emphasis on CBT in contemporary clinical psychology. 


\section{Chapter Two}

\section{The Dominance of Cognitive-Behaviour Theory and Therapy in Clinical Psychology}

In this chapter I discuss the current theoretical orientation of clinical psychology, in which a cognitive-behavioural model is dominant. Drawing on literature from diverse theoretical positions I argue that the pre-eminence of a cognitive-behaviour therapy (CBT) model $^{34}$ of clinical psychology has more to do with political and economic determinants than with the efficacy of this approach. Within this critical literature, claims about the superiority of CBT are shown to be based on positivist science assumptions that can marginalise other therapeutic approaches and privilege a realist, normative Eurocentric, masculinist epistemological standpoint.

The chapter begins with a summary of the status, nature and pervasiveness of CBT in contemporary clinical psychology. A range of critiques of CBT follow. In particular I draw attention to the epistemological basis of CBT in the context of feminist and social constructionist theories about knowledge, 'truth' and reality. I then address the way the individualism and reductionism of CBT deny the contextual nature of knowledge and experience. The focus on cognitions within CBT is also criticised in terms of the way this model minimises emotion and other forms of experiential knowing. I also direct attention to the way CBT minimises the therapeutic relationship and dynamic process of therapy. Finally, criticisms are presented concerning the way CBT marginalises women's gendered sociopolitical position and may perpetuate gender inequities and gender discriminatory practices.

Cognitive-behaviour therapy is the dominant and most commonly endorsed approach to research and training in contemporary clinical psychology throughout Britain, the

\footnotetext{
${ }^{34}$ The term CBT is variously used in the literature to refer to theory, therapy, treatment and/or techniques based on cognitive-behavioural approaches to psychology.
} 
United States of America, Canada and Australia (Baydala, 2001; Larner, 2001; Pilgrim and Treacher, 1992). A substantive body of international literature asserts the efficacy of CBT (Larner, 2001). Indeed, in clinical psychology CBT has become synonymous with 'empirically validated treatments', 'evidence based practice' and 'best practice' (Department of Health, 2001; Larner, 2001).

In Aotearoa New Zealand, CBT is the dominant model of clinical psychology training in all except one clinical programme, as evidenced in DipClinPsych course outlines. ${ }^{35}$ Many employment positions for clinical psychologists in this country emphasise CBT as the theoretical orientation of choice. Ongoing training in CBT is also promoted through a range of workshops and seminars. As CBT becomes synonymous with evidence-based practice or empirically validated treatments, third party payers such as the Accident Compensation Corporation (ACC) require providers of clinical psychological services to offer 'evidenced based cognitive-behavioural interventions'. ${ }^{36}$ The prevalence of CBT is also reflected in the establishment of schools of CBT such as the Auckland Institute for Cognitive and Behaviour Therapies and the postgraduate Diploma in Cognitive-Behaviour Therapy at Massey University.

In part, CBT's rise in popularity has occurred as the profession has responded to a progressively restrictive political and economic environment internationally. The provision of short term and inexpensive psychological services is preferred when government agencies and third party payers dictate the conditions of health funding (Baydala, 2001; Larner, 2001; Newman and Castonguay, 1999; Soldz and McCullogh, 2000).

Despite the active endorsement of CBT by clinical psychology academics, researchers and their professional organisations, CBT faces a growing body of criticism. The

\footnotetext{
${ }^{35}$ For example a psychology course titled Clinical Assessment and Intervention states: 'This course is a prerequisite for the clinical diploma programme...the adult section of the course draws primarily on a cognitive-behavioural theoretical model... [and] by completion of the course students should be able to demonstrate knowledge and use of behavioural methods of assessment' (Victoria University, PSYC 450, course outline, 2001: 1-2).

${ }^{36}$ For example see NZPSS Connections, December, 2000:2.
} 
efficacy of CBT, its effectiveness in 'real life' practice, its proclaimed superiority and the concomitant exclusion of other therapeutic approaches have all been challenged (Baydala, 2001; Larner, 2001; Newman and Castonguay, 1999; Pilgrim and Treacher, 1992). The gap between research and practice is also an issue of increasing concern (Soldz and McCullough, 2000).

\section{The Nature and Pervasiveness of Cognitive Behavioural Therapy}

Cognitive-behavioural therapy is an umbrella term used to describe a conglomerate of cognitive and behavioural approaches to psychological therapy, and encompasses a diverse set of ideas and practices. While CBT dominates much contemporary clinical psychology literature, there is considerable diversity in the use of the term depending on the theoretical orientation of the writer (Allen, 1996). While the adjunct 'cognitive and behavioural therapies' is used by some writers (for example Davison and Neale, 2001), others conflate the two as conveyed in the commonly used terms 'cognitive-behavioural therapies' (for example Basco and Rush, 1996; Goldfried, 1995; Lindsay and Powell, 1994; Salkovskis, 1996) and 'cognitive behavioural therapies' (for example Carlson, Buskit and Martin, 2000). Some writers differentiate cognitive therapies and cognitivebehavioural therapies (for example Bloch, 1996; Hollon and Beck, 1994) while others state that 'cognitive therapy and cognitive-behavioural therapy mean the same thing' (Allen, 1996:168).

Recent advances in the area of CBT are associated with moves away from a behaviourally orientated tradition towards a more cognitively focused model $^{37}$ (Beck, 1995; Davison and Neale, 2001; Hollon and Beck, 1994; Safran, 1998). Some texts referred to in this section are titled 'cognitive therapy', rather than 'cognitivebehavioural therapy', but include content that may be regarded or referred to as CBT (for example DiGiuseppe, 1993; Kuehlwein and Rosen, 1993; Persons, 1993; Safran, 1996). Others differentiate cognitive therapy and behavioural therapy but may include the umbrella term CBT when specifically discussing cognitive therapy (for example

\footnotetext{
${ }^{37}$ For example the Auckland clinical psychology programme course outline (1999) refers to students gaining competency in 'cognitive therapy' rather than 'CBT' as apparent in previous years.
} 
Bradley, 1994). It is apparent that these terms are used variably and at times interchangeably. Steven Hollon and Aaron Beck (1994: 429) comment:

[B]oth approaches (cognitive and cognitive-behavioural) combine cognitive and behavioral elements, albeit in different ways and to different extents, and both legitimately belong to the larger family of cognitive-behavioural interventions. ${ }^{38}$

Despite the increasing prominence of cognitive therapy, the term CBT remains commonly employed across a broad spectrum of clinical psychology and throughout its key academic journals and texts. Given its common usage in both the literature and the local professional community, the term CBT is used in this thesis.

The foundations of CBT were established in the early work of writers such as Albert Ellis (1962), Aaron Beck (1967, 1976), Albert Bandura (1977), Donald Meichenbaum (1977), Arnold Lazarus (1971, 1981), Michael Mahoney (1974), and Phillip Kendall and Steven Hollon (1979).

The proliferation of writing about CBT is accompanied by multiplicity in the meaning and application of this approach. While CBT is rarely defined in the psychological literature, it is more common to find definitions or documentation of the key elements of 'cognitive therapy' (for example N. Allen, 1996; J. Beck, 1995; Hollon and Beck, 1994) or 'behaviour therapy' (for example Drummond, 1996). When an outline of CBT is included it is often specific to a 'disorder' or details components of interventions (for example see Basco and Rush, 1996; Hollon and Beck, 1994; Lindsay and Powell, 1994).

While CBT may be deployed in diverse ways, reflecting the theoretical orientation of different writers, and involving different conceptual frameworks, techniques and processes of change, it rests upon some relatively unified philosophical foundations. ${ }^{39}$

\footnotetext{
${ }^{38}$ Nicholas Allen (1996:168) also comments that 'the terms 'cognitive therapy' and 'cognitive behaviour therapy' mean the same thing, except that the term 'cognitive-behaviour therapy' makes explicit reference to the fact that techniques derived from behaviour therapy are usually included in the treatment protocol.' He uses the terms interchangeably.

${ }^{39}$ For discussion of the historical and philosophical background, and development of cognitive-behaviour therapies see Dobson and Block in Dobson (1988) and Dobson in Dobson, (1988); for a more
} 
Put simply, CBT involves a theoretical rationale in which thought, behaviour and emotion are regarded as interrelated processes that are amenable to change. In an outline of psychotherapies used in the British National Health Service, CBT is described as:

$[\mathrm{T}]$ he pragmatic combination of concepts and techniques from cognitive and behaviour therapies...[b]ehaviour therapy is a structured therapy originally derived from learning theory, which seeks to solve problems and relieve symptoms by changing behaviour and the environmental factors which control behaviour...[c]ognitive therapy is a structured treatment approach derived from cognitive theories. Cognitive techniques... and behavioural techniques... are used with the main aim of relieving symptoms by changing maladaptive thoughts and beliefs (Department of Health, 2001: 8). ${ }^{40}$

This model is based on the following basic assumptions: cognitive activity affects behaviour; cognitive activity may be monitored and altered; and desired behavior change may be effected through cognitive change (Allen, 1996: 168).

Several writers distinguish rationalist and constructivist models of CBT, drawing attention to differences in epistemological and theoretical focus (Lyddon, 1997; Mahoney, 1993). A rationalist model of CBT holds to a realist epistemological position in which objective reality is assumed to exist. Psychological problems result from a lack of congruity between cognitive and behavioural functioning, and external reality. Incongruities are regarded as 'distortions' resulting in 'dysfunction' (Dobson and Pusch, 1993). Within a rationalist model of CBT, information processing is central to understanding human functioning and experience. This model is based on the following three key assumptions:

that irrationality is the primary source of neurotic psychopathology; that explicit beliefs and logical reasoning can easily overpower and guide emotions and behavioral actions; and that the core process in effective psychotherapy is the substitution of rational for irrational thinking patterns (Mahoney, 1993: 189).

contemporary discussion of the theoretical development of cognitive psychotherapies see Mahoney (1993).

\footnotetext{
40 See Department of Health (2001). Treatment Choice in Psychological Therapies and Counselling. Evidence Based Clinical Practice Guidelines (London: Department of Health). www.doh.gov.uk/mentalhealth/treatmentguideline; [2002]
} 
Within a constructivist model of CBT the political nature of knowledge and meaning making is central, and the diversity and multiplicity of experience is recognised and embraced, as are unconscious processes. Constructivists emphasise the processorial and developmental nature of knowledge and experience (Mahoney, 1993: 189). Constructivist theory 'promotes a complex systems model in which thought, feeling, and behavior are interdependent expressions of a life span developmental unfolding of interactions between self and (primarily social) systems' (Mahoney, 1993:189). ${ }^{41}$ While a constructivist model of CBT is increasingly common, it is apparent that most clinical psychology research and training is rationalist in orientation. It is the conventionally rationalist model of $\mathrm{CBT}$ that is the focus of this chapter.

Within a conventional model of CBT, 'distorted', 'irrational', 'maladaptive' thoughts, beliefs or schema, ${ }^{42}$ biased information processing and 'dysfunctional' behaviours, are believed to produce and maintain a range of 'psychological problems' or 'disorders' Hollon and Beck, 1994; Kuehlwein and Rosen, 1993). The purpose of psychological intervention is to facilitate change in cognitions and behaviours deemed problematic, thereby reducing emotional distress (Allen, 1996; Dattilio and Freeman, 2000; Hollon and Beck, 1994).

When used as the primary form of therapy, CBT is typically structured, directive, goal focused and time-limited (Allen, 1995; Allen, 1996; Dattilio and Freeman, 2000). Cognitive-behaviour therapy is usually oriented to the 'here and now' focusing on presenting problems, conscious thoughts and overt behaviours (Allen, 1995; Allen, 1996). As it is not my intention to trace the development of CBT, nor detail the typology of this approach, the reader is referred to texts about $\mathrm{CBT},{ }^{43}$ the publications

\footnotetext{
${ }^{41}$ It is also apparent that developments in CBT are associated with a broader interpretation and application of the original principles of this model, with greater emphasis on the role of cognitive and emotional components and the therapeutic relationship, and the inclusion of therapeutic approaches from diverse theoretical orientations (for example Linehan, 1993; Safran and Muran, 1996; Safran, 1998).

${ }^{42}$ Schema are described as 'deep, relatively stable cognitive structures reflecting fundamental beliefs about oneself, the world, and others that actively organize in systematic ways incoming data and the interpretations made on the basis of such data' (Kuehlwein and Rosen, 1993: 11).

${ }^{43}$ For example: Arnkoff and Glass, (1992); Chambless, Sanderson, Shoham, Johnson, Pope, CritsChristoph, Baker, Johnson, Woody, Sue, Beutler, Williams and McDurry, (1996); Dattilio and Freeman, (2000); Hollon and Beck, (1994); Rachman, (1996).
} 
of writers included in this section, and to the numerous contemporary psychology journals in which a CBT model of clinical psychology is prominent.

A proliferation of research suggests that CBT is effective in ameliorating a diverse range of disorders (Bergin and Garfield, 1994; Hollon and Beck, 1994; Lindsay and Powell, 1994). Many publications have linked CBT with the treatment of depression (Beck, Rush, Shaw and Emery, 1979; Hollon, Shelton and Loosen, 1991; McGrath, Keita, Strickland and Russo, 1990), depression and anxiety (Blackburn and Davidson, 1995), anxiety (Beck, Emery and Greenberg, 1985; Chambless and Gillis, 1993; Padensky and Greenberher, 1995), post-traumatic stress disorder (PTSD) (Foa and Rothbaum, 1998; Meichenbaum, 1994; Muran and DiGiuseppe, 1994; Smucker and Dancu, 1999), panic (Beck, 1988; Beck, Sokol, Clark, Berchick and Wright, 1992; Clark, Salkovskis, Hackmann, Middleton and Gelder, 1992), phobias (Beck and Emery, 1985; Butler, 1989, Bruce and Sanderson, 1998), obsessive-compulsive disorder (Salkovski, 1996), personality disorders (Beck and Freeman, 1990; Linehan, 1993; Turner, Becker and DeLoach, 1994), bipolar disorder (Basco and Rush, 1996) and psychotic disorders (Haddock, Rattier, Spaulding, Yusupoff, Kinney and McCarthy, 1998; Kingdon and Turkington, 1994).

Cognitive behavioural approaches have also been endorsed in addressing crisis situations (for example see Dattilio and Freeman, 2000) and a wide variety of problems such as relationship difficulties (Bennun, 1994), interpersonal difficulties (Spence, 1994), drug and alcohol difficulties (Gossop, 1994; Sobell and Sobell, 1996) problem gambling (Ladouceur and Walker, 1996), offending (Hollon, 1990; 2000), pain management (Pearce and Mays, 1994) and more general life difficulties or problems (Beck, 1995). The use of CBT in dealing with multiple co-existing difficulties has also been noted (for example Freeman, 1993). Cognitive behaviour therapy is also reported to be effective in working with people from a range of age groups (DiGiuseppe, 1993; DeVries and Gallegher-Thompson, 1994; Hollon, 1990; King, Ollendick and Tonge, 1997). While most literature about CBT focuses on individual adult work, it also includes the use of CBT with couples (Epstein and Schlesinger, 1994), groups (Courchaine and Dowd, 1994) and as an approach to structuring the therapeutic milieu of psychiatric admission wards (Perris, Ingelsson and Jonsson, 1993). 
These examples are exemplary of a body of research which makes claims about the efficacy of CBT in relation to an increasing range of psychological difficulties. However there is a growing body of contention about its effectiveness as a universally applied model with diverse groups of people, across diverse contexts and in relation to multiple co-existing difficulties. Critics challenge claims about the superiority of CBT and its dominance in contemporary clinical psychology. There is also increasing scepticism about the epistemological and theoretical foundations of CBT.

\section{Critiques of Cognitive Behaviour Therapy}

As discussed in Chapter One, feminist psychologists and scholars from diverse epistemological positions have long challenged the western dominant, positivist science basis of mainstream psychological theories (Lyddon and Weill, 1997; Abbott and Durie, 1987; Stoppard, 1999, 2000; Ussher, 1991, 1992, 2000b). Similarly, therapeutic models upon which clinical psychology is based have been the focus of much debate (Baydala, 2001; Lyddon and Weill, 1997; Stoppard, 2000; Ussher, 1992, 2000b).

Cognitive behaviour therapy in particular has become the subject of increasing criticism as this particular model of psychological practice takes hold as the dominant model of clinical psychology (Baydala, 2001; Larner, 2001; Lyddon and Weill, 1997). While recognising the usefulness of $\mathrm{CBT}$ as one of many possible approaches, it is the preeminent position of CBT in clinical psychology, and the privileging of this approach to the exclusion of other theoretical and therapeutic frameworks that is regarded as problematic.

While some feminist psychologists support the use of CBT in conjunction with a feminist orientation or as an adjunct to other approaches to therapy (for example, Allen, 1995; Fodor, 1988, 1993; Hurst and Genest, 1995; Toner, 1994), others are critical of the epistemological foundations of this model (for example Baydala, 2001; Kantrowitz and Ballou, 1992; Lyddon and Weill, 1997; Stoppard, 1999, 2000). Indeed, criticism of 
CBT ranges from macro perspectives in which its epistemic structure is challenged through to basic assumptions about this model and the micro level of therapy.

Epistemological Issues

Feminist and other critical psychologists have challenged the positivist-realist epistemological foundations of rationalist models of CBT in which knowledge, 'truth' and 'reality' are regarded as singular, stable phenomena that are externally defined and 'discoverable' through 'scientific', 'objective' research (Kantrowitz and Ballou, 1992; Lyddon and Weill, 1997; Ussher, 2000b). Grand theories or metanarratives such as CBT are regarded as problematic because they deny the discursively, socially and historically constituted nature of knowledge, and the existence of multiple, often competing or contradictory 'realities' (Gonçalves, 1997; Lyddon and Weill, 1997; Stoppard, 1999; 2000).

As a dominant psychological model, CBT is challenged on the grounds that it reflects the masculinist and Eurocentric worldviews and values of predominantly North American male researchers (Kantrowitz and Ballou, 1992; Pilgrim and Treacher, 1992; Stoppard, 1999, 2000). As with positivist psychology more generally, criticism is levelled at the way definitions of knowledge, reality and health are constructed in accordance with male notions of 'logic', 'reason' and 'rationality'. Equally, much attention is paid to notions of 'expert' knowledge and 'consensus' definitions of health (Ussher, 2000b). Thoughts and beliefs that do not correspond with those prescribed within a CBT model as 'rational' or 'objective' are regarded as 'unhealthy' or 'distorted' (Gonçalves, 1997; Lyddon and Weill, 1997; Stoppard, 1999, 2000). As Lyddon and Weill (1997: 82) comment, 'the validity of clients' beliefs (is measured) in terms of the degree to which such beliefs 'match' or correspond to therapist-defined standards of rationality and/or objectivity.' Not surprisingly, only those forms of knowledge and reality which accord with dominant cultural assumptions and the values and beliefs of psychologists are granted legitimacy in psychology. While these standards reflect social consensus, they are presented as a universal objective reality and used as to define peoples' experience. By insisting on a rationalist and objectivist 
epistemology, proponents of CBT deny the diversity of ways people experience and interpret the world, and the functional utility of people's responses in diverse situations (Gonçalves, 1997). ${ }^{44}$

While acknowledging contemporary developments in $\mathrm{CBT}^{45}$ and affirming its usefulness as a tool in psychological practice, feminist psychologists Ricki Kantrowitz and Mary Ballou (1992) have challenged the assumptions upon which rationalist models of CBT are based. They are particularly critical of the tendency to:

$[F]$ ocus on the individual and her symptoms; to prioritize cognition, deemphasize affect, and ignore other dimensions; and to define adaptive, appropriate behavior based on the norms of the existing culture (Kantrowitz and Ballou, 1992: 85).

While arguments put forward here can also be applied to other psychological approaches, a key criticism of the dominance of CBT in clinical psychology is its promotion as a superior form of 'therapy'. ${ }^{46}$ While CBT is promoted as the 'treatment' for an increasing range of 'disorders' and 'diagnoses', other theoretical models become marginalised and discounted as valid forms of practice. The process of 'Othering' different theoretical approaches is regarded by some writers as a strategy for ensuring one's own paradigm retains power in psychology (Safran, 1998).

Cognitive-Behaviour Therapy and Individualism

Within CBT the focus on cognitions means the contextual nature of knowledge, 'reality' and experience is denied (Gonçalves, 1997; Lyddon and Weill, 1997). Angelina

\footnotetext{
${ }^{44}$ Criticisms of the assumptions that underpin CBT are also applicable to other mainstream psychological approaches in that they tend to reflect affluent, white, and North American norms and beliefs (HareMustin and Marecek, 1997).

${ }^{45}$ For instance moves towards more integrative models in which the centrality of emotional and affective experience and the importance of the therapeutic relationship are recognised as integral components of therapy (Andrews, 2001; Goldfried, 2000; Linehan, 1993; Safran, 1998).

${ }^{46}$ Some writers do not regard CBT as 'therapy' and instead refer to this approach as the application of 'techniques' particularly in terms of research where standardised manuals based on CBT are used as 'treatment' (Baydala, 2001). Donald Polkinghorne (1999: 1429-1430 citing Woolfolk, 1998) discusses this issue referring to 'manualized validated psychological techniques' as 'psychotechnology' aimed at 'symptom removal not self-understanding' (Polkinghorne, 1999: 1430).
} 
Baydala (2001: 45) comments: 'the radical individualism of cognitive therapy separates persons from the influences that constitute them'. This results in a theoretical conceptualisation in which individual people and the way they think about the world are defined as problematic. This might include for example women's 'cognitive deficits', 'ruminative styles', 'dysfunctional attitudes', 'self-defeating thoughts' and 'ruminative self-focused coping' (Stoppard, 1999: 85), as well as their 'cognitive vulnerability' or problematic 'coping styles' (Ussher, 2000b: 213). Women are regarded as particularly prone to these 'problematic' styles of thinking (Stoppard, 1999, 2000; Ussher, 2000b). Such constructions are viewed in terms of the pathology of an individual, rather than constructions that serve a gendered and discriminatory psychology (Stoppard, 2000; Ussher, 2000b). In a critique relating to psychological formulations of 'depression' Janet Stoppard (1999: 84) comments:

the negative connotations of events in the social environment tend to be attributed to the negative, pessimistic slant of interpretations made by individuals whose cognitive style renders them depression-prone. ${ }^{47}$

Within this model the 'source' or etiology of psychological difficulties is located within the individual. The problems people experience are defined internally and classified in terms of a disorder. In this way individual people are held responsible for the source of their problems as well as for changing them (Fodor, 1993; Kantrowitz and Ballou, 1992; Lyddon and Weill, 1997; Stoppard, 1999, 2000; Ussher, 2000b). Indeed, Ussher (2000b: 212) comments:

In psychological models of madness, the emphasis on cognitions is arguably ... reductionist, the focus may not be on biology, but it is still an essentialist view of madness, looking within the woman for the problem and following a simple model of cause and effect.

By discounting or at best marginalising the context in this manner, proponents of CBT effectively negate the importance of diversity and positionality, and the influence of gender, 'race', class, (dis)ability sexual orientation, and other dimensions of power in constituting human experience (Kantrowitz and Ballou, 1992; Lyddon and Weill, 1997; Stoppard, 2000; Ussher, 2000b).

\footnotetext{
47 This is despite research that reports people who are defined as 'depressed' have a more accurate interpretation of their world than those who are not defined as depressed (Allen, 1995; Toner, 1994).
} 
By denying the material and sociopolitical conditions of women's lives, and failing to take account of women's experiences at different stages of life, CBT limits the provision of an holistic theoretical perspective in which an understanding of women's realities can be more fully appreciated (Stoppard, 2000). These issues relating to the individualism of CBT are further illustrated in its focus on cognitions and behaviours at the expense of other experiential phenomena.

The Primacy of Cognitions and Behaviours

While there is increasing attention to the importance of emotion amongst some proponents of CBT (for example Guidano, 1992; Mahoney, 1991; Safran, 1998; Safran (1996: 121) suggests that emotion has been treated by the 'cognitive behavioural tradition primarily as post-cognitive phenomenon'. Indeed, most standard psychology texts and clinical programmes in Aotearoa New Zealand endorse a realist rationalist model of CBT. Within this model the emphasis is on thought and behaviour. The place of emotion and other phenomena central to human experience is regarded in a peripheral manner (Allen, 1995; Fodor, 1993; Kantrowitz and Ballou, 1992). Both thought and behaviour are deemed separate from the sociopolitical, material and discursive context, yet these constructs are presented as if they embodied the entirety of people's experience and knowable reality. The separation and dichotomisation of thought/feeling, rationality/irrationality, mind/body and male/female perpetuates Modernist dualisms in which value is placed on those aspects traditionally associated with masculinity (Davar, 2001; Lyddon, 1997). By continuing to prioritise cognition and behaviour, CBT marginalises emotion and negates other knowledges such as embodiment, intuition, spirituality and unconscious forms of knowing which are often associated with 'women's ways of knowing' and non-dominant cultural worldviews (Davar, 2001; Durie, 2001; Fodor, 1993; Kantrowitz and Ballou, 1992; Lyddon and Weill, 1997). Bhargavi Davar (2001: 23) argues that 'the more diffuse, contextual, tacit, textured, creative, pre-verbal, unconscious and inarticulate realms of the personal, interpersonal, cultural and sociopolitical experiences' need addressing to adequately understand people in their communities and lived contexts. The failure of CBT to 
provide an integrated analysis of people's experience and realities limits what can be known or understood.

CBT has also been criticised for prioritising 'functionality' in the present. A person's past, their historical, cultural and sociopolitical context is typically relegated to the status of 'background information'. Lifetime issues and processes, and contextual factors that contribute a person's experience are considered in only a marginal way in the construction of "psychological formulations' and 'plans for treatment' (Baydala, 2001; Safran, 1998). While the practice of CBT in the main involves negation of the past, the theoretical foundations of CBT are actually based on the development of cognition and systems of thought throughout one's lifetime (Baydala, 2001). Consequently, while a developmental theory of cognition is propounded within this framework, the role of life stages, and developmental and historical factors (including for instance colonisation) in shaping human experience are denied (Kantrowitz and Ballou, 1992). Despite the obvious relevance of a person's past, and moves by some to advocate the use of 'historical reconstruction' as an integral component of therapy (Mahoney, 1991; Safran, 1998), this approach is not typically endorsed in CBT research or in local clinical training.

These criticisms of CBT raise a number of issues concerning the relevance of this particular model for many groups of people, not least women and girls. While the individualism and reductionism of CBT have been a primary site of criticism, so too has the way mainstream CBT negates the actual process of therapy.

\section{The Process of Therapy}

The almost exclusive focus of CBT on the interiority of an individual combined with an emphasis on skills and techniques, manualised treatment approaches and outcome oriented tasks has meant that practitioner variables, the process of therapy and dynamics of the therapeutic relationship are largely disregarded (Andrews, 2001; Fodor, 1993; Larner, 2001; Safran, 1998). 
In discussing the interpersonal nature of therapy, and the inseparability of practitioner variables from a specific therapeutic system, Andrews (2001) addresses a number of factors made invisible when therapy focuses solely on techniques or modes of intervention. In particular, the power and centrality of the therapeutic relationship is highlighted as a key determinant of effective therapeutic outcomes. Similarly a practitioner's interpersonal skills, including for example the ability to engage and support clients and develop rapport early in the therapeutic relationship, are considered essential to effective outcomes (Andrews, 2001). Further, the ability to understand a client's problems and accurately gauge the degree of distress a client is experiencing is regarded as crucial in the establishment of a therapeutic alliance, positive therapeutic outcomes and retention of clients in therapy (Andrews, 2001). It is not surprising therefore that those who are most likely to terminate therapy prematurely are people from a sociocultural position that is different from most practitioners (Andrews. 2001). These findings raise concerns about the relevance of a model such as CBT to people from diverse groups whose life experiences, culture, sociopolitical position and worldviews are different from that represented by mainstream clinical psychology.

\section{Marginalising Women's Gendered Social Position}

Feminists, Māori and others have long addressed the role of oppression and discrimination in contributing to psychological difficulties (for example Abbott and Durie, 1987; Fodor, 1988, Holland, 1992; 1993; Moeke-Pickering et al, 1996; Nikora, 1993; Stewart, 1995; Stoppard, 1989, 1999, 2000). In particular, feminist writers have drawn attention to the relationship between women's gendered sociopolitical position and women's experiences of emotional pain (Kantrowitz and Ballou, 1992; Ussher, 1992, 2000b). Cognitive-behaviour therapy has been specifically challenged for minimising social context and negating the role of women's material realities in constituting psychological disorders (Allen, 1995; Fodor, 1988, 1993; Hurst and Genest, 1995; Kantrowitz and Ballou, 1992; Stoppard, 1989, 1999, 2000; Toner, 1994). Feminist critics also argue that $\mathrm{CBT}$ reinforces gender inequities and gender discriminatory practices (Fodor, 1988; 1993; Hurst and Genest, 1995; Kantrowitz and Ballou, 1992). For example, the chronicity of stress resulting from the effects of adverse 
material conditions and life experiences which women often endure has received little attention in CBT literature (Fodor, 1988, 1993; Hurst and Genest, 1995). Questions are therefore raised about the relevance of CBT for women whose material conditions are oppressive. Susan Hurst and Myles Genest (1995) comment that oppressive day to day conditions are more likely than specific events to impact on mental health, yet this issue is rarely addressed in research on stress. They note that ' $[\mathrm{p}]$ oor single-parent women report that economic hardship is one of their largest sources of stress' (Hurst and Genest, 1995: 146).

In their discussion of various models for understanding depression in women, Hurst and Genest (1995) provide a pertinent example of the limited way social context is conceptualised within CBT. In particular they are critical of the way concepts of stress are restricted to specific, stressful life events such as a death, separation or redundancy. While low socio-economic status may be acknowledged in the context of CBT, it remains a 'variable' rather than a context that may cause chronic stress. They also note that the most commonly employed 'stressful life-events' checklists used in CBT do not include significant life issues particular to women, for example, sexual violence, adult relationship violence, pregnancy termination and miscarriage. In contrast, less personal issues such as financial and legal problems are included (Hurst and Genest, 1995: 245). Such examples support Stoppard's (1999) contention that the structural and material conditions in which women's lives are embedded remain invisible within dominant psychological models. By minimising the effects of adverse social conditions in this way, psychologists who use CBT as their only approach to therapy may unwittingly participate in the disempowerment of women.

More generally, feminist psychologists have addressed the relationship between women's sociopolitical position and poor psychological health. For example, gender inequities based on marital status, ${ }^{48}$ care-giving responsibilities, household demands and decision making, parenting alone, ${ }^{49}$ access to and affordability of childcare, social

\footnotetext{
${ }^{48}$ I intentionally use 'marital status' as it reflects research that indicates married women are at higher risk of poor psychological health than unmarried women (Stoppard, 2000).

${ }^{49}$ It is not parenting alone per se that is necessarily problematic but the limited financial resourcing, stigma, and devalued status of women who parent alone.
} 
support, income, ${ }^{50}$ employment status and conditions, pay differentials, and financial, social and political power, are all implicated in problems with psychological health ( $\mathrm{F}$. Allen, 1995; Hare-Mustin and Marecek, 1997; Hurst and Genest, 1995; Stoppard, 1999, 2000; Ussher, 2000b).

Women who do not have paid employment or receive low incomes and are raising children alone are particularly disenfranchised in terms of well-being. Indeed, economic hardship and poverty have been highlighted by many feminist and critical writers as a primary contributor to poor psychological health (Hurst and Genest, 1995; McGrath et al, 1990; Parnell and Vanderkloot, 1994). The adverse consequences of poverty are significant in reports of depression and other forms of emotional pain (Holland, 1992; McGrath, et al 1990; Stoppard, 2000). In the National Task force on Women and Depression, McGrath and her colleagues report that amongst a range of life stressors, redundancy and financial difficulties were most likely to be associated with high levels of depression (McGrath et al, 1990: 32).

The implicit and pervasive view within a CBT framework is that women who live with poverty, especially mothers parenting alone, are somehow 'deficient' and require corrective 'treatment' (Parnell and Vanderkloot, 1994). Furthermore, a corollary of the 'deficient' woman is that she is also personally responsible for her unemployed or low income status, with the associated assumption that gender inequities are an aside to psychological health. Current paradigms of psychotherapy, such as CBT, are inadequate in accommodating the realities of those who live with economic hardship and as Parnell and Vanderkloot (1994: 391) suggest 'must be redesigned and expanded, in order to be at least appropriate and at best effective, ${ }^{51}$

Despite an array of literature in which the relationship between women's sociopolitical position, material conditions, and psychological health are addressed, conventional

\footnotetext{
${ }^{50}$ Particularly for women parenting alone who require state funded income support, renown for being insufficient.

${ }^{51}$ As noted in the following chapter, criticism around the classism of CBT has also been made in relation to feminism and feminist therapy.
} 
proponents of CBT remain impervious to this body of knowledge. The gendered and decontextual nature of CBT raises serious questions about the appropriateness and relevance of CBT for women as well as those from other marginalised groups.

\section{Eclectic Approaches to Clinical Psychology}

While CBT remains the dominant model in clinical psychology research and literature, an eclectic or integrative approach to practice is increasingly common (Arnkoff and Glass, 1992; Jensen, Bergin and Greave, 1990; Soldz and McCullough, 2000). ${ }^{52}$ In addition, while CBT is presented as a relatively unified theoretical approach, recent developments in CBT indicate a broader interpretation and application of its original principles (Linehan,1993; Safran, 1998). Further, in the past decade greater attention has been paid by some integrative cognitive psychologists to the centrality of emotion and affective experience, and the importance of the therapeutic relationship to therapy (Linehan, 1993; Safran, 1998; Safran and Muran, 1996. 2000). For example, Jeremy Safran's (1998) work integrates diverse theoretical positions and highlights the central place of emotion and the therapeutic alliance in psychological work.

While eclecticism may be increasingly common in the practice of clinical psychology, this trend is not well reflected in clinical psychology research and literature, where epistemological and theoretical boundaries are rigidly adhered to. Furthermore the publishing practices of mainstream psychology journals ensure the exclusion of research that does not support the efficacy of CBT and this has an illusory function of constructing CBT as the model of 'evidence-based practice'. Some writers suggest that eclectic approaches which embrace diversity and encourage the development of a comprehensive knowledge base, diverse skills and appropriate levels of competency are denigrated in some quarters of the professional community (Pilgrim and Treacher, 1992).

\footnotetext{
${ }^{52}$ Note that 'eclectic' is used in this thesis to mean the use of a range of therapeutic approaches derived from diverse theories and informed by research and practice knowledges.
} 
However, feminist psychologists, along with other critical clinical psychologists, argue that an eclectic and multifaceted approach is integral to the provision of therapeutic practice that is flexible, adaptable and actively embraces an understanding of the diverse cultural, sociopolitical and economic contexts of people's lives. It is suggested that moves toward a critical-realist (Ussher, 2000b) and critical-practitioner model of clinical psychology (Larner, 2001), in conjunction with multi-level theoretical analyses (Stoppard, 1999, 2000; Ussher, 2000b) and eclectic approaches to research and practice, may offer a more appropriate, effective and informed approach for the future development of clinical psychology.

\section{Conclusion}

The positivist science epistemological framework of clinical psychology, in conjunction with the current dominance of a rationalist model of CBT as the archetype of evidencebased practice, has been questioned by critics from diverse standpoints. In particular, the way political and economic factors shape the positioning and status of CBT within clinical psychology and clinical psychology's promotion of CBT as the empirically validated treatment have been widely scrutinised. Attention has been drawn to the way CBT not only dominates research and literature in clinical psychology but is actively used to exclude and dismiss other therapeutic paradigms. It is argued that the wholesale use of CBT as a dominant model of clinical psychology works against the interests of women and other marginalised groups. By limiting definitions of experience and 'reality' to cognition and behaviour, conventional models of CBT negate a whole raft of experiential phenomena that are central to the worldviews of many groups of people, particularly women. These arguments have significant implications for the use of CBT as the dominant model of clinical psychology in most training programmes in Aotearoa New Zealand and the continued promotion of CBT by clinical psychology academics. 


\section{Chapter Three}

\section{Feminist Psychologies}

The notion of 'feminist psychology" 53 has long been the subject of debate amongst feminists who have taken various philosophical and political positions with regard to the relationship between feminism and psychology (for example Fine and Gordon, 1991; Kitzinger and Perkins, 1993; Unger, 1992, 1996; Ussher, 1991, 2000a). Discussion has centered around whether there can be a feminist psychology and how these two seemingly contradictory positions could be linked. Indeed, while the term 'feminist psychology' is widely used there is little consensus about its meaning. Nevertheless, Erica Burman (1998: 3) notes:

'feminist psychology' names a strategic space between feminism and psychology; it is not a stable topic area, but rather identifies a site of contest (over what counts as knowledge, who defines this, and how it is arrived at).

While recognising that feminist psychology is not an orthodoxy, I have drawn on Burman's (1998) use of the term when discussing feminist psychology in this thesis. Further, I generally use the term to encapsulate the broad terrain of feminist thought associated with the critique and re/construction of psychological knowledge, in order to put gender and power at its center.

I am also mindful of Sue Wilkinson's use of the term 'feminist social psychologies' (1996: 8). Drawing on social psychological theories that are explicitly informed by feminism, this work actively endorses an understanding of psychology that is social and political in focus. Feminist social psychologies 'challenge the discipline of psychology for its inadequate and damaging theories about women, and for its failure to see power relations as central to social life ... [they insist] upon exposing and challenging the

\footnotetext{
${ }^{53}$ I have used the term feminist psychology in the singular where it is appropriate as well as for stylistic purposes. However, I recognise the plurality of the field that this work embraces.
} 
operation of male power in psychology ... and the dangers of [psychology's] individualism' (Wilkinson, 1996: 3-4). Further, contemporary feminist psychology is diverse, reflecting a multiplicity of epistemological, theoretical and methodological positions (Burman, 1998; Unger, 2001; Wilkinson, 1996, 2001). Such plurality leads to use of the term feminist psychologies rather than the singular form characteristic of earlier feminist writing.

In this chapter I address contemporary developments in feminist psychology, drawing on themes central to feminist conceptual frameworks for psychological practice. I discuss the importance of theories of power and the politics of difference and then turn to the local context where the Treaty of Waitangi, bicultural developments and Māori challenges to dominant psychology have shaped the unique nature of psychological knowledge and practice in Aotearoa New Zealand. Here I draw attention to Māori ontological perspectives, and specifically Māori scholars' experiences of clinical psychology and research relating to the inclusion of tikanga Mãori in clinical psychology training programmes. I then provide a brief synopsis of the development of feminist psychologies in this country. The remainder of the chapter focuses specifically on feminist critiques of clinical psychology. While recognising the long history of feminist psychology, this chapter focuses on more recent developments. ${ }^{54}$

\section{Contemporary Feminist Psychologies}

From the 1980s feminist psychology has become a burgeoning field of inquiry with work relating to a number of key areas. These include: epistemology and theory (Burman, 1990, 1996a, 1996b; Jackson, 2001; Kitzinger, 1987, 2001; Ussher, 1991, 2000b; Unger, 1996; Walkerdine, 1986, 1996; Wilkinson, 1986, 1997a, 2001); methodology (Crawford and Kimmel, 1999; Kidder and Fine, 1997); practice (Henwood, Griffin and Phoenix, 1998; Worell and Johnson, 1997a), and the interface between these spheres (for example Brabeck and Brown, 1997; Burman, 1996a, 1996b; Unger, 1996; Wilkinson, 1996, 2001). Attention has been directed at the teaching of

\footnotetext{
${ }^{54}$ For discussions of historical developments in feminist psychology internationally see for example
} Chesler (1972, 1997), Russo (1995), Sherif (1998), Unger (2001b), Wilkinson (1986) and Worrell (2000). 
psychology and ideas for a critical feminist pedagogy (for example Chin and Russo, 1997; Gergen, Chrisler and LoCicero, 1999; Hollway, 2000; Kimmel and Worell, 1997; Madden and Hyde, 1998).

The range of issues addressed has become increasingly diverse as feminists expanded the meaning of psychological knowledge (for example Burman, 1996a, 1996b; Wilkinson, 1996). Indeed, the notion of psychological knowledge is now widely contested as feminists and other critics observe the ways in which psychology infuses the everyday or 'common' knowledge, and is central to the construction of meanings about gender (Burman, 1996a, 1996b). Equally, feminists have moved from critique to reconstruction in attempting to provide holistic, socially contextualised, and historically, culturally and politically specific analyses of human life and experience. As Michelle Fine and Merle Gordon (1991: 19) comment, the work that captures the broad field of feminist psychology is 'rich and interdisciplinary - but not always recognizable as psychology'.

The development of theories about difference and related issues of diversity are also an important focus of feminist psychology. For example, feminists have addressed the importance of social dimensions such as (dis)abilities (Banks, Ackerman and Corbett, 1995; Fine, 1993), 'race' (Bhavnani and Phoenix, 1994; Espin, 1996), sexualities (Kitzinger, 1987, 1996, 2001; Kitzinger and Coyle, 2002; Kitzinger and Perkins, 1993), social class (Hill, 1998; Walkerdine, 1996a, 1996b) and age (Healey, 1993). These issues have gained increasing emphasis as feminists have argued that oppression and privilege are complex phenomena reflecting the interplay of power across multiple social dimensions (Greene and Sanchez-Hucles, 1997). As this is an important theme in contemporary feminist psychology I will return to it in more detail later in this chapter.

Feminist research and writing commonly reflects the interrelationship of diverse subjects and issues, and multiple levels of analysis and application. For instance feminists have written about lesbians and motherhood (Clarke, 2000), young lesbian women (Mooney-Somers and Ussher, 2000), mature women and bulimia (Robertson, 2000), young women and social class (Phoenix and Tizard, 1996), women with Androgen Insensitivity Syndrome (Kitzinger, 2000) and increasingly comprehensive 
conceptual frameworks for integrating race, class, gender and sexuality (Weber, 1998). Further, discussions and debates in feminist psychology now go beyond the conventionally 'psychological' to include for example meanings and ideologies about motherhood (Phoenix, Woollet and Lloyd, 1991), discourses and technologies of (normative) heterosexual coercion/sexual violence (Gavey, 1990, 1996) as well as other broadly conceptualised ideas relating to the material and discursive regulation of women's bodies, sexuality, reproduction and 'madness' (Ussher, 1997a, 1997b).

Some writers have identified common themes in the ways feminists have attempted to transform psychology. Judith Worell and Claire Etaugh (1994) identify six broad areas of interest which include: challenging assumptions upon which scientific inquiry is based, focusing on the experiences and realities of women's lives, starting from a perspective that recognises the primacy of power relations and the effects of power inequities, recognising gender as a social construction, attending to the use of language as well as the power to name, and retaining a focus on justice, equity and social change (Worell and Etaugh, 1994: 446-7).

Others have addressed the theoretical foundations of a feminist theory of psychological practice. For example Mary Braebeck and Laura Brown (1997), with others, identified nine foundational concepts including: a primary goal of feminist social and political transformation, the development of feminist consciousness, the development of theory grounded in women's (diverse) experiences, an explicitly inclusive approach in which diversity and the importance of diverse discourses of knowledge are central, recognition of agency and multiple subjectivities, explicit attention to the multiplicity of causes of human distress with an emphasis on sociopolitical context, and recognition that feminist

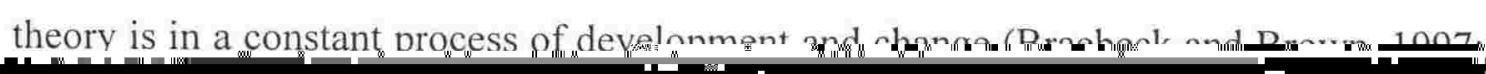


importance of ideas relating to difference and diversity in contemporary feminist psychology, I will now turn to a range of work which addresses these issues.

\section{Difference and Diversity}

Theories of power and the politics of difference have become an important focus of feminist psychologies. Indeed, there is increasing recognition of the way power operates to structure relations across diverse social dimensions (Greene and Sanchez-Hucles, 1997; Worell and Johnson, 1997a). Writers have variously discussed issues relating to culture (Landrine, 1995), 'race' and ethnicities (Afshar and Maynard, 1994; Espin and Gawelek, 1992), class (Walkerdine, 1996a, 1996b), poverty (Saris and JohnstonRobledo, 2000), sexualities (Kitzinger, 1987, 1995), (dis)abilities, (Appleby, 1993; Asch and Fine, 1992), age (Frith, 2001), and various matrices of these (Green and Sanchez-Hucles, 1997; Wyche, 2001). A body of work has also emerged which reflects the theorisation of sites of privilege including for example heterosexuality (Kitzinger, Wilkinson and Perkins, 1992; Wilkinson and Kitzinger, 1993) and 'whiteness' (Fine, Weis, Powell \& Wong, 1997).

Attention to difference was prompted by challenges to feminist psychology itself, which had in the main been dominated by the interests of white privileged women (Burman, 1996a; Green and Sanchez, 1997). The increasing presence of women from nondominant groups inside the academy and developing public consciousness led to greater awareness of these issues. In feminist psychology this was further facilitated via the 1991 launch of Feminism \& Psychology: An International Journal which aims to publish explicitly political feminist work reflecting diverse social, cultural, political and geographical perspectives. The journal's advisory group includes members from as far a field as The Netherlands, Costa Rica, Yugoslavia, Nigeria and Aotearoa New Zealand.

Developing theories and politics relating to members of marginalised groups led to an important Feminism \& Psychology Reader entitled Representing the Other (Wilkinson and Kitzinger, 1996). This work was influential in developing ideas related to the complexities of power and the conflicts and tensions involved in representing members 
of groups outside one's own. The editors go beyond common sites of Othering to include a multiplicity of ways women are Othered such as in relation to age, motherhood, HIV status and weight (Wilkinson and Kitzinger, 1996). They draw the reader's attention to the politics of 'research by "sane" women on madness' - a salutary reminder of the lack of interrogation of 'sanity' as a site of privilege (Wilkinson and Kitzinger, 1996: 2).

The politics of Othering is also explored in relation to social class with a special issue of Feminism \& Psychology (1996: 6(3)) devoted to discussions about social class as it relates to issues such as subjectivity (Walkerdine, 1996a), 'the dangerous classes' (Blackman, 1996) and feminist research (Reay, 1996).

On the other hand, discussions about the content of psychological research and reviews of PsychLit abstracts suggest that women on low incomes or living in poverty are also excluded from dominant psychology (Hall and Greene, 1996; Saris and JohnstonRobledo, 2000). When included, discussions focus on problematising poor women rather than addressing underlying inequities or positive features such as examining women's resilience and strategies for survival (Hall and Greene, 1996; Saris and Johnston-Robledo, 2000).

In the past decade feminist psychology has witnessed the advancement of an increasingly prominent body of work reflecting a focus on language and discourse (Burman, 1996b, 1998; Crawford, 2001; Gavey, 1996; Wetherell and Potter, 1992; Wilkinson and Kitzinger, 1995). Much of this writing is informed by social constructionist $^{55}$ and feminist poststructural ideas (Burman, 1996a). While approaches to discourse vary, Foucauldian influences are particularly notable (e.g. Gavey, 1996). Further, theories of subjectivity have gained increasing prominence (e.g. Hollway, 1992; Walkerdine, 1997). Work on discourse and subjectivity reflects a plurality of

\footnotetext{
${ }^{55}$ Here I am using Kitzinger's (1987) use of the term strong social constructionism to differentiate this ilk of work from other feminist writing which is less discursively focused. Further, I am distinguishing it from use in dominant psychology where the term is often confused with individualistic ideas relating to socialisation of gendered traits (Unger, 2001: 15).
} 
theoretical approaches. ${ }^{56}$ Though the ideas underpinning these shifts emerged some time ago (e.g. Gavey, 1990; Henriques et al, 1984; Kitzinger, 1987; Potter and Wetherell, 1987; Walkerdine, 1986), ${ }^{57}$ it is only more recently that they have gained prominence in the feminist psychologies literature. ${ }^{58}$

These theoretical developments have also led to a new wave of research using diverse methodologies and processes. In particular, discourse analysis has become one of the most prominent models of feminist research in the last decade (Burman, 1996a; Wilkinson and Kitzinger, 1995). This work includes for instance narrative analysis, conversation analysis, ethnomethodology, and psychoanalytic and poststructural approaches (Wilkinson and Kitzinger, 1995). A discourse analytic approach assumes that "language [is] an interactive activity, mediating linguistic and socio-cultural knowledge, and constituting a site for the construction of identities and subjectivities ... [language is also seen as] a key site for feminist resistance' (Wilkinson and Kitzinger, 1995: 3). In recent years, feminists have also turned their attention to topics typically regarded as taboo in dominant psychology, such as spirituality (Mattis, 2002).

Much of the discourse oriented work is now appearing in the critical psychologies literature (for example Fox and Prilleltensky, 1997; Prilleltensky and Nelson, 2002; Sloan, 2000). The launch of the International Journal of Critical Psychology and the Annual Review of Critical Psychology has furthered this project. Indeed, some feminist psychologists are leaders in this field, and have worked explicitly critical psychology contexts such as the Centre for Critical Psychology at the University of Western Sydney.

\footnotetext{
${ }^{56}$ For example in her chapter 'women's desire and sexual violence discourse', Gavey (1996) is described as using the 'framework of poststructuralist, discursive psychology, explicitly informed by radical feminist theory' (Wilkinson, 1996: 10-11).

${ }^{57}$ For example, the now classic publication Changing the Subject (Henriques et al, 1984) was significant in changing the route of feminist psychology. These writers advanced new ideas about subjectivity and highlighted psychology's role in social regulation. Likewise, The Social Construction of Lesbianism (Kitzinger, 1987) offered a radical lesbian feminist analysis using social constructionist arguments which remain current in feminist psychology today.

${ }^{58}$ It is also noted that there is an emerging body of evolutionary and biologically oriented feminist psychology (Gowaty, 2001).
} 
Dennis Fox and Isaac Prilleltensky (1997: 247) comment that 'feminist psychologists have instigated and maintained much of the critical effort to redirect psychology's theoretical assumptions, research methods, professional practices, and ethical guidelines.' However, some feminists express concern that feminist objectives may become invisible in critical psychology ${ }^{59}$ (Unger, 2001). After all, it is the "insistence upon exposing and challenging the operation of male power in psychology' that distinguishes feminist psychology (Wilkinson, 1997b: 250).

\section{The Local Context}

Work undertaken and published in the broad context of feminist psychologies in Aotearoa New Zealand reflects a plurality of political positions, epistemological models and theoretical perspectives (Cram, 2001a; Lapsley, Gavey and Cram, 2001; Nikora, 2001). It also highlights the specificities of a nation founded upon the Treaty of Waitangi (the Treaty), bicultural politics and recognition of the tangata whenua status of Māori. For Māori women 'this is a struggle about ethnicity, gender, socioeconomic status and political representation' (Lapsley, Gavey and Cram, 2001: 276).

While recognising the colonial history of this country and the pervasive harm colonisation continues to cause indigenous people, feminist psychology remains largely dominated by Pakeha women (Cram, 2001a). Indeed, Māori women have questioned the relevance of feminism to Māori women's lives (Cram, 2001; Te Awekotuku, 1996). Fiona Cram states that ' $[\mathrm{w}] \mathrm{e}$ could not form a common bond with white feminists as their feminism perpetuated our 'othering'" (Cram, 2001a: 405). While Pakeha feminists have yet to fully realise the ways Eurocentric feminism impact on Māori women, feminist psychology in this country maintains a 'commitment to social change, bicultural politics and feminist process' (Lapsley, Gavey and Cram, 2001a: 277).

\footnotetext{
${ }^{59}$ As lesbian feminist politics have been marginalised in favour of essentialist theories of sexuality apparent in lesbian, gay, bisexual and transgender psychology (Kitzinger, 2001)
} 
In the following sections, I present a range of Māori perspectives and critiques of psychology over the past decade. I then look briefly at developments in feminist psychology in Aotearoa New Zealand.

The Treaty, Bicultural Developments, Māori Knowledges and Critiques of Psychology

Do you seriously believe that you [psychologists], with the training that you get, are able to nurture the Māori psyche, are you able to see in to the soul of the people and attend to the wounded spirit? Do you consider for example the effects of the trauma of colonisation? (Turia, 2000: 3)

The Honourable Tariana Turia (Member of Parliament) put this question to a predominantly Pakeha audience in her address to the Annual Conference of the New Zealand Psychological Society (Turia, 2000: 10). She questioned the widespread public sentiment over (individual) 'home invasions' 60 while ignoring 'the invasion of homelands' of indigenous people' (Turia, 2000: 2) and 'the holocaust suffered by indigenous people including Māori' (Turia, 2000: 3). Turia (2000) also questioned psychologists' attention to Post-traumatic Stress Disorder while ignoring the devastating and pervasive effects of colonisation on Māori people. She posits the idea of 'Post Colonial Traumatic Stress Disorder in order to site the issue [of colonisation] in its proper historical, political and economic context' (Turia, 2000: 4).

Increasing recognition and understanding of the Treaty and bicultural practice by the dominant culture has led to changes in policies and the way psychology is organised and practiced. Some of these changes include the establishment of the Māori and Psychology Research Unit (MPRU) at the University of Waikato, Hamilton (1998), ${ }^{61}$ work at the Family Centre in Lower Hutt where a tripartite 'Just Therapy' model is used (Tamasese and Waldegrave, 1996), ${ }^{62}$ and the officially sanctioned National Standing

\footnotetext{
${ }^{60}$ A term used to describe intruders entering homes.

${ }^{61}$ The MPRU was 'designed to provide a catalyst and support network for enhancing psychological research with a Māori kaupapa, which has at its centre the psychological needs, aspirations, and priorities of Māori people' (Nikora and Evans, 1998:1).

${ }^{62}$ In Aotearoa New Zealand the Just Therapy centre has developed a unique social action model which takes issues of injustice, inequality and inequities as its starting point. Within this model issues of gender,
} 
Committee on Bicultural Issues (NSCBI) within the New Zealand Psychological Society (NSCBI, 1993; Nikora, 2001) as well as the associated regular commentary in The Bulletin of the NZPSS ${ }^{63}$ The NSCBI has also been instrumental in contributing to the review of the Code of Ethics for Psychologists Working in Aotearoa New Zealand (2002).

Māori writers have long critiqued the western dominance of mainstream psychology and have written widely about Māori ontological perspectives, Māori knowledges and psychologies, and kaupapa Māori research and ethics (Cram, 1993; Durie, 2001; Nikora, 1993; ${ }^{64}$ Smith, 1998). Mason Durie (2001: $i x$ ) discusses the ways health 'depends on the dynamic interaction of people with each other as well as with wider cultural, social, economic, political and physical environments'. He submits that 'marae-based attitudes, values, practices, and guiding philosophies... are important for the maintenance of healthy Mauri ${ }^{65}$ (Durie, 2001: 70). Further, drawing parallels between the experience of Māori and indigenous people elsewhere, Durie (2001: 71) discusses ways in which contemporary ideas and behaviours are shaped by traditions but 'adapted to the psychological hybridities of contemporary existence'. His work in the field of mental/health has been influential in shaping the terrain of Māori psychologies which reflects a diversity of Māori realities. With others, this work has prompted ongoing changes in the way dominant psychology understands Māori world views, processes and practices, and has placed Māori knowledges on the institutional agenda in this country.

Averil Herbert has also paved the way for developing a Treaty of Waitangi model of clinical psychology training (Herbert, 1998a, 1998b). This work operationalises the

race and class are located as integral to the provision of therapy. The Just Therapy Centre is an example of a parallel process model with identifiable Mãori, Pacific and tauiwi ontologies, processes and practices (Tamasese and Waldegrave, 1996).

${ }^{63}$ For example Herbert (1998a, 1998b). See also Black and NSCBI (2000) A Bibliography of books related to Tiriti o Waitangi and bicultural relationships in Aotearoa. The Bulletin. Sept issue.

${ }^{64}$ An important publication includes L.W Nikora (Ed) Cultural Justice and Ethics Proceedings of a symposium held at the Annual Conference of the New Zealand Psychological Society, University of Victoria, Wellington. 23-24 August, 1993.

${ }^{65}$ Mauri refers to 'life force' and is associated with the 'concept of a dynamic relationship between the many elements of the environment and people' (Durie, 2001: $x$ ). 
Treaty and involves a structural framework and rationale for the model as well as bicultural protocols and procedures. This work has clearly provided an important impetus for implementing the Treaty in clinical training at Waikato University and offers a model for other programmes. However, the maintenance of such changes continues to depend on Māori staff, and the commitment and knowledge of other staff within clinical psychology programmes and the wider discipline.

Pakeha Treaty Action education for staff and students which focuses on a 'pro Treaty analysis of contemporary and historical issues', has also been utilized by Auckland and Waikato clinical programmes (Yensen and McCreanor, 1993: 43).

The changes outlined above have led to an increasing awareness of Māori ${ }^{66}$ and indigenous knowledges in psychology, and the importance of understanding that knowledge is historically, culturally, socially and politically situated (Hirini and Nairn, 1996; Lapsley, Gavey and Cram, 2001; Lawson-Te Aho, 1993; Smith, 1998; Stewart, 1995). However there is ongoing criticism of the ways professional psychology training perpetuates dominant western discourses (Nathan, 1999; Lawson-Te Aho, 1993; Stewart, 1995).

Several scholars have undertaken research examining the way Māori knowledges, experiences and realities are addressed within professional psychology training programmes (Nathan, 1999; Paterson, 1993; Sawrey, 1993; Stewart, 1995). These writers argue that psychological discourse and psychology's structures and practices are dominated by western individualist models that preclude the provision of appropriate and culturally relevant mental health services. They also criticise the way psychology continues to mould Māori into existing structures, does not require bicultural training for all students, staff and practitioners, and therefore does not provide adequate training to ensure psychologists' competency and ethical conduct across diverse cultural contexts (Stewart, 1995).

\footnotetext{
${ }^{66}$ Māori constitute a diversity of people, identities, beliefs and values (Abbott and Durie, 1987; Herbert, 1998a; Turia, 2001).
} 
Averil Herbert (1993: 34) notes that the importance of understanding the articles and principles of the Treaty of Waitangi in acknowledging Māori as tangata whenua and the process of partnership and consultation is not explicitly mentioned in the Code of Ethics' (1986). Thus, there has been no official onus on the providers of clinical psychology training to adopt a Treaty based model. The recently revised code of ethics, the Code of Ethics for Psychologists Working in Aotearoa/New Zealand (2002), while including explicit reference to the Treaty, still poses questions about how the Treaty will be translated into practice by psychologists.

In discussing her experiences of clinical psychology training, Keriata Paterson (1993) highlights the cultural dilemmas faced by Māori students and staff. She says Māori students are often put in the position of being 'cultural watchdog[s]' over course content and face conflicts in challenging 'instances of misunderstanding, ignorance or prejudice implicit in staff members' or students' remarks' (Paterson, 1993: 57-58). She discusses how the onus is put on Māori staff and students to provide 'the Māori perspective' (Paterson, 1993: 57-58). She says that despite 'the external façade' (Paterson, 1993: 57) of clinical psychology training 'content and issues of...practical training...[are] unashamedly and uncompromisingly monocultural' (Paterson, 1993: 59).

Richard Sawrey's (1993) survey of psychologists' attitudes suggests that most psychologists regard their knowledge and professional training as inadequate to work appropriately with Māori clients. Despite widespread agreement on this issue there was considerable resistance to the implementation of compulsory taha Māori courses ${ }^{67}$ in clinical psychology training. Further, many psychologists lacked understanding of the significance of land and spirituality to Māori people, and the relationship of these domains to well-being. His work supports 'concerns about the serious inadequacy of appropriate psychological services for Māori people' (Sawrey, 1993: 72).

In more recent research, Sian Nathan (1999) follows up Abbott and Durie's (1987) well known publication to examine tikanga Māori content in contemporary clinical training

${ }^{67}$ Taha Māori refers "things Māori ", and comprised $20 \%$ of total training. 
programmes. Positive changes were notable in two training programmes. Most however had changed little, did not take a bicultural approach and the inclusion of tikanga Māori curriculum content was rated poorly by past and present students (Nathan, 1999: 78). Most students did not think they were prepared to work competently with Māori clients. Like other Māori psychologists, Nathan (1999) discusses the importance of locating Māori knowledges and concepts of well-being as integral to psychology at graduate and undergraduate levels, and in particular clinical training programmes. She highlights the shortage of Māori staff in clinical psychology ${ }^{68}$ and discusses the implications of not requiring all staff and students to have tikanga Māori or te reo ${ }^{69}$ knowledge. She also identifies barriers staff and students perceive to the inclusion of tikanga content. I will return to these in Chapter Ten.

Nathan's findings indicate a lack of action from clinical psychology trainers in relation to the Treaty of Waitangi and a failure to meet (minimal) ethical requirements in accordance with the then current New Zealand Psychologists Code of Ethics 1986. Nathan's (1999) findings suggest continued changes are required if clinical psychology programmes are to adequately prepare psychologists to work in a culturally safe, appropriate and competent manner across diverse contexts.

A recently released report by Michelle Levy of the MPRU (2002) also suggests many of these criticisms of psychology remain applicable into the $21^{\text {st }}$ century. In particular, her findings suggest that there is continued resistance to the "the incorporation of Māori paradigms, or changing the perspective from the inclusion of Māori paradigms being an optional extra to that of 'best practice' or core component of psychology' (Levy, 2002: 38). Indeed, Levy's report indicates that academic institutions remain a primary site of resistance to incorporating Māori paradigms (Levy, 2002: 39).

Linda Waimarie Nikora (2001) also observes that university psychology departments often fail to retain Māori staff or do not have any Māori staff at all, thus exacerbating the invisibility of Māori knowledges in psychology curricula. It appears that although

\footnotetext{
${ }^{68}$ In 1998 there was only one Mãori staff member in clinical psychology programmes (Nathan, 1999: 75).

${ }^{69}$ Tikanga Māori refers to Māori knowledges. Te reo refers to Māori language.
} 
some institutional changes have occurred within psychology, and committed staff in some clinical psychology training programmes have addressed the issues discussed in this section, there is some way to go in meeting the challenges posed by Māori commentators and adequately honouring the Treaty.

Within the broad parameters of psychology, Māori women have undertaken a range of research and published work on topics as diverse as male partner violence (Glover, 1995), the relevance of feminism to Māori women (Cram, 2001a; Jenkins and Pihama, 2001), and postcolonial theories of subjectivity (Moeke-Maxwell, 2003). For example, Moeke-Maxwell (2003) argues the need for understanding multiple subjectivities and incorporating an understanding of the notion of 'hybrid identities'.

While much of the work cited here has been produced in academic contexts, it reflects a long history of political activism and is grounded in the language, concepts, perspectives, experiences of Māori. Indeed, many of the issues raised in relation to colonisation and the position of Māori in Aotearoa New Zealand echo those articulated in relation to indigenous peoples elsewhere (LaFromboise, Choney, James and Running Wolf, 2002; Holdstock, 2000).

Pacific writers have also addressed the dominance of western conceptual and theoretical paradigms in psychology (Tamasese and Waldegrave, 1993; Tupuola, 2002). Kiwi Tamasese (1993) has addressed the interface of gender and culture, by providing an historical account of the abuses inflicted on Pacific peoples through the taking of land, the imposition of laws and regulations, and various forms of cultural desecration. She comments that "western science and thought throughout the Pacific ushered in western norms to which people are forced to adjust' and which are used to judge Pacific peoples' (Tamasese, 1993: 11).

In Making a Pacific Difference (Ministry of Health, 1997: 25-26), attention is directed at the use of 'inappropriate western counseling models' with Pacific peoples, the importance of environment, context, time period, culture, and the mental, spiritual and physical realms and traditional healing processes, and their neglect in western dominant models of practice (Ministry of Health, 1997). Anne-Marie Tupuola (1998) has also 
addressed the cultural dilemmas and associated psychological milieu faced by young Samoan women in this country.

Development of Feminist Psychologies in Aotearoa New Zealand

Aotearoa New Zealand has a long history of feminist activism and is renowned for being the first country to gain woman's suffrage (Lapsley, 1994). Women have been pioneers in psychology, as demonstrated in the work of psychologists such as Jane Ritchie and Pera Jackson Webb (Lapsley, 1994), and Betty Bernardelli (Lapsley and Ritchie, 1997). In the 1950s Rina Moore qualified as the first Māori woman doctor and practicing psychologist.

Jane Ritchie stands out as one of the most influential feminist psychologist pioneers in this country (Lapsley and Ritchie, 2001). She was the first woman (and feminist) to gain a doctoral qualification in psychology from a New Zealand university, the first woman professor of psychology, and is well renowned for her work regarding child rearing practices (Ritchie, 2001). She was also instrumental in implementing one of the first psychology of women courses in the 1970s at Waikato University (Lapsley and Wilkinson, 2001).

As occurred elsewhere, feminist psychology in this country developed in the context of the international women's liberation movement and other international social movements of the time. As this history has been discussed elsewhere, I will not retrace it here (see for example, example Lapsley, 1994; Lapsley and Ritchie, 1997; Lapsley and Wilkinson, 2001). However, I will briefly mention two identifiable periods in the development of feminism and feminist psychology in this country - grass-roots feminist initiatives of the 1970 s and 1980 s, and a new wave of feminist scholarship in the last decade.

During heightened feminist activism of the 1970s and 1980s, a number of then radical feminist psychologists were influential in advancing social change relating to women's health, including Donna Awatere (1984) and Miriam Saphira (1981, 1984, 2001). Much 
of their work was influenced by community collaborations with feminists and other activists who were not psychologists. ${ }^{70}$ An important focus of feminist work at this time related to (male perpetrated) childhood sexual abuse, (male perpetrated) sexual and physical violence, sexuality and women's health issues.

Other developments and social movements in this country were also influential in the development of feminist ideas relating to women's health and well-being, for example the establishment of the Human Rights Commission, Homosexual Law Reform, and Māori Sovereignty (Awatere, 1984). Throughout this time feminist and lesbian feminist psychologists were meeting informally to discuss issues relating to the way psychology dealt with issues affecting women, lesbians and other marginalised groups (Lapsley and Paulin, 1994; Lapsley and Ritchie, 1997; Oliver and Lapsley, 1994).

The work of feminists in Aotearoa New Zealand is characterised by the collaboration of ideas across disciplinary boundaries and practitioner, academic, community and policymaking spheres (Lapsley, Gavey and Cram, 2001: 276).

Feminists have argued for explicitly gender analytical frameworks and have drawn attention to the masculinist dominance of discourses governing mainstream psychology. Hilary Lapsley and Kate Paulin (1994) have addressed the way lesbian issues are dealt with in clinical psychology teaching, research and practice, and have highlighted institutional barriers to the inclusion of lesbian perspectives and knowledges in psychology. In addition, Hellenic perspectives on mental health relevant to Greek people living in Aotearoa New Zealand have been addressed (Gavriel, 2000).

In recent years a new wave of feminist scholarship reflects the influence of poststructural ideas, and discourse and narrative analyses (for example Bird, 1998; Gavey, 1989, 1992, 1996; Jackson, 1997, 2001; Moeke-Maxwell, 2003; Morgan and Coombes, 2001; Townes and Adams, 2000; Weatherall, 2002). Nicola Gavey has been described as representing 'a new generation of critical feminist scholarship in New Zealand' (Wilkinson, 1996: 10) and Margaret Wetherell, who is well renowned for her

\footnotetext{
${ }^{70}$ For a history of women and feminists in psychology at this time see Lapsley and Ritchie (1997).
} 
cutting edge work on discourse, is originally from Aotearoa New Zealand (Lapsley, Gavey and Cram, 2001). This work represents a change in emphasis for feminist psychology in this country and is influential in reshaping and reconstructing psychology, but there has been little feminist research specifically targeting local clinical psychology training.

\section{Feminist Critiques of Clinical Psychology}

Around the early 1990's a number of feminist critiques of clinical psychology were published (for example Adcock and Newbigging, 1990; Bekker, 1991; Brown, 1991; Burns, 1992; Holland, 1991; Marecek and Hare-Mustin, 1991; Perkins, 1991, 1992; Ussher, 1989, 1990, 1991, 1992; Ussher and Nicolson, 1992; Vickers, 1991; Williams and Watson, 1991a, 1991b, 1991c). This work identified clinical psychology as a key site of power in the construction and legitimation of psychological knowledge and the provision of psychological services. Clinical psychology was widely criticised for failing to theorise gender and power, and for maintaining the oppression of women and other marginalised groups (Marecek and Hare-Mustin, 1991; Ussher and Nicolson, 1992).

Feminists writing at this time produced critiques of dominant clinical psychology from their location in diverse work settings and from their experiences of different client groups. Jane Ussher and Paula Nicolson's (1992) landmark publication Gender Issues in Clinical Psychology provides an in-depth feminist analysis of clinical psychology. While presenting a comprehensive critique of the way positivist science 'sexes' psychology (Ussher, 1992) and the way clinical psychology's organisational structure perpetuates gender inequities (Nicolson, 1992), this collection includes writing from feminist psychologists across the vocational spectrum of clinical psychology (for example see Burns, 1992; Holland, 1992; Perkins, 1992; Vetere, 1992).

Feminist critics identified a range of problems with the way clinical psychology conceptualises gender, represents femininity and serves women. They addressed problems with the male defined ideological basis of clinical psychology and its 
positivist science philosophical foundations (Hare-Mustin and Marecek, 1991; Ussher. 1992). They also highlighted the effects of this epistemological position on the gendered nature of knowledge and the implications for women. These writers drew attention to the relationship between women's sociopolitical position and mental health, and emphasised the interconnection between sexual inequalities and women's health status (Hare-Mustin and Marecek, 1991; Ussher and Nicolson, 1992; Williams and Watson, 1991b).

Feminists also illustrated the ways concepts of gender and power are ignored, misrepresented, marginalised or treated as 'special' in the research, literature and teaching of clinical psychology (Bekker, 1991; Brown, 1991; Marecek and HareMustin, 1991; Ussher, 1992; Williams and Watson, 1991b). Many writers argued that these exclusions, distortions and misrepresentations have a significant bearing on the ways meanings of femininity are constructed, and in turn how women's lives and realities are regulated. Rachel Perkins $(1991,1992)$ shows how women with serious long-term mental health problems have been ignored in clinical psychology and the ways psychology's gendered practices have contributed to women's disempowerment, dislocation and devaluement. She addresses the vulnerability of this group of women in terms of heightened risk of sexual exploitation and violence, homelessness, stigmatisation and involvement in crime (Perkins, 1991: 137). Her work draws attention to gender disparities in the provision of psychological services and differential expectations on women and men with comparative levels of functioning. She argues that there is a general denial of the disabling effects of long-term mental health disabilities in terms of physical and psychological exclusion when one does not have a legitimate and valued social role or 'fit' into the community (Perkins, 1991, 1992).

Feminists writing at this time demonstrated how clinical psychology's lack of analysis and contextualisation regarding the social positions and conditions of women's lives reflected a failure to fully understand or engage with issues of gender and power (Adcock and Newbigging, 1990; Ussher and Nicolson, 1992). Clinical psychology was widely challenged to make gender and other relations of power central to an analysis of women's despair (Adcock and Newbigging, 1990; Brown, 1991; Marecek and HareMustin, 1991; Ussher, 1989, 1990, 1992; Williams and Watson, 1991c). For example 
Christine Adcock and Karen Newbigging (1990) specifically addressed ways clinical psychology can be dehumanising and compound the oppression of women who have learning disabilities as well as mental health difficulties. Arlene Vetere (1992) also drew attention to the ways gender is minimised in family therapy. She addressed the ways structural inequalities impact on women and the importance of incorporating gender 'as a fundamental organising principle of family life' which must be regarded as integral to clinical practice (Vetere, 1992: 140). Like Williams and Watson (1991b), Vetere advocates the integration of gender throughout clinical training and argues that it is simply inadequate to regard gender as a 'special issue' or marginalise it in the form of 'one-off workshops or seminars' (Vetere, 1992: 145). As with Nicolson (1992) she draws attention to the gendered organisational structure in which training occurs as well as the 'gender-bound' culture in which training is located (Vetere, 1992: 145).

As discussed in the previous chapter, feminist psychologists critiqued clinical psychology's reliance on a positivist scientific approach in which narrowly defined patriarchal concepts are constructed as 'reality' (Marecek and Hare-Mustin, 1990; Ussher, 1992). They argued that knowledge produced within this individualist and reductionist framework failed to reflect women's experiences, social relations of power and the sociopolitical context of women's lives. As discussed previously, women's low social status and inequitable access to power and resources has been linked to a range of 'psychological' problems (for example Marecek and Hare-Mustin, 1991; Stoppard, 1989; Ussher, 1991). Yet the effects of gender inequities such as the feminisation of poverty, the devalued status of motherhood, and male perpetrated violence and sexual abuse have yet to be adequately theorised and understood in clinical psychology (Adcock and Newbigging, 1990; Ussher, 1992). Indeed, feminist psychologists writing in the early 1990's held that clinical psychology continues to decontextualise structural and systemic problems, and to ignore the material conditions of women's everyday lives (Adcock and Newbigging, 1990; Marecek and Hare-Mustin, 1991; Perkins, 1991, 1992; Ussher, 1989, 1992; Williams and Watson, 1991b).

While clinical psychology was charged with individualism, constructing the political as personal, feminists also drew attention to the way women are pathologised within this theoretical framework and the practical implications of this. By focusing on the 
personal, feminists criticised clinical psychology for negating the systemic context of psychological problems (Adcock and Newbigging, 1990; Ussher, 1989, 1991, 1992). Feminist writers argued that by failing to adequately account for the social, historical, political, economic and cultural contexts of women's lives, clinical psychology contributed to women's distress.

Criticism of clinical psychology has also centred on the pathologisation of women via a taxonomic system based on male assumptions and definitions of reality. As many feminist writers have argued, clinical psychology's reliance on diagnosis, whether in the form of a DSM classification or a diagnostic formulation, perpetuates the personalisation of sociopolitical problems (Marecek and Hare-Mustin, 1991; Ussher, 1992). Further, the process of constructing diagnostic classifications, and judgments in using them, are widely regarded as biased and discriminatory, reflecting dominant cultural values about women and other marginalised groups (Caplan and Gans, 1991; Ussher, 1992). Feminists have been instrumental in challenging the political basis of DSM classifications and in highlighting the lack of 'scientific' legitimacy of this system which remains the backbone of clinical psychology's linguistic and theoretical framework (Marecek and Hare-Mustin, 1991; Marecek, 2001; Ussher, 1992). Drawing on the work of Foucault, feminist psychologists have challenged clinical psychology for using diagnoses as a means of social control, and denying the relationship between power inequities and psychological distress (Marecek and Hare-Mustin, 1991; Ussher, 1992). Indeed feminists argued that in using a classificatory system of this nature, clinical psychology is instrumental in labeling people, particularly women and minorities, and perpetuating oppression (Marecek and Hare-Mustin, 1991; Ussher, 1992). Thus, while 'the problem that has no name' (Friedan, 1963) now has multiple names, feminists critics argue that the structural, material and discursive sources of "the problem' have not been adequately theorised in clinical psychology. This means that any substantive understanding of gender in clinical psychology training and practice remains marginal. To examine these issues, Williams and Watson (1991a, 1991b) undertook research about the inclusion of gender in clinical psychology training in Britain. 
In reviewing feminist critiques of clinical psychology training, one study stands out as being directly relevant to my Aotearoa New Zealand research. A decade ago, feminist psychologists Jenni Williams and Gilli Watson (1991b) researched clinical psychology training in Britain. Their research, entitled 'Clinical psychology training: training in oppression?' involved a national survey of clinical psychology organisers and clinical student representatives. The study focused on sexual inequality, which the researchers identified as 'one of the root causes of distress and damage' for women (Williams and Watson, 1991a: 55). They investigated 'if, and how, clinical psychology training in Britain takes account of the existence of sexual inequality' (Williams and Watson, 1991b: 78).

Williams and Watson's (1991b) research demonstrated widespread inattention to sexual inequalities throughout clinical psychology training and a lack of awareness of the implications of these inequalities for women (Williams and Watson, 1991b). Indeed, participants showed confusion about the meaning of sexual inequality. While a minority of staff regarded sexual inequality training as important, most were uncommitted and had no specific or systematic plans for implementation. This was further borne out in students' low ratings of the inclusion of education about sexual inequality and its role in contributing to life difficulties.

The research findings point to the optional, contingent and marginal nature of sexual inequality education in clinical psychology training throughout Britain. They also demonstrate that most trainers attribute responsibility for education about sexual inequality to a minority of women staff. Williams and Watson (1991b) argued that the lack of inclusion of this education was not attributable to a lack of resources, but to a lack of commitment from trainers, and resistance to theory and research produced by feminist psychologists. Further, they argued that substantive change can only occur with official sanctioning from the British Psychological Society (BPS). 
Responses to Williams and Watson's (1991b) Survey

Feminist clinical psychologists working in Hong Kong (Cheung, 1991), the Netherlands (Bekker, 1991) and the USA (Brown, 1991) have made similar observations about clinical psychology training. For example, Brown (1991) and Marie Bekker (1991) point to the paucity of education about the effects of gender inequalities in clinical psychology training in the USA and the Netherlands. Brown (1991) suggests that the findings of Williams and Watson's survey (1991b) are consistent with her experience of clinical psychology training in the USA. While there is an expectation that education about gender would have improved considerably in the intervening period, it is apparent that this is not the case (Brown, 1991). Despite rhetoric to the contrary and US accreditation requirements to include gender education in clinical training, she notes that there remains a 'lack of integration of gender issues into the core curriculum, and the marginalization of psychology of women' (Brown, 1991: 91). Brown argues that when gender education does occur, it remains an optional extra and is regarded as a 'special' interest for women, not an essential and integral education for all psychologists (Brown, 1991: 91). Bekker (1991) reports a similar scenario in the Netherlands. She found that less than half of all pre-doctoral programmes addressed issues relating to sexual inequality and these courses were optional. In post-doctoral programmes education about sexual inequality was not integrated into the core part of clinical training. As in Britain, there was no official requirement for clinical psychology programmes to incorporate this education in the curriculum, or for clinical psychologists to have knowledge about the effects of sexual inequalities or women's sociopolitical position (Bekker, 1991). ${ }^{71}$

Laura Brown (1991) argues that the British survey (Williams and Watson, 1991b) highlights a number of myths about the inclusion of gender content in clinical training. She says that "without conscious and careful attention, content on gender issues and an analysis of the impact of gender inequality on phenomena studied by psychologists will

71 These findings are based on discussions with representatives from the Dutch Organisation of Psychologists, all the pre-doctoral university departments of clinical psychology, the post-doctoral institutes for training clinical psychologists and psychotherapists, and feminist organisations in the women's healthcare field (Brown, 1991: 96). 
almost never be found in the psychology classroom'. Brown (1991: 89) also emphasises the importance of validating the expertise of feminist psychologists in gender and power analyses, refuting claims that there are insufficient people to teach gender education in clinical training.

\section{Recent Feminist Criticisms of Clinical Psychology}

Despite a substantive body of feminist criticism of clinical psychology in the early 1990's there appears to have been little change in the way gender and power are addressed in clinical psychology today. Those who work in this area continue to reiterate and expand on problems identified in earlier work and contest the way clinical psychology constructs meaning and defines and prescribes normative ways of being (Bostock, 1997; Boyle, 1997; Hare-Mustin and Marecek, 1997; Marecek, 2001). Critics challenge clinical psychology's claims to scientific legitimacy when the profession continues to ignore experience in the construction of psychological theories and knowledge about human life (Bostock, 1997; Boyle, 1997). For example, Mary Boyle (1997) argues that the rhetoric of science is used to justify the exclusion of gender in clinical psychology on the grounds gender is politically laden. Janet Bostock draws on her experiences with working class women to show how mainstream psychological theories bear little relationship to these women's lives. Bostock argues that the experiences of women who live with status disadvantage, limited access to resources, inadequate income, and childhood abuse ${ }^{72}$ or other sustained exposure to adversity are not taken into account in clinical psychology literature, research or theory (Bostock, 1997). She provides ample illustration of the way 'material and status disadvantage is psychologically destructive for women' (Bostock, 1997: 239) and claims that 'little account of the role of environmental factors in causing and prolonging distress is given in the training of clinical psychologists or in orthodox journals and textbooks (Bostock, 1997: 240). Similarly, Boyle (1997: 232) maintains that 'women and men are positioned differently in our social structures, are constructed by very different discourses and have very different experiences of the world'. To ignore these experiential differences is to

\footnotetext{
${ }^{72}$ Emotional, sexual and/or physical (Bostock, 1997: 241).
} 
negate the relationship between women's subjugated social position and psychological distress. This negation of the experience of women, and other marginalised groups, contributes to a disjuncture between theory and practice in clinical psychology (Bostock, 1997; Boyle, 1997; Hare-Mustin and Marecek, 1997). This has implications for trainee clinical psychologists who can experience difficulties reconciling the discrepancies between what they read in clinical psychology literature and the stark realities of their experience in clinical practice (Boyle, 1997; Hare-Mustin and Marecek, 1997). Repercussions of the scientist-practitioner model and positivist science dominant framework thus remain central to feminist criticisms of clinical psychology (Boyle, 1997; Hare-Mustin and Marecek, 1997).

Feminist psychologists draw attention to the paucity of gender content in clinical psychology literature (Boyle, 1997; Bostock, 1997; Hare-Mustin and Marecek, 1997). They argue that this lack of attention to gender contributes to the marginalisation of women and constructs a knowledge base that inadequately represents women's experiences.

These contemporary writers echo the work of earlier feminists in their attention to the problematic use of diagnoses in clinical psychology (Boyle, 1997; Hare-Mustin and Marecek, 1997; Marecek, 2001). They claim that while many clinical psychologists are critical of diagnostic systems such as the DSM, reflecting awareness of issues concerning unreliability and bias, the disciplinary body continues to use maintain this system. For example feminists draw attention to the way titles and headings often used in mainstream clinical psychology texts and journals reflect diagnostic categories, and the way specific diagnoses are coupled with specific interventions in clinical research (Boyle, 1997; Hare-Mustin and Marecek, 1997; Marecek, 2001). The increasing use of managed care and profit driven work environments also means that clinical psychologists are compelled to use diagnostic systems prescribed by funding bodies. ${ }^{73}$

\footnotetext{
${ }^{73}$ For example in Aotearoa New Zealand, ACC requires a diagnostic classification for people seeking claims for sexual abuse. Furthermore, within specialty services in this country access to funding is also based on specific diagnoses. For example, this occurs in child and adolescent mental health services, youth specialty services and eating disorders services (personal communication, Celia James, therapist, specialist mental health services, 2002).
} 
Attention is also directed at the way classifications in the DSM reflect dominant cultural assumptions of particular people, in a particular time and place. For example feminists have been critical of the way categories of 'sexual dysfunction' reflect male, heteronormative assumptions about sexuality (Boyle, 1994). Feminist challenges have also been directed at the inclusion of Pre-Menstrual Syndrome as a diagnostic classification in the DSM (Caplan, McCurdy-Myers and Gans, 1992). This example is indicative of the way women's everyday experience can become medicalised, mystified and used to women's disadvantage. On the other hand, normative (macho) male behaviour and attitudes are not subjected to the same scrutiny, as reflected in Paula Caplan's (1991) discussion of a classification for Dominant Delusional Personality Disorder.

Mary Boyle (1997) argues that in attempting to include women, feminist challenges to clinical psychology can be easily assimilated into dominant theoretical and diagnostic models, thus depoliticising radical feminist analyses. Drawing on Leitner's (1995) work, Boyle (1997) highlights the way women are over-represented in discussions of gender, and positioned as somehow deficient in a way that men are not. She cites examples of literature where discussions about women who are in relationships with violent men include references to women's 'faulty thinking' or 'cognitive distortions'. In comparable discussions about male sexual offenders references to men include neutral terms such as their 'self talk' or comment on 'what was going through the offenders mind' (Boyle, 1997: 235). Similarly, in a recent discussion of research involving lesbian and heterosexual women at a women's mental health center in the USA, parental 'psychopathology' was a factor implicated in women's histories. While mothers were over-represented in statistics on psychopathology, fathers' physical and sexual violence was ignored. ${ }^{74}$ The combination of a patriarchally defined diagnostic system and the targeting of women in discussions of gender means that the consequences of gender inequality on men (such as male violence and domination of women) remain invisible (Boyle, 1997: 235). Given that attention to diagnostic statistics is one of the few ways 'gender issues' are included in clinical psychology, questions are

\footnotetext{
${ }^{74}$ Seminar presented by Dr Linda Crowther, Psychology Department, Victoria University, Wellington, Aotearoa New Zealand, November, 2002.
} 
again raised about the use of a diagnostic system that is value laden and renowned for its unreliability and lack of validity (Caplan and Gans, 1991; Kirk and Kutchins, 1992).

Boyle (1997: 236) argues that psychology 'needs alternative language to talk about psychological distress and disturbing behaviour which avoids assumptions of diagnostic categories'. She suggests articulating problems in more descriptive terms. Likewise, Hare-Mustin and Marecek (1997) draw attention to the way language structures reality. They argue that language is used by the 'powerful to label, define, and rank' (HareMustin and Marecek, 1997: 106). The way language is used in clinical psychology means that certain behaviours, feelings and experiences come under scrutiny. These phenomena are then named, which often leads to labeling and in turn to stigma. Most often, those who are subjected to scrutiny include women and other marginalised groups.

\section{Conclusion}

This chapter locates my thesis argument within the feminist psychologies literature internationally. The perspectives of feminist and Māori psychologies discussed in this chapter indicate how clinical psychology and the broader discipline construct meanings about women and contribute to women's oppression. The problems and criticisms canvassed in this chapter can no longer be brushed aside as the complaints of a disgruntled, homogenous minority. This echoes Ussher's (1992: 62) comment about clinical psychology over a decade ago when she said that 'rigid adherence to old ways of working could be the kiss of death for the profession'. In the next chapter I outline the epistemological stance taken in this thesis which offers an alternative way of constructing psychological knowledge located in the context of gendered relations of power and grounded in the realities, experiences and material conditions of women's lives. 
For over thirty years, feminists in psychology have monitored clinical psychology for biased, inadequate, and discriminatory conceptions and treatment practices. There is no reason to relax our vigilance at this point...feminist clinical psychology must retain its skeptical sensibility, along with its willingness to challenge established ways of doing things and accepted categories of meaning (Marecek, 2001: 316).

In the absence of a critical feminist analysis of both process and content, the private and unique pain of the client will not likely be tied by the therapist's analysis or interventions to the public and political realities the pain expresses (Brown, 1994: 21).

The question of the psychological effect of injustice and inequality is not as popular an enquiry amongst clinical psychologists today as are the more glamorous fields of national disaster and post-traumatic stress disorder, and yet the cumulative effect of the daily disasters of everyday living for those who are disadvantaged, is catastrophic...feelings of injustice have profound psychological consequences (Holland, 1992: 75). 


\section{Chapter Four}

\section{Feminist Standpoint Epistemology}

In this chapter, I outline the epistemological orientation of this thesis, and the relationship between epistemology and research practice. I discuss the contours of feminist standpoint epistemology drawing particular attention to Nancy Hartsock's interpretation of this approach, and also discuss some criticisms of this epistemological position. I conclude the chapter by outlining Jane Ussher's (2000b) use of feminist standpoint epistemology and critical realism in the context of a material-discursiveintrapsychic approach to psychological knowledge and practice.

Epistemology is concerned with theories of knowledge or questions about how knowledge is produced. Liz Stanley and Sue Wise (1993: 188) refer to epistemology as 'a framework or theory for specifying the constitution and generation of knowledge about the social world; that is, it concerns how to understand the nature of "reality'. Further, epistemology is about who can be regarded as a 'knower', the criteria against which knowledge is judged legitimate (Harding, 1997a) and the relationship between knowing and being. In this sense, epistemological issues are also concerned with ontological ${ }^{76}$ issues and underpin research methodology and research methods, both of which are discussed later in this chapter.

The centrality of women's lived experience and understanding of the social world is asserted through the epistemological position of feminist standpoint. While inferring a singular position, there are multiple feminist standpoints (Hekman, 1997a). Though theorised differently, feminist standpoint is integrally concerned with the relationship between power and knowledge, truth and reality, and women's diverse experiences in

\footnotetext{
${ }^{75}$ For discussion of feminist epistemology see Stanley and Wise, 1993: 222-228.

${ }^{76}$ Ontology 'is a way of specifying the nature of something'; it is concerned with the nature of 'being' and beliefs about the nature of existence for example whether gender is social or natural (Ramanazoğlu, 2002: 11-12).
} 
the context of a gendered social world (Hartsock, 1997a; Ramazanoğlu 2002). Patricia Hill Collins (1997: 376) states that standpoint refers to 'groups having shared histories based on their shared location in relations of power'. In general, taking a feminist standpoint means 'being able to produce the best current understanding of how knowledge of gender is interrelated with women's experiences and the realities of gender' (Ramazanoğlu, 2002: 60-61).

There are debates amongst feminists concerning their diverse conceptualisations of what feminist standpoint comprises, of its status as a theory, as an epistemology, or as neither of these things (Ramazanoğlu, 2002). ${ }^{77}$ For some, feminist standpoint epistemology is concerned with 'some theory of gender and power, a conception of feminist knowledge and conceptions of experience and reality' (Ramazanoğlu, 2002: 64). It is about 'examining how knowledge and power are connected, and so making visible both the hidden power relations of knowledge production' (Ramazanoğlu, 2002: 63) and 'the underpinnings of gender' (Smith in Ramazanoğlu, 2002: 63) It is concerned with 'establishing relationships between knowledge and power without abandoning the hope of telling better stories about gendered lives' (Ramazanoğlu, 2002: 63). Jane Ussher (2000b: 223) sug gests that feminist standpoint is a position that permits 'both the 'material' and constructed attributes of the body and personal experience' with a 'specific emphasis on gender at both a material and discursive level'. Stoppard (1999: 82) comments that feminist standpoint is based on 'the philosophical premise that knowledge is socially constructed'. She argues that it is also centrally concerned with the deconstruction of dominant hegemony (Stoppard, 1999). Stoppard asserts 'the role of human values, particularly sociocultural influences in restructuring and shaping all knowledge about the world' (Stoppard, 1999: 82).

Feminist standpoint is seen by some as 'a quaint relic of feminism's less sophisticated past' and has been relegated to the periphery of feminist theorising in the past 15 years (Hekman, 1997a: 342). However, feminist standpoint was central to the development of contemporary feminist theory and politics (Hekman, 1997a). As an epistemology,

\footnotetext{
${ }^{77}$ For discussion of these debates see for example Hawkesworth, (1999); Hekman, (1997a, 1997b).
} 
feminist standpoint began the paradigm shift in theorising knowledge about women's lives, and as such charted new epistemological territory (Hekman, 1997a: 342). Feminist standpoint provides the impetus for feminists to expose knowledge as multiple and situated. This reappraisal of 'knowledges' was central to theorising difference, and addressed questions that remain integral to contemporary feminism such as "how do we justify the truth of the feminist claim that women have been and are oppressed?' (Hekman, 1997a: 342). Alternatively, in Dorothy Smith's (1997: 397) words, feminist standpoint is concerned with:

experience in and of the everyday/everynight actualities of our lives, it is the oppressively routine organization, the persistence, the repetition, of capitalist forms of exploitation, of patriarchy, of racial subordination, of the forms of dominance Foucault (1980) has characterized as 'power/knowledge'.

In this chapter, I outline important features of feminist standpoint ${ }^{78}$ highlighting those writers whose work has been influential in shaping the framework for my research. In particular I examine Hartsock's notion of feminist standpoint epistemology. I address areas of contestation amongst feminist standpoint writers and identify some of the important criticisms of taking a feminist standpoint position. Finally, I argue the usefulness of feminist standpoint epistemology in the context of the aims of this particular research. Here, I discuss how I have utilised a feminist standpoint epistemology as the basis of a feminist critique of clinical psychology training and for the development of a future psychology that better constructs, represents and responds to the experiences, realities and knowledges of women.

\section{Key Features of Feminist Standpoint}

Feminist standpoint is located in the experiences of women and is concerned with positioning women's accounts of experience at the heart of knowledge production (Collins, 1997; Hartsock, 1997a; Hekman, 1997a; Ramazanoğlu, 2002; Smith, 1997). As Dorothy Smith (1997: 394) states, '[b]eginning in women's experiences told in

\footnotetext{
${ }^{78}$ While referring to feminist standpoint in the singular I acknowledge its multiplicity and the diverse ways different writers have theorised feminist standpoints (for example Nancy Hartsock, 1997a; Dorothy Smith, 1997 and Patricia Hill Collins, 1997).
} 
women's words was and is a vital political moment in the women's movement'. Here Smith draws attention to both the core of feminist standpoint, and its historical position and continued relevance as a politics of knowledge. While experience may be theorised differently by different feminist standpoint writers, a central concern of this position is to centre and legitimate women's accounts of experience as authoritative knowledge.

\section{Experience}

Women's 'experience' includes emotions, embodiment ${ }^{79}$, intuition, spirit, senses, the unconscious and any other experiential knowledge otherwise named (Jaggar, 1997; Mulinari and Sandell, 1999; Ramazanoğlu, 2002; Smith, 1998; Tompkins, 1997). Feminist standpoint rejects the dominance of traditional western concepts associated with thought and 'reason', typical of a positivist science epistemology. ${ }^{80}$ Similarly, within Māori epistemologies, experience and hence knowledge, involve integrated conceptions of the spiritual, emotional, mental, cultural, physical, environmental and social, involving the continuity of past and present (Durie, 2001; Smith, 1998). Mason Durie (2001) argues that this holistic understanding and conception of experience, in which emotion is central, is critical to well-being or mauri ora. ${ }^{81}$

In her discussion of the place of emotion in feminist epistemology, Alison Jaggar (1997) draws attention to the artificial dichotomies of knowledge associated with modern Western epistemology, particularly since the inception of modern science, positivism and the scientific method. In particular, she notes that reason and rationality have been positioned in a dichotomous relationship to emotion, the latter of which has been regarded as counter to 'knowledge'. This relationship is further borne out in other

\footnotetext{
${ }^{79}$ Stanley and Wise refer to embodiment as 'a cultural process by which the physical body becomes a site of culturally ascribed and disputed meanings, experiences, feelings' (Stanley and Wise, 1993: 196).

${ }^{80}$ For discussion of the splitting of thought and emotion within modern conceptions of knowledge see Jaggar (1997).

${ }^{81}$ Ora refers to 'wellbeing or health'. Mauri ora refers to 'a force that generates and sustains life, vitality, and health' (Durie, 200I: $x$ ).
} 
dichotomies reflecting gendered constructions of knowledge. As Jaggar (1997: 188-190) states, reason has been associated with:

the mental, the cultural, the universal, the public and the male, whereas emotion has been associated with the irrational, the physical, the natural, the particular, the private and, of course, the female...reason has been associated with members of dominant political, social, and cultural groups and emotion with members of subordinate groups. Prominent among those subordinate groups in our society are people of color... and women.

This separation of different forms of knowledge has had particular prominence in psychology where reason and rationality have been the mark of its status as an 'objective', 'value-free' science. Further, the separation of values from reason within the methodologies of positivist science has been occasioned by the rise of the "valuefree' scientist and claims to the 'objective' knower. The apparent neutrality of positivist psychology and the negation of emotion have had the effect of leaving a vast terrain of psychological knowledge uncharted and unaccounted for. It seems a peculiar irony that an area of inquiry such as clinical psychology, which marks out its boundaries on the basis of its specialist understanding of people and human suffering, should so malign emotion, feelings and other experiential knowledges (in the form of CBT for example), that are clearly central to human life. As Jaggar (1997: 190) comments:

rather than repressing emotion in epistemology, it is necessary to rethink the relation between knowledge and emotion and construct conceptual models that demonstrate the mutually constitutive rather than oppositional relation between reason and emotion.

While embracing emotion as an integral form of knowledge and asserting the centrality of experience, there is also recognition amongst feminist standpoint writers that the notion of experience is problematic. For example, questions are raised concerning 'how experience can be known' and 'how connections can be claimed between experience, knowledge and reality' (Ramazanoğlu, 2002: 65). Different feminist standpoint writers therefore offer diverse interpretations of experience, but commonly regard women's experience as central to a feminist standpoint position. Dorothy Smith (1997: 395-6) argues that:

taking women's standpoint and beginning in experience gives access to a knowledge of what is tacit, known in the doing, and often not yet discursively appropriated (and often seen as uninteresting, unimportant, 
and routine)...[women] speaking for themselves and from their experience has been a fundamental commitment of the women's movement.

Feminist standpoint epistemology asserts the need for new forms of knowledge involving representation and articulation of women's experience, using concepts defined and constructed from the standpoint of women. It provides a position from which to challenge the way women's experiences have been articulated in dominant discourses such as psychology, from the position, perspectives and concepts of white, ruling class men. ${ }^{82}$ Dorothy Smith (1997: 394) comments that women's experiences have had 'no prior discursive definition'. In dominant psychological discourse, for example, women's experience has not been articulated from the perspective of women, and so women's experience and realities are made invisible. According to Ussher (1991; 2000 b), when psychological knowledge is claimed to reflect women's experience, such accounts are frequently distorted or misrepresented. Diana Mulinari and Kerstin Sandell (1999: 288) also argue that women's experiences have been 'silenced, misrepresented and misinterpreted' in dominant processes of knowledge production. Feminist standpoint allows the construction of new ideas located in the experience and day-today material lives of women. Central to feminist standpoint is recognition that 'knowledge is situated and perspectival and that there are multiple standpoints from which knowledge is produced' (Hekman, 1997a: 342).

Feminist standpoint is integrally concerned with rejecting dominant male hegemony in which masculinist ideology is claimed as knowledge (Haraway, 1991; Harding, 1993, 1997a; Hartsock, 1983, 1997a, 1998; Smith, 1997). One example of ideology as knowledge is positivism. Feminist standpoint draws attention to the ways in which positivism as an epistemology ignores women as subjects, and systematically rejects women's experience as the basis for investigation (Harding, 1997a). While feminist standpoint aims to legitimate women's experience as central to the construction of knowledge, it is also concerned with addressing issues of difference.

\footnotetext{
${ }^{82}$ Dorothy Smith (1997) uses the term 'ruling class'.
} 


\section{Difference}

A central feature of feminist standpoint is the theorisation of difference (Collins, 1997; Mulinari and Sandell, 1999; Ramazanoğlu, 2002; Stanley and Wise, 1993). ${ }^{83}{ }^{84}$ While feminist standpoint is grounded in women's 'common experiences of subordination', it is also grounded in women's 'exclusion from knowledge production across their differences' (Ramazanoğlu, 2002: 73). Feminist standpoint does not assume that what different women, located in diverse contexts, experience is the same. Rather, it is concerned with the commonality in the collectively subordinate position of women, while simultaneously recognising difference across dimensions of class, race, ethnicity, nationality, ability, sexuality, and other relations of power (Ramazanoğlu, 2002). In other words, while feminist standpoint is about 'common experiences and understanding' it also 'encompass[es] internal fractures and fragmentations' (Stanley and Wise, 1993: 226). Further, it does not presume that knowledge from a feminist standpoint is certain, but rather that 'knowledge from any standpoint is open to challenge and disruption' and is only ever partial (Ramazanoğlu, 2002: 73).

Patricia Hill Collins (1997) draws attention to the centrality of power relations and 'intersectionality' in understanding standpoint. She highlights the multiplicity and complexity of structural inequities arising from social location, noting that group history and location can be seen as points of convergence within hierarchical, multiple, and changing structural power relations' (Collins, 1997: 377). Feminist standpoint is thus implicitly about multiple dimensions of power relations, and while asserting shared group experience, is about recognising the plurality of experience and reality. It is also concerned with recognising the place of conflict and tension in producing group narratives (Collins, 1997).

\footnotetext{
${ }^{83}$ Hartsock (1997a: 368) readily acknowledges that her original adaptation of Marx's two tier system of power was problematic in that it failed to account for the operation of multiple power relations and hence failed to theorise difference.

${ }^{84}$ Stanley and Wise (1993: 223) refer to difference as 'awareness of the multiplicity and complexity of experience'. They refer to differences between groups 'conventionally seen as sharing the 'same' social structural attributes, such as gender, class, sexuality and race/ethnicity' (Stanley and Wise, 1993: 220).
} 
Feminist standpoint epistemology, along with most other feminist theorising, has been criticised for minimising difference and therefore marginalising the experiences of women from diverse social locations, such as that of indigenous women, black women, older women, lesbians, women with disabilities, women from developing countries, refugee women, immigrant women, women who have been displaced, women who experience 'mental' health difficulties, women with intellectual disabilities, and working class, poor and homeless women.

Collins draws attention to the lived experience of black women in the United States in demonstrating inequities of power across institutional structures such as housing, health care and education. She comments (1997) that the historical and cumulative effects of these systems and social structures operate differentially for black and white women, whose different social locations lead to different material realities. Similarly, as Stanley and Wise (1993: 220) comment:

there is every reason to recognize that, for instance, broad shared differences in skin colour - those known as black, brown, yellow, white - are categories with immensely consequential political and social implications.

While critics have contested the ability of feminist standpoint epistemology to account for difference, others affirm its role in embracing difference. For example, in discussing difference in the context of experience and the postmodern turn, Mulinari and Sandell (1999: 293) affirm a feminist standpoint position stating that it allows a 'politics of representation' while continuing to affirm 'multiple subjectivities'. Further, they argue that being able to 'name oneself as a woman, or a lesbian, Black or Third World is a politically articulated notion of the self'.

Similarly, other socially constructed categories reflecting the hierarchically ordered binaries of modernism, such as 'woman' and 'man', 'lesbian' and 'heterosexual', must remain central to a feminist politics of difference to ensure continued attention to the relations of power within which they are embedded (Stanley and Wise, 1993). As Audre Lorde (in Crowley and Himmelweit, 1992: 53) once said:

it is not our differences that separate women, but our reluctance to recognize those differences and to deal effectively with the distortions 
which have resulted from the ignoring and misnaming of those differences.

Drawing on the work of bell hooks, Mulinari and Sandell are critical of the postmodern interpretation of difference. They argue (1999: 293) that while the notion of the Other is central to postmodern theorising, 'the notion of 'difference' is separated from structural forms of oppression and often turned into cultural differences'. Mulinari and Sandell (1999: 294) propose that the postmodern shift has resulted in 'distance from everyday life experiences of oppression and struggle and from the materiality of women's lives' and comment that 'experience has been emptied of its radical political potential'. Mulinari and Sandell (1999: 293) that a feminist standpoint, or a feminism that centres experience, permits continued attention to questions of, and research on the "concrete matters' that directly affect women, such as why 'so many women are raped, [why] so many Latina have been sterilized, [why] so many children are abused... [and so on]'. They remain adamant that retaining women's experiences at the heart of a feminist politics offers the most inclusive and productive means of addressing difference by linking 'individual lived experiences to collective identities and to structures of domination' (Mulinari and Sandell, 1999: 294). Attention to the 'lived experience' of women constitutes an integral feature of feminist standpoint and is central to the following discussion in which feminist debates concerning the nature of 'reality' are addressed.

\section{Realism-Relativism}

A major area of contestation and ambiguity with feminist standpoint concerns the relationship between experience, 'reality' and 'truth', and an understanding of these in terms of a realist-relativist dichotomy. Some proponents of feminist standpoint hold to a quasi-realist theory of knowledge which involves 'a knowing subject producing valid knowledge that adds to the general stock of truth' (Ramazanoğlu, 2002: 62). While rejecting conventional modernist notions of 'truth' and 'objectivity', such theorists endorse the strategic use of the language of 'objectivity' and 'truth' while 
reconceptualising their meaning. ${ }^{85}$ From this position it is argued that a 'real' reality exists that can only be known by subordinated groups who have epistemic privilege due to their outsider status (Stanley and Wise, 1993: 189). Others adopt a relativist model in which the socially constituted nature of experience, reality and knowledge is asserted (for example Smith, 1997). Within this model reality does not exist independently from the language within which it is constituted and the notion of 'truth' is rejected. Knowledge is therefore only ever partial and relative, with competing knowledge claims existing in the absence of a specific means of determining their authority (Smith, 1997). Feminist standpoint, which insists on the specification of location, that is, women's experience, simultaneously asserts a multiplicity of standpoints, offering an alternative to the realism-relativism dichotomy (Harding, 1991a, 1991b). Taking this position, I now address the work of Hartsock and others whose articulation of feminist standpoint rests on similar epistemological assumptions.

\section{Utilising Nancy Hartsock's Version of Feminist Standpoint Epistemology}

In this chapter I have drawn on an amalgamation of work that falls under the rubric of 'feminist standpoint' (for example Collins, 1997; Haraway, 1991; Harding, 1997a, 1993; Hartsock, 1983, 1997a, 1997b, Ramazanoğlu, 2002; Smith, 1997; Stoppard, 1999; Ussher, 2000b). In particular, I have utilised Nancy Hartsock's version of feminist standpoint to demonstrate the epistemological position I have adopted. Hartsock's articulation of feminist standpoint has changed over time. However, it is her later work that most informs my research.

Drawing on Marxist theory, Hartsock (1997a: 368) originally used an analysis of the 'institutional sexual division of labour' as a means of developing a feminist standpoint from which to critique 'patriarchal ideology'. She argued (Hartsock, 1983b) that women's subordinate position in relation to men allowed women to 'see' the socially constructed nature of power relations and the material basis of these relations, just as Marx argued that the proletariat could envision the workings of capitalism and the

\footnotetext{
${ }^{85}$ For example Harding's notion of 'successor science', 'strong objectivity' and 'less false' knowledge (1993, 1997a, 1997b).
} 
power of the bourgeoisie. In reading Hartsock's later work (see 1997a), she asserts a critical-realist notion of truth following Marx. However, rather than reducing ideology to capitalist relations, Hartsock explores more critically the operations of politics, and the connections between power and what counts as 'truth'. Here, Hartsock (1997a) argues that truth is produced through power relations.

Some critics have suggested that Hartsock relies on a conventional realist notion of truth (for example Hekman, 1997a). However, Hartsock (1997a: 370) explicitly states that she draws on Marx's notion of 'truth', which is centrally concerned with changing the 'criteria for what counts as knowledge'. She comments that 'truth' is 'historically specific' and that the 'search for knowledge is a human activity' (Hartsock, 1997a: 370). Hartsock herself questions the relevance of the category 'truth' 'for the knowledge that is a social production' (Hartsock, 1997a: 367). Her central concern is to 'understand power relations', and the relationship between knowledge and power (Hartsock, 1997a: 370). She comments that feminist standpoint must be understood as a counter hegemonic discourse' that is implicitly political (Hartsock, 1997a: 367). Her critical take on 'truth' is further demonstrated here in arguing that all discourses are socially constituted, reflecting politics and the workings of power.

Other feminist standpoint writers concur with Hartsock in their conceptualisation of 'truth'. For example, Collins (1997: 375) comments that 'standpoint theory never was designed to be argued as a theory of truth'. Indeed, Sandra Harding sums up a central assertion of feminist standpoint writers when she comments (1997a: 382) that they are concerned with 'relations between power and knowledge' - not 'truth' in its conventional sense, as "a static, eternally fixed state of affairs "out there"" (Harding, 1997a: 383). Hartsock's attention to macro processes of power and the collective subject further exemplifies her focus on the power-knowledge relationship.

Macro Power and the Collective Subject

Hartsock asserts the importance of distinguishing 'global', rather than 'totalising' theory, and argues that feminist standpoint is concerned with the 'macroprocesses of 
power' not the micro perspectives of individuals. Further, in accordance with Marxist theory, she argues that the subject of feminist standpoint is the 'collective' subject rather than the individual subject and in this regard distinguishes 'feminist standpoint' from 'women's viewpoint'. Drawing on Antonio Gramsci's work, Hartsock states that the 'individual' is a 'series of active relationships' and the 'synthesis of these relations and also of the history of these relations '(Hartsock, 1997a: 372). In this sense, she is eager to differentiate the collective subject from 'aggregates of individuals' (Hartsock, 1997a: 372). Collins (1997: 375) also states that standpoint 'refers to historically shared, groupbased experiences' and explicitly emphasises the 'social conditions that construct such groups'. She notes that 'it is common location within hierarchical power relations that creates groups' - they are not merely aggregates of individuals (Collins, 1997: 376). She goes further to say that:

race, gender, social class, ethnicity, age, and sexuality are not descriptive categories of identity applied to individuals. Instead, these elements of social structure emerge as fundamental devices that foster inequality resulting in groups (Collins, 1997: 376).

Thus, a key feature of feminist standpoint is attention to shared group experience and the rejection of the individualism characteristic of traditional western theorising (Collins, 1997; Hartsock, 1997a) and postmodernism (Stanley and Wise, 1993), as it is borne out in abstract notions of the subject, individualised accounts of subjectivity and the ascendance of personal narratives (Mulinari and Sandell, 1999: 293).

Hartsock further argues that standpoints are actively and consciously derived from the transformation of subject positions resulting from 'oppositional consciousness', ${ }^{86}$ and are aimed at radically changing the ways women's lives are structured and interpreted. Hartsock (1997a: 372) asserts the need for a collective identity (for example, women) as a strategy for political opposition. Similarly, other feminist standpoint writers argue the importance of the category 'women' for 'political mobilization' (Smith, 1997: 394). Collins (1997: 377) also comments "if the group has been theorized away, there can be no common experiences or perspectives ... [hence] race and/or social class, continues to matter'. While Hartsock asserts the importance of collective experience and feminist

\footnotetext{
${ }^{86}$ The notion of 'oppositional consciousness' is attributed to Chela Sandoval (1991, cited in Hartsock, 1997a).
} 
consciousness in her articulation of feminist standpoint, she also argues in favour of the notion of privileged knowledge.

\section{Hartsock's Notion of Privileged Knowledge}

In her discussion of 'privileged knowledge', Hartsock (1997a: 373) argues that by privileging ${ }^{87}$ some knowledges there is the potential to envision 'more just social relations' and to permit new knowledges that have hitherto been denied. Her conceptualisation of privileged knowledge embodies the notion of grounding in women's experience of subordination and the material conditions of women's lived realities (Hartsock, 1997a). Caroline Ramazanoğlu (2002: 68) states that Hartsock does "not claim that women actually have privileged knowledge of power relations, or privileged ways of accessing 'reality', as a result of being female'. It is the sharing of gender subordination, and development of a feminist consciousness that accords women 'privileged knowledge'.

Further, 'a patriarchal vision of gender serves to structure the material relations of gender in which both men and women are forced to participate' (Ramazanoğlu, 2002: 68). The compulsory and pervasive nature of patriarchal knowledge means that it is both powerful and 'real' in terms of the material effects it has on women. To reject it merely as 'text' or 'discourse' is to deny the 'actual' consequences it has for women. As Collins (1997: 381) states, 'oppression is not a game, nor is it solely about language - for many of us it still remains profoundly real'. In response to criticism that all knowledges are merely competing discourses (Hekman, 1997a), Hartsock (1997a) argues that the criteria used to establish the legitimacy of knowledge are political and ethical, and centrally concerned with power. For her, feminist standpoint is about the possibility of creating 'theories of justice and social change' (Hartsock, 1997a: 373). She argues that 'standpoint theories are theoretical devices that can allow for the creation of accounts of society that can be used to work for more satisfactory social relations' (Hartsock, 1997a: 370). It is Hartsock's focus on justice, power and social change that forms the

\footnotetext{
${ }^{87}$ Hartsock's notion of privileged knowledge is knowledge that arises in the context of oppositional consciousness and is permitted by virtue of being positioned as subordinate.
} 
epistemological basis of this thesis. While I have adopted Hartsock's particular version of feminist standpoint, I am aware of a range of criticisms of this epistemological approach.

\section{Criticisms of Feminist Standpoint}

Feminist standpoint epistemology is often assumed in the singular and has been criticised as 'flawed by aspects of modern thinking such as humanism, foundationalism, essentialism, conceptions of fixed identities, inappropriate claims to privileged knowledge or assertions of totalizing theory' (Ramazanoğlu, 2002: 74). However, as feminist standpoint writers cited in this chapter make clear, feminist standpoint does not necessarily prescribe a singular or a closed position (Collins, 1997; Hartsock, 1997b; Ramazanoğlu, 2002; Smith, 1997). Feminist standpoint is concerned with diverse, ongoing and shifting understandings of the relationship between power and knowledge, and allows self-critical appraisal of its own exclusionary practices. The following discussion briefly addresses criticisms of feminist standpoint relating to realism and notions of 'truth', problems with the notion of privileged knowledge and accusations of essentialism in terms of apparently fixed categories such as women, and those relating to difference.

\section{Realism}

I consider Hartsock's version of feminist standpoint epistemology as most fitting for the purposes of my research. However, her approach has been challenged as realist (for example Hekman, 1997a, 1997b). In response, my reading of Hartsock's work suggests that she is not asserting the existence of a 'real' reality out there waiting to be 'discovered', as it is often described ${ }^{88}$ Rather than taking this view of reality, Hartsock advocates a conception of reality that is socially and materially constructed, and located in relations of power. Or in Liz Stanley's words (cited in Ramazanoğlu, 2002: 73), ${ }^{89}$

\footnotetext{
${ }^{88}$ For example Ramanazoğlu, 2002: 73.

${ }^{89}$ I am not suggesting here that Stanley agrees with Hartsock's view, indeed it appears that she does not, but I found this a useful articulation of what I considered Hartsock to mean.
} 
'the structured and repetitive regularities and inequalities of social life' that are material, and have actual material effects. Hartsock endorses the view that reality is partial and perceived differently according to one's social position and material circumstances. Further, Hartsock $(1997 \mathrm{a}, 1997 \mathrm{~b})$ argues that feminist standpoint is about the actual power relations that underpin processes of knowledge production, the construction and authority of knowledge, and claims to who can 'know'.

Hartsock offers a critical-realist position in which knowledge, or 'truth', is conceptualised as a social construct produced in the context of power relations. For her, feminist standpoint is about theorising the relationship between experience and knowledge, and using a standpoint position for political purposes. It is not, as some critics suggest, about the discovery or establishment of a 'real' reality akin to the modernist pursuit of scientific 'truth'.

\section{Privileged Knowledge}

Critics of feminist standpoint have particularly maligned the notion of "privileged knowledge'. They argue that feminist standpoint is essentialist, and imply that women and other subjugated groups have some a priori, superior knowledge of power relations and access to reality (for example Barrett, 1987; Riley, 1987). Here, it is assumed that feminist standpoint universalises the experience of all women as knowable, by virtue of the knower being 'woman'. Hartsock argues that it is the experience of subjugation in association with feminist consciousness that gives rise to the knowledge she calls 'privileged knowledge'. What she is arguing is that there are 'real' or 'essential' gender relations that underpin patriarchal ideology (Ramazanoğlu, 2002). Hartsock 'does not claim that women actually have privileged knowledge of power relations, or privileged ways of accessing 'reality' as a result of being female' (Ramazanoğlu, 2002: 68). Rather, Hartsock states that (1997a: 373), 'the criteria for privileging some knowledges over others are ethical and political'. The purpose of locating some knowledges as privileged is that they allow the possibility of new knowledges and, as stated previously, enable the pursuit of 'more just social relations' (Hartsock, 1997a: 373). 
Others have questioned whether women would have bifurcated vision if not subordinately positioned (for example Cain, 1990 cited in Ramazanoğlu, 2002). Given that Hartsock argues for a specifically feminist standpoint, one assumes that it is the position of subordination and oppositional consciousness derived from a feminist analysis of power that enables the subjugated to 'see' reality. Hartsock (1997a: 373) discusses the notion of privileged knowledges as a means to 'the self-conscious transformation of individuals into resistant, oppositional, and collective subjects'. The whole point of feminist standpoint from Hartsock's position is 'to create theories of justice and social change' (Hartsock, 1997a: 373).

Essentialist Notions of 'Woman' and Categories of Difference

Feminist standpoint has been charged with essentialism ${ }^{90}$ by invoking the category of 'women' and drawing upon notions of 'women's experience' and 'women's knowledge' (for example Barrett, 1987; Riley, 1987). Similar accusations are made in relation to feminist standpoint arguments concerning difference, where categories such as black and lesbian are used to talk about subjugation on the grounds of race and sexuality (Collins, 1997; Jackson, 1998). However, feminist standpoint writers assert the sociopolitical and constructed nature of categories such as race, class, gender, and sexuality, arguing that these are central to the political project of standpoint and useful analytical categories. Liz Stanley (1997: 276) argues that the word 'women' refers to:

the social construction of women as a particular set of people who face - albeit with large and important internal differences - a common material reality rooted in oppression; and by material oppression here I of course mean categorisations or representations as much as physical material circumstances.

Stevie Jackson (1998: 138) suggests that the category 'women' can be 'brought into question without denying the material existence of women as a social group defined not by their 'essence' but by their location with the hierarchy of gender'. This approach also

\footnotetext{
${ }^{90}$ In the context of feminist theories essentialism is used to refer to 'appeals to a pure or original femininity, a female essence' or more generally, to 'that which is most irreducible, unchanging, and therefore constitutive of a given person or thing' (Fuss, 1997: 250).
} 
allows attention to diversity and women's differing material locations (Jackson, 1998). While recognising the heterogeneity, fluidity, intersectionality and fractured nature of such categories, their importance to standpoint is affirmed in terms of allowing 'marginalized groups...[to] name themselves and participate in defining the terms that structure their world' (Hartsock, 1987a: 189). The terms women, black, or lesbian for example, allow representation via a location from which to speak. Without these categories women are left 'with no position to speak from as women, or as black women or as lesbian women, no position around which to mobilise politically' (Jackson, 1998: 138). And as Hartsock (1990: 163) asks:

Why is it that just at the moment when so many of us who have been silenced begin to demand the right to name ourselves, to act as subjects rather than objects of history, that just then the concept of subjecthood becomes problematic?

Having outlined Hartsock's version of feminist standpoint and addressed a range of criticisms of this approach, I now direct attention to Ussher's (2000b) use of feminist standpoint in relation to a critical-realist approach to psychology.

\section{Jane Ussher's Material-Discursive-Intrapsychic Approach}

Drawing on feminist standpoint epistemology and taking a critical-realist position, Ussher (2000b) shows how this approach has relevance for psychology and conceptions of women's 'madness'. 91 She argues that critical realism ${ }^{92}$ provides a way of thinking around the problems inherent in both realist and relativist conceptions of feminist standpoint epistemology. The critical-realist conceptualisation of feminist standpoint epistemology advocated by Ussher (2000b: 207-230) posits a material and discursive and intrapsychic theorisation of knowledge, reality and experience. This model allows

\footnotetext{
"II Ussher (2000b: 227, note 1) uses the term 'madness' to refer to the 'discursively constructed category which effectively defines individuals so categorised as 'Other', as fearful or fragile'.

${ }^{92}$ Ussher attributes 'critical realism' to Bhaskar, (1989). Ussher (2000b: 221) describes critical realism as an 'approach that can reconcile both the biomedical and psychosocial aspects of experience, as well as incorporate the cultural and historical context in which the meaning about experience is created'. She states that critical realism 'affirms the existence of 'reality,' both physical and environmental, but at the same time recognises that its representations are characterised and mediated by culture, language, and political interests rooted in factors such as race, gender, or social class' (Ussher, 2002b: 221).
} 
an integrated approach to understanding people, the difficulties people experience, as well as the way 'everyday' and 'psychological' meaning is constructed in the context of differential power relations. Ussher (2000b) uses the analogy of the difference between what is captured on camera and what is captured on film to describe the shift from traditional realist/positivist accounts of 'reality' to a critical-realist approach. She states that:

neither provides a more 'true' vision of reality; the camera is merely more simplistic, limited, and can only show one fragment of the world at any one time, while a whole range of experiences can be captured - in all of their fluid complexity - with the more sophisticated medium of moving film (Ussher, 2000b: 227).

The 'moving film' is thus analogous to the tripartite model Ussher puts forward. While attending to the material effects of gendered social arrangements, as well as other relations of power such as race and class, this model allows an understanding of the physicality of the body, as well as the nature of constructed meanings assigned to or inscribed on the body. Further, it offers a model in which the discursive construction of 'reality' and knowledge are recognised as central to the ways people understand their experiences and the world they live in. This might include, for example, discourses of 'femininity' and 'masculinity', or those of 'madness' and 'mental illness' (Ussher, 2002b: 225). It also includes attention to the intrapsychic, such as personal ways of coping, the interpretation of experience, and accounts of well-being (Ussher, 2002b: 225). While the individualist, intrapsychic focus of psychology has been understandably maligned in feminist and contemporary critiques of positivism, and dominant psychological analyses of women's 'madness', attention to all three aspects - the material, discursive and intrapsychic - allows for an integrated analysis of experience. It also provides a means for producing more holistic accounts of 'psychological' knowledge, grounded in women's experience and the material effects of gendered and other dominant discourses.

\section{Taking a Feminist Standpoint and Critical-Realist Position}

The adoption of a feminist standpoint epistemological position and critical-realist stance suited the purposes of this research. I considered that advocating poststructural 
arguments in a context where analyses of gender, race and so forth have not yet been appropriately engaged, even within existing modernist theories and practices, would have likely closed off possibilities of being heard by this audience and thereby stimulating change within clinical psychology. From the outset, I wanted to engage mainstream clinical psychologists, who generally adhere to modernist, positivist epistemologies and modes of practice, to achieve change in the way gender and other relations of power are included in clinical psychology training. To this end, taking a feminist standpoint and critical-realist stance, while offering some resistance to the modernist orthodoxy of dominant clinical psychology, would be less alienating than perhaps a poststructural approach might be for this audience.

The above notwithstanding, a feminist social constructionist or poststructural approach would undoubtedly be useful in developing research of this nature in the future, as clinical psychology, and its wider disciplinary body begin to engage epistemological and ontological debates around the relationship between power and knowledge, and the social construction of reality.

\section{Conclusion}

Ussher's (2000b) approach provides an example of using a critical-realist, feminist standpoint epistemology in relation to psychology and conceptions of women's 'madness'. While I have not followed her actual model, I have argued for a similar application in the context of my research. This approach has allowed me to argue from the standpoint of women, and to promote a position that takes women's diverse experiences, concepts and languages as the starting point for constructing knowledge about women. Implicit to this approach is recognition of the legitimacy and authority of women's and other marginalised groups accounts of experience. Further, taking a feminist standpoint position has enabled me to challenge dominant positivist ideas about what constitutes 'experience' in clinical psychology. It has also permitted critique of the promotion of 'evidence based practice' which is embedded in masculinist conceptions of western science and reflects the perspective of so-called experts' theories. I have been able to examine traditional conceptions of clinical psychology, and to offer new 
ways of thinking about gender and the position of women in the construction of psychological knowledge. In particular, the use of feminist standpoint epistemology has allowed me to examine the relationship between knowledge and power, and the implications of gender relations for what counts as psychological knowledge. I argue that this approach offers a better understanding of women's diverse lives, more holistic conceptions of experience, broader interpretations of knowledge, and ultimately a more meaningful clinical psychology. In the next chapter, I outline the methodological foundations of my research which are informed by this feminist standpoint epistemological position. 


\section{Chapter Five}

\section{Feminist Methodologies}

Feminist methodology is concerned with the theoretical underpinnings of research, the ways knowledge is produced, and the grounds upon which knowledge claims are based (Maynard, 1994; Ramazanoğlu, 2002; Stanley and Wise, 1990). Debates about feminist methodology range from epistemological discussions to descriptions of techniques of research practice. Caroline Ramazanoğlu (2002: 9-10) comments that feminist methodology is about:

procedures for making knowledge valid and authoritative...[it is] one set of approaches to the problems of producing justifiable knowledge of gender relations.

In this chapter I address issues of feminist research practice as they relate to the epistemological and methodological processes and purposes of research. Key principles of feminist research practice are explored to provide some indication of the framework that informs this research. I then address contemporary issues central to feminist debates about research and discuss their relevance to my research. In particular I argue for a position beyond the qualitative/quantitative dichotomy. I address the potential power and strategic purposes of including men and non-feminist participants in feminist research, and explore issues concerning interviewing 'up' as well as interviewing nonfeminist participants. I examine the educative potential of feminist research practice when it encompasses critically challenging methods. Finally, issues of reciprocity are explored as they relate to participants and research contexts.

\section{Feminist Research Practice}

While the notion of a distinctively feminist methodology is now widely contested, with most feminist writers arguing against an archetypal feminist methodology (Harding, 1987a; Kelly, Burton and Reagan, 1994; Lather, 1991; Oakley, 1998; Ramazanoğlu, 
2002; Stanley and Wise, 1993), ${ }^{93}$ there is some consensus that what makes feminist research 'feminist', has to do with the epistemological and theoretical foundations that underpin feminist research practice (Maynard, 1994; Ramazanoğlu, 2002; Stanley and Wise, 1990, 1993). ${ }^{94}$ While feminist research is centrally concerned with producing knowledge about gender, Mary Maynard (1994) argues that two key factors guide feminist research practice. These include 'the position from which distinctively feminist research questions might be asked and the political and ethical issues involved in the research process' (Maynard, 1994: 14). In discussions of feminist methodology, feminist writers have directed attention to the theory that underpins feminist research and guides the interpretation and analysis of 'data' (Maynard, 1994; Ramazanoğlu, 2002). Ramazanoğlu (2002: 16) suggests that 'feminist knowledge has some grounding in women's experiences, and in how it feels to live in unjust gendered relationships'. Patti Lather (1991: 71) comments that 'to do feminist research is to put the social construction of gender at the centre of one's inquiry'. Feminist writers have written widely about issues concerning difference in feminist research, with particular attention to the interconnections of gender, race, ethnicity, class, poverty, sexuality, disability, to name a few dimensions of power that feminists have addressed (for example Collins, 1991; Du Plessis and Alice, 1998; Kitzinger, 1997; Marshall, 1994; Phoenix, 1994; Ramazanoğlu, 2002; Stanley and Wise, 1993). Liz Kelly argues that feminist research is distinguished by 'the questions we [feminists] have asked, the way we locate ourselves within our questions, and the purpose of our work' (Maynard, 1994: 14). Indeed the political foundations and objectives of feminist research are a particular feature of the research feminists do, with some writers arguing that feminist research "is politically for women' (Ramazanoğlu, 2002: 16). Ramazanoğlu comments that:

[W] hat distinguishes feminist researchers...is some shared political and ethical commitment that makes them accountable to a community of women with moral and political interests in common.

\footnotetext{
${ }^{93}$ For a clear discussion of arguments against the notion of a distinctly feminist methodology see Ramazanoğlu (2002: 15-16).

94 I have adopted Kelly's use of the term 'feminist research practice' (Maynard, 1994: 14) to draw attention to the diversity of issues feminists consider in relation to the process of research and to encapsulate the broad interconnectedness of feminist epistemology, methodology and method. By referring to 'feminist research practice' I am not arguing for a distinctly feminist methodology. My intention is to give some indication of the feminist epistemological framework that locates my research.
} 
It is this grounding in feminist politics, ethics and accountability, and an integral concern with relations of power, gender, justice, equity and social change that remains central to feminist research practice. These terms of reference situate the research I have undertaken.

\section{Contemporary Feminist Debates About Research}

\section{Beyond the Qualitative/Quantitative Dichotomy}

Feminist enthusiasm for qualitative approaches grew out of recognition of the limitations of positivist quantitative research enshrined as the authoritative and legitimate form of scientific inquiry. Positivism is the blueprint for research in clinical psychology. As discussed previously, criticisms of quantitative research echo those of positivism more generally. Briefly, concerns about quantitative research have centred on issues to do with: the objectification and quantification of human experience; the imposition of male defined structures, concepts, categories and classification; the negation of researcher subjectivity and separation of the (value-free) researcher from the research process; a lack of reflexivity; doing research 'on' rather than 'with' people; the exclusion of accounts of experience in the words of women and other marginalised groups; and the refusal to acknowledge the relationship between research, politics and power (Banister, Burman, Parker, Taylor and Tindall, 1994; Burman, 1997; Henwood and Pidgeon, 1995; Jayaratne and Stewart, 1991; Kidder and Fine, 1997; Marecek, Fine and Kidder, 1997; Maynard, 1994; Reinharz, 1992; Stanley and Wise, 1993). Quantitative research in the social sciences has been referred to as 'hygienic research', responsible for 'censoring out of the mess, confusion and complexity of doing research, so that the accounts bear little or no relation to the real events' (Kelly et al, 1994: 46). Indeed, quantitative research in psychology has been accused of 'mangling (women's) experience (whether through experiments or questionnaires) into preconceived (maleoriented) categories and presenting this as objective truth' (Banister et al, 1994: 123).

Feminist debates about qualitative and quantitative research have focused on the dichotomy between the two approaches. In particular, feminist researchers have been 
largely concerned with arguing the case for qualitative research while rejecting quantitative methodologies as a dominant, exclusionary and masculinist form of knowledge production (Harding, 1991; Maynard, 1994; Oakley, 1998; Reinharz, 1992). This has led to the development of an artificial dichotomy between the two approaches in which quantitative research has been associated with positivism and qualitative research with feminism (Maynard, 1994; Oakley, 1998; Reinharz, 1992).

In dominant psychology however, where the merits of qualitative and quantitative research have been vigorously debated, resistance to qualitative methodologies remains prominent (Burman, 1997; Henwood and Pidgeon, 1995; Marecek et al, 1997; Rabinowitz and Weseen, 1997). ${ }^{95} 96$ In research with psychology doctoral students in the USA, Vita Rabinowitz and Susan Weseen (1997) show how the positivist science underpinnings of psychology, in conjunction with structural power dynamics, operate to limit methodological choices psychology students make. In particular they discuss the way students' use of qualitative methodologies in postgraduate psychology has negative ramifications for their career options. The authors highlight the implications such limitations have 'for graduate training and the socialisation of psychologists, as well as the long-standing debates on what counts as knowledge in psychology' (Rabinowitz and Weseen, 1997: 606). Work by feminist and other critical psychologists, in which the importance and value of qualitative methodologies is asserted, has often been resisted, marginalised and dismissed within psychology (Burman, 1997; Marecek et al, 1997; Rabinowitz and Weseen, 1997).

Beyond dominant psychology, in an interdisciplinary context, feminist and other contemporary critical writers have moved beyond debates about the qualitative/quantitative dichotomy. Rather, discussions concerning qualitative and quantitative research are increasingly centred on the epistemological and political foundations of social research, and the institutionalised power relations within which

\footnotetext{
${ }^{95}$ Marecek et al (1997) report that this is particularly so in the USA. Reports of the over-representation of American research in clinical psychology training in Aotearoa New Zealand indicate this is also the case.

${ }^{96}$ While dominant psychology remains resistant to qualitative methodologies there is evidence of growing interest in methodologies such as grounded theory, action research and discourse analysis. However, as Burman (1997: 789) notes 'traditional power relations in research (in terms of definition, topic, process, and outcome) can remain unchallenged by this motley blend of research models that cohabit as "qualitative methods in psychology".
} 
research occurs (Burman, 1997; Henwood and Pidgeon, 1995; Marecek et al, 1997; Maynard, 1994; Oakley, 1998; Ramazanoğlu, 2002). Attention is directed at the potential usefulness of quantitative methods for feminist political purposes and other forms of radical social change (for example Burman, 1997; Fonow and Cook, 1991; Henwood and Pidgeon, 1995; Kelly et al, 1994; Maynard, 1994; Reinharz, 1992). Likewise, some writers draw attention to potential problems with qualitative research. They highlight the importance of epistemological, methodological and ethical issues, as well as attending to power in all research practice (Burman, 1997; Henwood and Pidgeon, 1995; Kelly et al, 1994). For example, prominent writers in the area of qualitative research in psychology, Erica Burman (1997) and Karen Henwood and Nick Pidgeon (1995), argue that qualitative approaches are not necessarily exempt from the problems feminists have attributed to quantitative research. They draw attention to the potential for exploitation, manipulation and maintenance of hierarchical power relations, arguing that qualitative approaches offer many opportunities for less than ethical and democratic practice. What is at issue, they argue, is not that qualitative approaches are inherently superior, but rather the way qualitative approaches are deployed, the epistemological framework within which they are located, the purposes for which they are used, and ultimately their radical political potential (Burman, 1997; Henwood and Pidgeon, 1995). Further, it is the interpretative, contextual and reflexive nature of qualitative research that sets this methodological approach apart from the quantitative methodologies typical of positivist psychology (Burman, 1997). Erica Burman (1997: 792) suggests that qualitative approaches

stand against positivism's assumption of an unmediated relation between the world and acts of investigation of it... [they put] objectivity in its place as a particular, and particularly deluded, form of subjectivity [which] continues to be one of the most powerful interventions in psychology prompted by qualitative work.

Feminist researchers have also discussed the use of quantitative methods within feminist epistemological frameworks for the purpose of emancipatory ends (Farran, 1990; Fonow and Cook, 1991; Greaves, Wylie and the staff of the Battered Women's Advocacy Centre, 1995; Kelly et al, 1994; Kitzinger, 1990a; Marecek et al, 1997; Oakley, 1998; Pugh, 1990; Reinharz, 1992). For example, Canadian research concerning male violence against women used quantitative methods within a feminist 
analytical framework to provide information about violence against women (Greaves et al, 1995). Alternatively, Celia Kitzinger (1990a) has shown how lesbian feminists used quantitative methods to respond to heterosexism and the pathologisation of lesbians in qualitative research. While recognising the potential political usefulness of quantitative methods however, she cautions against "colluding in the construction of a privileged "scientific" discourse' (Kitzinger, 1989: 15). In contrast, Burman (1997) argues that vigilance is required to prevent qualitative approaches from being appropriated by dominant quantitative models of research as if they comprised the same political framework and interpretative terms of inquiry. What remains central to the critical potential of qualitative methodologies includes their epistemological location, processes of analysis and interpretation, and a reflexive analysis of the structural relations of power that research is embedded (Burman, 1997; Henwood and Pidgeon, 1995; Kelly et al, 1994).

My research involved the considered use of qualitative and quantitative methods of data collection and analysis located within a feminist epistemological framework. It is this specifically feminist positioning that makes possible reflexive research using both qualitative and quantitative methods, while at the same time avoiding the pitfalls of positivist methodologies. This approach enabled me to examine issues of gender and power in clinical psychology training in a comprehensive manner.

My choice of quantitative methods in the form of questionnaires was for two main reasons. It allowed me to canvass the views of a sizeable group of participants, something that would have been difficult to achieve using qualitative methods of data collection. This approach also permitted the production of quantitative data, which I regarded as a strategic tool useful in arguing for change in the traditionally positivist context of clinical psychology. I was familiar with the old adages: 'well, where's the research?' or 'produce some statistics to support your argument'. I therefore regarded the combination of quantitative and qualitative approaches a valuable means to produce research that could achieve these goals, while remaining grounded in a feminist epistemological framework. 
The use of qualitative methods in the form of open-ended questionnaire items and indepth interviewing enabled elaboration and discussion of issues flagged as a result of quantitative data collection. The open-ended questionnaire items allowed participants to explain ideas that could not be captured using quantitative measures alone. Interviewing gave participants an opportunity to discuss their ideas in detail and to fill in the gaps produced using quantitative measures. I regarded interviewing as a cogent forum to obtain in-depth understanding of the workings of gender in clinical psychology, and to highlight the subtleties and contradictions involved in training. It also gave student participants an opportunity to discuss their experiences of clinical programmes. In particular, interviewing allowed pro/feminist participants a legitimate forum to discuss their views without reproach. In the next section, I discuss methodological aspects of interviewing in more detail. In Chapter Six, the method or research process is outlined, and includes discussion of the ways questionnaires and interviews were used.

\section{Interviewing}

Interviewing was identified as a central aspect of feminist research in the classic work of British sociologist Ann Oakley (1981). Her argument centred upon rejecting the myth of the detached, hierarchical 'objective' methods typical of 'scientific' research. Instead she argued for a process in which the interactive, interpersonal nature of the relationship between researchers and participants was valued, and in which egalitarianism, reciprocity, and validation of participants' realities were integral (Oakley, 1981.).

Since that time, 'the interview' has become a key feature of feminist research and has been widely written about by feminist writers (for example Banister et al, 1994; Cotterill, 1992; Kelly et al, 1994; Lee, 1997; Mies, 1983, 1991; Phoenix, 1994; Reinharz, 1992). Furthermore, feminist researchers have revisited issues relating to interviewing and are now taking a less orthodox approach than that originally advocated, and questioning aspects of the research interview that were originally thought beneficial. In particular, feminists have addressed assumptions relating to: power and empowerment; issues about who directs and controls research; rights of interpretation and authorship; the potential for exploitation and coercion; and excessive 
demands on researchers themselves when interviewing people who are anti-feminist or in other ways opposed to feminist research (Burt and Code, 1995; Kelly et al, 1994; Lee, 1997; Maynard, 1994; Phoenix, 1994; Reinharz, 1992, 1993). These issues are well documented in a range of feminist literature. My discussion therefore focuses on three aspects of the interview process central to my research. These issues include: aspects of power involved in interviewing anti-feminists and interviewing 'up'; issues concerning reciprocity and openly answering questions participants ask; and using the interview as a 'challenging method' for debate, education and politicisation. ${ }^{97}$

Interviewing Anti-Feminist Participants and Interviewing 'Up'

In its early phase of development feminist research was concerned with doing qualitative research 'on, with and for women' (Kelly et al, 1994: 29). More recently feminist writers have addressed the importance of doing feminist research with men, scrutinising problems associated with research with non-feminist women, and examining the power relations and institutions within which masculinist knowledge is constructed (for example Kelly et al, 1994; Maynard, 1994; Stanko, 1994; Stanley and Wise, 1993). In this regard feminist research needs to 'be concerned with all aspects of social reality and all participants in it' (Stanley and Wise, 1993: 31). Feminist research objectives have therefore led to feminist research practice that entails interviewing men, and people whose worldviews may be incongruous or antithetical to feminist thought and feminist political objectives (Kelly et al, 1994; Lee, 1997; Phoenix, 1994; Stanko, 1994; Stanley and Wise, 1993). Further, the goals of feminist research have led to 'studying up' or including participants located in positions of power within institutional hierarchies (Kelly et al, 1994: 34). This might include, for example, university professors and lecturers whose location within the academy accords them status, and invests them with decision-making powers and control over processes of knowledge production, as was the case in my research.

\footnotetext{
${ }^{97}$ Often referred to as 'consciousness raising' in traditional feminist research.
} 
Liz Kelly, Sheila Burton and Linda Regan (1994: 33) comment that:

studying women's lives as a feminist means that male dominance, masculinity and men are always part of the research... [it is about the] strategies men and male dominated institutions use to maintain their power.

These writers argue that what is important about feminist research is the nature of questions and issues addressed, and examination of the processes and structures of oppression (Kelly et al, 1994). They also maintain that feminist research requires examination of connections between dominant discourses, institutional and government policies, and the perspectives of individual professionals (Kelly et al, 1994: 33). This process requires the inclusion of research participants located in positions of power, which invariably involves men and those who reject feminist thought.

My research involved interviewing academics who have authority and status in the profession of clinical psychology and the institution of the university. My positioning as a feminist researcher located outside psychology exposed the contradictory nature of the power relations between most academic participants and myself. On the one hand, this group of participants had power within academic and professional institutional frameworks. In the context of feminist research, and the research relationship, however, their power was limited. Ultimately, in my role as the researcher I had the power to make decisions concerning the questions and methods of the research, and to analyse and interpret in accordance with a feminist epistemological perspective. This position was contrary to the positivist, 'scientific' worldview of many of the participants.

The inclusion of men and non-feminist participants in my research is also consistent with contemporary feminist research practice (for example Greaves et al, 1995; Kelly et al, 1994; Stanko, 1994). It raises issues concerning simplistic concepts of power and empowering research relationships typical of traditional feminist research (Kelly et al, 1994; Holland and Ramazanoğlu, 1994; Phoenix, 1994). Questions are now framed around the shifting nature of power and to what 'empowerment' means when participants express anti-feminist perspectives. The problematic nature of power is addressed when women research participants express racist, homophobic, or classist views for example (Kelly et al, 1994: 37). Feminists also argue that research involving 
men or institutions is concerned with how to minimise the effects of power and to 'limit its potential use against us...in this context the empowerment of research participants is not and indeed should not be our goal' (Kelly et al, 1994: 38). Instead, it is argued that feminist concepts of power should be concerned with those over whom dominant groups and patriarchal institutions exert power (Holland and Ramazanoğlu, 1994; Kelly et al, 1994). In this regard, my research is concerned with the ways gender is represented in clinical psychology and the impact this has for diverse groups of women, both through the construction of subjectivity and the production of knowledge about women, and through direct contact with women in clinical practice and research. Consequently, my research focuses primarily on the producers of psychological knowledge (academic staff), and the students who at once consume and produce knowledge themselves. However, my ultimate focus is women, whose very being is shaped by dominant psychological discourses.

Feminist discussions concerning the inclusion of men and non-feminist participants in feminist research have led to the development of 'challenging methods' (Kelly et al, 1994: 38). While feminists have long valued the consciousness raising or politicising potential of feminist research, ${ }^{98}$ the utilisation of challenging methods has been a more recent development. Challenging methods are referred to as strategies for undertaking research that 'are designed to question oppressive attitudes and behaviour... and encourage different ways of thinking' (Kelly et al, 1994: 38). Challenging methods encourage attention to issues that might not have previously been thought about by participants, or which may have been relegated to the periphery or deemed 'too hard'. Taking an actively critical approach to research offers a way of countering 'dominant/oppressive discourses' and challenging participants' discrimination (Kelly et al, 1994: 39; Phoenix, 1994). This process provides opportunity for debate and discussion, and the potential for increased awareness, insights and understanding of issues central to feminist research (Fonow and Cook, 1991; Kelly et al, 1994).

While challenging methods can be an integral aspect of research questionnaires, they are applicable in a more direct manner in the interview context (Kelly et al, 1994). In my research, I adopted this approach both when constructing research questionnaires,

${ }^{98}$ For example Fonow and Cook (1991). 
and as a component of the interview process. This method allowed questioning about issues which participants seemed to have little knowledge. It also functioned as a means to counter dominant masculinist views and to challenge discrimination. For example, some participants expressed views that assumed positivist science as the ultimate and only valid ontological and epistemological position. Other examples included dominant cultural assumptions, and overt discrimination relating to the Treaty of Waitangi, 'race', gender, ability, age, sexuality and class. Taking a proactive approach during interviews allowed me to challenge assumptions underlying these kinds of views and to pose ideas participants may not have considered. Discussion with interviewees about what they had gained from the research, in conjunction with comments made by participants about others' experience of the research, suggests this method served to generate debate and raise awareness amongst clinical psychology staff and students. In this way 'the potential of research to create change can become an aspect of our methodology' (Kelly et al, 1994: 40).

\section{Issues of Reciprocity}

As addressed previously, the relationship between researchers and research participants has been the topic of considerable discussion by feminist writers. While much attention has centred on issues of power, reflexivity and transparency, more recent discussions have examined the complex and shifting nature of power, and problematised simplistic conceptions of the research relationship (Kelly et al, 1994; Mies, 1991; Phoenix, 1994; Stanley and Wise, 1993). In particular, some feminist researchers have addressed issues concerned with reciprocity and answering questions participants ask in the course of the research (Cotterill, 1992; Kirkwood, 1993; Mies, 1991; Phoenix, 1994; Skeggs, 1994).

Reciprocity, or issues to do with how much the researcher discloses of her personal life, her political views and other facets of her 'self', was traditionally advocated by some feminist researchers (for example Duelli Klein, 1983; Mies, 1983; Oakley, 1981). It was argued that reciprocity was part of facilitating an interactive interview process in which participants were regarded as people, not objects, and as a means to diminish the researcher/researched divide characteristic of mainstream social science research. 
Reciprocity was regarded as a way to enhance the social closeness, intimacy and friendship of researchers and participants, which, it was thought, would lead to a more democratic, less hierarchical research relationship (for example Duelli Klein, 1983; Mies, 1983; Oakley, 1981). ${ }^{99}$ While the value of reciprocity in developing rapport, engaging participants, and generally facilitating an interactive research process is clear, problems with an uncritical or unreflexive approach have been raised by feminist researchers (Cotterill, 1992; Phoenix, 1994; Stanley and Wise, 1983, 1993). In particular, questions have been directed at the appropriateness of reciprocity in the context of research undertaken with those in positions of power, those who are antifeminist or those who could use personal information about the researcher in a detrimental manner (Phoenix, 1994; Stanley and Wise, 1993).

Clearly, issues of power and context impact on decisions about the degree of reciprocity feminist researchers are prepared to engage. These issues became apparent in my own research where using reciprocity could at times be useful and at other times potentially harmful. On the one hand, participants appeared actively interested in the research, and despite philosophical differences, were eager to engage debate about issues raised in the research. Frequently, participants were keen to hear what I thought about certain issues or how I thought clinical psychology training could develop. At times, the content of discussion was contentious and in some instances, it dealt with sensitive issues. Participants were also interested in my motivation for the research, which led to a range of personal questions about why I chose this particular research topic. Clearly, discussions of this nature require an openness and willingness to reciprocate and disclose information that reflects on 'the personal'.

While there were participants with whom I felt comfortable discussing personal issues, this was not the case with others. This was due to a range of circumstances. For example with some participants discussing personal experiences that contributed to my motivation for the research could have cast doubt on my research and placed me in a potentially vulnerable position professionally. In some instances, my reticence was to

\footnotetext{
${ }^{99}$ Some feminist researchers were more sceptical of reciprocity, questioning the legitimacy of developing friendships which could then be exploited by researchers and luring participants into a relationship within which they might disclose more personal detail than they would otherwise have done; and that disclosure may not be what participants want (for example Finch, 1984).
} 
do with the professional position participants held. At other times, it was to do with philosophical differences. More critically however, revealing aspects of my social locations and identities was most compromised with participants who held narrow views, had limited life experience or minimal insight or understanding of that experience, whose understanding of psychological distress was individualistically oriented, and who expressed judgmental comments during the course of the interview. Further, while the level of my disclosure depended on the degree of participants' analysis of power, this did not necessarily reflect participants' gender. The degree of dis/comfort I experienced with participants in the early phase of interviewing therefore shaped my approach to reciprocity in the latter phase of the research. While issues of power are addressed by feminists in the context of reciprocity, they are also central to ethical research practice, which is addressed in the next section.

\section{Ethics}

The development of feminist, indigenous and other critical research methodologies has been accompanied by scrutiny of the ethics governing research (for example Banister, et al, 1994; Brown, 1997; Cram, 2001b; Prilleltensky and Fox, 1997; Roberson, 2001, 2002; Smith, 1998; Stanley and Wise, 1993). Indeed, issues concerning ethics have been a central focus of feminist critiques and writing about research (Brown, 1997; Stanley and Wise, 1993). This focus on ethics amongst feminist researchers grew out of criticism of conventional social science research where the requirements of positivism meant research practice reliant on deception, depersonalisation and objectification (Banister et al, 1994: 5). In particular, those critical of ethics in psychology drew attention to research in which 'we call people 'subjects' but treat them as 'objects', and we pretend to be objective but are still always deeply subjective' (Banister et al, 1994: 5). Further, it was recognised that if the processes governing positivist research operate 'as a battle that must be won by the researcher if he (sic) is to extract good data', then the ethical implications for participants have yet to be adequately addressed in mainstream psychology (Banister et al, 1994: 5). 
Further, while 'standard tests of validity, reliability and objectivity', central to positivism, remain imperatives for judging research as 'ethical', issues of 'trustworthiness and authenticity' and 'research credibility', the hallmarks of ethical research from a constructivist position, remain marginalised (Gauld, 2001: 123). In psychology, critics argue that positivist notions of 'objectivity' and 'good science' mask unethical research practices (Banister et al, 1994; Brown, 1997; Fox and Prilleltensky, 1997). Sue Wise comments that the ethical guidelines of places such as the British Psychological Society (1993) and university departmental ethics committees have 'little bearing on actual research practice' (cited in Banister et al, 1994: 153). ${ }^{100}$

Other scholars have increasingly addressed ethics in relation to the protection of research participants and the nature of relationships between researchers and participants (Banister et al, 1994; Cram, 2001b; Kirkman, 2001; Prilleltensky and Fox, 1997; Ramazanoğlu, 2002). Issues relating to informed consent, confidentiality, anonymity and accountability have been central to debates about ethical research practice and there is acknowledgement that these concepts have different meanings in different cultural contexts (Banister et al, 1994; Cram, 2001b; Leibrich, 1993; Ramazanoğlu, 2002; Smith, 1998). Respect for the culture, 'well-being, health, values and dignity' of participants has also been advanced (Banister et al, 1994: 152; Cram, 2001b). Feminists have suggested that research ethics should go beyond issues concerned with preventing harm to participants, to the promotion of positive research outcomes. Attention is directed at the protection of participants not simply in the process of data collection, but in the interpretation of 'findings' and in how research knowledge is used (Banister et al, 1994; Cram, 2001b; Ramazanoğlu, 2002; Stanley and Wise, 1993).

While early feminist writers addressed ethical issues relating primarily to the protection of research participants and the prevention of exploitation by researchers, more recent

\footnotetext{
${ }^{100}$ Discussion with colleagues undertaking feminist or critical psychology doctoral research suggests that some Psychology Department Ethics Committees in Aotearoa New Zealand can operate to deny research that might challenge the status quo; indeed, "ethical approval" can read "mainstream psychology approval". This situation results in unnecessary battling between students along with their feminist or other critical psychology supervisors, and those who make decisions about "scientific" research. This can lead to applicants seeking ethical approval in other more critical or interdisciplinary schools of study (see for example Roberson, 2001, 2002).
} 
work is directed at the complex interplay of ethics associated with research undertaken by researchers who are 'outsiders' and/or from non-dominant groups, as well as research involving patriarchal institutions, male participants, participants hostile to feminism, and those in positions of power. ${ }^{101}$ Attention is directed at ethical issues involving the protection of researchers whose social location or identity positions them as vulnerable to discrimination and/or abuse (for example Phoenix, 1994; Stanley and Wise, 1991). There is increasing recognition of the complex nature of contemporary feminist research ethics and the need to adapt ones ethical position to the context of particular research. This development is associated with a shift in the focus of feminist research which traditionally involved women participants, particularly women from non-dominant groups, and the related assumption that such women were subordinate to the researcher and needed protection from exploitation. More recent feminist research is diverse in focus, with topic areas, participant groups and the physical and geographical location of research being as multifaceted as the protocols needed to guide ethical research practice. Now, research involving men, masculinity and patriarchal institutions, is as likely as research with women or about issues previously regarded as specific to women. The changing face of feminist research is accompanied by more complex discussions and debates about ethical research (Kirkman, 2001; Ramazanoğlu, 2002; Stanley and Wise, 1993).

Liz Stanley and Sue Wise (1993: 203) argue that ethical practice is not simply about 'being nice' nor specifying a static 'trans-situational' system of 'research morality'. Instead, they argue that ethical research concerns epistemological issues, such as an insistence that feminist knowledge should be accountable knowledge and should acknowledge and reveal the labour processes of its own production (Stanley, 1990a). Similarly, ethical practice is that which:

turns the scrutiny of readers towards writers and the texts they construct...[it] concern[s] whose knowledge, seen in what terms, around whose definitions and standards, and judged by whose as well as what criteria, should count as 'knowledge' itself (Stanley and Wise, 1993: 201-202).

\footnotetext{
${ }^{101}$ Including those who abuse, violate, and exploit.
} 
Stanley and Wise (1993: 203) suggest that research ethics should be concerned with 'a contextual approach to ethical ideals and practices' and 'adapted to the relational parameters of different situations'. Ramazanoğlu (2002: 157) claims that ethical practice requires ongoing negotiation of 'your ethical position'. This relates to decisions about a range of issues to do with research practice including for example: access to participants; what you decide to tell or not tell about the research and why; the content and manner in which the research aims and methods are provided; what you decide to present of yourself in terms of multiple aspects of your own social locations and identities; the nature of relationships with participants including for example issues of trust, exploitation and your own vulnerability; how you exercise power as a researcher as well as how you negotiate institutionalised power which may impact on research relationships; decisions about what constitutes 'informed consent' and what information it is appropriate to give participants in what contexts; and issues concerning your accountability for the research including for example the multiple and competing audiences you may be accountable to, the nature of your interpretations of data and of the 'knowledge' produced (Ramazanoğlu, 2002: 157-159).

There are also those who argue that the importance of ethics is heightened in research involving non-dominant groups and/or researchers from non-dominant groups, ${ }^{102}$ and participants whose social location is different from the researcher (Collins, 1991; Cram, 2001 b; Phoenix, 1994; Smith, 1998; Ramazanoğlu, 2002). In Aotearoa New Zealand, research ethics have gained increasing recognition as critical researchers have directed attention to ethical issues pertinent in terms of the Treaty of Waitangi, and ethical practices relating to research involving iwi and Māori communities (for example Cram, 2001b; Smith, 1998; Te Awekotuku and Manatu Māori, 1991). In particular, it is now widely recognised that research with Māori should be underpinned by Matauranga Māori ${ }^{103}$ and reflect Treaty of Waitangi principles, especially Article II concerning tino

\footnotetext{
${ }^{102}$ For example Marshall, 1994; Phoenix, 1994; Stanley and Wise, 1993.

${ }^{103}$ Matauranga Māori is concerned with recognising a) 'that indigenous peoples are the guardians of their customary knowledge and have the right to protect and control dissemination of that knowledge; and b) 'that indigenous peoples also have the right to create new knowledge based on cultural traditions' (Mataatua Declaration on Cultural and Intellectual Property Rights of Indigenous Peoples cited in Cram, 2001: 39).
} 
rangatiratanga ${ }^{104}$ and Article III which relates to equality and equity (Cram, 2001b). Further, Linda Tuhiwai Smith (1998) discusses the importance of decolonising methodologies in research involving indigenous peoples. Research based on kaupapa Māori ${ }^{105}$ and ethics reflecting Māori traditions, customs and values are also asserted (Cram, 2001b; Irwin, 1992; Smith, 1998; Te Awekotuku and Manatu Māori, 1991). In this respect, research involving Māori should be determined and co-ordinated by Māori, working with Māori, for Māori' with the aim of 'regaining control over Māori knowledge and Māori resources' (Cram, 2001b: 36-37).

Māori challenges to Pakeha dominated institutions and researchers have centred on the ethnocentrism of Pakeha research and the imposition of the "cultural standpoint of the researcher rather than the lived reality of the indigenous population' in which the unique 'history, society and culture' of Māori is ignored (Cram, 2001b: 36-37). In particular, criticism is directed at the effects of a colonial history and the perpetuation of colonial practices in the form of Western research (Cram, 2001b; Smith, 1998; Te Awekotuku and Manatu Māori, 1991). Criticism is also directed at the ways Māori people are objectified in Pakeha research (Cram, 2001b; Smith, 1998). Similarly, challenges are made concerning the way Māori are constructed as 'deficient' or in other ways in need of change (Cram, 2001b: 50). This is particularly so in disciplines such as psychology where positivist research is underpinned by assumptions of individualism, universality and objectivity and based on the values and norms of western male culture (MoekePickering, et al, 1996; Nathan, 1999; Stewart, 1995). This model ensures individuals and marginalised groups are targeted as problematic rather than the social structures and inequitable power relations within which they live. In some ways these criticisms parallel those made by feminists in relation to the way women have been treated in (male) western research and the way women's experiences and knowledge are distorted

\footnotetext{
${ }^{104}$ Article Il of the Treaty of Waitangi guarantees Māori status as 'tangata whenua and gives rise to rights of self-determination and tribal self-development. Rangatiratanga incorporates rights and responsibilities to make decisions on the use, control and protection of natural resources according to Māori cultural values and customary practices (Cram, 2001: 40). Tangata whenua refers to local indigenous people (Ryan, 1997: 274).

105 Kaupapa Māori is concerned with 'Māori philosophy and principles' and 'presupposes that: the validity and legitimacy of Māori is taken for granted; the survival and revival of Māori language and culture is imperative; and the struggle for autonomy over our own cultural well-being, and over our own lives is vital to Mãori survival' (Graham Smith cited in Cram, 2001: 41).
} 
or negated within western systems of knowledge. Fiona Cram (2001: 49) comments that there are calls for 'research to be holistic and to capture the realities of the peoples who are involved'.

Other commentators in this country have also raised ethical issues concerning research with Pacific Nation peoples, lesbians, gay men, people with disabilities and other marginalised groups (for example Kirkman, 2001; Tolich, 2001b; Tupuola, 1993). In particular, feminists have discussed ethics related to research amongst those from 'hidden' and 'stigmatised' groups (Kirkman, 2001: 57). Some writers have also drawn attention to problems with reporting research undertaken in a small country where people, places and events are easily identifiable (O'Brien, 2001; Tolich, 2001b). The publication of Research Ethics in Aotearoa New Zealand (Tolich, 2001b) provides a timely and considered account of ethical issues pertinent to research in this country.

Furthermore, a local and recent history in which medical research on women exposed gross breeches of ethical conduct, as evidenced in the cervical cancer inquiry (CCI) at National Women's Hospital (Coney, 1988), highlighted the need for the development of ethical protocols. ${ }^{106}$ The findings of the CCI provided impetus for ethical procedures aimed at the protection of research participants, promotion of consumer rights, a requirement of informed written consent, ${ }^{107}$ and the requirement that all human research be approved by ethics committees comprised of lay people and academics. ${ }^{108}$ This prompted a range of professional organisations to develop ethical guidelines that had not previously existed. While these moves are long overdue, Martin Tolich (2001a: 8) comments that ethical guidelines and approval by ethics committees tends to be based on the assumptions of positivist research, defined as 'good science'. This poses difficulties for those undertaking constructivist and interpretative forms of research (Gauld, 2001; Tolich, 2001b). As noted previously in this section, ethical approval can be misused to deny research that falls outside the dominant positivist paradigm

\footnotetext{
${ }^{106}$ The severity of research abuses involved in the National Women's cancer research led to the deaths of women who were not treated for cancer - see Coney (1988).

107 Where informed consent is inappropriate ethical requirements of 'do no harm', 'anonymity and confidentiality' and 'avoid deceit' are necessary (Tolich, 2001b: 6).

${ }^{108}$ While this has occurred in university and health research, it has yet to be developed in other areas of human research including government organisations and businesses (Tolich, $200 \mathrm{lb}$ ).
} 
(Roberson, 2001, 2002). Clearly, this has implications for the advancement of qualitative and interpretative research, common in feminist, indigenous and critical psychology.

In my research, ethical issues were accorded priority and addressed in a considered manner. Ethical dilemmas were resolved following consultation and discussion with a range of people regarded as having specialist knowledge on certain issues. In particular, ethics were addressed in relation to: The Treaty of Waitangi, and codified rules affecting academic research; issues concerning research with Māori participants; University Ethics Committee Approval; procedures for accessing students while accommodating Privacy Act legislation; informed consent; issues of confidentiality and anonymity in the context of small research groups; writing about sensitive and contentious research material; and balancing informed consent against being too specific.

Like many feminist researchers I regarded ethical research practice with some priority. To this end, I addressed ethical issues in relation to my research in a comprehensive manner. This process led to somewhat lengthy consent forms. However, their value is borne out in participants' requests to use the consent forms and feedback indicating that the research was ethically rigorous. My first priority in addressing ethical research related to principles contained in the Treaty of Waitangi.

The Treaty of Waitangi

In establishing ethical protocols for my research, I was cognisant of a range of issues contained in agreements or other documents that affect research of this kind. First, in attempting to actively engage with the principles of the Treaty of Waitangi (The Treaty), and being mindful of issues raised by a number of Māori writers (as discussed in the previous chapter), ${ }^{109}$ I attempted to develop research that would go some way to

\footnotetext{
${ }^{109}$ For example Linda Tuhiwai Smith, (1998); Fiona Cram, (2001); Ngahuia Te Awekotuku and Manatu Māori, (1991) and various publications by members of the NZPsS National Standing Committee on Bicultural Issues.
} 
addressing such issues. This included for example issues relating to the perpetuation of colonising methodologies, awareness of the ethnocentric nature of Pakeha research in which Māori are often objectified or constructed as somehow 'lacking' or in need of change, and attention to inequalities and the effects of inequitable social structures. Second, in adhering to the Victoria University Charter and the NZPsS rules (NZPsS, 1993) relating to the Treaty, in conjunction with awareness of criticisms of the NZPsS Code of Ethics 1986 (Nairn and NSCBI, 1995), I was conscious of the importance of respecting the spirit and intent of the Treaty. For example, the protection of Māori health is an issue that has been low on the ethics agenda in the history of dominant psychology in Aotearoa New Zealand.

While according priority to the Treaty of Waitangi, I soon realised that my research was constrained by academic regulations governing doctoral degrees. ${ }^{110} \mathrm{M}$ y position as Pakeha, in conjunction with being schooled in a Pakeha education system, together with a research topic, clinical psychology, that is embedded in Eurocentric positivist science and an institutional structure that reflects the culture, values and norms of the dominant culture, did not make for bicultural or Treaty defined research.

Pakeha Research with Māori Participants

Within this context, I grappled with issues relating to the under-representation of Māori in clinical psychology, both in terms of epistemic validity and numeric (in)visibility. ${ }^{111}$ At the same time I was aware of ethical issues concerning research by Pakeha researchers with Māori participants and was concerned not to perpetuate colonising

\footnotetext{
${ }^{110}$ While doctoral students may consult with Maori both in the design and practice of research, as I did, it is my understanding that regulations governing academic doctoral degrees do not permit collaborative design, implementation, interpretation or authorship - issues about power sharing and partnership consistent with a Treaty model.

${ }^{111}$ For example see several articles concerning The Treaty of Waitangi and bicultural issues relating to psychology in The NZPsS Bulletin (1993) March, No. 76.
} 
methodologies or to contribute to another singularly Pakeha dominant piece of research (Smith, 1998). ${ }^{112}$

\section{Ethical Approval}

All students at Victoria University who undertake research involving people are required to submit an ethical statement to the University's Human Ethics Committee. The statement I submitted covered five key issues. These included a clause relating to the Treaty of Waitangi, NZPsS rules, and University policy and regulations as discussed previously. It also specified procedures for ensuring anonymity and confidentiality, and indicated how transcribing and review of transcripts would occur. Clauses were included concerning the distribution of a research summary to participants, and information about forums in which the research might be used. Ethical approval was granted accordingly.

\section{Informed Consent}

In recognition of the importance of informed consent to ethical research practice, I was cognisant of adequately informing participants of the purpose of my research and details about the way the research would be undertaken. For this purpose, I developed a comprehensive set of informed consent forms. Different consent forms were used with the different groups of participants, and for different research methods. Copies of the following consent forms are appended. The Research Participant Consent (RPC) form was used with students and staff who completed questionnaires (see Appendix A). The Interview Consent form was used with students and staff who were interviewed (see Appendix B) and a combined participant and interview consent form was used with the group of feminist clinical psychologists who were interviewed.

\footnotetext{
112 After discussion with Māori friends and colleagues, and my academic supervisors, I considered facilitating a focus group of Māori health workers as a means to ensure some visibility of Māori knowledges and perspectives. However, due to a range of circumstances I did not pursue this option. I then left it to the few Māori students and staff in the two participants groups to decide whether they would participate in the research. While attempting to consult with Mäori at various stages of the research, and to include the concerns and publications of Māori writers in this thesis, I am aware of the limitations of research undertaken by a Pakeha, in a Pakeha dominant institutional context.
} 
The consent forms covered the general parameters of the research. This included a statement noting that participants had been informed about the aims and objectives of the research, and given background information about me. ${ }^{113}$ They also contained information about a range of procedures and ethical protocols of the research. ${ }^{114}$ While the consent forms are lengthy, they cover a range of possible options to protect participants and accommodate varying perspectives on the use of 'data'.

\section{Conclusion}

The feminist methodological processes that underpin this research have been discussed in this chapter. A range of issues have been highlighted concerned with using qualitative and quantitative approaches. Issues concerning interviewing, reciprocity and ethics have also been outlined. The importance of the Treaty, and Pakeha research with Māori participants have also been discussed. In the next chapter, I discuss how these methodological processes were applied during the research process.

\footnotetext{
${ }^{113}$ This was included in the letter of introduction about the research.

${ }^{114}$ A clause was included stating that participants had the right to withdraw from the research up until one month after the return of questionnaires or the completion of interviews. If participants had wanted to withdraw after this time, I would have obliged, but I did not want this being the general procedure for the research. Logistically it would have been too difficult. As it occurred, one participant withdrew after their interview. This was due to the sensitive nature of issues raised in the interview and fear of being identified by staff.
} 


\section{Chapter Six}

\section{The Research Process}

In this chapter I present the research process undertaken for this thesis. I discuss the participants involved in the research, the research methods used, ${ }^{115}$ issues that arose during the collection and analysis of data, and my commitment to the research principles of reflexivity and trustworthiness. In this research I used multiple methods and different groups of participants to examine issues of gender and power in clinical psychology training. ${ }^{116}$ The research involved: administering questionnaires to all clinical psychology students and staff at six universities in Aotearoa New Zealand; interviewing a self-selected subgroup of questionnaire participants; and interviewing feminist clinical psychologists. This process of method and data triangulation is widely advocated by feminist and qualitative researchers (Banister et al, 1994; Glucksmann, 1994; Kitzinger, 1987; Reinharz, 1992). Triangulation 'allows illumination from multiple standpoints, reflecting a commitment to thoroughness, flexibility and differences of experience' (Banister et al, 1994: 145).

The combined use of quantitative and qualitative questions in the questionnaires, as well as semi-structured in-depth interviews, served several purposes. First, the use of questionnaires provided a means to canvass ideas about the inclusion of gender in clinical psychology training from a potentially large group of participants. Second, the use of numerical data enabled the production of 'statistics' about gender, which could be strategically used to influence change. Third, the inclusion of qualitative approaches, both as part of the questionnaires and in the form of interviews, provided a context for

\footnotetext{
${ }^{115}$ Multiple methods (or triangulation) is a term commonly used when generating multifaceted research information (Denzin and Lincoln, 1994; Maykut and Morehouse, 1994; Reinharz, 1992). In my research, this involved forced choice and open-ended questions in the research questionnaires, semi-structured interviews, and the inclusion of three participant groups positioned differently in relation to clinical psychology training programmes.

${ }^{116}$ Many of the practices used in this research were informed by the work of Julie Leibrich. See Appendix A pp. 241-285 in Leibrich (1993).
} 
the quantitative data. The use of qualitative methods also permitted the production of indepth information and knowledge about the dynamics and nuances of clinical training and enabled the clarification of issues raised in the questionnaires. Interviewing gave participants the opportunity to discuss issues in some detail, and to raise contentious or sensitive topics that may have remained invisible if the research relied solely on questionnaires. It also meant that participants could raise issues I had not anticipated.

By using quantitative and qualitative methods I was able to accommodate some of the tensions that arise from the limits of each approach. This combination of methods permitted comprehensiveness, depth of meaning and attention to the subtleties, contradictions and ambiguities of information that would have been unlikely to arise from quantitative or qualitative methods alone. In short, each method 'fleshes out the other' (Reinharz, 1992: 197). As noted previously, the use of quantitative approaches meant being able to canvass a broad range of issues across a sizeable group of participants. The combination of information from questionnaires and interviews, combined with multiple participant groups, was a means to strengthen the credibility of the research amongst the target audience while also being credible with my own reference group (i.e. feminist psychologists). This multiple method strategy gave rise to a broad but in-depth understanding of issues that had they been addressed in a singular way, would likely not have been so comprehensive.

The research also included multiple sources of data. This comprised three distinct participant groups whose position in relation to clinical psychology differed. Miriam Glucksmann (1994: 158) suggests that the use of several sources of data permits the analysis of 'socio-structural divisions', and enhances the meaning and understanding of issues addressed in research. ${ }^{117}$ In my research, these included students, academic staff and feminist clinical psychologists.

\footnotetext{
${ }^{117}$ While I refer to these groups as distinct, and have treated them as distinct in the research, in practice individuals could be members of more than one group.
} 


\section{Participants}

My research involved three different participant groups reflecting diverse positions, experiences and perspectives in relation to clinical psychology training. These included clinical psychology students, clinical psychology academics and feminist clinical psychologists. While I had initially anticipated the inclusion of women who had used psychological services, and employers of recent graduates in clinical psychology, the need to limit the size of the research resulted in confining the research to the three groups identified above. Due to the limited number of Māori clinical psychologists and trainees, I had also anticipated running focus groups with Māori psychologists and related health workers. However, this did not occur.

Clinical psychology students were defined as those enrolled in the postgraduate Diploma of Clinical Psychology at one of the following six universities in Aotearoa New Zealand during 1996. These included: Auckland, Waikato, Massey (Palmerston North), Victoria, Canterbury and Otago. The research included students from each year of the possible three years of clinical psychology training. In writing this thesis I use the terms year one, two, and three. ${ }^{118}$

Clinical psychology academics included those who were employed as staff in a university postgraduate Diploma of Clinical Psychology Programme. Throughout the thesis, participants from this group are referred to as either 'staff', 'academic staff' or 'academics'. This group also includes staff titled 'clinicians' or 'clinical advisors' who may not technically be on the academic scale, but who are central to clinical training and specifically employed to teach clinical psychology as it relates to clinical practice.

The group called feminist clinical psychologists included clinical psychologists who identified as 'feminist' or whose clinical work was underpinned by feminist thought. All participants in this group had completed the Diploma of Clinical Psychology or its overseas equivalent.

\footnotetext{
${ }^{118}$ In some clinical psychology training programmes these years are referred to as years four, five and six.
} 
There were around 118 students enrolled in Clinical Psychology Programmes at the time the study was undertaken. Due to privacy constraints and a lack of exact information from the various institutions, I was unable to determine how many students were enrolled. However, in each of the three years of clinical training there were between five and nine students enrolled. It is therefore estimated that each University had between 15 and 24 students enrolled in clinical training. 
feminist within a Women's Studies department, and hence my positioning as an 'outsider' in terms of clinical psychology. I thought these factors might be a deterrent to some staff and students. Thirdly, due to recent programme reviews and personal grievance action, I was told that some staff might be feeling some sensitivity in relation to some clinical programmes. Further, at times clinical programmes have been the focus of criticism from community groups and agencies. I was informed that this had left some staff feeling sensitive about the clinical programme within which they taught. These factors culminated in the need for particular care in the way I managed my initial contact with programme directors and the manner in which I enlisted their support for the research.

With this in mind I wrote to each of the six clinical psychology programme directors introducing myself, inviting them to participate in the research and requesting their assistance in accessing students enrolled in their clinical programme. With the letter to directors, I also enclosed letters to be given to students. Student letters comprised an introduction to the research and a request to consent to the release of their name so that I could contact them directly. The student letter included a name consent portion that could be returned to me via pre-paid post. Each director was sent a pack of student letters with a request to distribute them in class or post them to students enrolled in their programme. After writing to directors, I phoned them to follow-up the letter of introduction, to make personal contact, and to provide an opportunity to discuss the research. Those students who agreed to the release of their names were sent a letter containing a research participant consent form, a questionnaire and an interview participation form.

Despite my initial reservations, contact with the majority of directors and other staff was positive and I was encouraged by their support for this research. Further, most staff were obliging in facilitating access to clinical students, arranging distribution of questionnaires and generally accommodating my requests. I am aware that some staff actively encouraged students to complete the questionnaires. I appreciated the support from staff given their heavy workloads and the multiple demands of clinical programmes. I later learned that they receive numerous requests to participate in 
research and rarely hear about the outcomes, so the support I received was particularly helpful.

Access to Clinical Psychology Staff

The names of staff teaching in each clinical programme were obtained via programme directors or psychology department secretaries. All staff were then sent a letter introducing the research, letting them know I had been in contact with the director of their programme and that I had administered the student questionnaire. Because of the small number of staff and the fact I had been able to obtain their names, I addressed them each personally in the cover letter and in addressing correspondence. The letter also contained a portion that could be detached and returned, to let me know if they did not want to participate in the research. This gave me some idea of how many staff had received the questionnaire but did not want to participate in the research. It also gave me some indication of who I should continue to follow-up. Letters to directors also included a brief update on the progress of the student questionnaires and were more personalised because I had previously been in contact with them by phone and/or email.

Access to Feminist Clinical Psychologists

Participants in the feminist clinical psychologists group (FCPs) were identified via a snowball approach. I obtained names of women regarded as feminist clinical psychologists from clinical psychology staff and students I met during the course of the research, and from friends involved in psychology. Participants identified for inclusion in the feminist group were perceived by others as actively and overtly feminist. Further, each potential participant was identified by more than one other feminist clinical psychologist. Participants in the feminist clinical psychologists group were subsequently self-defined in terms of identifying themselves as feminist, or regarding their work as underpinned by feminist thought. Once the FCP interviews commenced, I 
was also given names of other feminist clinical psychologists who might want to participate. The use of a snowball approach was very effective in this context. ${ }^{120}$

\section{Questionnaires}

Two different questionnaires were constructed for use with student and staff participants (see Appendices C and D respectively). While the general orientation of the questionnaires was similar, some questions were specific to each group. ${ }^{121}$ Questionnaires incorporated a range of questions relating to concepts of gender and power within clinical psychology training. While some questions comprised quantitative rating scales, most were open-ended requiring participants to write what they thought about certain issues.

Due to the relatively small and easily identifiable sample of clinical psychology students and staff in this country, little demographic information was obtained. As the research proceeded it became clear that even this limited demographic information could inadvertently identify some participants. For this reason there are many instances where demographic details are not reported, or are discussed in general terms.

Questionnaire construction and revision

During the process of constructing and revising the questionnaires, problems were experienced in relation to use of the terms 'feminist', 'women' and 'gender'. I had initially presented the research as a 'Feminist Analysis of Clinical Psychology Programmes' and had referred specifically to women in the first draft of questionnaires. Upon reflection and following feedback from reviewers, changes were made. I was advised not to use the terms 'feminism' or 'feminist' when introducing the research as this could create resistance, or be off-putting to participants who had negative ideas or

\footnotetext{
${ }^{120}$ It is noted that this process did not result in the inclusion of any Māori or Pacific Nation women, or women from ethnic minority groups. The feminist clinical psychologists group included self identified lesbians and women from working class backgrounds.

${ }^{121}$ See Appendix C for the Student Questionnaire, and Appendix D for different questions included in the Staff Questionnaire.
} 
stereotypes about feminism, were anti-feminist or did not agree with feminist perspectives. Reviewers indicated that use of this term might deter mainstream psychologists from participating in the research. References to 'feminist' or 'feminism' were therefore dropped from the questionnaire and presentation of the research. ${ }^{122}$ As noted in chapter two, the term 'feminist' is frequently associated with stigma, negativity and even hostility.

In view of the conceptual issues I wished to address in the research I used the term gender, and referred specifically to women and specific groups of women, to reflect the diversity of this social category when it seemed more appropriate. There were two main reasons for this. First, use of the term 'women' on its own failed to encompass issues of gender and other relations of power the research aimed to address. In contrast, use of the term 'gender' on its own failed to address issues specifically relevant to women, nor did it convey that the research centred on the way women's experiences and knowledges are addressed in clinical psychology. Second, reviewers suggested that reference only to women could be off-putting or alienate some participants, and that the term gender was perceived as more neutral. As it happened, most participants interpreted gender to mean women. One interviewee who held views antithetical to feminism suggested that the questionnaire should have referred explicitly to women given that this was the focus of the research. In reflecting on this issue, the combination of terms served to address issues in accordance with the aims of the research and seemed the most appropriate way to accommodate reviewers' comments.

\section{Questionnaire pilot}

Once I had incorporated reviewers' feedback, a draft student questionnaire was informally piloted with two registered clinical psychologists and a third year undergraduate Psychology and Women's Studies student. As a result of the pilot changes were made in layout, and the length and complexity of the questions was reduced. Language regarded as 'feminist' was also minimised and language familiar to psychologists was used.

\footnotetext{
${ }^{122}$ To accommodate ethical issues associated with transparency, my location in the Women's Studies Department at Victoria University was included on all questionnaires and letterheads.
} 
Questionnaire administration - Students

Questionnaires were initially administered to students and staff during the 1996 academic year. Students who had consented to the release of their name were directly sent a questionnaire pack. The pack contained a covering letter, the Research Participant Consent Form and the questionnaire for students. Programme directors distributed questionnaires to students I had not made contact with. The questionnaires were either distributed in class or mailed to students.

The administration of questionnaires was timed to accommodate various demands on students and staff, and other factors that might influence participation. However, due to the time and process required to make contact with students and delays in questionnaires being given to students, many did not receive the questionnaire until well into exam preparation or engaged in other work such as completing Masters theses and clinical practica. Participants were asked to return their questionnaire within five weeks of receiving it, after which they were sent a reminder letter. Many participants returned their questionnaires in the months following the given deadline. Some students did not receive questionnaires from their director until after the deadline. In another programme, students commented that staff could have been more encouraging of the research when it was first introduced, and that this would probably have increased student participation. It appears likely that the timing of the research combined with the interest or involvement of staff, impacted on students' participation.

These factors contributed to a low student response rate for the initial administration of the questionnaire. The questionnaire was therefore re-administered at the beginning of the 1997 academic year. The later questionnaire contained the same content as the original one and was reformatted to enhance user friendliness. One director suggested that the instructions about what to do with the questionnaire and associated documentation needed to be simplified and made clearer. Consequently, a checklist was included which aimed to simplify instructions about the return of questionnaires, the consent forms and interview participation form. Participants were asked to answer the 
questionnaire with reference to their experiences of the 1996 academic year. Readministration of the questionnaire led to an increase in the student response rate and corresponding increase in the number of students who agreed to an interview.

Questionnaire administration - Staff

The questionnaire to staff was administered late in the 1996 academic year. Staff were sent a cover letter, the questionnaire for staff (Appendix D), the Research Participant Consent Form (Appendix A), and an Interview Consent Form (Appendix B). Staff who completed a questionnaire, but did not agree to an interview were sent a letter of thanks. Those who agreed to an interview were sent a letter thanking them for completing the questionnaire and informing that I would contact them nearer the time of interviews. As with students, a reformatted questionnaire was sent to staff who had not returned a questionnaire, or had not returned a non-participation slip in the first questionnaire administration. All questionnaires from staff were allocated a pseudonym to protect the identity of those who did not want to be identified in the research.

Pseudonym Allocation

All students and staff who returned a questionnaire were allocated a pseudonym. ${ }^{123}$ This served to protect their identities. The pseudonym was written on the front of questionnaires as they were received, and the consent and interview forms were detached. Questionnaires were stored separately from participants' personal details.

The process of allocating pseudonyms was more complex than I had anticipated. This largely reflected the politics of naming, and issues of visibility and anonymity. In particular, the small number of male and Māori students meant the allocation of names typically regarded as 'male' or 'Māori', proved problematic. I did not, however, want to use solely gendered or Anglo-Saxon names, as this would not reflect the diversity of those who participated in the research and would make some groups invisible. After discussion with others, I selected as many gender neutral names as possible and a few

\footnotetext{
${ }^{123}$ The small group of FCPs meant it was feasible for this group to select their own pseudonym.
} 
Māori names that are so frequently used that they are not necessarily associated with being Māori. While this approach was not completely satisfactory, it seemed the best solution in the context of my research. In hindsight, I would probably have asked all participants to choose their own pseudonyms, attributing them some degree of selfidentification.

\section{Interviews}

Interviews - Students and staff

Following administration of the second questionnaire I wrote to participants who had agreed to an interview or had indicated interest in participating in an interview but required more information first. An Interview Consent Form was also sent. After hearing back from potential interviewees I contacted them to arrange an interview time. A letter was then sent to confirm the interview arrangements. Once I arrived at each university city, I again telephoned participants to confirm interview details.

With the exception of Dunedin, where resource constraints mean only phone interviews were possible, I travelled to each university city to undertake the interviews. I commenced interviews at Victoria University as I felt it would be appropriate to interview staff and students at the local university first. It also gave me an opportunity to streamline the interview process, to ensure I had all the necessary documentation and equipment, and to have colleagues available to discuss issues if I encountered any problems.

During interviews, I used semi-structured interview guides, which consisted of questions I wanted to ask participants in relation to the research. The interview guides used for students and staff were the same (see Appendix E). I also used an interview checklist or cover sheet prior to the interviews upon which detailed interview arrangements, the venue, start and finish time, and specific needs or requirements. It also prompted me to double check with participants about their year of study, taping consent, confidentiality and anonymity, and to have them complete a consent form if 
they had not already done so. The checklist proved useful not only as a back-up concerning informed consent, but in recording the location of interviews, how long they took, and other contextual factors that I could later use to jog my memory about the interview.

The entire interview process worked well. The punctuality, reliability and commitment of participants aided this. I had also maintained contact with participants throughout the research process and I think this contributed to the high level of interview attendance. Indeed, many participants commented that they had felt well informed and that I had maintained good contact throughout the research process.

With the exception of two cancellations all participants who agreed to be interviewed in person were interviewed as arranged. One of the people who cancelled phoned to say they felt too 'stressed' and 'burnt-out' from being constantly 'political' in their programme. It was evident from discussion with this person that their reference to 'political' meant the kinds of issues I was addressing in my research. All interviews were audiotaped. Interviews took place in offices or homes - whichever was most convenient for participants.

Participants living in Dunedin, and one participant unable to attend an interview when I visited their city, were later interviewed by phone. Prior to these interviews I had written and phoned participants to confirm a suitable time. While interviewing by phone relies on voice and intonation, and is less personal than a face-to-face situation, I found it reasonably easy to establish rapport and these few interviews went well. However, in the face-to-face interviews I was able to get to know many of the participants in a more personal way and found it easier to reciprocate and discuss issues that were of interest or importance to them. Following completion of the interviews, I sent participants a thank you card and some personal comment about their involvement in the research. 
Interviews - Feminist Clinical Psychologists

All women identified as feminist clinical psychologists were approached during 1997. They were sent a letter introducing myself and the research. I then phoned each person to discuss the research in more detail and to arrange an interview time. I subsequently sent a follow-up letter confirming the details of the interview and enclosed a research participation and interview consent form (as noted previously) which participants were asked to return before their interview. All participants were asked if they had any particular or special needs for the interview. They were phoned again immediately prior to their interview to confirm arrangements. Face-to-face interviews were undertaken in a range of settings including, for example, workplace offices and individuals' homes (see Appendix F). Two phone interviews were also undertaken. These occurred in situations where I had made contact with FCPs during the process of interviewing others, but had been unable to return to their city. Each participant selected a pseudonym at the time of the interview that was then recorded with her transcript. This process simplified difficulties associated with the allocation of pseudonyms for other groups.

\section{Transcripts}

\section{Transcripts - All Participants}

After completion of the research interviews I began transcribing the interview tapes verbatim. Most tapes were over an hour long and in conjunction with resourcing and health difficulties, I eventually had the interviews professionally transcribed. The transcriber was required to complete a confidentiality agreement to ensure ethical procedures were adhered to. The tapes, transcripts and computer discs were kept in a secure place to which no one else had access. Other than the transcriber and me, no one else listened to the tapes or read the completed transcripts. This was important given the sensitive nature of some interviews and the concern of most participants to have their identity protected. 
The transcript review process

All interviews were transcribed and returned to participants along with a transcript receipt form. The receipt form was enclosed for participants to sign and return, to let me know they had received their transcript. Interviewees had indicated at the time of their interview whether they wanted to review their transcript, have it returned for their own use, or not receive one at all. Given the lengthy time between the initial interviews and subsequent production of transcripts, I decided to return all transcripts to give participants a final opportunity to review what they had originally said. A pre-paid envelope was enclosed for participants to return their amended transcript and/or the transcript receipt form. Participants either let me know that they had received their transcript and did not require changes, or returned their transcript with corrections noted. I subsequently made the appropriate amendments and returned the final transcripts with another request that they let me know the transcript had been received. Amendments were few, but those required by participants largely related to ensuring their anonymity by making sure there was no way what they had said could be identified, especially concerning the more contentious issues.

While this process was designed to maximise the transparency of the research and ensure that all participants had a chance to change what they had said at the time of their interview, it was very time consuming. Further, in some situations participants wanted to read what I had written in this thesis when using quotes or contentious content from their transcripts. Changes required by participants largely related to the protection of their identity. While the transcript review process was one means of enhancing research transparency and reflexivity, a research question specifically aimed at gauging participants' perceptions of the research process was also included.

\section{Reflexivity}

Reflexivity is regarded as a central feature of feminist research (Maynard, 1994; Reinharz, 1992; Stanley and Wise, 1993). It is referred to as 'an attempt to make explicit the process by which the material and analysis are produced' (Banister et al, 
1994: 149). 'The research topic, design and process, together with the personal experience of doing the research, are reflected on and critically evaluated throughout' (Banister, 1994: 150). Reflexivity was central to the way I designed and undertook my research. One aspect of this process included the use of specific research questions that sought participants' views on their experience of the research process. Participants were asked what they had gained, if anything, from the research and how well they thought the research process had worked for them. Opportunities were also provided for participants to give any feedback on the research. While the inclusion of a specific question on participants' experience of the research process comprised one aspect of reflexivity in this research, issues concerning the trustworthiness of the research also illustrate the practice of reflexivity.

\section{Trustworthiness of the Research}

An integral component of research is its trustworthiness (Maykut and Morehouse, 1994; Reinharz, 1992). This concerns the degree to which readers can 'place confidence in the outcomes of the study' and asks, '[d]o we believe what the researcher has reported?' (Maykut and Morehouse, 1994: 145). In the write-up of this thesis I have attempted to illustrate the trustworthiness of the research by providing detail about: the aims and purposes of the research; how and why participants were selected; the way I conducted my research and the rationale for particular choices I made; the ethical practices I adhered to; the processes used to enhance reflexivity; and how I approached the collection and analysis of data. I have also included autobiographical information and my location in relation to the research. Together, this detail attempts to enhance transparency and allow critical scrutiny of the research.

\section{Data Analysis}

The term data analysis encapsulates the entirety of the research process from the inception of research questions through to the final research product (Denzin and Lincoln, 1994; Maykut and Morehouse, 1994; Ramazanoğlu, 2002; Reinharz, 1992). It 
is an interpretative process requiring decisions about the selection, inclusion, exclusion, categorisation and use of data. In other words:

just as data are not lying around waiting to be collected, so meanings are not lying in your data waiting to be found. Data do not speak for themselves. You have to do the work of deciding what you take your data to mean (Ramazanoğlu, 2002: 160).

Data analysis is therefore a multifaceted and multidetermined process, producing contingent, partial and incomplete knowledge about the research topic. It involves multiple levels of interpretation that occur throughout the process of the research (Denzin and Lincoln, 1994; Maykut and Morehouse, 1994; Ramazanoğlu, 2002; Reinharz, 1992). In my research, data analysis was shaped by the particular feminist ontological, epistemological and methodological framework that underpinned my research. The interpretation of data was also influenced by the ethics guiding my research, practices of reflexivity, my motivation for the research topic and my location in the process of data production (Ramazanoğlu, 2002).

Consequently, though interpretation of data occurs throughout the process of research, specific approaches are used in the formal analysis of data. My research was based on an inductive approach to data analysis that included systematic, thematic analysis using constant comparative analysis, and the production of quantitative data in the form of numerical frequencies.

Qualitative researchers, in particular, have used thematic analysis which involves systematic constant comparison, for wide ranging research purposes (for example, Banister et al, 1994; Leibrich, 1993: 279; Maykut and Morehouse, 1994). Thematic analysis is described in relation to interviewing as:

a coherent way of organising or reading some interview material in relation to specific research questions. These readings are organised under thematic headings in ways that attempt to do justice both to the elements of the research question and to the preoccupations of the interviewees (Banister et al, 1994: 57).

While discussed here in the context of interviewing, this procedure is also used in the analysis of qualitative items in questionnaires. In my research, thematic analysis was used for both the questionnaires and interviews. 
I adopted a hands-on approach to the analysis of the qualitative data from the questionnaires and interviews. Similar analytical procedures were used for both sources of data, though clearly, interviews required a more complex approach to deal with the 'messiness' and overlap of material produced through the semi-structured approach. I drew on Julie Leibrich's research (1993) and the work of Pamela Maykut and Richard Morehouse (1994) as practical models to guide the management and thematic analysis of the data. In brief, this involved coding each page of data in terms of student participant's gender, university and year of study, and noting the source of data (i.e. whether from the questionnaire or interview transcript) for student and staff participants. Pseudonyms were also recorded on each page of data. Following several readings of participants' responses to the quantitative and qualitative questions in the questionnaire, as well as in their interview transcripts, I proceeded to create files around recurring themes and patterns in the data. Using this constant-comparative approach, I simultaneously identified inconsistencies and incongruities in the data, both within individual participant responses, and between participants within and across each group. On each data page I coded the theme or themes identified and subsequently filed these. This hands-on approach ensured that I remained close to the data throughout the process of analysis. A similar approach was taken to analyse the feminist clinical psychologists' interview transcripts.

I produced a range of themes around the specified research questions and identified other issues participants regarded as important. While identifying general themes in the data, I was also interested in identifying overlaps, inconsistencies, contradictions and ambiguities. In particular, I attended to incongruities between quantitative and qualitative responses, and highlighted instances where quantitative data alone would have produced misleading findings. For example, questionnaire participants were asked whether any education about gender issues was included in their clinical training programme. Frequencies for this question suggested that gender was included to a significant degree. Examination of qualitative responses however, indicated that while participants may have responded 'yes' to this broad yes/no question, content actually included was minimal. Further discussion about this issue is included in Chapter Seven. 
The thematic analysis approach comprised a useful way of examining responses to predetermined research questions, as well as permitting the identification of issues participants regarded as important that arose during the course of the research. In addition to this approach, I used quantitative analysis to deal with numerical data.

While recognising that quantitative data are limited in enabling the production of meaningful and nuanced accounts of experience and social relationships, I regarded this mode of data production as useful in terms of making generalisations and giving 'authority' to claims I made in relation to clinical psychology training.

A Microsoft Excel programme was used to record numerical data from the research questionnaires, which had been pre-coded. This involved straightforward frequency counts and conversion to percentages.

\section{Conclusion}

The use of multi-method quantitative and qualitative research located within a feminist methodological framework was regarded as an effective means of researching the inclusion of gender in clinical psychology training programmes for the purposes of this particular research. Further, the inclusion of three different participants groups located in diverse positions in relation to clinical programmes was a means to provide a range of perspectives about clinical training. The next five chapters comprise analysis of quantitative and qualitative data from these three participant groups. 
[It] seems to me that clinical psychology...is sort of like putting people through a processing plant, and they have to turn out a certain way, it's all predetermined, there's very little real room to do anything different....critical thinking and people being really aware of their own practice, of how they're using power...is just so important...I don't think we really support that as much as I would like to. [Traice]

I think that the slant that we tend to have in our course... is to look at the person and say, well society's out there, too bad, it's a terrible thing, if you want to do something about it you've got to vote for the right party, but in the meantime lets just deal with making you feel comfortable within your place in society, which is all very well, but it's quite a shallow way of looking at it...we're the ambulance at the bottom of the cliff... we don't broach the broader issues and that doesn't just go for women's issues, that deals with quite big issues about what is a mental disorder anyway?... what is our role?... who are we working for? [Viv]

Lecturers think that issues to do with gender or feminist theory are rubbish or they're sceptical about it...psychology as a whole has been slow to recognise feminism, feminist theory and its practices...it's definitely not thought to be relevant. [Jamie] 


\section{Chapter Seven}

\section{Meanings of Gender and the Inclusion of Gender Education}

The relationship between clinical psychology, and gender and other issues of power, has long been a focus of criticism. Feminist psychologists, along with others, have critiqued the positivist/realist foundations of clinical psychology and the dominance of individualist psychological theories that position people, rather than structures as problematic (Prilleltensky and Nelson, 2000; Ussher, 2000b). As outlined in Chapters One to Three, feminist psychologists have also addressed the effects of ignoring or marginalising gender and power in clinical psychology and have drawn attention to the way this practice works to the detriment of women and other marginalised groups (Hare-Mustin and Marecek, 1997; Ussher and Nicolson, 1992). In particular, clinical psychology training programmes have been scrutinised for failing to incorporate gender and power analyses (Adcock and Newbigging, 1991; Boyle, 1997; Willliams and Watson, 1991b). This failure reinforces dominant discourses that pathologise women and contributes to the structural inequalities that shape women's lives and impact on women's health and well-being (Hare-Mustin and Marecek, 1997). Indeed, clinical training has been charged with producing psychologists who do not recognise or adequately understand the effects of women's subjugated sociopolitical position, thus perpetuating the very source or cause of women's despair (Adcock and Newbigging, 1990; Hare-Mustin and Marecek, 1997; Williams and Watson, 1991b).

In the following chapters that present an analysis of the data gathered for this thesis, I draw on responses from clinical psychology students (students), academic staff who teach clinical psychology (staff), ${ }^{124}$ and feminist clinical psychologists (FCPs), in order

\footnotetext{
${ }^{124}$ This includes those called 'teaching clinicians' or 'clinical practitioners'.
} 
to examine the way gender relations are conceptualised and incorporated within clinical psychology training programmes. ${ }^{125} \mathrm{I}$ also examine the inclusion of diversity education

by exploring content relating to diverse groups of women. Further, the thesis presents a discussion of the ways clinical programmes incorporate analyses of power relating to the Treaty of Waitangi and male partner violence. I also explore the position of feminist perspectives and knowledges in clinical psychology training and address the theoretical orientation of clinical programmes.

In Chapter Seven, I begin with demographics which includes a basic description of the three participant groups involved in the research, as well as participants' positions and experience in relation to clinical psychology in Aotearoa New Zealand. I then examine student and staff participants' ideas about meanings of gender. An analysis of the ways gender education is included in clinical psychology training programmes is subsequently presented based on student and staff participants' responses to a range of questions concerning the nature and scope of gender content. This includes: time allocated to education about gender, how education about gender is included, examples of education about gender, the inclusion of education about gender deemed primarily relevant to women, and gender education relating to power differences between the groups men and women. ${ }^{126}$

\section{Demographic Information}

In this section, I provide information on the three participant groups involved in the research and include background details about the work experience of academic staff

\footnotetext{
${ }^{125}$ Responses to qualitative questions from the staff and student questionnaires provided a context to understand responses to quantitative questions asked about similar issues. Issues addressed in the research interviews were, on the whole, an extension and development of responses given to both quantitative and qualitative questions in the research questionnaires. Merging these different sources of information was a way to give greater depth of meaning and highlight inconsistencies in the data. It also served as a useful way to minimise repetition and verbosity, and to write about some complex issues in the context in which they arose.

${ }^{126}$ Many participants in the research stressed the importance of maintaining their anonymity. To this end all universities were allocated a random alphabetical code from A-F so that individual participants could not be identified with any particular university.
} 
and feminist clinical psychologists. I also address possible reasons for differences in participation rates between programmes and pose ideas about why students and staff may not have participated in the research. The three participant groups included students enrolled in clinical psychology training programmes (students), academic staff teaching in clinical programmes (staff), and feminist clinical psychologists (FCPs).

\section{Student Participant Group}

In 1996 the total number of students enrolled in clinical psychology training programmes in Aotearoa New Zealand was estimated to be $118 .^{127}$ The total number of students who participated in this research was 50 . Of these 38 were women and 11 men. ${ }^{128}$ Table 1 shows the total number of students from each university who only completed the questionnaire, and those who participated in both the questionnaire survey and an interview.

Table 1: Total Number of Student Participants

\begin{tabular}{|l|lllllll|}
\hline Uni & $\mathrm{A}$ & $\mathrm{B}$ & $\mathrm{C}$ & $\mathrm{D}$ & $\mathrm{E}$ & $\mathrm{F}$ & Total \\
name & $\left(18^{*}\right)$ & $\left(15^{*}\right)$ & $\left(20^{*}\right)$ & $\left(21^{*}\right)$ & $\left(20^{*}\right)$ & $\left(24^{*}\right)$ & \\
\hline \hline $\begin{array}{l}\text { Questionnaire } \\
\text { Only }\end{array}$ & 8 & 6 & 8 & 10 & 7 & 10 & $50^{* *}$ \\
& $44 \%$ & $40 \%$ & $40 \%$ & $48 \%$ & $35 \%$ & $42 \%$ & \\
\hline $\begin{array}{l}\text { Questionnaire and } \\
\text { Interview }\end{array}$ & 4 & 2 & 4 & 6 & 4 & 6 & 26 \\
\hline $\begin{array}{l}\text { * Total maximum number of students in programme (estimate only) } \\
\text { ** } 1=\text { demographics not included }\end{array}$
\end{tabular}

\footnotetext{
${ }^{127}$ Discrepancies appear to be due to the unclear enrolment status of students who may have deferred, been part-time or on temporary leave. Further, because Privacy Act legislation prohibits the release of student details held by universities, I was unable to directly identify students enrolled in each programme. The student participant figure was based on data obtained from a combination of sources.

${ }^{128}$ One student did not provide any demographic information.
} 
As shown in Table 1 students from all universities are represented in this research. While there was little variation in actual numbers of student participants, proportionately more students were from University D, and fewer from University E.

The low number of participants from University B may be due to students not receiving the questionnaire prior to the deadline for questionnaire return. As no staff from University B participated in this research it could be inferred that there was little interest or support for research of this kind. However, the student participant rate for University E was also low despite a good participation rate from staff. On the other hand, University D students comprised one of the larger participant groups yet no staff from this programme participated in the research.

Table 2 indicates that most participants were in their second or third year of clinical training.

Table 2: Total Number of Students in Programme

\begin{tabular}{|l|lll|}
\hline & Year 1 & Year 2 & Year 3 \\
\hline \hline Participants & 14 & 17 & 18 \\
& $(37 \%)$ & $(43 \%)$ & $(45 \%)$ \\
Total (est.) & 38 & 40 & 40 \\
\hline
\end{tabular}

These findings suggest that students in their second or third year of training were a little more likely to participate in the survey possibly reflecting greater experience of the course and more interest in this research. ${ }^{129}$

Additional demographic information was not obtained due to the lengthiness of the questionnaire and the need to protect the identity of research participants. However, anecdotal information obtained from staff and students suggests most clinical students

\footnotetext{
${ }^{129}$ To protect participants' identities 'third year' included all students who were undertaking doctoral degrees, were in their final year of the Diploma or were part-time in the third year of clinical training.
} 
at the time this research was undertaken were women, Pakeha, middle-class, ablebodied, heterosexual and aged under $35 .^{130}$ It appeared that there were disproportionately few male, Māori, lesbian, gay or bisexual students. ${ }^{131}$ Pacific students, students with self-identified disabilities, transgendered students, students from working class backgrounds and/or ethnic minority groups were rare or absent. ${ }^{132}$

Based on the estimated total number of student participants the response rate was $42 \%$. This response rate is comparable, if not slightly higher, than other research involving clinical psychology students in this country (for example Nathan, 1999). A number of factors may have influenced students' decisions not to participate in this research. These include for instance the potential sensitivity of the research and students' concern not to be seen as participating in research of this kind. ${ }^{133}$ Feedback from staff and students suggested that the attitudes of staff and their encouragement for the research were factors that may have influenced student participation at the outset. It is also likely that the involvement of staff in the initial stages of the research process may have deterred some students. Additionally, situations where staff collected completed questionnaires directly from students (rather than having students post them back to me themselves) may have been inhibiting for those who were concerned about being identified.

Students who were involved in this research commented that they knew of others who were interested but did not have time to participate. Some students who completed a questionnaire noted that they were taking leave, preparing for exams or were otherwise pressed for time, and so could not participate in an interview. Due to the length of time taken to obtain students names or to administer questionnaires through directors, the research ended up coinciding with the final academic semester, when many students

\footnotetext{
${ }^{130}$ Nathan (1999) reported that during 1998 the majority of students enrolled in clinical training were aged between 20 and 29 .

${ }^{131}$ According to Nathan (1999: 64-65) there were 69 women students and 18 male students enrolled in clinical psychology training in 1998. Further, the majority of students identified as Pakeha, six students identified as Māori, three identified as Māori and Pakeha, and four identified as 'Other'.

${ }^{132}$ Based on Nathan's research (1999) there were three students who identified as being of Pacific Islands or Asian descent.

${ }^{133}$ As reported by students who did participate.
} 
would have been preparing for exams. It was also likely that some students were not sufficiently interested in the research topic to warrant participation.

Once participants had agreed to participate in the research the retention rate was high. Only one participant eventually declined an interview due to work pressure. Another student who was interviewed later withdrew their transcript due to fears about being identified by staff in their clinical programme. This person agreed to their questionnaire being used without the use of quotes. Three other students were not interviewed due to time constraints.

\section{University Staff Participant Group}

A total of 24 academic staff was identified as teaching in clinical psychology training programmes at the time this research was undertaken. Of these, there were 12 women

and 12 men. There was only one Māori staff member employed as a permanent member of staff. ${ }^{134}$

Of the 12 staff who participated in this research (which was half of the total academic staff teaching in clinical psychology training at the time), nine participated in an interview as well as completing the research questionnaire. Three completed a questionnaire only. Four additional staff provided feedback indicating that they did not wish to participate in the research.

Staff participants included women and men from a range of positions (for example, senior clinicians/senior tutors, lecturers, senior lecturers, and directors). Staff from Universities A, C, E and F are represented in this research. Academic staff had diverse work experience including areas such as justice, social welfare, child and family services, adult mental health, community and counselling services, private practice,

\footnotetext{
${ }^{134}$ Based on Nathan's research (1999: 74) only one Māori staff member was employed in a clinical psychology training programme during the period 1996-1998, although three other North Island programmes sometimes brought in Māori educators or supervisors. All other staff at this time were Pakeha.
} 
sexual abuse, disabilities, neuropsychology, psychopaedic, rehabilitation, research and academic. Demographic information relating to 'race', ethnicity, age, and sexuality was not obtained due to the potential sensitivity of this material and the easy identification of members of this small participant group.

Feedback from staff suggests several factors may have inhibited staff participation. In particular, staff commented that the length of the questionnaire combined with high workloads and the volume of research questionnaires that come through programmes may have been off-putting. One staff member commented that they did not agree with the methodology used in this research. As with students, there were probably staff members for whom the research topic was of little interest, priority or importance. Finally, the participation rate for staff who agreed to be interviewed was high. Only one potential interviewee was unable to attend a scheduled interview.

\section{Feminist Clinical Psychologists Participant Group}

Eleven clinical psychologists who identified as 'feminist', or whose work was informed by feminist philosophical and theoretical knowledges participated in an interview. All participants in this group identified as Pakeha or European and most were aged 3544. ${ }^{135}$ Participants were from three of the six university cities. All participants held a Masters degree and the Diploma in Clinical Psychology or its overseas equivalent. The time period in which these participants undertook clinical training ranged from the 1970 's to the early 1990 's. Three participants also held doctoral degrees.

Most participants in this group were experienced clinical psychologists whose backgrounds were diverse. All but two FCPs had clinical psychology experience spanning at least ten years. Some had worked in the field of psychology for more than 20 years. Their professional lives had involved many roles, employment in a range of psychological service organisations and engagement with diverse groups of people. They had worked in areas such as justice, social welfare, child and family, adult psychiatric, community mental health, family court, private practice, sexual abuse,

\footnotetext{
${ }^{135}$ Participants were also included from the age categories 25-34 and 55-64.
} 
refuge, community and women's centres, counselling services, drug and alcohol, eating disorders and rehabilitation. Participants in the FCP group had been or currently worked as consultants, advisors, service developers, trainers and managers within government organisations; as researchers; as clinical psychology programme advisors, teachers and/or supervisors; as practitioners; as supervisors of psychologists, counsellors and other health related workers; as trainers of supervisors; and in corporate training and individual coaching.

With this amalgamation of student, staff and feminist clinical psychology participants all positioned differently in relation to the structural organisation of clinical psychology - the research aimed to examine how gender and analyses of power were conceptualised and addressed in clinical psychology training programmes.

\section{Meanings of Gender}

Theories of gender have been widely written about by feminist writers and are central to ideas about the relationship between meanings of femininity and women's sociopolitical positioning (Jackson, 1998; Richardson, 1996; Whelehan, 1995). This feminist literature is indicative of the multiple ways gender and power relations are conceptualised, and highlights the material and ideological effects of patriarchal discourses. In addition, it highlights the sociological nature of gender, which is integrally concerned with principles of organisation and categorisation. As such, an understanding of gender is regarded as central to social and political change (Jackson, 1998; Richardson, 1996).

Within psychology, feminists have addressed the importance of understanding concepts of gender, and the relationship between gendered social arrangements and discourses, and psychological health (Stoppard, 2000; Ussher, 2000b). Janet Stoppard (2000: 17) suggests that the positivist science dominance of psychology precludes an understanding of the effects of gender relations because gender is solely regarded as 'a person's sex of assignment' or as a single 'characteristic of the bounded individual'. This individualist conceptualisation of gender means that psychology often ignores or takes for granted the 'substantial ways in which the everyday experiences of women and 
men are likely to differ' and impact on women's lives (Stoppard 2000: 18). Further, by focusing on individual characteristics, psychology can ignore the way gendered discourses around femininity and masculinity shape and regulate women's lives and experiences (Stoppard 2000). By not taking into account the combined effects of gendered discourses and gendered structural arrangements, psychology decontextualises women's lives thus precluding an understanding of the effects of gender on women's realities.

In research concerning the inclusion of 'sexual inequality' in clinical psychology training, Jennie Williams and Gilli Watson (1991b) reported considerable confusion amongst trainers and trainees in their understanding of the concept. Indeed, many participants in their research confused sexual inequality with 'biological sex, sexuality, sex differences and sex roles' (Williams and Watson, 1991b: 80).

In my research, participants conveyed a diversity of understanding in the way gender was conceptualised. While this diversity was reflected in participants' responses to a range of questions about gender throughout the research, I begin by addressing student and staff responses to specific questions about the meaning of gender.

Participants who were interviewed were asked to describe in their own words what they understood by the term 'gender'. ${ }^{136}$ This question provided an initial interview prompt to get participants thinking about gender. While responses were not expected to be highly formal or theorised they were expected to provide some indication of participants' ideas about gender. It was anticipated that these responses could then be contextualised within the wider parameters of participants' thinking about gender relations and their analysis of power throughout the research. Collectively, participants' ideas about gender and power were expected to give some indication of the way they understood women's sociopolitical position and the relationship between this and women's experiences and realities.

\footnotetext{
${ }^{136}$ The term gender was operationally defined in the questionnaire to give participants a basic idea of what was meant by gender and gender relations for the purposes of this research. Given that the administration of the questionnaire occurred some time prior to interviews it is unlikely that interviewee responses were based purely on the working definition included in the questionnaire.
} 
Examination of responses to this question suggests that participants' conceptualisations of gender were diverse and reflected a variety of theoretical positions. Their understanding of gender ranged from limited lay knowledge through to sophisticated feminist theoretical analyses. Some participants who reported having little theoretical knowledge about gender found answering the question somewhat formidable. Others considered the question difficult to respond to due to their comprehensive knowledge and awareness of the complexities of contemporary theorising about gender.

Meanings of gender most commonly conveyed reflected conventional social science conceptions of 'sex' and 'gender' as distinct and dichotomous concepts, with associated notions of 'male' and 'female' located in a binary relationship. Participants commonly said that sex pre-existed gender, and that sex was innately prescribed and immutable. Typically, gender was contrasted with sex, with the latter variously referred to as biological, genetic, chromosomal, anatomical, physical and/or physiological. Many participants conceptualised gender as a 'social construct' as it is often understood within mainstream social science. ${ }^{137}$ References to gender in terms of socialisation, social roles, modelling, learned behaviour, stereotyping and other forms of learning theory were common. For example a student, Sarah, commented that gender was a 'social type of definition' that was about 'social constructs which dictate males and females in terms of...the way in which we're socialised...[and] educated around what it means to be males and what it means to be females, and everything in between. Another student, Jay, suggested that gender was 'a construct that's derived from the society that you live in...it's the individual's and society's perception of how somebody of a particular sex should behave...like a normatively prescribed view.' In contrast, a staff member, Claud said that gender was 'all' that being male and female means. This included 'sex roles, roles in terms of training and those influences that make us different or exaggerate the existing biological differences'. Claud commented that 'at a superficial level [these influences] come from the media and television...schools...parenting...we treat boys and girls differently and have different expectations, so it's pretty pervasive.'

\footnotetext{
${ }^{137}$ Use of the term 'social construct' is to point out that gender was commonly regarded as a socially produced entity which may be understood from diverse theoretical positions, and in particular within the context of psychological learning theory.
} 
Societal expectations and the notion of identification were also common themes. Many participants referred to 'how one identifies' or 'who you identify with' as being central to meanings of gender. Within these responses there was recognition of the fluidity of gender and the idea of gender being on a continuum. Jessie, a student, commented to this effect when they reported that gender was not a 'fixed thing' and that it was not something that was 'black and white'. Jessie suggested that gender was about 'how a person identifies themselves as being [which] was on a continuum [and] not really one or the other.' Jessie also noted that gender was something that was 'socially constructed...built up from the way a person interacts with the environment [and] part of a person's heredity as well... [it was] a mix of those things.'

A few participants drew upon poststructural and social constructionist theories of gender to discuss the way sexed bodies are imbued with social meaning. Traice, a staff member who took a 'social constructionist view' commented that gender was broadly 'to do with being a woman or a man'. However, Traice noted that gender was 'the end product of a social process that's mapped onto bodies that are deemed initially to be different, it's a process that develops as a result of differential experiences to do with those bodies as well as social conventions.' Traice remarked, 'I wouldn't want to neglect body stuff but I wouldn't really want to separate those out either'.

Some participants' ideas about gender reflected hierarchical relations of power and structural inequities that cohere around gender. Concepts related to the normativity of masculinity or 'maleness' were considered. Gender was also addressed in the specific context of being a woman and women's positioning as Other. A student, Mia, noted that gender was 'not just an anatomical difference, it's our whole sense of entitlement in the world, it's about status and all of those things'. They commented that 'gender is far more important for women than it is for men because men have that entitlement built in from an early age'. Likewise, another student, Freddie reported that gender reflected 'socially ascribed roles that are given to people and that people internalise on the basis of what sex they're born'. However they also commented, 'there is definitely a power imbalance in the gender identity of men and women [and that] historically...men have had a lot more power'. Similarly, Jamie, also a student, commented that gender was to 
do with being 'male and female but also a bit more than that like the culture of masculinity and femininity...almost a way of viewing the world that can be gendered.' Jamie said that they were 'strongly aware of living in a world that's very much gendered male, [where] male is the norm and female is the Other'.

Academic staff also provided examples of the way gender is thought about in an academic context and in relation to the gendered structural organisation of psychology. Staff also referred to gender in terms of women, 'women's issues' and academic departments of Feminist, Gender or Women's Studies. Vic reported that gender was about two key things. The first related to traditional meanings 'referring to somebody's sex [and] whether they're male or female or some combination thereof'. The second related to 'gender studies [and] gender issues'. Vic said: 'those mostly seem to me to revolve around women's issues and women's studies.' Vic thought that the focus on women was "probably because those issues have not been of central concern historically in the social sciences given that so many of the academic and research areas are dominated by men'. They also noted that 'women scholars [have] had to make a point of saying "well these are issues that need to be studied and investigated". Consequently, they noted that gender issues often seemed to be 'synonymous with women's issues'.

Jacks reflected on their experiences of psychology in the 1960s and 1970s noting that 'there was actually nothing in terms of gender at all'. Jacks also noted that at that time there was little in the way of 'careers for women' and that women were 'fairly actively discouraged' from continuing at university. Further, Jacks regarded psychology as 'very male dominated' and noted that 'senior positions still are'. Indeed, in Williams (2000: 10) discussion of the social sciences she commented that the continued overrepresentation of men in top positions, the prioritizing of areas of inquiry that ignore gender, and the hegemony of certain research methodologies (especially the exclusive use of statistical procedures) make it difficult to recognize alternative standpoints'.

Some participants commented that they had observed changes in the use of terminology concerning sex and gender, and that the term gender was now commonly used as a 
demographic variable when undertaking academic research. Other participants commented that they had not really thought about concepts of gender. Rae, a staff member reported that gender was "similar to the notion of sex, although sex is a biological term [such as male and female and $\mathrm{x}$ and $\mathrm{y}$ chromosomes]... whereas gender has broader meaning.' They thought that gender included 'all the social aspects... [including]...everything that's learnt through society and culture'. Rae also commented that they had not 'really thought about it' but had observed that 'people [now] talk about gender instead of talking about sex' when undertaking research. This meant that participants were no longer asked 'their sex' but instead were asked about their 'gender'.

Meanings of gender provided by some participants appeared unclear. The terms 'sex' and 'gender' were sometimes used synonymously, while simultaneously being referred to differently. References to 'sexual identity', 'sexuality', 'sexual orientation' and 'gender' were sometimes used interchangeably or the ideas associated with each were conflated. Laurine reported confusing the term 'sexual preference' with 'gender' in academic work they had been involved with. They referred to a question they had used in a research questionnaire which asked participants about their sexual preference. Laurine commented that they later realised that 'all the way through [the questionnaire] it should have been gender' because they had sent the questionnaire to women who all answered that they 'prefer the same sex partner [despite] most of them hav[ing] been heterosexual married women'. Laurine said 'that has highlighted the difference for me between sex and gender'.

Rob also seemed to confuse ideas about sex, gender and sexual orientation. They commented that gender was 'the male or female, the sex that you identify with rather than your biological [part]...[which was] something you're born into... and gender is something you...identify with...you identify as being a man or a woman. They then commented:

using that definition then allows you to use it for gay, bisexual, transsexual type clients as well...it's who they identify with. Do they identify as being a man or a woman? So it's really I guess the sex...that you identify yourself with... as opposed to the inborn biological sex that you are. 
As noted earlier, other feminist researchers have reported similar confusion about the meaning of gender or gender inequality amongst clinical psychologists (Williams and Watson, 1991b).

\section{Summary}

Meanings of gender articulated by participants, both within and between universities were variable. There did not appear to be any consistent patterns within or between staff and students, or in relation to different universities. Indeed, staff participants' conceptualisation of gender appeared to be as diverse as that of students. Participants' comments about the meaning of gender provide an initial indication of how they thought about this concept. However, their responses to questions about gender, power and women's social position in other sections of the research provide a context within which to more fully comprehend their understanding of gender. As discussed later in this chapter, participants' understanding of gender seems to have impacted on their appraisal of the inclusion of gender content in clinical psychology training programmes. Indeed, this supposition is supported by Williams and Watson (1991b) who reported that confusion about the meaning of gender or sexual inequality amongst research participants was likely to result in over-estimates about the inclusion of this content in clinical training.

\section{The Inclusion of Gender Education}

The inclusion of analyses of gender and other power relations in clinical psychology have long been the subject of attention by feminist writers (Ussher and Nicolson, 1992;

Hare-Mustin and Marecek, 1997). Indeed, the findings of Jennie Williams and Gilli Watson's (1991b) survey of clinical psychology training courses in Britain, and their subsequent workshop, ${ }^{138}$ indicated that education relating to the "psychological and

\footnotetext{
${ }^{138}$ The workshop comprised consumers, trainees, trainers, feminist psychologists and representatives of relevant groups within the British Psychological Society (BPS).
} 
social implications of sexual inequality was extremely inadequate' (Williams and Watson, 1991c: 101). This work identified a range of issues relating to the lack of inclusion of gender perspectives. In particular, they drew attention to a lack of understanding about the meaning of sexual inequality and its relationship to 'psychological' health; the optional and contingent nature of education relating to sexual inequality; the confinement of gender perspectives to issues concerning the mental health of adult women; reliance on students and pro/feminist staff; the difficulties students experience raising these issues; and a lack of inclusion of literature, theories and research produced by feminist psychologists (Williams and Watson, 1991b).

\section{The Nature and Scope of Gender Education}

In my research, staff and student participants were asked a range of questions relating to the nature and scope of gender education in clinical psychology training programmes. These included specific quantitative questions relating to the inclusion of gender education using several key indicators. These included: whether or not gender education was incorporated; the proportion of class time allocated to gender education; how gender education was included; examples of gender education; whether gender education included issues primarily relevant to women; and the inclusion of gender education relating to differences in the social positioning of men and women. Qualitative data was also obtained via questionnaires and interviews to contextualise and further explain responses to these quantitative questions. While this group of questions related directly to the inclusion of gender education they were part of a wider context in which the examination of gender education in clinical psychology was addressed. For this reason, the analysis of quantitative and qualitative data from the student and staff questionnaires and interviews is amalgamated where appropriate. This

integrated approach to the analysis and subsequent write-up seemed a sensible way of conveying the interrelationship between themes emerging in the various sets of data and was a useful means for highlighting incongruities and inconsistencies as they arose. This approach prevented the thesis becoming too repetitive and verbose. 
Whether Any Education About Gender Issues was Included

A high proportion of students (eighty two percent) and all staff reported that education about gender issues was included in their clinical psychology training programmes. However, evaluation of the six key indicators mentioned above, in conjunction with confusion about the meaning of gender, suggests that only minimal gender content was actually included in most clinical programmes.

Time Allocation

Fifty percent of all students who completed a questionnaire estimated that education about gender accounted for less than $5 \%$ of total class time. A further $22 \%$ estimated that $5-10 \%$ of total class time was allocated to education about gender. Fourteen percent reported time allocations of $10-15 \%$ or $15-20 \%$. The remainder of student participants stated that education about gender was not included in their training.

Staff perceptions about time allocation were sketchy. Five staff reported not knowing how much time was allocated to education about gender in any year of training. Estimates given by other staff varied from between less than $5 \%$ in year one, to $15-20 \%$ in year three. ${ }^{139}$

Several participants indicated that it was difficult to estimate how much time was allocated to education about gender because it was integrated throughout courses or because it was so spasmodic. Students reported that rather than 'time being allocated to education about gender,' they themselves raised issues during the course of training. Consequently, education about gender could be included because students happened to be in a programme and were interested enough to raise issues, or because it was a planned part of clinical training and therefore provided through the programme - the latter of which may more accurately qualify as time 'allocated' to education about gender.

${ }^{139}$ One did not respond to the question. 
Other students commented that while issues relevant to women were addressed in clinical training, these were not necessarily examined in the context of gender. For example, one participant discussed the way that their programme included attention to rape and domestic violence, but focused on (male) offender assessment and rehabilitation, and not on women. When issues were addressed which were perceived as relevant to gender, such as 'eating disorders', they were not addressed in terms of a gender analysis. Several staff members noted that it was difficult to answer questions about the inclusion of gender content in clinical programmes because they did not know what other staff included in their courses. ${ }^{140}$ Additionally, one staff member said that they had 'a tagged position' and as such were 'constrained mainly to teaching about crime and criminals' who were primarily male. Furthermore, Alesha an FCP who was also a recent graduate commented: 'I think the intention is there... but I guess it's almost a feeling too that it's a bit tokenistic in terms of the amount of time spent on it'. Alsesha remarked that they did not 'really think it's adequate',

While recognising the difficulty associated with gauging the amount of time spent on content as diffuse as gender, these ratings, and feedback about other aspects of gender education suggest that relatively little time is allocated to gender or other issues of power in clinical psychology training.

\section{How Gender Content is Included}

Many students commented that gender education included in their training was 'descriptive', 'ad hoc', 'added on', 'haphazard', 'non-systematic', 'informal' and overly 'reliant on students'. Indeed, reports of clinical psychology training in Britain, the United States of America and Netherlands also suggest that education concerning sexual inequality is not integrated into the core curriculum, is not planned and systematically included and is largely initiated by students (Bekker, 1991; Brown, 1991; Williams and Watson, 1991b).

\footnotetext{
${ }^{140}$ In hindsight it may have been more useful to ask each staff member how much time they allocated to education about gender within their own courses.
} 
In my research, students variously described the lack of inclusion of gender education. For example Lisa commented that any content included in their programme was 'descriptive' and only reflected 'what we directly ask for or do ourselves'. Similarly, Mia reported that while there were references to gender, these were 'an add-on, like biculturalism'. In addition, Mia suggested that the reason for this was that 'in essence the structure is male...[and]...the power base is male [so] gender considerations are added into that, they're not an integral part of it'. Mia said that it felt as though it was like, 'oh whoops - well maybe women's understanding and experiences differ and how could we add that on'? Mia remarked that gender education did not 'inform the very fundamental theory' of clinical psychology training. Louie commented that while 'power issues are alluded to in implicit ways [there was] no direct discussion of social/cultural system factors that impact on gender issues'. However, Louie also mentioned that students initiated the introduction of feminist or ethnicity perspectives. Jamie reported that while gender issues may have been mentioned in "very minimal ways' such content was not necessarily positive. Indeed, they commented that gender and feminist issues had 'at times been rubbished by lecturers' or lecturers had been 'sceptical'. This finding is supported by Williams and Watson (1991b) who reported that some clinical psychology lecturers were hostile to the very notion of sexual inequality or others issues of gender. Issues of resistance have also been discussed by Boyle (1997) who argues that rather than overtly rejecting feminist ideas, some academics have assimilated these ideas into existing theoretical frameworks of clinical psychology, thereby neutralising the radical or critical potential of feminist theories and knowledges.

Students repeatedly commented that the inclusion of gender content was reliant on students raising issues. Other critics of clinical psychology training have also observed the reliance on students, typically those from non-dominant groups, to raise issues counter to the dominant hegemony (Brown, 1994; Sayal-Bennet, 1991; Williams and Watson, 1991b). In my research students variously commented on this issue. Jay commented that most content relating to gender education was "not brought up by lecturers but highlighted by students in the diploma, most of who are women'. Jay noted that in the 'actual Diploma papers' there had been no specific inclusion of gender 
content but noted that individuals within the course would 'touch on those issues as they relate to cases that we're doing or topics that we're covering'. However, Jay also mentioned that such inclusions were 'very informal'. Alesha a recent graduate, also commented that students carried the burden for raising issues about gender. They noted that this 'was tiring and boring' and reliant on 'the same old two people'. Alesha reported that being repeatedly responsible for raising these issues had felt like 'nagging' and that a minority of students 'carried the load again'.

While students were critical of how gender content was included in clinical programmes, most staff reported that education about gender was integrated throughout one or more courses, was mentioned in all courses, and was compulsory. These findings are at variance with feedback provided by staff elsewhere in the research and stand in contrast to students' reports about the inclusion of education about gender in their training. While some of this variance may be accounted for in terms of the wording of the relevant question relating to how content was included, it appears more likely to reflect staff members intention rather than practice. Indeed, Traice, a staff member, commented that while gender education was 'theoretically integrated into all courses' they were unsure about the extent to which this actually occurred. In addition, they noted that the programme utilised guest lecturers, some of whom probably did not include gender issues. Further, Petra, an FCP involved with clinical training, commented that while staff may think they are including gender education 'you might not be, there may be lots of ways you could be doing that more and you're not'. While it seems likely that staff may have intended including gender content, and assumed that others did so as well, participants' feedback suggests that this was not necessarily occurring. In addition, several staff commented they did not know what other staff included in their courses making it difficult for individuals to know what was included in clinical programmes more generally. This lack of a co-ordinated approach to clinical training and lack of recognition of the importance of gender across all courses was emphasised throughout the research, highlighting the need for explicit guidelines about the inclusion of gender education in all clinical training programmes. 
Student and staff participants provided various examples to illustrate the inclusion of gender education in their clinical programmes. While the range of examples included was considerably more diverse than that reported in Williams and Watson (1991b) earlier study, it was similar in that most gender content arose in the context of adult women's mental health. Analysis of qualitative data from both questionnaires and interviews suggests that education about gender was often confined to descriptive content about differential diagnostic rates between men and women, gender biased assumptions in assessment, therapist-client relations and male sexual/violence against women. As in other parts of the research many students qualified their examples noting that such content was limited, included only in passing or was raised primarily by students. Jay reported that education about gender was included in the context of diagnostic differences. They commented that "most of the gender information we discuss comes from prevalence or incidence figures but we never discuss the reasons for this on a deeper level'. Other students also reported that while their programmes included information about gender differences in statistics about diagnosis, there was no analysis or critique of these apparent differences. Feminist psychologists have also drawn attention to the way attempts to include gender in clinical psychology often focus on alleged gender differences relating to diagnostic statistics and the purported overrepresentation of women as service users (Boyle, 1997; Hare-Mustin and Marecek, 1997; Ussher, 1992). In addition, Dorothy Smith (1990: 131) has offered an insightful critique of gender differences in diagnosis noting that the production of such statistics reflects underlying gender relations and the 'textually mediated relations of ruling in contemporary society'.

Gender differences were also commented upon in relation to gender biased assumptions in assessment, and occasionally in relation to power issues associated with therapy or intervention. In particular, stereotyping, labelling and diagnostic biases were addressed. Ani reported attention to this issue in relation to "diagnoses of adult psychopathology with women' noting that 'some disorders were more likely to be given to women.' Ani commented that the DSM-IV classification of 'Dependent Personality Disorder' was an example of gender bias. However, most students commented that content included 
about gender differences in diagnosis and gender biased assumptions in assessment were superficial and devoid of any analysis of gender or understanding of gendered relations of power.

Students also gave examples of the inclusion of gender education concerning power relations between therapists and clients. While some students included examples that emphasised gender issues relating to male therapists working with female clients, others commented only on the power dynamics between the generic therapist and client. Bonnie noted that in the first year of clinical training power imbalances were discussed in terms of 'therapists and woman clients' and 'working with Māori clients'. In these examples there was implicit recognition that women and Māori occupied specific

identity groups positioned subordinately within clinical psychology. At times attention to power relations between therapists and clients was restricted to issues relating to sexual abuse such as Pam's reference to the 'appropriateness of male clinicians working with female victims of sexual abuse'. Viv also commented on 'ethical issues surrounding sexual relationships between therapists and clients'. Less commonly reported examples included gender issues relating to work with families, sexism and racism, sexual orientation and sexual 'dysfunction'.

Participants who reported examples relating to sexual abuse commented on the lack of gender analysis in the content that was included. For instance, one student reported that content relating to sexual abuse occurred only in relation to male offending and did not include survivors. Another student reported that sexual abuse content related to children but not women (or adult male) survivors. A further student who reported sexual abuse as an example of gender content stated that this only included 'description and effects'. Students reported that there was minimal attention to the wider context in which abuse occurs and that specific lecturers lacked a gendered analysis of abuse. One FCP commented that during her relatively recent training she was responsible for presenting a seminar about sexual abuse to the rest of the students and noted that 'it wasn't taught by the people who were teaching us'. She commented that this was the sum total of 'teaching on sexual abuse' and that this extent of education 'was appalling'. 
Staff members reported a range of examples similar to those given by students. However, there were important differences between students and staff perceptions about the extent of curriculum content relating to gender education. The examples and associated qualifiers given by student participants, in conjunction with time allocated to education about gender, suggests that there was only limited inclusion of gender content in most programmes. Students repeatedly commented that there was a lack of gender analysis or formally structured and systematic integration of gender education. These findings are similar to those reported by Williams and Watson's research (1991b: 80) over a decade ago, who noted that the inclusion of sexual inequality content did not include a systematic theoretical analysis and was not the consequence of planned teaching.

\section{Content Primarily Relevant to Women}

Participants were asked to report on the inclusion of education about gender in the context of content deemed primarily relevant to women. Examples provided in the questionnaire included rape, 'postnatal depression' and 'domestic' violence. Forty two percent of students indicated that women focused content was not included in their training. There was considerable variation between programmes in relation to this issue.

All staff who responded to this question reported that education about gender included attention to issues primarily relevant to women. They cited the following key examples: rape, sexual abuse, sexual violence, domestic violence, therapist-client sexual abuse, eating disorders and depression.

Most students who reported that content primarily relevant to women was included were from Universities $\mathrm{B}$ and $\mathrm{E}^{141}$ although there were also a high proportion of University $\mathrm{F}$ students $(70 \%)$. A range of examples was provided. Those most commonly cited

\footnotetext{
${ }^{141}$ Examples given for University E, while relevant, were frequently qualified. For example students commented: 'a topic picked by a classmate to present'; eating disorders included but 'not really dealt with in terms of gender'; 'briefly touched on Post-natal Depression and domestic violence'. Further, some examples given for University B while specific to women appeared to reflect little in the way of gender education or critical analysis including: 'fertility cycles - physiology', 'sexual dysfunctions', and 'Premenstrual Dysphoric Disorder'.
} 
included: depression, postnatal depression, sexual violence, adult survivors/childhood sexual abuse, and male partner violence. ${ }^{142}$ Attention to 'eating disorders' and 'premenstrual syndrome' ${ }^{143}$ was also included. Students also reported a range of one-off examples, which in part may have reflected their interest and individual pursuit of a given topic rather than being content explicitly included in their training programme. ${ }^{144}$ Most examples participants regarded as primarily relevant to women were similar to those reported as 'women's issues' in the context of examples of gender education in the previous section. Variability in reports of the inclusion of gender content seems likely to reflect differences in participants understanding of the meaning of gender and gender relations as discussed in Section One.

Several students who reported that content primarily relevant to women was included qualified their examples. For example Phil reported that content primarily relevant to women was included in the context of gender education, however there was 'no systematic [attention to] gender issues.' Likewise, Cam commented that content was included 'although limited' and Simone said it was 'briefly touched on'. Kit said that 'a little is expected on postnatal depression, yet [this was] not really taught.' Further, some examples did not appear to reflect gender education but rather addressed topics particular to women. While Premenstrual Dysphoric Disorder was mentioned by some students, no one mentioned feminist critiques of this diagnosis. Likewise, although sexual abuse was reported, some students commented that this only addressed children, not adult survivors of abuse.

It seems likely that many of the examples provided in this section reflected the selection of literature review topics or case studies undertaken by individual students rather than content specifically included in the course of training. As Loren commented, students'

\footnotetext{
${ }^{142}$ Also referred to by participants as 'domestic violence' and 'Battered Women Syndrome'.

${ }^{143}$ Also referred to as 'Premenstrual Dysphoric Disorder'.

${ }^{144}$ These included: miscarriage, socialisation of women, the incidence of women seeking psychological assistance, the demands of multiple roles on women, working with offenders, feminist critiques of family therapy, female sexual offenders, sexual dysfunction, fertility and girl physiology, women and alcohol, 'young mother syndrome', power inequalities, diagnostic issues and unspoken assumptions, ethical issues between therapists and clients, cultural issues relating to women.
} 
choice of topic 'depends on personal interest' and those 'most in need of the knowledge may not seek it out.' Further, while content regarded as primarily relevant to women may be included in clinical training, most students reported that it was of a descriptive nature and lacked a gender analysis. Thus, although clinical programmes may have addressed issues such as rape, sexual abuse and male partner violence, much of this content was at the level of individual 'assessment' or 'treatment' without attention to an analysis of power or the sociopolitical context within which violence occurs.

Those who said that gender content primarily relevant to women was not included in their training made various comments relating to this absence. Two students noted that it was not included in year one of their training. Becs reported that while sexual abuse was included they did not regard this content as gender education because it only dealt with child sexual abuse and working with violent male offenders. This student commented that they had recently worked with women who had experienced physical abuse and commented that they 'did not have a model' and were insufficiently acquainted with the issues to deal with them effectively. Kas summed up this absence of gender education by commenting: "when I think about this I become more and more horrified about how little is gender oriented...I hadn't really thought about it until now and I consider myself a feminist!' These examples of gender content deemed primarily relevant to women, along with those provided more generally in relation to education about gender earlier in this section, provide some illustration of the nature and scope of gender education reported by participants in this research. To further examine education about gender in clinical training participants were asked about the inclusion of education relating to power differences between the groups men and women.

Power Differences Between the Groups 'Men' and 'Women'

Participants reported on the inclusion of gender content in the context of education about power differences between the groups men and women. For instance, participants were asked to think about gender differences relating to financial inequalities following separation, inequities associated with parenting alone, and the predominantly gendered nature of sexual violence. These sorts of issues, which feminists have argued are central 
to women's sociopolitical position, are renown for their role in the development of 'psychological' health difficulties (Kantrowitz and Ballou, 1992; Stoppard, 1999, 2000; Ussher, 1992, 2000).

In my research, all staff (with the exception of one) reported that their programme included attention to power differences between the groups' men and women. University F staff gave a range of examples similar to those given in the questionnaire. They also included others such as poverty, isolation, self-blame, diagnostic labelling, differences in hegemonic world view and structural organisation. Likewise, all students in this programme reported attention to power differences between men and women. While examples given by staff and students at university $\mathrm{F}$ were comparable, some students commented that the extent of attention to power differences was 'relatively small' or 'only in passing'.

Examples given by staff from the other five universities were limited. For example Laurie said attention to power differences was addressed in 'a low key way' and gave the example of difficulties women might have 'in leaving safely a relationship with a violent man and what the costs of that might be'. Dale commented that 'the ethics workshop considers gender/power issues with respect to dual relationships in professional conduct'. Vic said that attention to power differences was included in relation to 'professional roles and solo mothers'. Rae commented that it would 'depend on the individual lecturer's own point of view'.

In contrast, the majority (61\%) of students from these five programmes reported that attention to power differences was not included in their programme. Feedback from students in these programmes suggests that content concerning power differences related primarily to sexual violence, domestic violence and ethical issues relating to the therapist-client relationship. These examples were consistent with those given by students elsewhere in the research and were frequently qualified with comments such as 'again, this is mostly brought up by students' or 'some attention' or 'some discussion' suggesting that content of this nature was only minimally included. 
In some instances the kind of content included about gender differences appeared piecemeal with little structural analysis of power. For example Laurine commented that sexual violence and abuse were considered in terms of 'sexual and emotional factors in the genesis of disorders'. Jessie noted that rape was examined in terms of 'reasons and attributions males and females give to it'. Some students who reported that gender power differences were not addressed in their programme noted that they had given this response because students, not staff, raised these issues.

\section{Conclusion}

Clinical psychology students and staff in this research conveyed a diversity of understanding about meanings of gender and the power relations that underpin an analysis of gender. While participants' understanding of gender was theoretically diverse, there was a prominence of conventional social science conceptualisations of gender which appeared to influence participants' reports of the inclusion of gender education in clinical psychology training. Indeed, the nature and scope of gender education reported by participants in this chapter is indicative of a typically limited analysis of gender, combined with a lack of understanding of the significance of the relationship between gender and clinical psychology. It also highlights marked differences between students and staff in their perceptions of the inclusion of gender education, with students in most programmes reporting minimal inclusions across the six key indicators.

As highlighted throughout this chapter, there is ample indication that the inclusion of gender education is minimal, infrequent, only included when regarded as relevant, and non-analytically added on to what is perceived as the 'fundamental' clinical curriculum. Indeed, there was general agreement amongst student and staff participants that most clinical programmes allocated very little time to gender education. ${ }^{145}$ While examples of gender education provided by staff and students were generally consistent, many

\footnotetext{
${ }^{145}$ It could be argued that because this research was undertaken in the period 1996-1997 these findngs may no longer be applicable. However, anecdotal information, discussion with current trainers, and the examination of current research and literature upon which clinical psychology training is based suggests that there has been little fundamental change in the way programmes incorporate analyses of gender.
} 
students regarded such content as limited, descriptive and not systematically integrated into their clinical training. Many students reported that education about gender lacked an analysis of power or critical inquiry. Further, the majority of students in most programmes reported that there was no education about gender included in the context of power differences between the groups' women and men. Additionally, a significant minority of students reported that content primarily relevant to women was not included within the context of a gender analysis. When included, gender education was frequently initiated by students rather than being actively raised by staff or included as an integral feature of the clinical curriculum. In contrast, staff generally regarded the inclusion of gender education as integrated throughout one or more courses, mentioned in all courses and compulsory.

Students repeatedly discussed the reliance on students and pro/feminist staff to include education about gender. Students expressed widespread dissatisfaction with both the means by which gender content was included in clinical training and the lack of analysis of power when education about gender does occur. These findings are consistent with views expressed by feminist writers who argue that 'making gender visible involves considerably more than putting the topic on the curriculum' (Boyle, 1997: 233). Indeed, Adcock and Newbigging (1991: 175) suggest that the inclusion of gender in clinical psychology requires "the political perspective feminism offers...going far beyond "adding women in"...but rather envisages the transformation of existing power inequalities'. While this chapter has focused on the nature and scope of gender education in its generic form, the next chapter centres on the inclusion of gender education relating to diverse groups of women. 


\section{Chapter Eight}

\section{Gender Diversity Education}

Psychology has been widely criticised for ignoring the effects of structural relations of power relating to diverse social groups (Asch and Fine, 1992; Durie, 2001; Fine and Asch, 1988; Frith, 2001; Landrine, 1995; Walkerdine, 1996a, 1996b; Wilkinson and Kitzinger, 1993). More specifically, as outlined in Chapters One to Three, critics have challenged clinical psychology for reproducing Eurocentric epistemological, theoretical and methodological paradigms and monocultural practices (Hare-Mustin and Marecek, 1997; Sayal-Bennet, 1991; Ussher, 1992). Indeed, psychological research has been described as 'over-represented by white, middle class, urban, educated participants...the results of which are generalised to all but not vice versa' (Hare-Mustin and Marecek, 1997: 117). Such challenges have drawn attention to the way clinical psychology excludes the knowledges, experiences and material realities of those regarded as Other. Alternatively, when psychology does include non-dominant cultural groups it does so by objectifying and problematising group members (Espin and Gawelek, 1992; Kitzinger, 1997; Sayal-Bennet, 1991; Nikora, 1993). Sue Holland (1992: 75) also comments that psychology has ignored the effects of poverty and injustice, and notes that the "cumulative disasters of everyday living for those who are disadvantaged are catastrophic.'

Feminist psychology has also been charged with reproducing the cultural meanings and values of feminists from dominant cultural groups and focusing on gender at the exclusion of other power relations (Kitzinger, 1996; Greene and Sanchez-Hucles, 1997; Nikora, 2001; Walkerdine, 1996a, 1996b). While recognising the interplay of power across diverse social dimensions, and the recent development of critical work advancing conceptual frameworks for integrating multiple sites of inequality (Jenkins and Pihama, 2001; Madden and Hyde, 1998; Weber, 1998), my research takes gender as its focus. As mentioned in the introduction to the thesis, I concentrated on gender as a way to ensure the manageability of the research, to reignite debate about the relationship between 
women, gender and clinical psychology, and to contribute to an already established body of work by Māori that challenges clinical psychology's epistemological, methodological and theoretical frameworks. However, the research offers some inclusivity by examining the ways clinical psychology training represents women's diversity.

In this chapter, I examine the inclusion of gender education relating to diversity by exploring the way clinical psychology training includes analyses of power across different groups of women. In particular, I address student and staff participants' perceptions of the inclusion of diversity education relating to Māori women, women of Pacific Nation descent, lesbians, women with disabilities, women who are economically disadvantaged, and older and younger women.

\section{The Inclusion of Gender Education Relating to Diversity}

Sixty percent of student participants reported that gender education did not include attention to diverse groups of women specifically referred to in the research questionnaire. Forty percent of students reported that attention was given to at least one of these groups. With the exception of University F, 75\% of students from all other programmes reported that their training did not include attention to diversity as a part of gender education.

Seven staff said that attention was given to education about gender in relation to different groups of women, however three staff members said that the groups of women mentioned were not included and one reported inclusion about disabilities but not in the context of gender. ${ }^{146}$

\footnotetext{
${ }^{146}$ One did not respond to the question.
} 
Table 3: Student Reports on the Inclusion of Diversity Education

\begin{tabular}{|ll|}
\hline Programme & Yes Response \\
\hline \hline A & $37 \%$ \\
C & $50 \%$ \\
D & $25 \%$ \\
E & $10 \%$ \\
F & $14 \%$ \\
& $90 \%$ \\
\hline
\end{tabular}

Ninety percent of students from University $\mathrm{F}$ reported attention to diverse groups of women. In comparison, $90 \%$ of students from University D and $86 \%$ from University E reported that attention to different groups of women was not included in the context of education about gender.

Despite apparent variation across universities A, B, C, D and E it appears that the extent of actual inclusions of gender diversity education may be similar. Analysis of examples given by staff and student participants in these programmes indicates the inclusion of only limited content relevant to gender and diversity. This pattern is consistent with student ratings of the adequacy of education about gender and with students' explanations for their ratings. As discussed previously, there are a range of possible reasons for these variations and different interpretations of this data. Students from each year of training were fairly evenly spread in their response to this question, suggesting that if final year students are reporting exclusions as much as first years, then there are gaps that remain unresolved throughout the course of training. 
Given the wording of the question about gender diversity education, these findings are notable. First, the question was phrased to include reference to any of the groups of women included in the given example. Second, the term 'attention' was used to infer minimum reference rather than substantive inclusion of education relating to these groups. Equally, some participants (justifiably) included gender non-specific content as examples of diversity. Further, some examples related only to different epidemiological rates $^{147}$ and at times inclusions related only to one select group of women (for example lesbians). Equally, participants who reported the inclusion of diversity frequently qualified their comments, noting that it was 'minimal' or 'very little' or only 'a glancing acknowledgement'. The inclusive possibilities of the question meant that an affirmative response was likely even if there was only minimal mention of gender diversity.

While University $\mathrm{F}$ included more substantive content related to diversity than other programmes, inclusions reported by staff and students related primarily to Māori women and lesbians. Indeed, staff and students from University $\mathrm{F}$ acknowledged that the diversity content included was minimal. Students made a range of comments to this effect. For instance, George reported that it was "really only a glancing sort of acknowledgement that there are gender considerations...in reference to Māori, Pacific Island, lesbian [and people who are] economically disadvantaged'. Likewise, Mia commented that diversity education was limited, included a little content relevant to lesbians and Māori, but nothing concerning other cultures, economics or age. Pat reported that the Pakeha Treaty Action (PTA) group had included 'issues relating to Māori women'. Students from this programme regarded the PTA group, lesbian guest lecturers and proactive staff as valuable sources of education.

Staff members from University $\mathrm{F}$ acknowledged that while some issues of diversity were addressed, more substantive education was required. Claud commented that the inclusion of content relating to diversity 'varies from one lecturer to another depending on their familiarity with different groups'. They noted that there were 'one or two sessions on lesbian and gay issues in the whole programme' and recurrent attention to the effects of poverty or economic disadvantage. However, Claud commented that other

\footnotetext{
${ }^{147}$ Rather than reflecting critical analyses about why such differences are reported.
} 
than a passing mention of physical disabilities there was 'nothing on disabilities .... and nothing on other ethnic [groups], other than the one session on Pacific Island cultures...nothing on Asian and nothing of any other cultural groups'. Recent separate reports on mental health services for Pacific and Asian peoples in Aotearoa New Zealand indicate that the experiences, worldviews and conceptual paradigms of health of these groups remain invisible in the provision of mainstream services and public health policy (Ho, Au, Bedford and Cooper, 2002; Ministry of Health Manatu Hauora, 1995). Furthermore, the costs and consequences of living in a disabling society, combined with the high incidence of reports of discrimination against people with disabilities in this country, remain a prominent concern for people with disabilities (Minister for Disability Issues, 2002).

In other programmes, most students who reported the inclusion of diversity also indicated that it was minimal, dealt with only one or two groups of women or issues, or included gender non-specific content. For example, Rob commented that diversity content included attention to poverty but not Māori women or women with disabilities. Similarly, Viv reported that while their programme included education relating to people with disabilities it did not address issues specific to women with disabilities. Likewise, Hilary, a staff member, commented that 'disabilities [were] included but not specifically related to women'. In another example, Jessie reported that their programme only addressed diversity in the context of 'epidemiology rates among different individuals of disorders/mental health problems and issues' and did so by focusing on Māori women, and older and younger women. Viv noted that their programme gave some emphasis to gender 'in the discussion of cultural differences and difficulties arising in assessment and treatment'. Suzette commented that their training had not included attention to diverse groups other than in the context of the Treaty and Māori.

Students often commented that when diversity content was included it occurred in the context of case presentations and class discussions and was not systematically or formally included as part of the curriculum. Consequently, there was a reliance on students who possessed relevant knowledge or were proactive about these issues. In addition, students commented that although diversity content was not structured into 
clinical training it was something staff thought students should know about. Jay commented that staff 'expect that's something we'll do on our own ... the responsibility is on us to really come up with these things'.

Some participants suggested that staff did not regard issues of diversity as relevant, necessary or important enough to warrant inclusion in clinical training. Lisa commented that staff 'believe that what they're teaching us is universal and can be applied to anybody' so they did not regard diversity as particularly relevant. Lisa further noted that while staff would not consider diversity as 'totally irrelevant', when compared with course content that they do teach, staff would think it 'wasn't really that important'. Indeed, Lisa remarked that staff just believe that nothing that happens to you beforehand is relevant at all'.

Leo, a staff member from the same programme as Lisa, acknowledged that little was included about diversity in clinical training despite students' recurrent requests for inclusion. Leo discussed the impact of time pressures and the subsequent prioritisation of clinical course content. They commented that the programme was so "crushed for time that something's going to come out'; consequently, content such as diversity was not typically included. Leo remarked that while this was 'an omission...it is one we are willing to live with if it means we have to take out other things... what we want to train people to do is become clinicians'. When asked about the compulsory status of criminal justice and neuropsychology in some programmes, Leo replied that diversity content 'was less important' in terms of 'the overall goal of being a clinical psychologist'.

Participants thought that the lack of a political climate and professional environment in which gender and diversity were valued also influenced decisions about the inclusion of this knowledge in clinical training. Several students discussed the way that the Treaty was increasingly politically legitimised in psychology in a way that gender and other issues of power were not. ${ }^{148}$ Loren reported that 'culture' was included 'because of the climate of New Zealand'. They noted that 'everyone's really hot on the Treaty of

\footnotetext{
${ }^{148}$ This was generally regarded as a positive shift. Simultaneously, many students thought that issues concerning gender, 'race', ethnicity, class, disabilities and sexual orientation should also be central to their training.
} 
Waitangi...you can't ignore that...everybody has got commitments to honour the Treaty, so there's a definite compulsion'. However, they also noted that there was not the same 'pressure to include those other [diversity issues] because there's not the same awareness politically'.

Alex, a student from another programme, suggested that structural issues relating to diversity were not regarded as part of clinical psychology despite the obvious relevance of these issues to clinical work. They commented that diversity issues were 'talked about but it's not [perceived as] a role of the programme.... or a psychologist to change those things'. Alex reported that, while there was an assumption that you could 'agitate for change on a structural level... in your spare time or if your workplace is that kind of workplace', that these structural issues were not dealt with in the programme unless students drew attention to them.

Many students commented on the pressure to pass exams and emphasised the importance placed on exam content at the expense of other content like gender and diversity. Jay discussed this issue and noted that if there was more focus on gender issues in the exam then it would be covered more often in lectures and people would take more notice of it'. They noted that 'the only thing that people really are doing is working to pass the exams...the main focus is on the actual clinical work' and implied that gender and diversity were not regarded as a priority by staff.

Feedback from staff members also indicated that the inclusion of education about diversity was minimal and suggested that there was little systematic integration or interactive class learning. Instead, it was apparent that education about diversity was largely included in an ad hoc manner, relied on the occasional distribution of articles and ultimately on students having time to read relevant material out of class time. For example, Vic, a staff member, discussed the inclusion of diversity content in the following way:

[O]ccasionally I've tried to formally introduce a reading or some material that might be relevant to... anyone who is discriminated against in our society, who is disadvantaged by being a member of a minority, who is subject to social pressures...it's a big topic but I think it gets raised in a variety of ways and typically if there's a good article that 
seems particularly to alert people, again you know...so much of our material does come from behaviour therapy, there was an article recently in an issue of the Behaviour Therapist on current trends in gay and lesbian issues and how therapists can, [or] should be involved in this and what they should know about...I think we distribute that to students and say, well this is worth reading.

Reliance on reading from behaviour therapy research or literature alone is unlikely to provide much in the way of understanding issues of oppression and discrimination, which are central to the experience of being lesbian or gay, nor is it likely to provide an analytical framework for understanding these experiences. Indeed, Hilary Lapsley and Kate Paulin (1994) suggest that the inclusion of lesbian perspectives and knowledges in psychology generally is poor.

Other staff members commented that content relating to diversity was largely absent, although there were occasional inclusions over the years when students selected topics or worked for agencies with an interest in specific issues. Dale, a staff member, reported that none of the groups referred to in the research questionnaire were included and that issues relating to diversity were not 'specifically' included as part of the curriculum, although there had been 'a couple of exceptions'. These related largely to individual students initiating work on a particular topic such as 'lesbian parenting' and the lecturer occasionally referring to issues in class 'if the opportunity arose'. In addition, some students had the opportunity to prepare a literature review for their placement patron, which may address issues of diversity such as 'how poverty might impact on parenting skills'. However, Dale concluded that 'it's not going to be a universal experience of everybody in the course'.

Students who reported that education relevant to diverse groups of women was not included in clinical training expressed dismay about this situation. Kas commented that these issues were not included 'at all' and did not even 'crop up...incidentally', unless they were definable in terms of the DSM-IV. In addition, Kas reported that the programme had 'barely focused on what the problems of even major women's groups might be, like women on the DPB ${ }^{149}$ bringing up children' and that there had been

${ }^{149}$ Domestic Purposes Benefit 
nothing about 'really glaring social issues like poverty.' In view of reports on poverty in this country, and the relationship between lone parenting, poverty and health, these findings are particularly notable (for example Stephens, Waldegrave and Frater, 2000). Kas noted that the lack of attention to issues of diversity in their programme made them 'feel ashamed'.

Some participants gave personal and frank accounts of their lack of awareness of particular groups of people and highlighted the importance of including diversity education that has traditionally been ignored in clinical training. For example, Pat, a student, reported that they had attended 'one workshop on working with gay and lesbian clients'. Pat commented: 'I'll be totally honest, my initial perception was that anyone who was gay or lesbian...was coming to deal with their sexuality'. Pat said the workshop "was like "Hello!" and that it had challenged their 'narrow thinking'. They also commented that during a placement they had sat in with a couple of gay men and the clients had explicitly said: "look sexuality is not the issue here". Pat reported that the workshop had prompted increased awareness but that 'there needed to be a bit more' done in the programme.

While some participants initially appeared well versed in their awareness of issues of diversity, further discussion revealed the sometimes rhetorical nature of this knowledge and the absence of an analytical framework. The following example illustrates how one student articulated ideas about power and concepts of Otherness, then later maintained that all people are born heterosexual.

[W]e had at each year...a specific session on talking about gender issues and power issues...it... like the power differential within the counselling therapy type situation, power issues involved in bicultural, race issues, and ... between adults and children in relation to sexual abuse ... we also had other sessions where we talked about dealing with difference, dealing with Other, what it means to be Other and that was in relation to working with gay or lesbian clients... people of other cultures... people of different ages [and] cultural backgrounds... It [role play] was really effective in helping you to shift your thinking, but I guess it doesn't ever quite hang true in that biology is heterosexual, so it's never going to quite be a total parallel...the world might be gay, but in fact you must have been born in a heterosexual manner, that's how you came into the world, so you can never exactly draw a parallel. 
Thus, despite an apparent awareness of relevant issues, acknowledgement of the absurdity of the now outdated DSM categories pertaining to 'homosexuality', and discussion about lesbian and gay views on the origins of sexualities, the participant proceeded to assert the 'natural' status of heterosexuality. This example highlights the heterocentrism that continues in clinical psychology and the way such assumptions reinforce normative (hetero)sexuality. Lesbian feminists have widely challenged psychology for reinforcing heteronormative assumptions (Kitzinger, Wilkinson and Perkins, 1992), ignoring the effects of 'homophobia' and thereby perpetuating oppressive theories and practices (Kitzinger, 1987, 1990, 1997). Indeed, critiques of compulsory heterosexuality forward by Adrienne Rich (1980) over twenty years ago remain applicable to psychology in the present day.

In another example relating to lesbians, a student noted that this had been included under the heading 'sexual functioning'. When questioned about the nature of this content they noted that 'not a lot' was included and commented that 'we would have just basically covered the basics in terms of attitudes towards homosexuality...that they're out there and you know .it used to be considered a disorder'. It was unclear whether the heading was one the participant chose, or whether it was used in the clinical programme. Irrespectively, the association of lesbians with 'sexual functioning' raises questions about the context of diversity content when it is included. This example further illustrates the need to ensure a comprehensive understanding of issues of power and the way assumptions in clinical psychology can reinforce the status quo. As Vic, a staff member commented 'I'm sure students vary greatly in their actual knowledge [of diversity]'.

These particular examples illustrate the kinds of assumptions psychologists can make, the likelihood of research and practice based on misinformed ideas, and the potentially adverse consequences for clients. Equally, that lesbian and gay clients feel compelled to state that sexuality is not an issue, is testimony to the kinds of assumptions lesbians and gays experience, and learn to expect, when engaging with psychologists.

In other instances, participants' ideas about diversity were constrained by the individualism of clinical psychology. Consequently, while they might recognise that 
education about diversity influenced the kind of assumptions psychologists hold, the ability to transfer this knowledge to practice sometimes appeared problematic. For instance, Laurine reported that they had spent 'quite a large proportion of...time looking at specific Treaty issues'. However, Laurine also said: 'when you get a Māori client, while you were able to appreciate where the cultural group as a whole was coming from it doesn't leave you any the wiser about the individuals'. It seemed that there was a lack of understanding of the purpose of Treaty education in terms of its relevance to clinical practice. In another example, Kim who was also a student, conveyed a somewhat rudimentary and decontextualised understanding of education relating to Māori. The language Kim used to discuss content included in the context of 'diversity' was indicative of the Othering of non-dominant groups. Kim commented:

I mean all you can do is try and learn as much as you can about other cultures so that when you're confronted by them - when you encounter them...then you're in a position to actually act appropriately, not sit on tables...not try and expect a Māori adolescent to look you in the eyes. Adolescents full stop don't like looking into your eyes, Māori adolescents will see it as a complete sign of disrespect on the whole... if they're brought up with their Māori heritage and stuff.

While recognising the importance of not making assumptions, some participants then inadvertently discussed issues using language which reflected dominant culture assumptions and stereotypes. Participants from non-dominant cultural groups, and/or pro/feminists, ${ }^{150}$ reported that this practice pervades clinical training. For example, in case studies or vignettes descriptive detail about clients was only included if people were identified as Other. Lisa reported that "even just in things like...two paper referrals...one was for a "young Indian man" ... and the other was for "a man"'! Lisa commented: 'it was so blatant ... of course [it was assumed] this person's white because we don't say [because] white is "normal". In another example, Lisa discussed a role play in which 'it never crossed their mind that [it might be] about a woman having an affair with [a woman] rather than a man'. Lisa commented that assumptions of this kind were commonplace and remarked: 'the most salient thing for me is who it is we choose to label'. Laurine also drew attention to assumptions inherent in clinical training and commented that a 'heterosexual white couple would not be described that way, whereas

\footnotetext{
${ }^{150}$ The term pro/feminist is used to include women who adhere to 'feminist' ideas or worldviews as well as men who subscribe to these views and is akin to Liz Stanley's use of the term (Stanley, 1999)
} 
anyone who had something by way of characteristics that was slightly varying on that would be described specifically'.

Language reflecting the Othering of non-dominant groups was common in the context of participants' discussion about diversity. Typical examples included the recurrent use of words such as 'them', 'they', 'that', 'it', 'a Māori' and 'a lesbian' as illustrated throughout this section. Further, some participants used outdated and/or inappropriate language such as 'victims' of sexual abuse, 'homosexuality' and those used in Sarah's comment about lesbians:

The way [the programme] addresses that issue would be to have one session on it, maybe each year, but definitely one session on the course where a clinician who identifies as being a lesbian would come in and talk to us about some of the things she is aware of that may be important when working with someone like that.

Similarly, while discussing the lack of inclusion of education relating to poverty or class, Viv commented: 'there seem to be more disorders common among people in a lower class'. Kim, who used the words 'confronted by' in relation to Māori clients earlier in this section, also referred to 'expectations of a man towards his wife'. In addition, Kim discussed their 'cultural awareness' in the following way:

Well you know, Samoan culture, and I'm not claiming to know very much about this, but one of the things I think I do know and I'm not wrong in saying this, is that you know all Samoan... whew got to be so careful when you say this stuff... one of the things that I understand Samoan adults feel obligated to do, or responsible for, is all Samoan children...so if one of them's acting up you smack 'em on the head...that's acceptable.

In conjunction with a range of implicitly discriminatory references, the language used in these examples contributes to an ideology that perpetuates dominant cultural assumptions and locates people from non-dominant groups in a subordinate and marginal position. Finally, other comments made by Kim who was reporting about his knowledge of diversity content are somewhat disturbing:

[O]f course you'll have individual clients that are women who have disabilities and you will find out that their ability to use pads or tampons is much impaired or impeded by their having no front fingers. 
Kim also made other inappropriate sexual references when he talked about 'whether there was a penis or vagina' in terms of meanings of gender. Furthermore, while being able to articulate an analysis of gender and power to some extent, he then made comments that contradicted this position:

I'm a free individual, fuck I can go where I want. Okay, you have difficulties with money, none of these are insurmountable if that's what you want to do, I'm a firm believer in that, I don't believe in the helpless minority, I think that's bullshit.

Kim was also of the view that if students needed to find anything out for their clinical work, they could do it themselves. While this may apply to some content in clinical training, it is unlikely that this would be appropriate to adequately develop an analysis of gender and power. For example, while responding to a question about power in the context of domestic violence, he said:

I've got no idea because I haven't done anything on domestic violence [it's not in our training] but... what you do is you provide people with the resources to work safely, and to know when they don't know something, [they just] need to know where to look to find it, so if I was to do work with domestic violence then I would go and find the answer.

\section{Conclusion}

Examination of student and staff participants' reports about the inclusion of gender diversity education in clinical training suggests that most programmes allocated little, if any, time to this content. While the majority of students in most programmes reported that there was no education about gender included in the context of diversity, most staff reported that diversity content was included. An analysis of discrepancies between students and staff in their perceptions about the inclusion of diversity education in most programmes, suggests only minimal inclusion of gender education relating to diverse groups of women. Moreover, when interpreted in the context of the nature and scope of gender education (as discussed in Chapter Seven) the paucity of diversity education is further highlighted. Indeed, omissions were particularly apparent in relation to women of diverse Pacific Nation descent, women with disabilities, and older and younger women. However, other groups of women and girls not specifically named in the research questionnaire, such as those from diverse Asian groups, migrants and refugees, 
those who are incarcerated, and women lone parents who live in poverty, were rarely if ever mentioned by participants from most programmes. These findings highlight significant gaps in clinical training and the need for continued vigilance in the way clinical psychology conveys an analysis and understanding of power, and represents women's diverse experiences, material lives and worldviews. 


\section{Chapter Nine}

\section{Analyses of Power - Example One: The Treaty of Waitangi}

In this thesis I argue that an analysis of power is central to understanding the relationship between 'psychological difficulties' and the construction of psychological knowledge. Unequal power relations between different groups in society are in part illustrated by differences in access to meaning or knowledge making processes. Thus, those in power in society are more able to generate meanings, and to influence and control the kinds of language used to make sense of people's lives. This process results in the privileging of particular accounts of 'reality' that reflect the values and experiences of those located in positions of power.

An analysis of power is central to critiques of psychology by feminist, Māori and other critical psychologists (Burman, 1996a, 1996b; Cram, 1993; Hare-Mustin and Marecek, 1997; Marecek, 2001; Nikora, 2001; Prilleltensky and Nelson, 2002). Feminists have discussed how dominant versions of reality are produced. By taking alternatives, a gendered analysis of power has been identified as integral to an understanding of the connection between women's sociopolitical position and women's psychological health. Likewise, Māori have offered analyses of power in relation to the Treaty of Waitangi, and have drawn attention to abuses of power by the Crown (and Pakeha), and the effects of ongoing colonial practices in psychology and academic research (Cram, 1993; Nikora, 2001; Smith, 1998; Turia, 2000).

In the next two chapters, I examine staff and students' ideas about power relations, and the way clinical psychology training conveys an analysis of power in relation to two specific areas. These include: a) participants' perceptions about the way clinical programmes incorporate the Treaty of Waitangi, Mãori knowledges and worldviews, and bicultural approaches to training; and b) participants understanding of power as it relates to male perpetrated violence. 


\section{The Treaty of Waitangi, Māori Knowledges and Bicultural Practices in Psychology}

An analysis of power is integral to an understanding of the Treaty of Waitangi (the Treaty), bicultural policy and practices, and the position of Māori in Aotearoa. In particular, an understanding of the way processes of colonisation impact on Māori is fundamental to an understanding of Māori health and well-being. Indeed, various writers have addressed the way abuses of the Treaty have led to the marginalisation of Māori, Māori knowledges, practices and values, and have highlighted the ongoing harm resulting from colonisation (Durie, 2001; Nathan, 1999; Nikora, 2001). Further, some writers have addressed the impact of colonisation on Māori women (for example Cram, 2001a as discussed in Chapter Three).

The National Standing Committee on Bicultural Issues (NSCBI) which is an officially sanctioned committee of the NZPsS, has actively challenged psychology to operationalise the Treaty (NSCBI, 1995; Nairn and NSCBI, 1997). In recognition of Rule 3 of the New Zealand Psychological Society (NZPsS, 1993) the NSCBI has recommended that the Society develop 'psychological theory, research, teaching and practice that is specifically useful and relevant to iwi and Māori community development'. ${ }^{151}$ Averil Herbert, a Māori clinical psychologist, developed a Treaty based framework for clinical psychology training programmes. She emphasises the significance of partnership, participation and protection ${ }^{152}$ which are integral to the Treaty and underpin a bicultural protocol (Herbert, 1998a; 1998b). Herbert highlights the way theories and methodologies in psychology reflect dominant cultural values and ideologies of North America and Britain.

\footnotetext{
${ }^{151}$ Cited in Clinical Practicum I Bicultural Component Readings, University of Waikato, 1998: 358.

${ }^{152}$ In this context the notion of protection 'provides for the development of kaupapa Māori psychology within a Māori worldview' and recognises sovereignty and the tangata whenua status of Māori in the provision of Mãori mental health services' (Herbert, 1998b: 26). Protection means that 'the State's policies and programmes guarantee Mãori the same rights and privileges as other New Zealanders' (Orange, 1987 cited in Clinical Practicum I Bicultural Component Readings, University of Waikato, 1998: 15). Kaupapa Māori means 'the validity and legitimacy of Māori is taken for granted; the survival and renewal of Māori language and culture is imperative; the struggle for autonomy over our own cultural wellbeing, and over out own lives is vital to Māori survival' (G. H. Smith, 1990, cited in Cram, 2001: 404).
} 
Linda Waimarie Nikora (2001) has emphasised the significance of Treaty principles relating to the Kawanatanga ${ }^{153}$ - Rangatiratanga ${ }^{154}$ dynamic and has challenged psychology to develop practices that embody this. She also challenges psychology to further its contribution to bicultural development by translating Treaty based policies into practice (Nikora, 2001). Like other critics, she raises questions such as "where is the Māori content in psychology courses?' 'Why aren't Māori graduating from professional training programmes?' 'Why does it seem that Māori are always on the 'client' side of the professional/client equation?' (Nikora, 2001: 377). Furthermore, as Cram (2001a: 404) comments the discipline of psychology has 'remained largely untouched by Māori realities'.

In the current research, interviewees were asked about the ways clinical psychology training programmes included education relating to the Treaty, endorsed bicultural protocols and incorporated Māori systems of knowledge. Reports by student and staff participants suggested that two programmes had made significant inroads in terms of these issues. In the other four programmes participants indicated that there was not an active commitment to the Treaty or bicultural education. This finding is similar to that reported by Nathan (1999) in her evaluation of tikanga Māori content in clinical psychology programmes.

\section{Treaty Proactive Clinical Programmes}

At the time this research was undertaken, two clinical programmes were actively engaged in the process of implementing Treaty of Waitangi protocols, and bicultural policies and practices. While these two programmes differed in approach, there was a recognisable commitment and attempt by clinical staff to endorse the Treaty and incorporate Māori systems of knowledge. Content included in clinical training was incorporated in a structured and consistent manner, drawing on multiple sources of knowledge and methods of learning. Both programmes utilised landmark documents,

\footnotetext{
${ }^{153}$ Kawanatanga means governance but also 'invokes the idea of protection' (Nikora, 2001: 377).

${ }^{154}$ Rangatiratanga means 'autonomy and independence... the right to an identity, both individually and in the group, and the right to express that identity without being impeded in any way' (Nikora, 2001: 377).
} 
legislation and social policy relating to the Treaty and bicultural practice. These programmes also used publications by prominent Māori writers and drew on interdisciplinary knowledge to inform and educate clinical students. In one of these programmes a Treaty of Waitangi framework had been developed and was in an early stage of implementation. Further, bicultural protocols for training and practice had been established and the programme included a specifically bicultural clinical paper.

Students and staff from these two programmes discussed a range of ways their programme endorsed the Treaty and bicultural protocols, and incorporated Māori systems of knowledge within the curriculum. Jacks, a staff member, discussed use of the Treaty as a foundational model for clinical training. They reported that students had a whole paper on the Treaty and bicultural practices which included involvement with 'Māori agencies and having people talk about different models for Māori mental health', and recognition of 'different knowledge bases'. Jacks discussed the importance of drawing on literature from a broad disciplinary foundation including 'anthropology and politics', indigenous psychology and specifically addressing 'Treaty grievances and settlement claims'. Jacks highlighted the use of landmark documents including the Treaty, the Treaty of Waitangi Act (1975), Puao-te-Atatu (Ministerial Advisory Committee, 1986), the April Report (Royal Commission on Social Policy, 1988) and publications of the NSCBI. Jacks discussed the way these documents reflected communities and social change, and should inform psychologists' professional ethics. Students in this programme were required to undertake assignments based on these documents by making recommendations to other clinical psychologists on how they would 'look at a service or mental health agency with the Treaty in mind'. The programme included various Māori speakers reflecting a diversity of knowledges, different 'tribal ways of looking at things' and 'different views within Māoridom'.

Jacks thought that some degree of implementation of a Treaty framework was feasible within clinical training despite the limitations of a Pakeha dominant academic institution. However, Jacks also considered that a truly bicultural system would mean having 'by Māori, for Māori' institutional structures, processes and practices including: 
[A] whare wānanga ${ }^{155} \ldots$ a whole different way of learning...a tutor would select their students...the student doesn't sit there and say I think I'll do these papers [and] the whole system [would be] completely different...[it would include] the spiritual and the Tohunga aspect [of Māori mental health]...you need a whole different support system for that...I can't imagine how you could actually promote that in a setting like this.

A Pakeha staff member also questioned how effectively the Treaty and a bicultural approach to clinical training could be implemented within existing institutional structures. In this regard, Traice commented that being bicultural meant more than 'bringing a Māori flavour to a white Pakeha thing' and noted that 'to do otherwise would require a whole different course structure and a whole different institutional base'. Traice also discussed the broader issues and difficulties of 'four Pakeha lecturers in a Pakeha institution' being able to teach in a bicultural way. ${ }^{156}$ Another Pakeha staff member, Claud, commented on tensions involved in "teaching issues around biculturalism' and 'teach[ing] people how to be clinical psychologists, as currently defined'. Claud noted that it was 'a very hard balance to get' and that the programme did not always get it right. They also commented that staff and Māori students were likely to prompt discussions relating to bicultural perspectives in most classes 'so those issues are pretty near the forefront all the time'. However, Claud also reported that these issues could 'disappear into the background pretty quickly' especially when staff were 'trying to get across some really Pakeha concept like cognitive behaviour therapy'.

In one of the Treaty proactive clinical programmes, a staff member expressed views that seemed contrary to the bicultural approach and achievements made in this programme. For instance they discussed the validity of a western science epistemological model of psychology and concluded that "there was no comparable thing in the case of bicultural issues'. They commented:

nobody's saying there is a Māori approach to science...there's a Māori approach to knowledge and to discovery... but there isn't a version of western science that has a Māori equivalent, whereas you could say that there are aspects of western science which are culturally and gender related.

\footnotetext{
${ }^{155}$ University, school of higher learning (Ryan, 1997: 369).

${ }^{156}$ This programme was staffed entirely by Pakeha academics.
} 
Tess Moeke-Maxwell, a Māori bicultural advisor remarked that 'a holistic approach is our [Māori] science'. ${ }^{157}$ She also commented:

the clinical psychology approach is only one dimension and that is at the hinengaro level which is too shallow to accommodate everything, therefore it is against biculturalism because it is not upholding the principles of our world views as Māori which is not giving us rangatiratanga - the right to define ourselves.

Despite individual perspectives of the kind reported by Vic, and the institutional parameters of clinical psychology training, staff in these two programmes attempted to implement Treaty protocols and bicultural practices in accordance with the aims, goals and general direction of the NSCBI. Staff also reported using the work of Mason Durie and other prominent Māori writers/orators who have challenged psychology to address its Treaty responsibilities, implement bicultural practices, and incorporate Māori knowledges and models of health.

Participants in these programmes talked about the importance of having staff members who were actively committed to bicultural education. Mia, a student, commented that their programme had 'reasonable sensitivity about biculturalism' and noted that 'it comes back to a staff member who feels strongly about those issues and has influenced the flavour of the programme...[they are] a very good role model'. Jacks also talked about the importance of having women and Māori staff role models, particularly for Māori students, whose success often depended on having staff they 'could relate to ... and talk to about [clinical psychology]'.

Despite changes these two programmes have made in terms of implementing Treaty and bicultural education, participants reported that there was an over-reliance on the knowledge and energy of individual Māori staff and students to ensure this content was included. Indeed, many non-Māori students discussed the role Māori students occupied in ensuring the inclusion of Māori knowledges, bicultural perspectives and Treaty education. They also acknowledged the costs and consequences for Māori students of being positioned as cultural educators. For example, Ro commented that pro-activeness around bicultural education came primarily from Māori students and noted that 'they're

${ }^{157}$ Personal communication with Dr Moeke-Maxwell (May, 2003). 
the ones that have to work the hardest... it wouldn't be happening much if they weren't in the programme [I can] absolutely guarantee [that]'. Furthermore, Sarah reported that Māori students often got 'burnt out' because there were so few Māori in clinical programmes and 'had to work so hard' because they were relied on to do 'all the Māori things in terms of protocol and so forth'.

In one of these two programmes, participants discussed staff concerns about the limited extent to which their programme included Treaty and bicultural education. George noted 'there's always the complaint or the criticism that there's not enough or it's not in depth or it's insufficient'. Quita, a feminist psychologist who had contact with this programme commented that while there was recognition of the importance of the Treaty and bicultural education there was a sense of this being tokenistic. She commented that while the programme exhibited an 'intellectual understanding' of biculturalism and acknowledged its importance to clinical training, the institutional structure did not actively support this. In addition, she noted that there had been 'ructions' in relation to marae visits for instance, and that some staff members thought such visits were a 'waste of time'. Quita further discussed tokenism in terms of the lack of appreciation by Pakeha of the 'benefits' and 'insights' that can be gained from Māori perspectives and worldviews, and noted that this was not 'engendered into students' in such a way that they recognised how these experiences could give them a 'richer kind of practice.' She commented: 'I think Pakeha haven't figured out that there are major benefits in actually looking at different ways of seeing the world, different cultural models, and different definitions of what mental health is'.

Quita also discussed how the wider profession lacked an understanding of power and equity in relation to the Treaty and bicultural practice. She observed that there was confusion amongst some non-Māori psychologists about the meaning of power sharing:

[I]t's not just knowing what the Treaty of Waitangi is, it's actually about addressing issues...[like] what is the dominant culture in this environment... an organisation [I've been involved with] now has equal numbers of Māori and Pakeha staff and it's now being said..."well enough has been done for Māori now, there's equal numbers so it must be equal" and so there's a whole lack of understanding about what that means. 
While acknowledging the advances these two programmes have made in terms of the Treaty and bicultural education, participants from both programmes highlighted problems they perceived in the way this education was delivered. In particular, some non-Māori students reported difficulties they had experienced with Pakeha Treaty Action (PTA) education, ${ }^{158}$ noting that they had addressed much of the content covered in these workshops in prior learning. Other Pakeha students indicted that they would have learnt more that was relevant to their work by having more Māori practitioner sessions. For instance, Sarah commented that in their third year 'we didn't actually want to have PTA teach us...[we] would rather spend the other two [sessions] actually hearing from Māori practitioners which we did have as well, but we would have preferred more of that'. However, it seemed that other students who reported only a limited knowledge of the Treaty wanted PTA classes extended throughout their training. For instance, Pat thought that 'Pakeha Treaty Action was great in the first year because it was fairly regular... [about] once a month'. However, they also reported that this decreased to only three times per year, for an afternoon at a time, in the second year of training. Pat commented that this 'seem[ed] strange... since we're actually out there in placement where these issues would probably be coming up quite often...so I would have thought they would have included much more of it...I don't think there's enough of it'.

There appeared to be considerable variation in the awareness and knowledge base of Pakeha students in terms of the Treaty and bicultural education. In turn, this seemed to have implications for the perceived efficacy of PTA workshops. Traice, a staff member, commented that they thought there were problems in contracting out Treaty education classes in terms of the programme not having 'an overall' and integrated system of knowledge. Traice also commented that they 'felt uncomfortable looking at Mãori mental health...if there aren't any Māori students' and commented on the sensitivity of issues relating to 'Pakeha students going and writing an essay on Māori mental health

\footnotetext{
158 Pakeha Treaty Action (PTA) comprises education for Pakeha clinical psychologists and other professionals (Pakeha Treaty Action, 1997). At the time this research was undertaken PTA was facilitating three year training modules for clinical psychology students at two universities (Pakeha Treaty Action, 1997: 152). PTA is based on a pro-Treaty analysis which fundamentally addresses Māori rights and Pakeha responsibilities (Pakeha Treaty Action, 1997: 146).
} 
which inevitably they want to do'. Instead, Traice thought it was important for all courses to address Treaty and bicultural issues, and for Pakeha students to:

look at Pakeha issues around race...Margaret Wetherell's Mapping the Language of Racism... ways Pakeha talk about Māori-Pakeha relations and the ways they're sensitive to, or not more likely, biculturalism and racism... [and] how that's dealt with more regularly within other topics.

Indeed, while students were aware of singular issues such as those relating to Pakeha psychologists working with Māori clients, and the associated importance of supervision and accountability, some students conveyed a limited, and decontextualised knowledge of the Treaty and bicultural perspectives. Some students did not appear to have developed an analytical framework and analysis of power from which to understand the Treaty and its relevance to clinical psychology.

In one of the two proactive Treaty programmes, students indicated that little content relating specifically to the perspectives, experiences and position of Māori women was included in their programme. Some students commented that while individual lecturers may incorporate this content, Māori women were often made invisible within the context of Māori (men) or (Pakeha) women. A Pakeha lecturer in this programme who actively encouraged the inclusion of content specific to Māori women commented that it was important for Māori voices to come through in training and to use 'literature written by Māori writers'.

Another staff member, Vic, raised issues concerning the under resourcing and over utilisation of Māori agencies and said that they had sometimes 'discouraged' students from taking placements in these settings. They commented that they did not want students 'to be qualified on the backs of people who [were] still very under funded' but also noted that during community assignments 'students had linked up with quite a number of groups and developed ... collaboration[s]'. Further, Vic commented that the under resourcing of Māori agencies and lack of 'appropriate financial support' meant there was 'a shortage of professionally qualified people' to supervise students.

While the two programmes discussed in this section were more progressive than other programmes in establishing Treaty-based frameworks and developing bicultural 
education, there was acknowledgement by some staff that this process was still in the early stages of implementation. Some participants indicated that this work was an important but challenging task requiring ongoing development and engagement with complex issues and debates. Further, the NSCBI was regarded as an important initiative within the institutional structure of psychology and was identified as crucial in guiding the development of bicultural practices within clinical psychology and the wider profession. One staff member commented that the presence of the NSCBI had been influential in changing the attitudes of some traditionally not 'overly interested' psychologists, but noted that there were still 'some very staunch unchanged attitudes in the profession'. Despite resistance of this kind these two programmes had made significant progress in meeting some of the challenges of a bicultural approach to clinical psychology training (Nathan, 1999).

\section{Treaty Non-Proactive Clinical Programmes}

Participants in the other four clinical programmes indicated that little was included about the Treaty, bicultural perspectives, tikanga Māori or Māori knowledges. Some students reported that there was little or no reference to the Treaty and minimal attempt to incorporate bicultural perspectives or practices. When content was included, students noted that it was ad hoc and not discussed within wider contexts of power or partnership.

Students from these four programmes reported that any inclusion of Treaty, bicultural or Māori content was 'in no depth whatsoever', 'was fairly low key stuff' and was not usually included in the 'formal part of the course'. Lu commented that their programme had included 'a two hour session discussing some papers [that looked at the Treaty and biculturalism] and there has been the odd mention of issues in passing'. Col, a fellow student reported that any inclusion of this content had been from 'informally organised seminars or students getting together and trying to do something about it'. Col also noted that 'there was one lecture on bicultural issues' in the prerequisite 'abnormal psychology' course which was taken by a Pakeha psychologist. This included 'some introduction... [like] how as a psychologist cultural issues might impact on how people 
are presenting or how you might be viewing [them].' They also noted that there was "one part of the course at the end which...[was] called "bicultural issues". Viv, a student from another programme, commented that their programme had an 'appalling' commitment to the Treaty and bicultural education. Viv reported that the programme had included:

a couple of hours literally on cultural issues, that [included] considering the sorts of issues in the same way you might consider someone who's blind or deaf... [it included] what sort of pragmatic problems are going to come up... what sorts of body language are you likely to come up against...I'm fairly certain that I haven't touched on [the Treaty in the programme]...I don't think we've done any specific seminars or workshops on that.

Jamie, from another programme commented: "we learnt nothing...I mean...we did have this one lecture [about bicultural perspectives]' but nothing at all was included about the Treaty. Jamie also reported that it would be possible for students to complete their clinical training without having done anything other than this one lecture. Thus, although students reported the inclusion of some content defined as "bicultural issues," they also indicated that this content often neglected the Treaty altogether or focused only on "cultural issues" relating to an individual client, as evident in Col, Jamie and Viv's comments. It could therefore be argued that clinical training contributed to the individualisation of problems, negated the consequences of colonisation, and ignored the effects on Māori of the Crown's failure to honour the Treaty.

Other students talked about the inclusion of education relating to the Treaty in the general context of 'culture' or 'ethnicity'. Freddie discussed the 'brief training' they had received 'on the Treaty of Waitangi presented by a Māori lecturer' and while noting that this was the 'only reference it got' they also commented that students were often told by staff that they must address 'ethnicity.' Freddie discussed how these references to 'ethnicity' specifically included attention to Māori and the Treaty but were 'often generalised' to other marginalised groups. Similarly, Alex from the same programme commented that they did not think they were "ever given an assignment that explicitly addressed cultural issues' and noted that 'over the three years there would be a couple of workshops to give some cultural input to the programme'. They also noted that the programme did not include readings or references to Māori writers. Indeed, Viv from 
another programme said that the couple of hours included in their programme on cultural issues had nothing to do with Māori or the Treaty. They commented:

a lot of the literature we read was actually American based and it was talking about, for example, Latin Americans, I mean for goodness sakes...I did some Māori 101 [an introductory course] years...ago, so I have an idea of what I absolutely do not know, which is nothing.

Some students reported that when their programme included content relating to the Treaty or Māori it was in the context of ethics or issues concerning Pakeha psychologists working with Māori clients. Rob mentioned that they 'did have a seminar on ethics and [the staff] just drew our attention to the fact that for most of us dealing with Māori clients there's going to be some...cultural differences and you need to know where to go to get help with those cultural differences, but they didn't tell us where to go...that was it'. Some Pakeha students reported being unsure of appropriate practices relating to Māori clients and were uninformed about appropriate consultation procedures. They were also frank about their lack of knowledge and the inadequacy of their training in equipping them to work competently in this area. One Pakeha student remarked that they would be 'unfit' to work with Māori clients if the need arose.

In another programme, Pam reported the inclusion of content relating to the Treaty and 'Māori issues' but noted that this was typically in the context of Pakeha psychologists working with Māori clients, reflecting Nikora's (2001) criticism earlier in this chapter. Pam also mentioned the importance of consultation, although discussion of issues concerning the resourcing of consultation were not included. Pam reported that they had been to 'at least a couple of [workshops]' which addressed 'the Treaty and what that means.' They commented that these workshops covered content such as:

raising awareness of Māori issues and of culturally appropriate practices... meaning that if you've got a Māori client...check to see how they feel about seeing a Pakeha and that it might be more suitable for them if at all possible to be seen by a Mãori therapist...if they're in a situation where this is all you've got and you can't do anything about it, then you should have somebody... with whom you can consult, and be aware of fairly basic things like...they may want to have their whanau with them...to have karakia....and have a consultant that you can discuss things with... being aware of...the emotional and physical and the cognitive and spiritual dimension. 
While students regarded workshops of this kind as an important aspect of their training, it was apparent that content covered in these workshops was not a part of the core curriculum nor integrated throughout their clinical psychology training.

Students in these four programmes also talked about a lack of endorsement of the Treaty and bicultural practices in terms of support from clinical programmes and the wider psychology department. Lu commented that although staff talked about increasing the number of Māori students in clinical psychology, this was 'not supported by the department' and 'actually [it's] a battle field if you're coming from any different perspective'. Likewise, Kas who was in the same programme as Lu, talked about the 'superficial commitment in the department'. Kas commented that despite widespread support from students for Treaty workshops and the inclusion of Māori health perspectives 'nothing would be done and there would be no funding for it'. Kas discussed the way past conflicts between non-Māori clinical staff and Māori staff or consultants was used by clinical staff to justify the exclusion of Treaty or bicultural education. For instance Kas commented how students in their programme "would hear stories that it hadn't worked in the past.... and [that] there'd been an altercation at one stage'. Likewise, Lu discussed a range of student initiated Treaty workshops and training, and Treaty based student work groups which 'all the students supported very, very strongly'. However, Lu also noted that in their programme 'it was incredibly hard to push anything through in terms of culture'. Most students in these four programmes expressed concern about the limited bicultural education provided in their training, recognised the importance of this knowledge to their work as clinical psychologists, and conveyed enthusiasm for its inclusion in their training. However, many students reported that when they had raised these issues with clinical staff it was difficult to effect even minor changes. They also noted that it was difficult to maintain even a limited knowledge of the Treaty, tikanga Māori and bicultural perspectives in practice settings where these were marginalised.

Non-Māori students from these four programmes attributed their learning about the Treaty, tikanga Māori and bicultural perspectives to Māori students in their programme and to learning outside clinical psychology, such as in other university courses and at conferences. For instance Kit reported that they had 'got a lot more out of Māori studies 
and going to Family Therapy conferences' than they had from clinical training. In another programme, Col said that what they learnt about 'the Treaty and bicultural issues had been from other courses in education and sociology...than in the clinical course'. Jamie, from yet another programme remarked that their knowledge about the Treaty came from other work they had done and 'informing myself'.

As in the two proactive Treaty programmes, many students in these four programmes reported that the presence of Māori students in clinical training provided an impetus for the inclusion of Treaty education, and greater inclusiveness of tikanga Māori, Māori systems of knowledge and issues particular to Māori. Indeed, many non-Māori students reported that the most influential source of learning came from Māori students in their programme. However, there was also recognition amongst students in these four programmes that positioning Māori students as cultural educators had potentially adverse repercussions for Māori students. Some students likened this position to that of feminists in clinical training and discussed the way Māori students had little option but to raise questions that challenge Pakeha dominant assumptions or to remain silent and leave Māori perspectives excluded and misunderstood. As discussed in relation to the inclusion of feminist knowledges, students who were proactive in presenting other conceptual frameworks or perspectives risked marginalisation and the associated stress this can bring about. One self identified Māori student discussed the tensions they had experienced in clinical training and noted that while there was rhetorical support for the Treaty this was not translated into practice. They commented:

[A] lot of things made me really angry, just the whole pressured nature of the training, the workload and the real focus on cognitivebehavioural techniques, and the lip-service that "was given to things like. for me cultural issues and having to defend my perspective all the time and yet having the department give lip-service to the Treaty of Waitangi and talk about how important it was for psychology to be culturally sensitive, but when you actually started talking about things that I actually thought should be done, it was challenged quite seriously.

\section{Conclusion}

In this chapter, I have addressed the way the Treaty of Waitangi, Māori knowledges and bicultural practices have been incorporated into clinical psychology training. I have 
highlighted two programmes where significant developments have occurred, and pointed to ongoing limitations in the other four clinical training programmes. While the Treaty, and relations between Māori and the Crown, and Māori and tauiwi, provide a poignant illustration of power in a bicultural context, an analysis of power in the context of gender and male violence is also a useful example of the importance of an understanding of power in the context of clinical psychology training. This is explored in the next chapter. 


\section{Chapter Ten}

\section{Analyses of Power - Example Two: Men's Violence Against Women}

Feminists and others have discussed the gendered nature of violence against women and the perpetuation of male violence ${ }^{159}$ within a sociocultural context of unequal power relations and persistent structural inequalities. Indeed, the international pervasiveness of violence against women has warranted the establishment of academic journals that focus solely on violence, special editions of journals dedicated to the examination of issues related to violence (White and Sorenson, 1992) and a proliferation of publications in which the nature, context and effects of violence are discussed (Booker, 2002; Hanmer and Itzin, 2000; MacKinnon, 1992, 1996; Sriram and Mukherjee, 2001; West, 2002). In this research, I have taken male violence towards female partners ${ }^{160}$ and male sexual violence ${ }^{161}$ as two examples of reasonably clearly delineated gender power relations to explore the way clinical psychology training conveys an analysis of power.

In Aotearoa New Zealand there has been a considerable body of work undertaken in relation to violence against women (for example Adams, Towns and Gavey, 1995; Busch and Robertson, 1997; Glover, 1993; Towns, 1998) and the structural inequities that perpetuate male violence (James and Saville-Smith, 1994). The New Zealand National Survey of Crime Victims is indicative of the prevalence of (reported) male perpetrated violence against women in this country (Young, Morris, Cameron and Haslett, 1997).

\footnotetext{
${ }^{159}$ Including male partner violence, sexual violence and child sexual abuse.

${ }^{160}$ In the research questionnaire the term 'domestic' violence was used based on participants presumed familiarity with the term and the Domestic Violence Act (1995). Although 'domestic violence' obscures the gendered nature of relationship violence this term is generally used in the thesis write-up to maintain consistency with questionnaire terminology. Where appropriate I have used the preferred term male partner violence.

${ }^{161}$ The term male sexual violence is used in the thesis to draw attention to the gendered nature of sexual violence. However, in the research questionnaire the term sexual violence was used as it was considered more acceptable and provided an opportunity to gauge participants' identification of the gendered nature of sexual violence.
} 
The effects of men's violence are widely recognised as integral to women's experience of psychological distress (Koss, Bailey, Yuan, Herrera and Lichter, 2003). For example, research examining women's experience of depression and post-traumatic stress disorder (PTSD) has highlighted the impact of men's violence in women's lives (Koss et al, 2003). Because of the relationship between men's violence and women's experience of emotional pain, an understanding of male violence is considered an important aspect of clinical psychology training.

In the current research, male partner violence and male sexual violence were chosen as areas of investigation that could usefully illustrate the way clinical programmes addressed the effects of violence in women's lives and assess the degree to which programmes conveyed a gendered analysis of power. Male partner violence was also used as a topic to explore student and staff conceptualisations of a gendered analysis of power and to canvass their ideas about the relationship between men's violence and women's experiences of psychological pain.

\section{Education Relating to Male Violence}

As discussed in Chapter Seven, most students reported some inclusion of domestic violence and sexual violence as examples of education about gender, or content deemed primarily relevant to women, in their clinical training programmes. However, the majority of students also reported that these topics were only mentioned or minimally included in the course of training and a significant proportion of students reported that education about domestic violence and sexual violence was not included in their clinical training.

In Chapter Seven, students reported that education about male partner violence and sexual violence were not among the range of topics allocated most time, despite the majority of students regarding these topics as central to an understanding of women's lives. Although depression and anxiety were given widespread attention in clinical training, most students reported that male violence against women, which is frequently 
associated with women's experience of depression and anxiety, was rarely included. Likewise, although students thought that PTSD was important in understanding women's lives, few programmes addressed the relationship between PTSD and male violence. Students reported that when male violence was included this content was often piecemeal and did not include a gendered analysis of power.

Throughout the research, staff and students perceptions of the nature and substance of gender education included in clinical training often differed. This disparity was particularly notable in relation to education concerning male violence. Staff identified depression and anxiety as topics given priority in clinical training, and reported that domestic violence, rape, sexual abuse, and abuse by therapists were often included as examples of education about gender. While the degree of inclusion of these topics varied, most staff thought that the inclusion of education about gender in their programme was adequate.

On the other hand, students in most programmes reported that little if any education was included about male violence. They indicated that staff assumed students would possess sufficient knowledge and understanding of male violence prior to entering clinical training. Furthermore, when students raised issues about male violence they received little response from staff. For example, Jay commented:

[Domestic violence is] again another thing that I think we are just supposed to know when we come into the programme...it's not really looked at much at all, no. [O]ne of the women in our year is quite concerned about those issues and she brings them up sometimes but it just never goes anywhere.

Likewise, Suzette who was in the same programme as Jay, indicated that nothing was included about domestic violence during their training. They reported that unless students specifically elected a postgraduate course on violence then it was possible for students to go through training without any education about this issue:

Within clinical psych we don't [learn about the context of domestic violence] - not clinical papers - but I've done [a psych Masters paper where] we looked at violence in society...the thing with that though is that... as a clinical psych student you actually have to choose to go into that paper and I'm probably the only psych student in the last three or four years that has. 
A student from another programme also commented that while they had learnt about male violence through taking an optional course it was not included in clinical training. Furthermore, they reported that staff assumed students would acquire this knowledge without it being specifically included in their programme:

I've looked at [domestic violence] in an education paper...maybe [it's included] in relation to the likes of something like helplessness... [but]...it's expected you gather this sort of information from elsewhere.

Other students reported that unless they actively selected male violence as a research topic it was not included in their clinical training. For instance, Louie commented that their programme did not include domestic violence, though they had independently addressed male violence in an assignment. Further, feminist knowledge was not included as a matter of course in relation to male violence or necessarily encouraged by programme educators.

In another programme, Freddie reported that while domestic violence was mentioned in their training there was no theoretical model for understanding male partner violence and the effects of this on women's lives:

We haven't [done anything on domestic violence] - no. It's certainly been mentioned incidentally...but it was very much in passing and there's been no specific model, no specific thing about violence and its effects, which I find amazing given its prevalence and given people's myths and misunderstandings about it...the programme that I'm on doesn't have a very strong...sociocultural component, it's largely cognitive-behavioural and (... $)^{162}$ I don't think they're ideal models for looking at men's violence towards women.

Freddie also reported that though their programme had included education about sexual abuse this had not been located within a sociopolitical context and did not include a gendered analysis of power:

We have had [child sexual abuse] as part of our training in one paper...it wasn't really put into a sociocultural context either as part of say men's abuse of women...its been covered as a specific topic and its

162 (...) voice unclear. 
effects on children and adults and how they might present as clients, and it's also been covered in case examples... but it hasn't been tied into the overall gender imbalance.

Furthermore, some students reported that the lack of inclusion of education about male violence within their clinical programme meant that they might not learn anything about these issues until directly working with clients. Suzette reported that this had been their experience and once working with a client it was assumed students would read literature to obtain understanding of relevant issues:

You could go right the way through [without looking at sexual violence or domestic violence]. A lot of the time, a lot of the specific stuff that we learn about those issues is not until you actually have case studies with clients and then you will read a lot more of the literature...so if you hadn't done any papers on women in abusive relationships then you might never come across that until...you're working with a client.

Rob, a student from another programme, commented that they had not had any education relating to sexual abuse within the context of their clinical training and that students regarded this as a gap in their training:

No [we've done nothing on sexual abuse] unfortunately. That was another gripe of ours at the end of fourth year that we hadn't done anything on, oh not in terms of strict course work, I've been to a seminar, a two day workshop on sexual abuse but not in terms of what's provided by our clinical programme'.

Kit, from another programme also commented that their programme had not included education relating to adult survivors of sexual abuse so students may not learn anything about sexual violence until directly working with clients during their internship year:

Well not really, no, no, [we had nothing about adult survivors of sexual abuse] although in internship and endorsement level, some of the clients you might see might... you know be suffering from those conditions, so you can get some kind of individual teaching on that level.

Another student from this programme, Pam, also commented that they 'couldn't remember having done anything specific...in the clinical course...or in Adult Clinical Psychology' relating to adult survivors of sexual abuse, although a child and family paper had included several sessions relating to child sexual abuse. 
Viv reported that while their programme had included some content about male partner violence they personally knew little about this issue and had not undertaken a specific project on this topic. Further, Viv commented that if students encountered this issue in clinical practice they 'would probably be encouraged to refer on to a more appropriate person [like] an ACC funded counsellor...counsellors attached to Women's Refuge or Rape Crisis or a similar women's group who has support groups as well.

In some programmes, education about male violence was restricted to specific issues that students said were of limited use to their work with women or children. For example, students from some programmes reported that while their programme focused on the treatment of male sexual offenders, little content was included relating to work with survivors of sexual abuse. Lu commented:

I don't think we've looked at [sexual abuse] in our course. We've looked at it...in terms of male offenders...but not in terms of victims on the other end of it, very, very little...no, hardly even in relation to PTSD, it's something that most of us have been quite annoyed about because it hasn't actually been a subject in our training.

Lu also talked about having little knowledge concerning sexual abuse:

I had an issue... where there was a suspicion that a...child was being sexually abused and I had no idea of how to handle the situation, had no idea what to say, what not to say, anything like that and so we [students] gave a lot of feedback to the university about that lack of addressing the whole issue.

Other students reported that when sexual abuse content was included it largely supported a false recovered memory position rather than affirming survivors. For instance Jay commented '[we] talked about [adult survivors of sexual abuse] a little bit but only in terms of....recovered memory... but it wasn't... about working therapeutically with them as in terms of what you'd actually do. Jay also commented:

there have been a number of workshops lately [outside the university]...Felicity Goodyear Smith ${ }^{163}$...DSAC [Doctors for Sexual Abuse Care] offer workshops... we get given the pamphlets and some people have gone to them, there's also a woman... who has worked to discredit...children's eyewitness memory for abuse...so the culture is more around disbelief than belief in recovered memory...certainly I

\footnotetext{
${ }^{163}$ Who promotes a false recovered memory position.
} 
think we're probably more pushed in the way of disbelief than belief in that.

This issue, which has been a topic of some debate in Aotearoa New Zealand in recent years, has particular ramifications for women survivors of abuse. I ndeed, the New Zealand Psychological Society's sponsorship of Professor Elizabeth Loftus as the keynote speaker at their conference in 2000 signalled the Society's endorsement of this stance. A pro-false memory position has also been widely reported on in the media creating a public milieu of disbelief of women survivors. While views and research on the status of recovered memories (in relation to sexual abuse) vary, it is of concern that students felt they were being 'pushed' to accept a stance which is so potentially damaging and oppressive without counter arguments and research being presented.

Other students reported that content relating to male violence, while brief, was largely concerned with domestic violence legislation. Furthermore, in one programme, students reported that while there was little attention to the effects of male sexual violence on women, the programme included content about female sexual offenders. Finally, as noted in Chapter Seven, several students reported that while their programmes mentioned child sexual abuse, nothing was included about working with adult survivors of sexual abuse and other forms of male violence.

While students in most programmes reported that male violence, if included at all, was addressed in only a rudimentary way, one programme appeared to have included education about male violence in a more systematic manner and within the context of a theoretical analysis of power. Traice, a staff member from this programme commented on the significance of gender in relation to sexual abuse and noted the importance of feminist literature in understanding this issue. In addition, Traice noted that not having an adequate understanding of gender and Māori mental health issues meant working in an oppressive manner:

$[T]$ here's also particular gender issues like sexual abuse... when you think about gender it opens you up to a whole different literature hopefully, which is really important...not relying on conventional positivist psychological research literature but a much broader feminist writing...and the whole Māori mental health area...I think is really essential... and if psychologists go out there and they don't have an 
understanding of those issues they're really going to be acting...even with goodwill....in quite an oppressive way.

Likewise, Lyndsay, a student in the same programme discussed a range of issues central to understanding male partner violence which included a gendered analysis of power, the role of control in men's subjugation of women, and the cultural context in which male partner violence occurs:

Domestic violence would have been constructed in terms of predominantly being male violence towards females... or violence against children and both of those would have been viewed in terms of a control issue... [and] in terms of the new Domestic Violence Act...so it wasn't simply hitting...it was controlling by abusive words, by denigration, by fear, by taking away power, by taking away freedom of mobility... and all of those were constructed as violence...in the male control of women there's a whole kind of culture...that this is the way that being male is.

Although reports about the nature of inclusion of education relating to male violence in this programme were better than in other programmes, some participants suggested that more substantial coverage was required. Pat, a student, commented:

[Gender issues including rape and domestic violence are] not explicitly raised...[though]...last year, we had a speaker talk about [domestic violence] for an hour and a half, and this year we've learnt a bit about the Domestic Violence Act and our role as psychologists... but I don't think it's been covered in as much detail as it should.

Rosie, an FCP also discussed this programme in terms of the progressively decreasing number of workshops concerning male partner violence in recent years. Rosie suggested that if workshops were not a part of clinical training, students were unlikely to develop a comprehensive analysis of power and understanding of the complex ways male partner violence impacts on women's lives. She commented:

there still needs to be a lot of discussion about violence issues... particularly in relationships...I can't quite understand how they can't teach that stuff...it went from two workshops to one last year...then none this year...they've had a year with no workshops on men's violence against women partners....it's basic safety... [students are] not going to have that when they go out...I find that extraordinary... [they] can't understand what the lived experience is for women in those situations...so if we're assuming that [students are] going to have no more than the lay knowledge then that's a real worry. 


\section{Student and Staff Participants' Understanding of Power in Relation to Male Violence}

Student and staff participants were asked a range of questions to gauge their understanding of power in relation to male violence. In particular, their ideas about male partner violence and sexual violence were explored. The majority of student and staff participants regarded domestic violence as primarily male violence towards women. Although a minority of student and staff participants thought this was categorically the case many participants qualified this stance by noting that in their experience women were also violent, and often, just as violent as men. Many participants gave individual examples of clients they had worked with to justify this perception. Few drew upon contemporary violence research and literature, or current policies and community practices to support their view of domestic violence. For example, Lu commented that domestic violence was 'primarily male violence to women' though they did not think it was 'always male to female'. They noted that male clients often said: "Oh the wife she beats me back just as hard", suggesting that the violence men and women perpetrate is equitable. Laurie, a staff member commented that they 'suspect[ed] women's violence [wa]s more common than [they] would like' but also noted that 'in terms of severity of [domestic violence] occurring in a context of dominance and control' then domestic violence was primarily male violence against women.

Other participants suggested that male violence may just be reported more. Jessie commented: 'I do not deny that women may be domestically violent to males [but] it may just be that male perpetrated violence is reported more'. Likewise, Ingrid also suggested that 'male violence (physical) is more evident or reported'. Thus, though these participants agreed that domestic violence was primarily male violence against women they qualified their responses by raising doubts about reporting practices.

Many students and staff also differentiated the kinds of violence they thought men and women used. So, although many participants may have agreed that domestic violence was primarily violence against women, they subsequently commented that women were likely to use psychological violence whereas men were more likely to use physical violence. For instance, Ingrid remarked that in their "limited experience... some female 
partners are quite verbally, emotionally and psychologically violent (i.e. withholding affection)'. Laurine also commented on women's use of 'manipulation' and 'verbal and emotional abuse'. They commented on the 'subtle abuse that females perpetrate on males' and noted that this occurred in the context of male 'sexual dysfunction in terms of erectile dysfunction'. Furthermore, Kas commented on women's use of 'psychological violence', which was regarded as 'probably more equitable but underreported and understudied'. Sarah also reported that they thought 'psychological violence (manipulation and coercion) by women towards men [was] increasing'. Indeed, many participants conveyed gender stereotyped views about the kinds of violence they thought women and men engaged in. Furthermore, while subscribing to a scientist model of clinical psychology, most students indicated that their response was based on their experience - typically, their 'limited experience' of clinical practice.

Other participants questioned whether the term domestic violence, as used in the questionnaire, included psychological violence. ${ }^{164}$ Several participants noted that if the term 'domestic violence' meant physical violence, then they agreed that domestic violence was primarily male violence against women. However, if the term included psychological violence then domestic violence was not primarily male violence and instead, was more likely to reflect women's use of violence against men. Vic, a staff member, questioned the definition of domestic violence in this way and then proceeded to comment on women's use of psychological violence:

$[\mathrm{P}]$ sychological abuse, emotional abuse does happen the other way round [female to male]...that psychological exploitation can take place regardless of gender and regardless of direction, female clients are perfectly capable of using various coercive tactics, to manipulate a relationship in a maladaptive, undesirable way.

Participants who disagreed with the questionnaire statement that domestic violence was primarily male violence against women also differentiated the kinds of violence they thought men and women used. For instance, Maria commented that 'although males may constitute the majority of perpetrators... women are also involved and quite capable

\footnotetext{
${ }^{164}$ It was assumed that if participants were familiar with power and control models of violence and the Domestic Violence Act 1995, they would understand that 'domestic violence' is explicitly about both psychological and physical violence. A minority of participants included children in their definition of 'domestic' violence. This position is likely to reflect broader definitions of domestic violence contained in the Domestic Violence Act 1995.
} 
of domestic abuse'. Likewise, Mal referred to women's use of 'emotional, verbal and physical violence' and commented that 'men's violence leaves scars... and can create political issues'. Presumably Mal was referring here to the political nature of debates about (male) violence and like other participants expressed some resistance to dominant models of violence that are founded upon a gendered analysis of power.

Leo, a staff member, clearly disagreed with the perspective that domestic violence was primarily violence against women. Leo claimed that women were just as violent as men and produced just as many casualties. Leo drew on the rhetoric of "good" literature to justify their position and intimated that arguments counter to the one they held were untrue and basically the product of propaganda:

I think that domestic violence literature, the good stuff, will just show you that women are just as horrible as men, equally, with just as much force and use just as many weapons and hospitalise just as many men...the fact that it's equal, at least the amount of violence is equal...would be almost laughed out of courts because of the way in which it's been sold to us...I actually don't say this because I get a very hostile reaction as though I don't know what I'm talking about, and that's patently ridiculous, and I think that's a measure of how the message has been sold to the public.

The frequency with which participants who both agreed and disagreed with the research statement distinguishing psychological and physical violence raises some interesting issues. First, if programmes were utilising contemporary models of violence in which an analysis of power and control is central, participants would be expected to understand the implicitly psychological nature of this relationship and recognise that physical violence is only part of a broader repertoire for maintaining power and control. Second, if participants were familiar with contemporary research and literature, and commonly used models of violence such as the Deluth model (Pence, 1993), then they would also be aware that psychological violence is implicit to domestic violence (Towns, 1998). Furthermore, if participants were familiar with changes to domestic violence legislation in this country, as evidenced in the Domestic Violence Act (1995) - which some participants reported was included in their training - then they would also know that psychological violence was implicit in contemporary definitions of domestic violence. Indeed, a central focus of the Act is the definition of domestic violence that recognises the psychological sequel of violence, and the expanded conceptualisation of violence. 
Furthermore, statistics about domestic violence in this country indicate that men are the primary perpetrators (Young, Morris, Cameron and Haslett, 1997).

Many students seemed unfamiliar with current analytical models of domestic violence, or contemporary research and literature or recent legislative changes relating to domestic violence. This unfamiliarity was evident in students' lack of understanding of the gendered dynamics of relationship violence, their negative stereotypes about women and their reliance on personal views. Indeed, language used in reference to women by some students and staff in this chapter such as 'manipulation' and 'coercive tactics', and the way ideas about male violence have been 'sold to the public' are indicative of attitudes that belie some participants understanding of male violence. Furthermore, there seemed to be little awareness of the subtle psychological strategies by which men abuse and use power to maintain control over women (such as intimidation, withholding finances, restricting social contact), which are central to understanding currently endorsed models of domestic violence (for example Pence and Paymar, 1993). Participants also appeared to have little understanding of unequal power relations between men and women within heterosexual relationships and concepts of fear which are integral to understanding male partner violence (Towns, 1998). Further, men's use of or threat of sexual violence as a means of controlling women was rarely noted despite being widely recognised in research and literature.

\section{Contributors to Male Violence}

Participants understanding of domestic violence was also conveyed in terms of the kinds of factors they thought contributed to domestic violence. These factors fell into three broad groupings. The first, and most predominant group, reflected a micro or individualist analysis in which factors relating to individual people were identified as problematic. The second group, which was mostly staff, reported a combination of individual and social contributors. The third group reflected student and staff members who provided a macro analysis in which the sociopolitical context and an understanding of gender relations were central. 
All programmes included participants who conveyed an individualist understanding of relationship violence. These participants often reported a combination of contributors relating to familial learning history and personal "deficits". Annette noted that "family upbringing and parents' modelling' were primary contributors to domestic violence. Likewise, Mal, drew on 'the literature' to suggest that '(male) spouse abusers have a learning history in which relationship violence was observed' and an individual's 'skills deficits such as self esteem, assertiveness, and communication skills' were also contributors. Further, Mal suggested that traditional beliefs about gender roles contributed to domestic violence and included 'approv[ing] of relationship violence'. Similarly, Becs reported that 'learning through modelling and imitation that violence is an acceptable way to express anger' and traditional ideas about the privacy of the family were contributors to domestic violence. Celia, also commented on the effects of 'modelling of violence by parents and peers' and referred to personal variables such 'hopelessness and helplessness, deficits in self esteem, problem solving, impulse control and self-efficacy'. Celia noted that drugs and alcohol contributed to domestic violence as did 'low levels of education'. ${ }^{165}$ Likewise, Stevie reported that domestic violence reflected 'alcohol and drug abuse' as well as a range of personal factors such as 'communication and social skills, lack of intimacy and attachment, difficulty expressing emotion ... and limited coping skills'. They also included 'modelling' and 'psychopathology' as contributors to domestic violence and drew attention to the impact of 'financial stressors'. Suzette commented on personal factors such as a 'lack of communication, low self-esteem and learnt patterns of behaving'. However, they also included attention to a social context in which there is a "low community response to "domestics". While Stevie and Suzette included some mention of social contributors, the bulk of participants in this group provided individualist explanations.

Most staff reported a combination of personal and social factors, though typically with most emphasis on individual learning. For example Leo noted that 'inadequate social skills, modelling and unemployment' were key factors in domestic violence. Glen reported that domestic violence reflected 'male socialisation, poor emphasis on relevant social competencies, especially intimacy and problem solving skills...[and a] general

${ }^{165}$ Reflecting widely held myths about domestic violence. 
failure to educate people for relationships'. Likewise, Laurie suggested that 'the way men and women are raised' combined with 'peer support, stress, the privacy of the family, wider societal support and alcohol' were contributors to domestic violence.

Participants in the third group, representing all programmes, conveyed an understanding of male partner violence in terms of a broad sociopolitical context. They also included references to dominant discourses around masculinity and the normative nature of male violence. Further, participants in this group included a gendered analysis of power and addressed material factors that maintain hierarchical power relations. For instance, Ro reported that domestic violence reflected 'patriarchal attitudes that subtly and overtly support a culture which allows and condones violence' and traditional heteronormative ideas concerning a "belief in the "privacy" of domestic life and the unique privileging of the family unit'. Ro also referred to the impact of 'unemployment, racism and poverty'. Likewise, Bonnie commented on the impact of living in a "patriarchal society where male economic and social values are privileged over women's'. Bonnie also commented that "the construction of male heterosexuality reinforces notions of "natural" male dominance and female submission'. Pam, a student, commented that domestic violence was due to an 'imbalance of power in society' with 'many men growing up believing they are superior to women or that their rights should take precedence' as well as men 'believ[ing] they have the right to control [women]'. In addition, Louie from a different programme, suggested that gender inequalities shaped and perpetuated domestic violence through 'a social and cultural system which designates traditional gender roles' and an unwillingness [by men] to let go of power inherent in these unequal positions. Val thought that "the "macho" ideal of strong men in control of their environment combined with the powerlessness many men feel if unemployed, poor or depressed contributed to domestic violence'. Further, Val noted that 'men's difficulties communicating emotions and asking for help', in conjunction with 'bad attitudes towards women and [men's] ideas of ownership of women' also underpinned domestic violence. Traice, a staff member noted that male partner violence reflected 'subtle' and "deeply seated cultural "views" that men are superior to women and...entitled to various privileges in heterosexual relationships'. They also commented that these "views" were 'the product of, and supported by, structural power inequities between men and women'. 
It was apparent that those with a less comprehensive understanding of gender and power were more likely to individualise their explanations of male partner violence. In contrast, those who exhibited a more comprehensive analysis of gender and conveyed an understanding of power and control models of violence, were more likely to report that male partner violence was due to factors related to the broad sociopolitical context and not to individual learning or "deficits". While not denying the role of individual factors in contributing to male partner violence these cannot be understood as separate or independent from the sociopolitical context.

\section{Difficulties Leaving Violent Relationships}

While participants varied in their ideas about male partner violence most participants demonstrated a comprehensive understanding of difficulties that could prevent women leaving violent men. Indeed participants' comments on this issue rarely reflected ideas relating to individual "deficits" or "psychopathology" as occurred in the context of contributors to male partner violence. Instead, participants drew on an array of factors ranging from discourse, the gendered dynamics of power, social, cultural, economic and material inequalities, societal attitudes and perceptions of women, the sanctity of heterosexual relationships (particularly marriage) to issues concerning women's fears for herself and children. Participant's comments about the difficulties women may experience leaving violent men reflected implicit recognition of the gendered nature of domestic violence.

The above not withstanding, some participants seemed inconsistent in their analysis of male partner violence. While recognising the diverse array of sociopolitical and individual factors that can operate to make it difficult for women to leave violent men,

many participants conveyed an individualist analysis of contributors to domestic violence and were resistant to the idea that domestic violence was primarily male violence against women. Indeed, several participants conceptualised domestic violence as an exchange of behaviour between equally positioned adults. At times there appeared 
to be little recognition of the power differences or disparities that exist between men and women, and the different ways men and women are socially positioned.

\section{Application of Knowledge About Male Violence and Exploitation}

In the course of this research, participants in two different programmes discussed situations they had encountered involving male violence and sexual exploitation by men within their department. Participants discussed the way staff had failed to translate their knowledge about gender and power in dealing with these situations. They also expressed concern and disillusionment at how these situations had been managed by other authorities involved in psychology. Furthermore, participants reported how they had been silenced, marginalised, and labelled "feminazis" despite using official procedures to bring a situation of male violence to the attention of the profession. These participants also reported that their careers had been affected by endeavouring to have this situation addressed within psychology. In the other situation, a participant discussed the damaging consequences of a male staff member's sexual exploitation of women students and the lack of response to this situation by other staff in the department. They also highlighted the way staff seniority and the associated power their position accords provides protection against accountability in relation to professional ethics. These examples raise questions about the way knowledge about male violence is translated into practice and highlight the professional protection that occurs when women do try to have these issues addressed. They also bring to the fore questions relating to criteria for entry to clinical programmes and the registration of psychologists, and the need for routine police checks as mentioned in the introductory chapter. As Brown (1994: 224) comments ethical responsibilities extend to 'colleagues and their personal and political communities...failures to act ethically go beyond the given therapy encounter to spread throughout the social matrix'.

\section{Conclusion}

Most participants agreed that domestic violence - if it was physical - was primarily male violence against women. However, many participants were eager to point out 
incidents where women had used violence against men, and to suggest that male violence was possibly just reported more than women's violence. More significantly, many participants distinguished physical and psychological violence according to gender. This typically involved attributing physical violence to men and psychological violence to women. There appeared to be little understanding of the interrelationship between physical and psychological violence and the gender dynamics that operate to shape and perpetuate male partner violence. Furthermore, most students conveyed an individualist analysis of contributors to domestic violence, often referring to personal factors relating to individual people. While staff were more likely to include a combination of personal and social contributors, few staff or students provided a comprehensive understanding of male partner violence based on an analysis of gender, power and the sociopolitical context. In contrast, most participants seemed to have a sound knowledge of difficulties that can prevent women leaving men who are violent. Some participants highlighted the importance of transferring knowledge about male violence into practice.

Throughout this thesis I have argued that the integration of an analysis of power in clinical psychology training is central to understanding women's lives and the experiences and realities of other marginalised groups, particularly Māori, who continue to live in a context of (while also actively resisting) colonial oppression. The two examples discussed in this Chapters Nine and Ten, the Treaty and male violence, are salient reminders of the ways most clinical programmes marginalise education relating to gender, 'race' and bicultural power relations, as well as other dimensions of power. By continuing to negate the importance of the historical and sociopolitical context, clinical psychology perpetuates a system of knowledge and practices that leave significant components of peoples lives and worldviews unaccounted for. 


\section{Chapter Eleven}

\section{Women and Psychological Health: Barriers to the Inclusion of Gender Education}

This chapter explores student and staff participants' views concerning a feminist analysis of women's sociopolitical position, and their understanding of the relationship between women's position and psychological health. I also report how adequately participants considered their programme addressed the impact of women's gendered sociopolitical position on well-being. I then briefly assess student and staff participant's ratings of the importance of gender education in the training of clinical psychologists. This is followed by participants appraisals of the adequacy of gender education included in their clinical programme. I subsequently present participants' views on the presence of barriers to the inclusion of gender education, and based on their feedback throughout the research, identify a range of factors that may impede the inclusion of gender education in clinical training.

\section{Women's Sociopolitical Position and Psychological Health}

The relationship between women's sociopolitical position and psychological health has been widely documented (Belle and Doucet, 2003; Bostock, 1997; Ussher, 1992, $2000 \mathrm{~b}$ ). Indeed, feminist writers have long addressed the link between women's low social, economic and political status and women's experience of psychological/health difficulties (Kantrowitz and Ballou, 1992; Stoppard,1999, 2000). For instance, feminists have addressed the psychological costs and consequences for women who live with economic hardship or poverty (Belle and Doucet, 2003; Holland, 1992; McGrath et al, 1990; Stoppard, 2000). Indeed, the high correlation between poverty and women parenting alone is well established (James and Saville-Smith, 1994; Parnell and Vanderkloot, 1994; New Zealand Council of Christian Social Services, 2001). The 
cumulative effects of poverty and parenting alone, which are commonly associated with low social status, stigma, high stress and poor nutrition, health care and housing, have a considerable impact on well-being. Janet Bostock (1997) regards the cumulative effects of women's subjugated sociopolitical position as psychologically corrosive. As argued throughout this thesis, an analysis of gendered structural arrangements is central to understanding women's health and well-being.

In the current research, participants were asked several questions about the relationship between women's sociopolitical position and women's psychological health. Collectively, $94 \%$ of students agreed with the following statement:

Some people consider that women's social, economic and political position in this society means women have less power and status than men. For example, women are more likely than men to raise children alone, be poor, to have been sexually abused or violated, to have been subjected to domestic violence and so on. Equally women are less likely than men to hold positions of power or decision-making in political, economic, educational, employment and health related arenas.

Further, the majority of staff also agreed with the above statement. For example, one staff member affirmed the statement and subsequently discussed the strong relationship between women's sociopolitical position (as well as the position of other marginalised groups) and psychological health. Claud drew attention to the impact of gender, ethnicity, class, colonisation, poverty, and abuse on psychological health, but also noted that this perspective ran counter to the dominant paradigm that largely attributes psychological difficulties to the individual:

There is a hugely dominant assumption about people with psychotic disorders or illness as they're currently known, that their situation has little if anything to do with their life circumstances, their socioeconomic class, their gender, ethnicity or levels of trauma they've been through and it's all assumed to be genetically predetermined...my belief is that is inaccurate...one of the strongest relationships...is between class and schizophrenia...the longitudinal studies... show that poverty leads to madness not madness to poverty. But that flies in the face of a very powerful dominant paradigm, economically backed by the drug companies...so their control over the training agencies and doctors prescribing habits and so forth and the media is quite a substantial factor in why we cannot look objectively at for instance the fact that $50 \%$ of...female psychiatric inpatients... have been physically and sexually abused as children, two to three times higher than the rest of the population...I'm quite clear that things like poverty and 
colonisation and oppression in terms of gender roles plays a very powerful role in all mental health area.

However, one staff member strongly disagreed with the statement. While recognising gender inequality, Vic justified their response by referring to the individual success of a minority of women and noted that because some women hold power the statement was invalid:

[A]s a rule can you say that women don't have power...the answer is no. But as a numerical problem, then yes, there is not equality...but it's not the case that women don't hold power. You say they're less likely [as a group] well yes...that's not true of all women... we need to get away from the notion that women are always the down trodden victims...I think there is the danger of that general kind of position....if we're actually going to achieve greater equality then I think the individuals who defy the norm need to be properly validated.

Despite this example, the majority of students and most other staff affirmed the link between sociopolitical position and psychological health, and used various adjectives such as 'enormous', 'huge', 'tremendous', 'heaps' and 'important' to describe this relationship. While most participants recognised the importance of the relationship between women's sociopolitical position and psychological health, there was considerable variability in their understanding and theoretical analysis of this relationship.

Participants who reported that there was a significant bearing between women's sociopolitical position and health typically conveyed a comprehensive analysis of power which was central to their conceptualisation of clinical psychology. For example Claud commented that women's sociopolitical position has 'a very significant bearing' on psychological health and noted that it 'accounts for most or all' of gender differences in prevalence of psychological difficulties and the 'overall use of mental health services'. Likewise, another staff member, Traice, commented that there was a 'considerable bearing' between women's position and psychological health with 'many women struggling in very unfair, inequitable, and oppressive conditions'.

Students who thought there was a strong relationship between women's position and psychological health also conveyed an understanding of the way gendered relations of 
power operate to subjugate women. Some students referred to the male dominant ideology and practice of clinical psychology, which they regarded as a source of oppression. Zoe commented that women's sociopolitical position explained the 'disproportionate number of women suffering various mental illnesses, their continued suffering in treatment developed by men, on men, and [the use of] treatments that are oppressive to women'. Jay drew attention to the relationship between women's position and economic status noting that 'mental health problems are always over-represented in lower socio-economic and disadvantaged groups - groups in which women and children are disproportionately [over] represented'. Lyndsay suggested that women's health was affected by a "male dominated interpretation of what "normality" is' noting that being aggressive was regarded as 'better' and more 'healthy' than being 'submissive'. Likewise, Freddie commented that women's position meant women were more likely than men to be 'labelled as pathological' and gave the example of men's aggressiveness being normalised and minimised as 'assertiveness'.

Other participants, while recognising a relationship between women's sociopolitical position and psychological health regarded women's position as one of many factors affecting women's psychological health. Many of these comments echoed the individualism of dominant theoretical models of clinical psychology. For example Laurine commented that women's position was 'a factor that exacerbate[d] conditions that [were] due to [low] self esteem, helpless[ness] and a perceived lack of power'. Phil noted that women's position was a "risk factor" for psychological difficulties. Several students talked about the relationship between women's position and low self esteem which they regarded as central to the development of psychological difficulties such as depression, anxiety and mood disorders.

While many students and staff acknowledged that women's health was affected by women's sociopolitical position, some participants understanding of power concerning this relationship was fragmented and often involved conceptualising individuals as somehow separate or independent from their social context. For example, several participants commented on women's low self-esteem as if this existed in isolation from women's sociopolitical position. In these examples, being a woman was reduced to a 'risk factor' rather than being conceptualised in terms of the structural inequalities that 
shape women's lives and experiences. Thus, instead of psychological difficulties being structurally determined they were regarded as an individual's response to a set of conditions.

Other participants recognised women's position as having some bearing on well-being but also thought that factors specific to the individual, including biological factors, were a source of psychological difficulties. They expressed views consistent with an individualist and quasi medical conceptualisation of psychological difficulties. Felix, a staff member, commented that women's position 'create[d] the context for an underlying vulnerability to be triggered'. Rae commented on the role 'genetic[s], family history and personality factors' played in psychological health. Thus, while social context was regarded as a partial factor in psychological health, there was a sense in which people who experienced difficulties were understood as autonomous individuals who had "particular vulnerabilities" which were compounded by their sociopolitical context rather than being constituted by it.

A minority of participants reported being unsure of the bearing women's position had on women's psychological health. Laurie, a staff member, compared men and women's psychological health. They commented that "women are still living longer than men...and cope much better with the complexities of life than many men...having worked with a lot of pretty fucked up men I'm not sure how to answer this'. Others thought that women's position in the present day was less problematic than it had been in the past. For example Suzette noted 'it's difficult to say' what bearing women's position has on psychological health, while the "past treatment of women has seriously affected their psychological health...this [was] becoming less so for younger women'. While participants were generally in agreement with the statement reflecting a feminist analysis of psychological health, they were somewhat varied in their appraisals of the adequacy of education relating to the relationship between women's sociopolitical position and psychological health included in clinical training. 
Adequacy of Education About Women's Position and Psychological Health

Table 4: Ratings of Adequacy of Education about Women's Sociopolitical Position and Psychological Health.

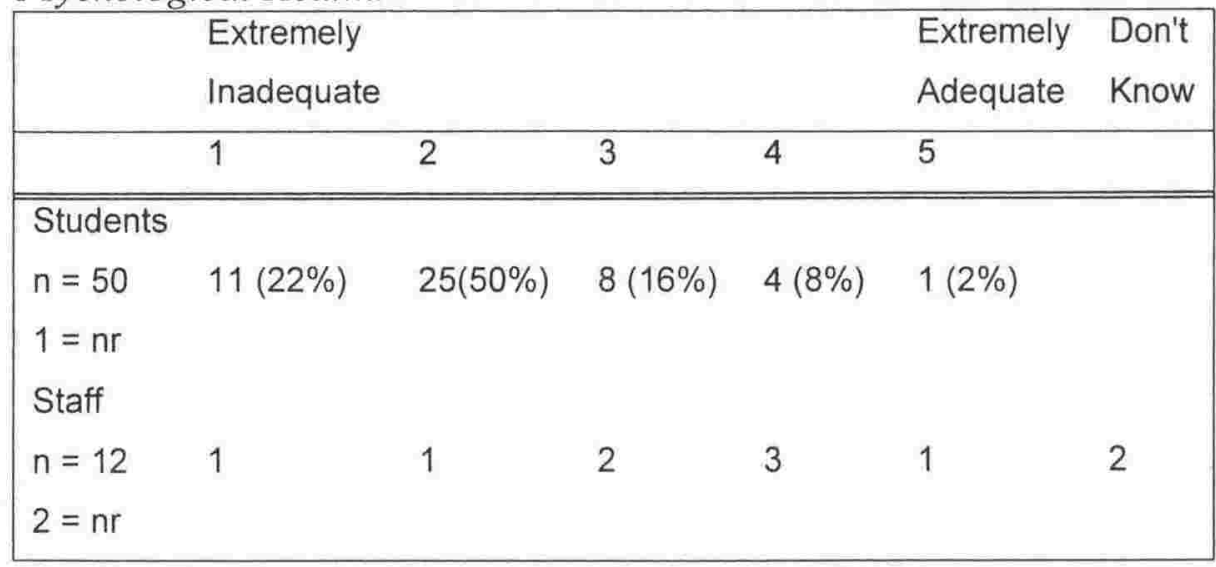

As shown in Table 4 seventy two percent of students reported that their programme was inadequate or extremely inadequate in providing education about the impact of women's sociopolitical position on women's well-being. Table 4 also indicates that staff varied in their reports of adequacy with most rating their programme as middling to adequate in addressing this issue.

Table 5: Student Ratings of Inadequacy of Education about Women's Sociopolitical Position and Psychological Health

\begin{tabular}{|ll|}
\hline Programme & $\begin{array}{l}\text { Inadequacy/ } \\
\text { Extreme } \\
\text { Inadequacy }\end{array}$ \\
\hline B & $75 \%$ \\
C & $66 \%$ \\
D & $62 \%$ \\
E & $90 \%$ \\
F & $84 \%$ \\
\hline $1=n r$ & $60 \%$ \\
\hline
\end{tabular}


Table 5 indicates that most students at all universities rated their programme as inadequate or extremely inadequate in addressing the impact of women's position in society on well-being. With the exception of one student from programme $\mathrm{F}$, no students rated their programme as extremely adequate in addressing the impact of women's social position on well-being.

Table 6: Student Ratings of Inadequacy by Year of Training.

\begin{tabular}{|ll|}
\hline Year & $\begin{array}{l}\text { Inadequacy/ } \\
\text { Extreme } \\
\text { inadequacy }\end{array}$ \\
\hline \hline 1 & $85 \%$ \\
2 & $81 \%$ \\
3 & $55 \%$ \\
\hline
\end{tabular}

As shown in Table 6 students in years one and two of clinical training were more likely than those in the final year to rate their programme as inadequate or extremely inadequate in addressing the impact of women's social position on well-being. This pattern is consistent with responses about the inclusion of gender education elsewhere in this research. As discussed previously, these differences may be attributable (at least in part) to the strong practitioner focus in the final year of training and a move away from university based academic learning. Some students reported that their place of internship provided a broadening of perspective and greater awareness of gender and other social issues. While this may not be the case in all instances, it appeared that exposure to diverse practices and theoretical orientations enhanced students' breadth and depth of learning.

Alternatively, it may be that students in the final year of training become less sensitised to the importance of social context in their endeavour to meet narrowly defined clinical course requirements. Students often reported that the combination of a pressured workload and focus on the final examination during the internship year restricted their 
learning. Equally, students who were particularly socially aware reported feeling considerable stress during their university based learning because of the lack of attention to gender and other power issues. However, once distanced from the academic environment they may have perceived their clinical course more favourably.

Students in the present research expressed a range of concerns about the way clinical programmes addressed the relationship between women's sociopolitical position and well-being. In particular, they drew attention to a prevalent assumption amongst trainers that clinical psychology is concerned with science not values, the latter of which is equated to analyses of power, especially those related to gender. Louie summed up this view, commenting:

[Women's social position is] not seen as fundamental to our learning, it's seen as a topic for interesting discussion, but it smacks... of a political ideology which may be a euphemism for feminism...in the clinical psychology view, and getting ones hands in a political dog fight isn't advisable...I think there's a strong view that [sigh] values and science don't mix.

This view is echoed throughout feminist and other critical analyses of psychology which refute the idea that science is apolitical (Marecek, 2001; Ussher, 1992, 2000b; Prilleltensky and Nelson, 2002). Indeed, these critics actively locate values, politics and power as integral to an understanding of human life and experience. It seems an odd paradox that contemporary theorising about male violence (as discussed in Chapter Ten) which captures the very essence of a gendered analysis of power, and is implicit to power and control models of violence, has now filtered into clinical psychology where once it was dismissed as "non-scientific" and the "political views" of "extremist feminists".

\section{Summary: Women's Sociopolitical Position}

Despite general agreement amongst participants that women's health and sociopolitical position are related there were wide variations in their understanding of this relationship. Many participants gave examples reflecting a limited and fragmented conceptualisation of the link between health and sociopolitical context, and rather than 
focusing on broader issues around power, frequently offered individualising and pathologising explanations. Further, for some participants there seemed to be a tension between a structural analysis of power and individualising of women. These findings are consistent with those elsewhere in this research that highlight variations in participants' conceptualisation of gender and power in relation to clinical psychology. This variation may in part be explained by the adequacy with which programme educators convey an understanding of the relationship between women's health and sociopolitical position and incorporate other issues of power in their teaching of clinical psychology.

While responses from staff and students about the relationship between women's sociopolitical position and health were generally affirmative, there was considerable variation amongst both participant groups in their understanding of an analysis of power in relation to this issue. Further, although the curriculum content in most programmes now includes for example a gendered analysis of power in relation to male violence, there remain significant disparities between what the majority of staff say about the relationship between women's sociopolitical position and psychological health, and what students say is actually included in most clinical programmes. These disparities were highlighted by students throughout this research in their examples of staff attitudes and/or lack of knowledge, and the limited inclusion of an analysis of gender in most clinical programmes. It seems that clinical training has some way to go in more comprehensively and consistently integrating an analysis of power throughout the curriculum and in adequately conveying an understanding of the integral connection between women's sociopolitical position and psychological health. In the next section I address the participants' appraisals of the importance of education about gender.

\section{Appraisals of the Importance of Education about Gender}

Seventy four percent of students rated education about gender as important or extremely important in the training of clinical psychologists. Indeed, most students in all years of training rated education about gender as important or extremely important. 
Staff ratings of the importance of education about gender were fairly evenly spread between mid-range and extremely important, with 58\% rating gender education as important or extremely important. No staff participants rated gender education as unimportant or extremely unimportant.

While the majority of student and staff participants regarded education about gender as important in the training of clinical psychologists, this was not reflected in the priority staff placed on gender education in clinical training. Indeed, students reports about the lack of priority placed on gender education, and the lack of priority accorded to topics central to understanding women's lives, are indicative of the way gender education was not prioritised in most clinical programmes. Indeed, most programmes addressed gender education in only a cursory manner, with little analysis or systematic integration. To provide a quantitative evaluation of student and staff participants appraisals of the adequacy of education about gender participants were asked to rate their programme on this indicator.

In this section, the participants' appraisals of the importance of education about gender have been addressed. Most consider that the inclusion of education about gender is important. In the next section I discuss participants' ratings of the adequacy of the inclusion of gender education in their clinical programmes.

\section{The Adequacy of Education about Gender}

In this section I address participants ratings and experiences of the inclusion gender education in clinical psychology training programmes. Table 7 presents staff ratings of the adequacy of education about gender in their clinical psychology training programmes. 
Table 7: Staff and Student Ratings of Adequacy of Gender Education

\begin{tabular}{|c|c|c|c|c|c|}
\hline & $\begin{array}{l}\text { Extremely } \\
\text { Inadequate }\end{array}$ & & & & $\begin{array}{l}\text { Extremely } \\
\text { Adequate }\end{array}$ \\
\hline & 1 & 2 & 3 & 4 & 5 \\
\hline $\begin{array}{l}\text { Students } \\
n=50 \\
1=n r\end{array}$ & $9(18 \%)$ & $23(46 \%)$ & $8(16 \%)$ & $6(12 \%)$ & $2(4 \%)$ \\
\hline $\begin{array}{l}\text { Staff } \\
n=12 \\
2=n r\end{array}$ & 0 & 4 & 4 & 2 & 0 \\
\hline
\end{tabular}

As shown, staff ratings of programme adequacy were centrally clustered with no ratings of extremely adequate or inadequate.

In contrast, Table 8 indicates that overall, the majority $(66 \%)$ of students rated their clinical psychology training programme as extremely inadequate or inadequate.

Table 8: Students Rating of Inadequacy of Gender Content by Programme

\begin{tabular}{|ll|}
\hline Programme & $\begin{array}{l}\text { Inadequacy/ } \\
\text { Extreme } \\
\text { Inadequacy }\end{array}$ \\
\hline \hline B & $63 \%$ \\
C & $67 \%$ \\
D & $62 \%$ \\
E & $90 \%$ \\
F & $57 \%$ \\
\hline $1=\mathrm{nr}$ & \\
\hline
\end{tabular}


While there was only marginal variation between universities in students' ratings of programme adequacy, overall, a high proportion of students from University D ( $90 \%)$ rated their programmes as inadequate or extremely inadequate in providing education about gender.

Students' ratings of the adequacy of gender content also varied according to their year of training. Ratings given by students in their first and second year of clinical training tended to be skewed towards the 'extremely inadequate' or 'inadequate' end of the spectrum. Those in the final year of training gave ratings that were more evenly spread across all five ratings.

It appears likely that differences in ratings between programmes and years of training reflect a combination of factors. First, differences in ratings of adequacy between programmes $^{166}$ could lead to the simplistic interpretation that some address gender issues more comprehensively than others. When ratings of adequacy are examined in the context of responses throughout the research it seems that gender content included in all programmes, except University F, was similarly limited. In contrast, University F, which was rated like the majority of other programmes in terms of inadequacy, was likely to be different from all other programmes in terms of the gender education it provided. Feedback throughout this research suggests that there was more planning and systematic integration of gender and power related content within the University $\mathrm{F}$ programme than in any other programme. So, differences and similarities in ratings between programmes need to be interpreted in the context of the research in its entirety. Further, the small number of student participants from each university means that slight differences in actual numbers of participants give the appearance of inflated differences when converted to percentages. Thus, apparent differences between programmes need to be interpreted cautiously.

Second, students' ratings appeared to be influenced by their awareness and analysis of gender. For example while one programme may have included more gender content or

\footnotetext{
${ }^{166}$ Such as the apparently high rating for University D.
} 
more in-depth analyses of gender than another, more students in this programme may have been better informed and critically aware than in other programmes, leading to lower ratings of adequacy. Alternatively, in programmes where the inclusion of gender was minimal students' analysis of gender may have been less comprehensive. Because of a lack of knowledge, students may have given a higher rating of adequacy than they might if they were well informed. Hence programmes that were quite disparate in gender content and comprehensiveness may have been rated similarly, or vice versa.

Third, differences in rating between first, second and third year students may reflect differences in curriculum content and modes of teaching between earlier and later years of training. For example in year one, student seminar presentations are reported to be a primary mode of education. Consequently, the amount of time spent on education about gender reflected, at least in part, students' selection of seminar topics. It appears that unless topics were perceived as relevant to gender (e.g. 'depression' and 'eating disorders') then analyses of gender were not generally included. Furthermore, some participants commented that a student's choice of seminar topics, combined with their awareness of education about gender, influenced the inclusion of gender content in seminars. For example Sina commented that while the inclusion of gender content depended on the 'priorities of the tutor' it also depended on 'the interpretation and research of the subject matter by students'. Consequently, if students were not particularly well informed about gender issues, and staff were providing little input, guidance or criteria concerning the inclusion of gender, then little gender content was likely to be included.

In year three, students were undertaking internships or long-term placements where they had exposure to a range of colleagues and placement supervisors as a source of learning. They also reported being focused on (passing) the final examination and of being 'exhausted' or 'burnt-out' from clinical training. Some students reported that as they progressed through training they became desensitised to issues such as gender, which they might have been critical of in previous years of training. It is also likely that by year three students have had some exposure to gender content which may have influenced their ratings of programme adequacy. This combination of circumstances may account for the slightly higher rating of adequacy by final year students compared 
with those in their earlier years of training. Further, students from all years of training commented that the research had had highlighted 'the gaps' in their training and had rekindled awareness, interest and recognition of the importance of gender education.

Students elaborated on their concerns about the inadequacy of gender content in clinical training and repeatedly commented that such education was 'near invisible'. Pat commented: 'overall I think very little time is allocated to gender issues which is quite scary considering how much gender is likely to impact on the clients we will be seeing'. Furthermore, they noted that 'a token lecture on gender and power issues is definitely not enough'. Suzette reported that 'very little specific attention has been placed on women's issues'. They noted that there was acknowledgement of 'gender equal language and the odd comment made if stereotypes are used' but that this was 'virtually all'. Similarly, Kas commented 'we have not spent any time discussing gender issues specifically and only very minimal time (again $<5 \%$ ) is gender mentioned at all'. When included it was usually just 'an aside'. Kas gave the example of course content concerning 'sexual dysfunction' where students were told "by the way this doesn't apply to women". Val stated that while gender issues 'are really important in psychology' they were 'almost completely neglected', and Mia concluded that 'as with culture, gender should inform every aspect of the course'.

These students' views are consistent with comments made by some staff. For example one staff member commented that the importance of gender is often underrated by clinical psychologists and/or given lip service'. In addition, they suggested that their colleagues 'might think they have a feminist perspective' and would 'think they really prioritise gender issues'. However, this was not necessarily the case.

In contrast, other staff considered that the inclusion of gender education was middling to adequate, or better than adequate. Examination of staff comments in the questionnaires, combined with discussion during interviews, suggests a less than consistent position in relation to appraisals of the inclusion of gender education. While staff may judge their programme as middling to adequate, some then proceeded to discuss barriers to the inclusion of gender education, including for instance a lack of resources and time. Staff who rated their programme as less than adequate mentioned similar barriers. Others 
gave explanations, which, while recognising that their programme could be better, were unable to see how more content could be fitted into an already overburdened schedule. For example Rae commented that 'all clinical programmes can improve' and noted that 'there are topics in our programme which deserve more time'. However, they also said that the workload was already excessive and commented 'I do not know how we can put more into a 3 year programme'. Glen, justified their middling rating of adequacy on the grounds that 'the major focus' of the programme was on 'psychopathology rather than non-disorders, therefore some areas of gender concern....are not directly covered'. This staff member also noted that gender issues 'are dealt with where relevant' suggesting that an analysis of gender was not generally relevant to clinical psychology.

\section{Summary: Adequacy of Education about Gender}

A significant proportion of student participants rated their clinical programme as inadequate or extremely inadequate in providing education relating to gender. While most staff members thought their programme was middling to adequate, some thought there was room for improvement and four reported that their programme was inadequate.

While there was little variation between programmes in students' reports of inadequacy, University D was rated most poorly on this indicator. However, in the context of participant feedback throughout all sections of the research, it appears likely that this programme was similar to four of the others in providing education about gender. In contrast, the programme at University $\mathrm{F}$, which was rated similarly to the other programmes in terms of inadequacy, was likely to be different. Based on participants' feedback throughout the research this programme appeared to offer a more consistent and comprehensive education about gender and other issues of power, although, as some participants commented, there was still room for improvement. To provide some indication of factors that might impede the inclusion of gender education in clinical programmes participants were asked to identify possible barriers. 


\section{Barriers to the Inclusion of Gender Education}

Feminists have discussed a range of barriers to the inclusion of feminist knowledges and gender education in psychology (Burman, 1996a, 1996b; Hare-Mustin and Marecek, 1997; Marecek, 2001; Nicolson, 1992; Ussher, 1992, 2000b; Wilkinson, 1996). More specifically, feminists have identified barriers to the inclusion of this content in clinical psychology training and have drawn attention to the way dominant discourses and practices in clinical psychology inhibit the integration of knowledge based on women's experiences, material realities and worldviews (Bekker, 1991; Hare-Mustin and Marecek, 1997; Nicolson, 1992; Ussher, 1992; Williams and Watson, 1991b, 1991c). Participants in my research were asked about the presence of barriers to the inclusion of gender education in their clinical psychology training programmes and provided a range of examples to illustrate the kinds of barriers they thought existed.

Fifty six percent of students thought there were barriers to the inclusion of gender education in their Clinical Psychology Training Programme. A further eighteen percent reported not knowing if there were barriers. Of the twenty six percent who reported that there were no barriers, several subsequently qualified their response or indicated elsewhere in the research that there were indeed barriers. The majority of staff reported the existence of barriers to the inclusion of education about gender.

Students from all universities and each year of training were represented in the group who reported the presence of barriers. Students in years two and three were slightly more likely to report barriers to education about gender than those in year one. As shown in Table 9 there was some variation between universities. 
Table 9: Student Reports of the Presence of Barriers

\begin{tabular}{|ll|}
\hline University & Yes Response \\
\hline \hline A & $50 \%$ \\
B & $50 \%$ \\
D & $50 \%$ \\
E & $50 \%$ \\
F & $71 \%$ \\
\hline
\end{tabular}

At face value this variability could suggest differences between programmes in the inclusion of education about gender. However, participants' feedback in relation to other aspects of the research suggests that this is not likely to be the case. Indeed, variations between universities appeared to reflect differences in students' awareness and understanding of gender and power rather than the quantity or quality of education about gender. As indicated elsewhere, findings from this research suggest that University $\mathrm{F}$ incorporated more substantial gender education than did any other programme. Further, most students in this programme appeared to be aware of and well informed about issues relating to gender. However, students in this programme were also amongst those most likely to report the presence of barriers suggesting that those most knowledgeable about gender were also most attune to the substance and quality of gender education included in their training.

Participants reported a range of barriers to the inclusion of gender education. Those most commonly reported by students dealt with issues relating to staff. Indeed, students frequently reported that staff attitudes and knowledge about gender were major impediments to the inclusion of gender education. Students also reported that this factor was compounded by the male institutional dominance of clinical psychology and the broader discipline. Louie reported that a prominent barrier was 'resistance from teaching staff'. Likewise, Lisa noted that 'people involved in the organisation and 
running of our course would think [gender education was] irrelevant or not important enough to warrant its formal inclusion'. Viv also remarked that the inclusion of gender education was 'always to some extent dependent on the education and political viewpoint of the lecturer'. Further, Val discussed barriers in terms of the interplay between staff attitudes, such as a 'lack of awareness of the relevance of these issues as well as conservative attitudes and lack of knowledge or interest' and a 'predominance of males' in the psychology department. More specifically, Becs commented: the 'course director is male, in a privileged position and is unlikely to recognise these issues as important'. Becs also reported that 'he controls the entire content of the Diploma courses and is unlikely to want to delegate any control over this to anyone else'. Jessie commented that the only real barriers are 'people's ignorance and not paying attention to what needs to be talked about, what's important and prioritising that'. Indeed, feminist writers have also drawn attention to barriers in terms of the interplay between negative staff attitudes, a lack of staff interest and knowledge and psychology's male dominant institutional structure (Bekker, 1991; Nicolson, 1992; Ussher, 1992; Williams and Watson, 1991b).

Libby, a feminist clinical psychologist (FCP), discussed barriers in terms of staff awareness and individual interests combined with an academic structure in which it was difficult to effect change. She commented that there were 'varying degrees of consciousness [amongst staff] and 'vested interests' which universities protected. She noted that universities were 'not accountable structures' and had 'hugely tradition laden, arcane buddy systems...that are very hard to do anything about'. Libby likened the university structure to that of a church, noting that it "is very effective at resisting change [and could] absorb huge amounts of protest and input' without changing. Libby also talked about the power individual staff have in deciding on course content and noted that with some staff the lack of inclusion of gender education reflected a general inertia, whereas with others there was deliberate resistance. Staff resistance to the inclusion of gender education in clinical psychology training has been reported by other feminist psychologists (Bekker, 1991; Williams and Watson, 1991b).

Two staff participants also indicated that the attitudes or knowledge of academic staff could be a barrier to the inclusion of education relating to gender. One staff member 
commented that while priorities and time were the most obvious barriers, staff attitudes were important in determining course priorities. Another staff member commented: 'I suspect at least one of my colleagues would be strongly opposed to using the G [gender] word at all, I'm also alarmingly middle of the road at work and have little interest in teaching about gender per se.' They commented that they left teaching about gender to another colleague who taught postgraduate courses but was not involved with the clinical programme. Both participants noted that there was resistance amongst some staff to the idea of gender education.

Some students discussed barriers in terms of the combination of a lack of women clinical staff who possessed feminist theoretical knowledge and an academic structure in which men dominated positions of seniority. Col commented that 'there aren't enough female lecturers in the department and at present the only female staff member in the clinical programme [was a] tutor'. They said: 'most of the [education] we've had in the past on feminist perspectives [or aspects] of psychology have been presented by women'. While Col acknowledged that being a woman did not mean having a feminist perspective or being sensitised to gender issues, it would be more likely. Kas remarked that although 'a few individual staff made an effort to be considerate of women's issues, overall [the department was] very male dominated'. Similarly, Loren talked about 'lecturers' interest' as a barrier and commented that 'lecturers went into areas they were interested in and that is what they focused on and spent time talking about'. Loren commented that this was 'not a good enough reason' to exclude gender education and that staff needed 'to decide more objectively' about curriculum priorities. Claud, a staff member, discussed the 'lack of consistency in the programmes' and also commented that "what gets taught is...too influenced by speciality knowledge and interests of individual people'. Claud suggested that what was missing in this country was 'a standardised accreditation system which spells out - "this is what you need to know to become a professional clinical psychologist" "and noted that it was "a little bit arbitrary at the moment'. Indeed, feminists have drawn attention to the importance of including gender and diversity as a clearly defined and official requirement of clinical psychology training and integral to training guidelines, accreditation or other registration criteria (Marecek, 2001; Williams and Watson, 1991b). 
Students also reported that lack of time was a barrier to the inclusion of education about gender. Indeed, time was the most common barrier reported by staff. While lack of 'time' and an intense workload impact on what can be included in clinical psychology training, the availability of time seems to be compounded by the prioritisation of course content. For instance Loren, a student, noted that a combination of 'time, interest of lecturers and no female teaching staff' were barriers to the inclusion of education about gender. Likewise, Sina reported that time could be a barrier because there was so much course content to cover, but they also noted that the 'priorities of the tutor' were a barrier. These findings are consistent with previous reports of the inclusion of gender education in clinical psychology training in Britain and the Netherlands and indicate that the interests and priorities of clinical staff have the most significant bearing on decisions about curriculum content (Bekker, 1991; Williams and Watson, 1991b).

Petra, a FCP with experience teaching clinical psychology, indicated that barriers to the inclusion of feminist content were complicated, but basically reflected a combination of not enough time, and the inadequate staffing and resourcing of clinical programmes. She reported that although there were 'about three new lectureships' these positions had yet to be filled. Further, the historical shortage of staff had 'really stretched' those currently teaching making it 'too hard to have a lot of planning time, thinking time, reading time' and 'just the things that oil...relationships'. She noted that recent budget cuts made it increasingly difficult to employ staff to teach specific content such as gender education. However, Petra commented that feminist content needed to be 'attend[ed] to in a more explicit way', it required a good body of literature to resource students, and involved 'mentoring staff, having enough time to plan...the meta level planning [related to] longer term objectives...philosophies of work and how we actually work together'.

Dale, a staff member also thought that time was a barrier, noting:

there was now so much to cover, there's just so many topics and I think that the response has been an incrementalist response, so we just keep adding material and adding material and students I suspect are now...they're working, you know sixty to eighty hours a week.. 
Glen also commented that 'time constraints are a phenomenally important issue' and noted that 'students are grossly overworked in the three years' of training. They mentioned that the course needed to be extended to between four and five years although they recognised that few students could afford to pay for this. Claud also noted that there was too much to cover in available class time and Traice suggested that a combination of 'priorities and time constraints would be the most important' barriers. While Rae thought time constraints and financial limitations were a barrier they also commented 'our priority is the clinical training which must come first'. Thus, although participants often reported time as a barrier to the inclusion of education about gender, their responses in other parts of the research suggests that other factors which impact on time may be more critical barriers. For instance, participants' feedback relating to the prioritisation of course content, together with staff ratings of the importance of gender education and decisions governing clinical programme prerequisite courses suggests that these factors may be more significant barriers to the inclusion of education about gender. As Suzette, a student commented, 'if [gender] was a high priority it would be happening... and it isn't happening'. They compared the inclusion of gender education to that of bicultural education and noted that the latter 'is seen to have a higher priority.... and has become an integral part of the programme', however 'the gender stuff hasn't'. Likewise, Petra commented on staff priorities and the importance of having support for the inclusion of feminist education. She said that 'a lot of things drop off the bottom... because they may not be first on everyone's list of priorities...there's nobody carrying the banner for it...for a feminist approach to work, to be actively supported, you need more than one person very actively talking about it'. Indeed, feminist writers have emphasised the importance of a united approach to gender education and the need for feminist psychologists to maintain political pressure as an 'essential precondition for effecting long-term change in training' (Bekker, 1991: 100).

Some participants reported that a lack of resources and/or funding was a barrier to the inclusion of education about gender. Staff thought this was a key barrier. However, Bekker (1991) has noted that even when there is adequate resourcing and funding for sexual inequality education, most institutes still did not integrate this content into the core curricula nor have it as a mandatory part of training. In my research, staff who did think gender was important also commented that a lack of staff who have adequate 
knowledge of gender issues and/or a lack of funding for guest lecturers was a barrier. There appeared to be little interdisciplinary exchange of specialist knowledge, or the utilisation of staff from other disciplines who could provide gender education. Kit commented that if the lecturers were unable to teach difficult topics like gender and ethnicity... rape or sexual abuse, they should have been able to get people in to each of those things'. Viv reported that there was little active commitment to the inclusion of gender education and commented that the programme needed:

people coming from another department who really know about the stuff, who can put together a really quite coherent piece of work to explain a whole lot of aspects that perhaps we would never have thought of or that the lecturer in charge couldn't possibly have found for themselves... why not invite somebody from Women's Refuge... why don't we hear it from the people who're really out there and in the front of it.

Some participants indicated that gender was not politicised in clinical programmes or the wider academic or professional environment. In this context, Dale compared awareness about gender issues with that of the Treaty and bicultural issues:

I think we're [staff] all aware that there's strong institutional and collective sort of societal pressure specifically about biculturalism, there isn't any longer I think quite the same perception about pressure to incorporate gender issues...it's not as politicised.

As discussed in Chapters Nine and Ten, students also commented that while the Treaty and bicultural perspectives were increasingly validated within clinical training and the institutional framework of psychology, feminist knowledge remained marginalised and was not accorded legitimacy. In conjunction with a wider feminist backlash, the inclusion of gender education in clinical psychology training therefore remained minimal. Thus, the lack of politicisation and institutional validation of gender issues was perceived as a significant barrier to the inclusion of this knowledge in clinical training.

Some students reported that the philosophical orientation of psychology and the strictly clinical focus of training were a barrier to the inclusion of gender education. These issues have been widely addressed by feminist psychologists who have highlighted the way clinical psychology's positivist foundations and individualist, decontextualised 
theoretical orientation preclude recognition of women's devalued sociopolitical status and its relationship to psychological health difficulties (Adcock and Newbigging, 1990; Ussher, 1992, 2000b; Hare-Mustin and Marecek, 1997). In my research, Louie discussed 'the dominance of an ethnocentric psychological philosophy [which was] largely imported from America'. They noted that there was a 'corresponding absence of 'indigenous' psychologies'. Further, Louie commented that there was a 'slowness within clinical psychology to recognise the need for a more systemic analysis of mental health issues' and that focusing on the 'micro level' did 'little to change oppressive social systems'. Likewise, Jamie remarked 'that psychology as a discipline [was] slow to recognise [gender] issues'. Furthermore, Kit commented that the very 'clinical' perspective of lecturers and the 'medical model' approach meant that 'gender and ethnic issues [we]re the two most obvious examples of content that was neglected in clinical training'. Further, Lu commented that the term clinical psychology had connotations of being 'sterile, making orderly, describing something in factual terms [and the] removal of subjectivity'. Adcock and Newbigging (1990: 184) made similar observations of clinical psychology noting that it fits within a 'health/illness framework' rather than a contextual, social or systemic one.

Students also reported that a reliance on student seminars as a forum for classroom education hindered the inclusion of gender education. Sina commented that unless students' were aware of or interested in issues related to gender this content was often not included because it depended on 'students interpretation and research of the subject matter'. Further, it seemed that clinical staff did not generally give direction or set requirements concerning the inclusion of a gender analysis in student seminars, literature reviews or other course work.

Staff in most programmes indicated that students were given the opportunity to have some involvement in decisions concerning course content and were offered course evaluations as a forum to provided feedback on their training. However, students expressed a general feeling that decisions about programme content were fait accompli and commented that they had achieved little change as a result of feedback given to staff. Zoe noted that despite 'challenges to the programme by each year of students', there was the same 'stock answer' from staff about why the programme could not 
include more gender content. These included 'the same old chestnuts [including] limited time, staffing and funding'. Similarly, Kas spoke about staff inaction in response to something like institutional sexism or sexist behaviour, noting that staff would 'be quite upset to hear [about] it, but by the same token...it wouldn't make them do anything about it'.

While staff reported that they responded positively to students' requests for the inclusion of gender education, students who did raise issues about gender reported feeling silenced stigmatised, or considered problematic by some staff. Lisa commented that while staff in their programme did not say anything 'overt', 'it felt like a silent kind of..."oh here she goes again". Lisa also talked about the responsibility placed on individual students, noting 'you just get into a place where it becomes your job, [you're] the person who raises these things' and 'it's tiring me out'. Lisa commented that she was regarded as a "difficult" student because she raised these issues and noted that parts of the course were quite 'unsafe'. Lisa discussed how she would have liked to use her real name in this research but noted that staff would have a problem with what she was saying. Lisa commented that because staff 'are in such a powerful position it just isn't worth it'. Rosie, an FCP with clinical teaching experience, also discussed the 'antifeminist sort of stuff that goes on' and the associated assumption that 'if you define someone as a feminist that you're going to be overtaken by a bunch of lesbian butches or something'. She said that these negative attitudes hindered the inclusion of feminist knowledges and were still 'really common' in psychology. Worell (2000) echoes this view, noting that where the term "feminism" is used to define content or processes in psychology there remains considerable resistance within academic psychology and the wider profession. Further, Williams and Watson (1991b: 81) also reported that students thought it was 'illegitimate and risky' to discuss gender issues in the context of clinical psychology training in Britain.

Other students also talked about the stress and consequences associated with taking responsibility for raising issues about gender and other issues of power. Mia reported that despite repeatedly raising issues within the clinical programme this did not 'shift the perspective or overall focus of the course'. Furthermore, Mia commented that there were risks in continually being 'the person' raising issues and that it could leave 
proactive students in 'a very exposed position'. Likewise, one Māori student discussed the way they had constantly challenged issues within the clinical programme, and although staff recognised the need for this, the student reported that 'it was just a grind...I'd get sick of it and I would need support...[from] people with similar attitudes to me'. Sian Nathan (1999: 80) has also discussed the role and reliance on Māori students within clinical psychology programmes and argues that this places Māori students in 'a culturally unsafe position'. Likewise, feminist writers have noted the difficulties and risks feminist students take when raising gender issues within the context of clinical training (Williams and Watson, 1991b). Furthermore, Laura Brown $(1995,147)$ has discussed issues relating to the safety of students from non-dominant race and class groups in clinical training in the USA, and notes that this position is exacerbated for trainees who also advocate feminist knowledges.

Some participants regarded the epistemological and theoretical orientation of psychology, and attitudes of staff in the broader psychology department, as barriers to the inclusion of gender education. Terri, a staff member, commented that there was a backlash or 'strong reaction against' feminist ideas within the department. Terri thought this was largely due to the 'individualist culture' of the department. Further, Kit discussed the way people within psychology did not tend to talk to staff in different departments so 'different views are not shared in a way that they could be'. Kit remarked that this 'encourages rigidity'. Nathan (1999) has also addressed issues concerning the dominance of an individualist philosophical position in the broader structure of psychology and the implications this has for the inclusion of tikanga Māori and a bicultural approach to clinical training. Similar parallels can be drawn in relation to the inclusion of gender education within psychology and the role of Heads of department and other psychology staff in supporting or promoting this.

\section{Summary: Barriers to the Inclusion of Education About Gender}

Barriers to the inclusion of feminist knowledge and gender education appear to be multifaceted. Barriers reported in this section, in conjunction with those raised throughout the research suggest that the most significant barriers relate to staff attitudes, 
knowledge and interest. These barriers are compounded by the philosophical and theoretical orientation of clinical psychology, the narrow "clinical" focus of programmes, and the individualism and male dominance of the wider discipline. In turn, these factors impact on the availability, recruitment and support of feminist staff and students, and the validation of feminist knowledges within psychology. The theoretical orientation of clinical psychology combined with staff attitudes and knowledge also influences decisions about the prioritisation of course content and the selection of compulsory or prerequisite courses. Similarly, funding and resourcing of programmes impacts on decisions concerning priorities. In a circular fashion, the prioritisation of content is also influenced by the availability of time, the latter of which is used to justify the lack of inclusion of gender education. Moreover, the way clinical psychology is taught means that there is an over-reliance on students as gender educators. Students reported that this approach to training was problematic and that staff needed to take responsibility for integrating gender content throughout clinical training. Further, despite staff reports of the importance of education about gender, the value staff placed on gender education was not sufficient to warrant its prioritisation in clinical psychology training. Indeed, other research about clinical psychology training suggests that clinical staff exert considerable control over curriculum content (Nathan, 1999; Paterson, 1993) and the inclusion of education about gender is primarily dependent on lecturer knowledge, interest and commitment (Williams and Watson, 1991b; Bekker, 1991).

\section{Conclusion}

This chapter brings to a close specific attention to an analysis of the nature and scope of gender education included in clinical psychology training programmes and contributes to an overall picture of the way clinical programmes incorporate an analysis of gender and other relations of power in the training of clinical students. Most participants considered the inclusion of gender education as important for the training of clinical psychologists. However, most students considered that inclusion of content concerning the relationship between women's sociopolitical position and psychological health, and the more general inclusion of gender education was inadequate. However, most staff 
considered their programmes adequate in this respect. Indeed, it appeared that staff thought they were including more content of this nature than students reported was being included. While Chapters Seven to Eleven have focused on specific areas of curriculum content included in clinical training, the final chapter explores the theoretical orientation of clinical programmes. In particular, Chapter Twelve draws attention to the dominance of CBT, the associated lack of analyses of power and sociopolitical context in the training of clinical psychologists, and consequent gaps between clinical training and the diversities and complexities of people's lives. 


\section{Chapter Twelve}

\section{The Theoretical Orientation of Clinical Psychology Training}

A cognitive-behaviour theoretical model located within a scientist-practitioner framework is the blueprint for clinical psychology training in Aotearoa New Zealand. The New Zealand Psychological Society (NZPsS), psychology's principal professional organisation, implicitly endorses CBT which is promoted as the 'gold standard' of 'evidence-based' practice at the present time. The utilisation of CBT and a scientistpractitioner approach to clinical training is also prevalent in other countries (Baydala, 2001; Larner, 2001). While recognising larger debates about the scientist-practitioner model discussed in Chapter One, and the significance and ramifications of this model for the theoretical basis of clinical training, I have not focused on this in my research. Instead, I have looked more specifically at the theoretical approach taken in clinical training as an integral part of the conceptual framework programmes endorse and the way clinical psychology conveys an understanding of women's lives, gender, and other relations of power.

This chapter explores a range of issues relating to the theoretical orientation of clinical psychology training programmes in this country. First, I report student and staff participants' accounts of the theoretical orientation of their clinical programme. I subsequently explore rationales provided for the adoption of a cognitive-behavioural model of training as evidenced in most programmes. Student, staff and feminist clinical psychologists' criticisms of the dominance of CBT in clinical training are then discussed in conjunction with an exploration of the adequacy of this model for conceptualising and understanding the life experiences and material realities of women and diverse groups of people. An eclectic approach to clinical training is then briefly described based on reports from participants in one clinical programme. Feminist clinical psychologists endorsement of eclectic approaches are then discussed. I conclude the chapter by examining the inclusion of feminist perspectives in clinical programmes 
and highlighting the association between the dominance of a positivist-science, CBT framework and the marginalisation of feminist knowledges in clinical training.

\section{The Dominance of Cognitive-Behaviour Therapy}

Most academic staff who participated in this research endorsed a cognitive-behavioural theoretical model as the primary framework for clinical psychology training. Some staff who adopted this position also included some theoretical content drawn from feminist theory and therapy, family therapy, systems theory, and developmental and interpersonal approaches. However, these approaches were secondary, and additional to, the dominant CBT model. Three of these staff participants also reported that the theoretical position they adopted was based on a scientist-practitioner model of training. ${ }^{167}$ One further staff member reported endorsing an operant social learning model and included cognitive-behavioural perspectives as an adjunct to this.

Two out of the 11 staff participants who answered this question reported teaching clinical psychology from an eclectic theoretical position. While the range of theoretical perspectives advocated by these two lecturers varied, collectively they described these as feminist, social constructionist, poststructuralist, political, psychodynamic and/or psychoanalytic.

When asked specifically about the inclusion of feminist theoretical perspectives, five clinical staff reported that they advocated feminist perspectives in their teaching of clinical psychology. Upon closer scrutiny however, only three staff members included feminism as a theoretical stance from which they taught clinical psychology. The other two staff members noted that they did not actually advocate feminist perspectives, but rather 'pointed' them out and did not include them 'loud[ly] enough'. Student reports of the inclusion of feminist theoretical perspectives were consistent with staff accounts.

\footnotetext{
${ }^{167}$ In constructing questions concerning the theoretical basis of clinical training I had not anticipated the scientist-practitioner model being identified as a 'theoretical' approach per se. Rather, I had thought of it more as a framework for clinical training within which a range of theoretical approaches could be located. However, it was clear from discussion with staff and students that the scientist-practitioner model underpinned the theoretical approach of most programmes.
} 
Collectively, these findings indicate that few staff actively engaged feminist ideas or approaches and that CBT remains the dominant model of clinical psychology training.

\section{Rationale for the Dominance of Cognitive Behaviour Therapy}

Staff and student participants identified a number of reasons why they thought CBT was the preferred approach to clinical psychology training. In particular, participants thought CBT fitted a scientist model, was amenable to empirical research and measurement, and was relatively easy to teach and learn. Leo, a staff member, described two reasons for endorsing CBT. The first, 'a cynical one' was that CBT was 'easy to teach'. The second reason was that 'it works'. Leo commented that there was now 'a lot of research on cognitive behavioural [approaches] which suggests it actually works for a wide range of conditions that clinical psychologists are likely to see'. Further, Leo remarked that 'it has a good empirical base and there is evidence for it'.

Students from most programmes also indicated that CBT was the dominant theoretical model in their clinical psychology training. Some students conveyed an uncritical acceptance of CBT while also asserting its scientific legitimacy and 'proven' research status. Viv commented that 'it works' and when asked how they knew that CBT worked, responded 'because we've pummelled the research'. Further discussion with Viv revealed that Viv thought CBT did not 'seem any better than, for example, psychotherapy'. However, Viv noted that 'it fits... a scientist-practitioner...scientific academic model' and 'the theories are empirical [and] you can test them'. Viv subsequently commented that they actually had 'no idea' why clinical staff chose CBT as the dominant model of training. Rob also reported that their programme included a strong 'CBT, scientist-practitioner model' and that 'nothing else' was included. Rob commented that CBT accords well with a scientist model of clinical psychology and supported the notion that clinical psychologists are scientists who are 'supposed to be objective and measure things'. Rob commented that CBT was 'in line with tutors [who had] a strong research emphasis' and discussed the programme's focus on 'so called scientific' research and the application of this knowledge to clinical practice. Rob also reported that CBT was 'concrete', involved looking at behaviours and cognitions which 
could be measured, and was 'proven' by research. Rob remarked that 'you've got to be able to measure something to actually do anything with it'. Loren also reported that CBT was the model of choice in their programme because 'most of the effective validated treatments nowadays are based on that model...they're teaching what works and what's shown to work'. Indeed, many participants drew on the argument that CBT is well researched and empirically validated to justify its prominence in clinical psychology training. As discussed in Chapter Two, this argument has been the subject of widespread criticism (Baydala, 2001; Lyddon and Weill, 1997).

Criticisms of the Dominance of Cognitive Behaviour Therapy

Feminist clinical psychologists in this research were sceptical of claims made about the empirical status of CBT. They raised questions about the kinds of claims being made about CBT and the research methodologies and practices upon which CBT research was based. They argued that the "scientific" basis of CBT was used to invoke authority and give validity to the wholesale use of CBT. They expressed doubts about the effectiveness of CBT and questioned the progressively greater range of "problems" or "disorders" for which CBT was supposed to be effective. Tina acknowledged that there was 'a lot of classic scientific, quantitative statistical research [that] does show that cognitive behavioural treatment is very effective' however she also commented that it was only applicable to 'specific problems.' She suggested if 'feminist type research and analysis' was used then researchers would produce 'other data or different data as well'. Furthermore, Tina commented that there are 'other approaches and other problems and other methods of research and therefore other conclusions that may then give a greater context to statements about an approach'. Likewise, Yve commented that 'there's research on everything that will back up anything... at the end of the day it comes down to personal philosophy'. Yve noted that CBT fitted well into a 'hierarchical male model'. In addition, she said that if psychology can present a body of research... and say this works and this works... and it will take this many sessions and it will cost you this much...[it's] going to go down a treat with the powers that be, with the people who actually want to be able to quantify what happens in therapy, so it fits the system'. However, Yve commented that a lot of clinical work was to do "with that indefinable 
something that's between two people...you're talking about people relating, communication on many levels and you're not taught that... when you're talking about cognitive behavioural stuff'.

Petra, who had taught clinical psychology, was also doubtful about the growing number of claims made about CBT and commented that 'basically you could just show the model to be useful for nearly everything'. She thought such claims could all be critiqued 'given the philosophy of science type issues' but noted that 'the drive for most organisations to be economically effective and output driven means that we have been forced into this model being the justified model for a lot of the work in the $\mathrm{CHE}^{168}$ and in the Department of Corrections for example' so programmes were compelled to teach CBT.

Nina discussed the relationship between CBT and psychology's increasing emphasis on the scientist-practitioner model. She commented that 'CBT fitted very neatly with that model' which also contributed to psychology's attempts to be seen as a science. She talked about the strategic move by university psychology departments to gain recognition as 'hard science[s]' rather than 'soft arts' and that this occurred in the context of changes in how departments were funded. She noted that psychology departments now 'got funding from big funding bodies for research'. Nina also thought that the current emphasis on CBT and the scientist-practitioner model was partly to do with psychologists wanting to be seen as different from other disciplines and other health professionals such as counsellors, therapists or psychotherapists. Arguments raised by FCPs echoed those highlighted in Chapters One and Two of this thesis where critics condemned the $\mathrm{CBT}$ and scientist dominant model of clinical training (Kantrowitz and Ballou, 1992; Lyddon and Weill, 1997).

Along with claims about the scientific efficacy of CBT, feminist clinical psychologists drew attention to the increasing rhetoric positioning CBT as "evidence-based practice". Some FCPs regarded this as another strategy used by psychology to promote itself as a scientific enterprise. Libby discussed this issue in terms of the broader context of

${ }^{168}$ Crown Health Enterprise (now called District Health Boards). 
psychology noting that there had long been a tension between the idea of psychologists as 'scientists' and psychologists as 'practitioners'. She commented that there was a 'kind of dance that we do and have done for all these years to make it okay with the scientists.' She suggested that 'evidence-based practice' was just the latest 'buzz word' and was akin to psychology's emphasis on the 'scientist'. Libby concluded that these were 'sacred cows' called upon 'to make us okay with our academic brethren and ...with the "real" scientists because psychologists ha[d] always been a bit defensive' about their professional position. Megan also addressed issues around evidence-based practice and commented 'if you only measure one thing and it works then that's not necessarily the most effective'. She commented that 'just because... you can measure it doesn't mean it's the best thing'. This approach often meant that other more subtle or complex processes are excluded. She discussed a recent seminar in which the presenter said 'we should be using evidence-based therapy which is CBT and behavioural and get rid of the bullshit therapy'. In Megan's view this was 'not evidence-based practice' because there is research that indicates that other approaches are as effective, or more effective, than CBT depending on the nature and complexity of difficulties people faced.

In conjunction with claims about the empirical basis of CBT and the scientist dominance in clinical training, some students reported that the focus on CBT was due to a bias in the recruitment of staff who had a background in CBT. Suzette noted that while 'a lot of the validated treatments are cognitive-behavioural', staff were probably chosen for their CBT orientation. Lisa, another student, remarked that CBT 'works' but also noted that there was a lot of research about this model, it was easy to teach and it was the model staff themselves preferred. Lisa also commented that CBT was the 'flavour of the month' reflecting current trends in the wider profession. Freddie suggested that the major reason CBT was the dominant model of training was 'because of the individuals who are involved in the clinical programme'. Col noted that the dominance of CBT reflected lecturers' 'expertise and interests'. Kas thought that CBT was prominent due to its research backing, but also observed that it had so much backing 'because that's what's taught in universities' hence creating a 'bit of a vicious cycle'. Thus, several students thought that the employment of staff with a CBT orientation perpetuated the proliferation of academic research and publishing which 
further legitimised a CBT position. It is also noteworthy that most employment vacancies for clinical psychologists in this country specifically include knowledge and proficiency in the use of CBT. ${ }^{169}$

Discussion with students revealed that those who took a more critical stance were somewhat sceptical of the research apparently backing CBT and noted that processes involved in the funding and publication of CBT research were stacked in its favour. Likewise, students raised issues concerning a lack of attention to the effectiveness of CBT with multiple and/or complex 'problems' or with clients from marginalised groups. Furthermore, some students reported that there was scant attention to situations where CBT was unlikely to be appropriate or effective, or to the use of alternative approaches when CBT did not 'work'. While students in most programmes were well versed in mainstream literature endorsing a CBT model of practice, few were familiar with research or literature that documented the effectiveness of other psychological theories and therapeutic approaches. Feedback from participants also suggested that there was little critical analysis of CBT research and that few publications documented contradictions and incongruities within $\mathrm{CBT}$ research. Likewise, students in most programmes were rarely encouraged to pursue research and literature based on diverse epistemological and methodological positions. While students in one programme were encouraged to take a critical stance when considering different theoretical and therapeutic approaches, most were not encouraged to consider questions such as whose interests CBT serves, who controls psychological research funding and how this impacts on the kinds of research methodologies and topics of inquiry that gain approval for funding, and who determines publication criteria and dominates processes of peer review for mainstream psychology journals.

Students in several programmes talked about being resigned to the narrow focus on CBT and said they would eventually practice from other theoretical positions. Others felt considerable pressure to work within the limited parameters of contemporary

\footnotetext{
169 One of many similar examples included a 2003 advertisement for a Lecturer in Clinical Psychology, Department of Psychology, University of Waikato [Ref 210403] stated that 'You will define yourself within the scientist-practitioner model of training, with a cognitive-behavioural orientation' http://psychology.waikato.ac.nz/staffprofile.cfm? ID $=25$.
} 
clinical training and to comply with CBT requirements perceived as necessary to pass the final exam. Several students regarded their successful completion of the PGDipClinPsych as a ticket to theoretical and intellectual freedom. For example Kas commented 'as soon as I get my PGDipClinPsych I'm going to psycho-drama workshops and narrative therapy and really...become a therapist, this is just my rote learning to get my ticket...we all acknowledge that as we're going through the programme'. Kas also commented:

[I]t's so didactic..."you be client, I be almighty therapist, bow to my superior knowledge, these are your homework tasks" ... I mean it's really unrealistic, there's some good parts to it but it's this feeling of, well go through the motions, tick the right boxes, rote learn it and then once you get your PGDipClinPsych you're free!

Kas reported that the narrow focus on CBT and the scientist-practitioner model was a reason some people 'dropped out' reporting that some students 'got so sick of [the] "I do this because you tell me sort of thing"'. Indeed Kas talked about students who had either left the programme because they 'got so sick' of this model or had not applied because they 'couldn't really stomach the idea of doing a three year clinical programme where you have to toe the line...you can't swerve away from the line or you fail your placement or you fail your exam'. Col also said that their focus was on the clinical exam and thought that it would 'be set by examiners who probably think a certain way, so it's sort of like playing their game...because they've got the power'. Likewise, Kit talked about the clinical exam, commenting: 'I'm interested in narrative approaches [but] my interest this year is to pass the clinical exam so I'm doing what I need to do' to achieve that. Kit also indicated that they were keen to work in the child and family area but that the cognitive-behavioural focus of the programme did not prepare them well for this kind of work.

Other participants expressed dissatisfaction with the current emphasis on CBT and the scientist-practitioner model of clinical psychology training noting that it was limited and important to engage other theoretical and therapeutic approaches. They regarded CBT as an individualist model that limited the capacity for understanding the diversities and complexities of human life. For instance, Terri, a staff member who did not take a CBT dominant approach, commented: 
the clinical psychology perspective has been an individualistic perspective, and a lot of the literature that comes out of America is very individualistic and I don't think it adequately deals with the whole person at all, and that's why I teach the bit I do, because I think it's fundamental, you might be able to do a functional analysis but...the things that maintain things are broader than specific environmental immediate consequences...I mark people down who haven't looked at the issue more broadly...taken into account other possible interpretations or critiqued the research methodology.

Another staff member who took an eclectic approach to clinical training also talked about problems with relying on a singular model and noted that this restricted clients options. Claud commented that they did not 'like any one model claiming to have all the answers' and reported that this insular focus led to 'difficulties' in clinical practice. They suggested that 'there's a bit of hero worship[ping] going on in New Zealand... at the moment around cognitive behaviour therapy' and commented that this was 'not realistic' and 'not empowering' because 'clients should be given choices [about] different ways to work'. Sarah also discussed the shortcomings of a CBT dominant model and commented 'I always saw the limitations of it in the sense that you're not looking systemically and you're not always looking politically when you're working like that.

Feminist clinical psychologists (FCPs) also echoed these views and while recognising the usefulness of CBT as a 'set of tools', expressed concerns about its dominance in contemporary clinical training. Some FCPs talked about the limitations of CBT with people who have experienced significant emotional distress or trauma. Megan stated this clearly when she said: 'well, if you try and use cognitive-behavioural when you work with people who've been sexually abused...they wouldn't come back'. Megan further commented that 'for anything like women who've been battered or women who've been sexually abused or raped...the basic framework [of CBT] doesn't really help because people have to go back and sift through what's happened to them... [and CBT] is too structured for that'. Tina also discussed the inappropriateness of CBT with clients who have experienced trauma and emphasised the point that CBT 'may only touch the surface' which means that 'the experience' of the client may not actually be addressed and changed at the 'emotional' and 'non verbal' level. 
Students also thought that the focus on CBT was inappropriate for a range of client groups and problem areas. Pam discussed the problems of using CBT when working in the area of sexual abuse and 'especially with younger children'. Similarly, Lucia discussed the importance of looking at 'life issues' when working with 'someone with depression resulting from loss'. In their experience 'CBT for depression was only part of the process'. Jamie, a student who identified as feminist and who was an experienced counsellor, commented that fellow students had encountered difficulties working with 'problems' or groups of people for whom CBT was ineffective. Jamie reported that 'new graduates' were 'really struggling with how to work with women...or people in trauma.' She said, 'I don't think that CBT is... a very good way of working' in this context and noted that 'the trauma model involve[d] really different [approaches]' that students did not learn about. She also commented that the CBT approach to training was 'a very medical, assess, diagnose, treat, kind of model' which was probably not the 'most helpful'. Furthermore, Jamie indicated that some students were unsure about being allowed to 'sit and talk with a woman and do emotional validation' because they thought clinical staff perceived this as too 'counselly'. Jamie also referred to other people in the course who 'never use[d] anything else but CBT' and 'wonder[ed] why it doesn't work sometimes'. Furthermore, Jamie questioned why their programme spent such a 'substantial amount [of time] on neuropsych [and] disorders' when it would have been more useful being introduced to other theoretical models and ways of working.

Several participants discussed the shortcomings of CBT in terms of its emphasis on thought processes and behaviour. This issue, which was discussed in Chapter Two, has been widely addressed by critics of CBT who have drawn attention to the gendered nature of this theoretical model. Indeed, arguments have centred on the philosophical foundations of $\mathrm{CBT}$ which attribute legitimacy to reason and rationality, while devaluing diverse subjective experiences such as feelings, emotions, and subconscious, embodied and/or spiritual experiences (Baydala, 2001; Lyddon and Weill, 1997; Stoppard, 1999, 2000; Ussher, 2000b).

Feminist clinical psychologists were also critical of the way CBT reflected a 'male' approach to perceiving and interpreting the world reflecting the philosophical focus of western societies. FCPs argued that CBT was 'a model designed by men for men' and 
questioned the way this approach was lauded as universally applicable despite differences of gender, race, class and other social positioning. Further, like critics cited in Chapter Two, FCPs were critical of the decontextualisation of CBT which largely disregarded the historical, cultural and sociopolitical context of peoples lives. Tina commented, '[CBT is] incredibly male, it's very much a rational, logical, cognitive approach...it doesn't take into account a number of things, and one of the things...is context...it's really important to look at...the broader context...the historical context.'

Petra was also critical of the 'highly individualised' nature of CBT and like other critics regarded this model as 'not cognisant enough of the systemic influences on an individual'. She argued that the focus on changing an individual's thinking so 'they can adjust within a bad situation' was less than satisfactory. Yve suggested that CBT reflected 'the way that men think, it's the way that men actually work in the world...you'd do A plus B equals C... a linear way of looking at life'. She argued that if programmes only teach CBT then they are 'missing a whole great big part' peoples lives.

\section{An Eclectic Approach to Clinical Training}

While most clinical programmes endorsed a CBT dominant model of training, and minimised the inclusion of feminist perspectives, one programme actively engaged an eclectic theoretical approach and feminist knowledges. Staff in this programme, who incorporated diverse theoretical perspectives, discussed the ways this model of training equipped students to work with a range of issues across diverse groups of people. Further, staff actively encouraged awareness of the significance of social, cultural, political and economic contexts for understanding human experience. Likewise, they endeavoured to make issues of power, justice and equity central to training. Indeed, students were encouraged to adopt a holistic approach to clinical practice based on a range of theories and informed by contemporary philosophical debates.

George, a student, discussed the way this programme had helped them become 'more sensitised and more aware of a broad range of issues'. George reported that the eclectic 
approach 'gives me more options to explore [where] I'm not performing,...or where I'm not being effective' and noted that a more specific skills based programme would have been likely to leave 'large holes' in their training. Furthermore, George commented that they 'like[d] the narrative approach' because it was 'a model which allows me to include a variety of issues which include power and gender and disadvantaged groups'. Similarly, Ro, another student, reported that the programme had included psychodynamic approaches which fitted 'so clearly with people who have been traumatised'. They particularly liked this model because it 'thinks about power' and makes power explicit. Lyndsay discussed a range of theoretical models included in this programme such as CBT, psychodynamic, narrative and multiple feminist approaches which also paid 'a lot of attention to... power'. While there was some variability in the degree to which feminist perspectives were incorporated in this programme, trainers encouraged critical analysis and the inclusion of theories, research methodologies and literature reflecting critical psychology perspectives.

While most students favoured the eclectic theoretical focus of this programme, staff indicated that some members of the professional community regarded the programme as not sufficiently "skills based". Given the current professional bias toward CBT it is likely that such claims reflect a lack of emphasis on CBT. If students did lack appropriate skills they would probably not continue getting internships and would not be passing the final, externally assessed, clinical exam. Indeed, the resistance to an eclectic model of training seems to reflect the general reluctance of most clinical trainers to explore a range of theoretical perspectives that deviate from the established norm.

While an eclectic approach to clinical training is not common in Aotearoa New Zealand, about a third of clinical programmes in Britain endorse this model (Pilgrim and Treacher, 1992). While there is recognisable variation in meaning and orientation of these eclectic programmes, the ones at Leicester and Exeter Universities (Pilgrim and Treacher, 1992: 91) seem to embrace the general ethos of the eclectic New Zealand programme. Eclectic models of clinical training may intimidate people used to a singular model of clinical psychology, however, FCPs in my research highlighted the importance and validity of bringing a range of theoretical and therapeutic approaches to 
clinical practice, and in using diverse epistemological and methodological models of inquiry. This stance is consistent with general discussions in feminist psychology where plurality, diversity and eclectic models of practice are commonplace.

\section{Feminist Clinical Psychologists' Endorsement of Eclectic Models of Training}

All participants in the FCP group combined diverse theoretical approaches in their work as clinical psychologists. While underpinned by a feminist analysis, these included: systems, family therapy, narrative, social constructionist, psychodynamic, Just Therapy, Rogerian, developmental, attachment, group work, cognitive-behavioural, cognitive, and behavioural. FCPs were united in their focus on the systemic and contextual backgrounds which were regarded as central to a comprehensive understanding of people's lives. Their adoption of an eclectic model of practice reflected a willingness to address this wider context and to offer services that were appropriate and responsive to diverse groups of people, as well as multiple, co-existing difficulties.

Feminist clinical psychologists emphasised the importance of selecting a range of approaches based on their appropriateness and effectiveness with different people and difficulties. As Tina commented, an eclectic approach did not mean 'random eclecticism'. Indeed, FCPs discussed the importance of having a thorough understanding of different theoretical and therapeutic approaches. However, they also emphasised that it was the integrative nature of an eclectic model that made it valuable; the whole being greater than the sum of its parts.

Feminist clinical psychologists discussed the importance of broadening the disciplinary boundaries of clinical psychology to embrace diverse meanings and ways of conceptualising psychological knowledge. In this regard, FCPs regarded feminist, social constructionist and poststructural ideas as valuable but also engaged specific forms of therapy. They regarded the interweaving of these different frameworks and therapeutic approaches as integral to their effectiveness as clinical psychologists and important in broadening the scope of psychological research. Petra commented that she was 'very eclectic' in her work and that the postmodern shift had made a big impact on her work 
'in terms of not believing any one truth'. She noted that this approach was very useful for understanding that "one needed to be multi-modelled in order to work with different people'. Similarly, Tina commented that a postmodern and social constructionist approach allowed 'a number of realities' which were all valid. She noted that this was particularly useful for validating the experiences of women, people with disabilities and people from diverse racial and religious groups.

Feminist clinical psychologists thought that an eclectic approach was important in countering the individualism of clinical psychology and in promoting a psychology that fully engages the historical, cultural and sociopolitical contexts of people's lives. Tina commented that 'any problem or issue needs to be looked at in a system context'. She noted that locating problems in a systemic context enabled clients to have a lot of control and direction. Likewise, Nina discussed the value of a systems approach in terms of moving away from the "whole idea of the psychologist as just working with an individual'.

Feminist clinical psychologists also found a systems approach useful in understanding issues of power such as violence. They discussed the ways this approach permitted an understanding of the structures that perpetuate power asymmetries and encouraged intervention across the systemic whole. Tina said that she would like to see the 'systemic framework taken into account especially with things like violence because [it] stems from power and/or lack of power and a lot of it relates back to things like economic structures, lack of access to resources and things like that'. She noted that the systemic approach addressed the 'person...family...social environment and next level of society so you can intervene through those levels as you need[ed] to'.

Feminist clinical psychologists emphasised that an eclectic model of practice gave clients choices about how they wanted to work. Rosie commented that while a feminist model underpinned all her work, she also used a narrative model and wove in cognitive approaches and CBT. She said that part of working with clients was to offer a choice and to talk about which approaches 'click'. 
Feminist clinical psychologists acknowledged arguments that students being taught an eclectic approach might lack a cohesive basis for practice and experience difficulty absorbing multiple approaches. Alesha, who was a recent graduate, referred to the difficulty of learning several approaches at once. However, she also commented that 'one isn't adequate' and that it was useful to 'have a few models and know them well' and to include 'a balance between talking therapies... and action oriented therapies. FCPs who supervised or taught clinical students noted that those from the eclectic programme were well grounded and exhibited considerable competency in their clinical placements and internships. Indeed, many FCPs commented that an eclectic model of training was common in the past and that as students they had accommodated this approach well.

\section{The Inclusion of Feminist Knowledges and Perspectives in Clinical Training}

While some staff endorsed feminist perspectives and engaged critical debates about the epistemological and ontological foundations of clinical psychology, the majority did not. Indeed, participants indicated that course content or knowledge deemed 'feminist' was regarded as 'value laden', or 'political', in a way that cognitive-behavioural approaches were not. This belief, which has been widely reported by feminist and other critical psychologists elsewhere (Baydala, 2001; Kantrowitz and Ballou, 1992; Stoppard, 2000; Ussher, 2000b), reflects the dominance of a positivist science discourse in which the 'objective' and 'measurable' are valued. It excludes non-dominant knowledges and effectively subjugates feminist worldviews.

Students in this research demonstrated the way their training was premised upon a narrow definition of clinical psychology and was constructed within tight disciplinary boundaries. When feminist content was included it was frequently marginalised by staff. Louie reported that 'there's not a lot of discussion or interest in feminist perspectives... in the clinical programme generally'. Louie thought this was due to 'the training of the people who are giving us the training' but also drew attention to the scientist dominance of clinical psychology and the political nature of decisions made about the inclusion of different theoretical approaches. 
Why the decision was made to have say a cognitive-behavioural perspective and not incorporate feminist perspectives...I guess is a political one, it may be something to do with science and...the perceived ability to come up with hard conclusions, grounded in accepted ways of doing things and an ignorance of, or a mistrust, of other ways.

Lisa suggested that the lack of inclusion of feminist ideas was due to staff members having 'very very strict ideas about what they think clinical psychology is'. Lisa noted that feminist perspectives would not be part of that definition and neither would 'other' approaches such as psychotherapy or counselling. Indeed, Lisa recounted how staff had made it quite clear that 'if you're here to do psychotherapy or counselling or any of those things then you're in the wrong place'. Suzette drew attention to the strictly scientist model of clinical psychology commenting that 'for feminist therapies or theories to be used in the programme, they'd have to have some sort of scientific validation'.

Some students discussed the way feminist perspectives were not included by staff in their training programme. They thought this was due to a combination of factors, including in particular, a lack of understanding and undervaluing of feminist knowledge, and negative staff attitudes. They discussed the ways some staff were overtly critical of feminist ideas and were opposed to the inclusion of these ideas in students' work. Lisa commented that one staff member 'had a serious problem with feminism' and seemed to be 'terribly threatened by it'. Lisa also noted that while some staff 'do little bits', other staff 'don't think it's important... and just wouldn't view it as part of clinical psychology'. Likewise, Lu thought that issues related to gender were not 'seen as important' because they were not part of psychology's 'normative view'. Lu discussed the way feminist perspectives were seen as 'radical' or 'extremist' within clinical psychology.

Students gave examples to illustrate how feminist ideas were marginalised or minimised in class. Jamie reported that there was a certain amount of "oh there she goes again"...it was kind of like that's very interesting but let's get back to the important stuff". She discussed the way some "lecturers think that issues to do with gender or 
feminist theory are rubbish or they're sceptical about it'. Freddie talked about the way feminist theoretical ideas were not 'acknowledged or given weight within the programme', were regarded as 'extremist' and that staff perceived those who advanced these ideas' as having 'some axe to grind or a chip on [their] shoulder'. Freddie commented that the absence of feminist theories and perspectives suggested that they were 'obviously not clearly understood as a way of looking at the world'. Freddie commented that it was 'pretty dangerous to not look healthy when you're on the clinical programme, you have to look so "normal" which includes having [and] accepting the view held and purveyed by the clinical programme'. One student, who identified as feminist, discussed the 'personal costs' of continuing to raise feminist ideas or issues about gender. She said: 'even though I expected it, being faced with it is hugely draining'. Indeed, students throughout this research drew attention to the pressure of 'accepting' the dominant theoretical stance and the consequences of advocating feminist ideas or other critical perspectives contrary to the status quo.

Students who reported that feminist perspectives were included in clinical training commented that this typically occurred in the context of topics regarded as specifically relevant. As noted earlier, this was limited to topics such as depression, domestic violence, sexual violence, PMS and eating disorders. Rob reported that their programme included feminist ideas but only in relation to 'eating disorders' and Freddie noted that feminist ideas were given 'slightly more weight [than usual]' in relation to 'anorexia or sexual abuse'. However, these students also reported that the inclusion of feminist perspectives and literature was only 'a little add on' and subordinate to the dominant CBT model. These findings are similar to those of Williams and Watson's (1991b) who reported that content relating to sexual inequality was restricted to eating disorders and depression. Students' feedback suggests that this focus on individual topics inhibits the development of a comprehensive and cohesive feminist analysis applicable to all clinical work.

In other instances, staff did not regard as legitimate gender-specific topics which were also the focus of a considerable body of feminist research. In these situations students reported that feminist content was only permissible if it was located within a scientist framework and included CBT as the primary theoretical model. Louie discussed the 
'hamstringing that goes on with research and clinical psychology' which involved being 'able to cite the [mainstream] literature' even when it was inadequate. Jamie talked about a paper she had done on sexual abuse in which she included a discussion of power, the use of feminist theories of abuse and an understanding of why abuse occurs. While Jamie was an 'A' grade student and regarded this approach as 'quite valid' she reported that the paper was knocked back as 'unscientific twaddle'.

The lack of inclusion of feminist perspectives and a comprehensive feminist analytical framework often means students have difficulty understanding the theoretical basis of feminist psychology and how to bring a gender analysis to their work. Students reported that although they might independently seek feminist readings, the use of occasional readings was not conducive to the development of a comprehensive analytical framework. In some instances, students reported that although their programme did not give attention to gender and other issues of power, and only rarely included references of this kind, students were expected to include this content in their course work. For example, Jay related an attempt to 'read a couple of feminist discourse [papers]' while undertaking an assignment on PMS but found they were 'totally lost... because it's something we'd never been exposed to'. Jay commented that 'it was really hard to get a handle on it...it was so different than what we do that I think it would have to be something that you'd have to be introduced to relatively early on so that you could carry the thread of it through your training'. Jay also observed that while social psychology and community psychology included discourse analytic approaches, clinical psychology generally resisted alternative approaches on the grounds that they were not 'scientific'. Jay commented that this meant that clinical students did not have the opportunity to obtain a knowledge of feminist discourse 'to make a difference in our practice'.

Jamie discussed the absence of feminist analytical approaches in her programme but also noted that students were told that they should take gender and other issues of power into account. However, the programme did not model how to do this because it basically provided a 'specific recipe... [that is] cognitive-behavioural [which] very much focused on...the individual level of thoughts and behaviours'. Similarly, Jessie reported that while feminist theoretical perspectives might be 'talked about' it was a 'very broad brush-stroke thing and not the focus of ongoing teaching'. 
Some participants commented on lecturers' unease when students attempted to construct arguments from a feminist theoretical position. They noted that a feminist approach was not seen as a practice model in its own right but rather additional to another more legitimised theoretical model such as CBT. Some staff commented that while they respected a feminist model it was not generally given the legitimacy of other psychological approaches. Rather, feminist perspectives were seen as a theoretical framework within which specific psychological therapies could be incorporated. Claud, a staff member, said:

I think there is no reason why cognitive behaviour, or psychodynamic or narrative therapies can't be worked into a feminist framework, in fact that's how a lot of people end up talking about it, feminism is the framework and then the other models are within that or just the techniques...integrating the models and understanding how they work together is something we encourage.

George, a student, commented that there was no recognition by staff 'that there is a model of feminist therapy'. Instead, staff regarded the 'feminist approach as being a framework within which to do other forms of therapy...so as a model feminist therapy is not included'. A staff member who actively endorsed feminist knowledges commented that other staff "wouldn't really strongly advocate a feminist perspective...they see that [as] on the side [like] "it's fine if that's what you want and yes it is important" but it's not a central thing".

While a minority of staff encouraged students who wished to take a poststructural or critical epistemological position and to employ qualitative research methodologies, this was uncommon. Instead, most students were encouraged to work within the narrow frameworks of positivist science using empirical and experimental methodologies. Students discussed the way most staff would not explicitly reject feminist or other critical research approaches but would implicitly exclude them by giving students little support. This process of exclusion appears to be reinforced through the allocation of awards and funding of research. The titles of graduate research and the kinds of research awarded funding is indicative of the value placed on research that falls within, rather than outside, the mainstream mould. Some students commented that they had to be regarded as "perfect" or be 'straight A' students in order to voice alternative 
psychological perspectives or to adopt feminist or critical research methodologies. Lisa noted that it was 'like women in the same job having to be twice as good to be considered half as good, if you're going to have alternative views then you have to be perfect in every other regard'. Lisa thought the same attitudes applied in relation to 'women doing qualitative research' and indicated that students who used alternative methodologies were challenged for doing so, the implication being that they 'can't do "real" research' and that feminist approaches were 'a load of crap'. Lisa reported that staff in their programme had indirectly questioned how these approaches 'could be of any use to anybody'. Another student in this programme, Jamie, commented that the stigma about feminism meant a feminist psychology paper had 'to be called something like Psychology and Gender...it still can't be openly promoted as feminist or psychology from a feminist perspective'.

Participants reported that even in programmes where feminist knowledges and critical psychology were legitimated, the inclusion of this content remained the responsibility of one or two feminist staff. Indeed, staff in most programmes seemed to lack knowledge or understanding of feminist theories, methodologies and perspectives. While some staff openly acknowledged gaps in their knowledge and said that they depended on colleagues to incorporate feminist perspectives, others did not recognise the relevance of feminist ideas. Those who held strongly positivist views were most likely to position themselves in opposition to feminist theories or perspectives. One staff member who conveyed a lack of understanding of feminist ideas and critiques of positivism also expressed negative attitudes towards them. Leo reported being 'so confused' as to what feminist theoretical models or perspectives comprised and commented: 'I'm not sure that feminists know what [these approaches entail] you get a different answer if you ask one...versus another'. Furthermore, Leo commented:

I absolutely oppose...[the idea] that science is being manipulative, oppressive, all those usual things us middle-class white guys do all the time and I just don't accept that...nor do I...understand [what feminism] is trying to do when it says it's trying to feminise science, feminise is not the word but whatever...yeah well I'm a positivist I think...I can't understand that critique to be honest.

Another staff member, Vic, who was receptive to feminist critiques of science and feminist research methodologies, noted that in the past they thought "science was 
science'. More recently Vic had considered issues relating to 'the way science is conducted, the way research questions are posed...the actual methods and presumptions of research, the meta theory of science...ways of thinking about things which are stereotypically male'. Vic noted that while it was 'incumbent on [psychologists] to be aware of implicit influences on assumptions that you make about what's good research, what's bad research and so forth' the clinical programme did not address these issues. This was because the 'standard statistics and methodology courses [were] actually taught from a conventional perspective'.

Echoing comments by other participants reported earlier in this section, Vic reported that staff members who have "an interest in alternative methodologies...end up teaching those as [an] aside thing or a separate issue' but not as part of clinical psychology. However, staff who held narrowly defined views about the parameters of the clinical curriculum justified their failure to include feminist and critical content by saying they thought others (i.e. feminist lecturers) were including it. Other participants discussed how the inclusion of feminist and critical theoretical perspectives was dependent on individual staff who were employed at any given time. Indeed, the absence of certain staff members ${ }^{170}$ resulted in the exclusion of a significant body of knowledge that other staff members were unable to teach. Consequently the provision of a systematically structured curriculum involving a range of theoretical viewpoints was often precluded.

Another key factor underpinning the lack of feminist theoretical content in clinical psychology training was the infrequent use of research and literature published outside the mainstream. Some participants remarked that what was regarded as 'mainstream' was highly prescribed and included only a narrow range of dominant psychology publications based on research undertaken in North America. Jamie commented that their course included 'mostly American [CBT research]' and 'a lot of research on American male populations or American populations in general.' Jamie also noted that 'a lot of the tests [were] normed on men and not necessarily women'. Likewise, Col commented that while the literature presented varied 'from lecturer to lecturer...the

\footnotetext{
${ }^{170}$ For instance when a staff member was on leave, no longer working in the clinical programme, or when their course was not taught every year.
} 
bulk of what we read does tend to be from a white male, North American, able, competent, rich sort of point of view' and this defined what was regarded as 'normal'. Feminist psychologists and other critics have long addressed the dominance of North American derived research and literature in psychology (Leitner (1995) cited in Boyle, 1997; Hare-Mustin and Marecek, 1997; Saris and Johnston-Robledo, 2000). ${ }^{171}$ This focus has meant that valuable sources of material such as that found in internationally renown journals like Feminism and Psychology, the Psychology of Women Quarterly, Women and Therapy, and Feminist Family Therapy were rarely included or referred to. This process effectively marginalises the work of prominent international feminist psychologists who have contributed to cutting edge work in the development of contemporary psychology. The reliance on mainstream clinical psychology literature means that other important bodies of knowledge are also excluded such as indigenous, community and critical psychologies and a considerable body of work relating to diversity.

\section{Conclusion}

The theoretical dominance of CBT in most clinical psychology programmes in Aotearoa New Zealand, combined with a reluctance to embrace feminist and more eclectic and diversity inclusive models of training, has adverse implications for women and other marginalised groups. The prevalence of CBT as the modus operandi of clinical training and its location as the model of "evidence-based" practice (as discussed in Chapter Two), has significant ramifications for understanding the connection between gender and other dimensions of power, and psychological health, and as such is central to my thesis argument. Further, clinical psychology's endorsement of CBT, and associated claims to the scientific authority of this model, mask the power clinical psychology holds in constructing partial and distorted accounts of peoples lives and experiences, thereby perpetuating the oppression of women and other marginalised groups.

\footnotetext{
171 Feminists from marginalised groups have noted comparable exclusions in feminist psychology literature based on 'race', class and sexual orientation (for example Greene and Sanchez-Hucles, 1997; Kitzinger, 1996).
} 
While recognising the usefulness of CBT in specific contexts, or as one of many approaches to practice, some participants in my research were critical of it and questioned the dominance of CBT in clinical psychology programmes. These participants identified a range of problems with relying on a singular, reductionist model of training and drew attention to the distinction between 'therapy' and 'techniques'. In particular, they challenged the appropriateness and effectiveness of CBT for complex, multiple co-existing difficulties, and for addressing serious historical forms of distress and traumatic experiences. Participants also questioned the adequacy of this model for conceptualising and understanding the life experiences of diverse groups of people. Scepticism concerning the context in which CBT research is proliferating, and apparent biases in the employment of clinical psychologists who have a strong CBT focus were important issues raised.

FCPs and other participants, emphasised the way eclectic theoretical and therapeutic approaches located within feminist frameworks can encompass diversity, the systemic and contextual, and permit an analysis of power integral to an understanding of gender and other structural relations. Furthermore, these participants addressed the way eclectic approaches better enable relational, multi-level analyses and a more holistic understanding of health and healing.

This chapter has also highlighted how the dominance of CBT seems to co-exist with the marginalisation of feminist knowledges. Participants discussed some staff members" rejection of feminist ideas as "political" and "unscientific". The scarcity of feminist research and literature in most programmes is indicative of the continued marginalisation of feminist psychology and is a reminder of the limited extent to which feminist knowledges have entered the mainstream. 


\section{Concluding Comment/Future Directions}

In this_final chapter I summarisethe_kefv findings of the research, discuss ideas for the

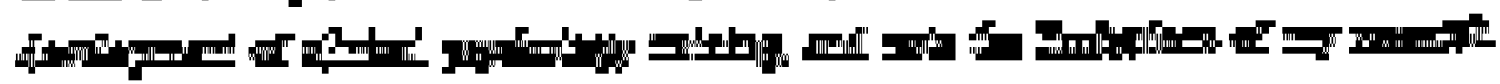

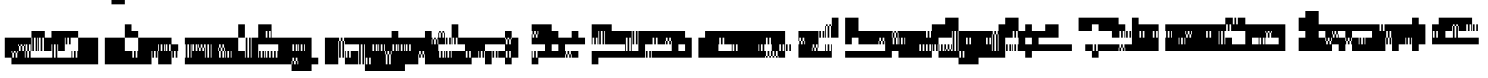

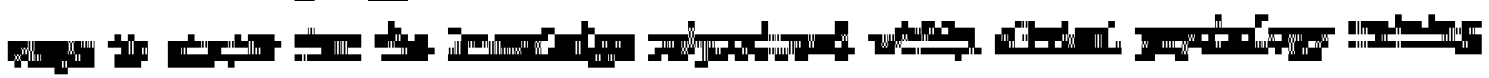

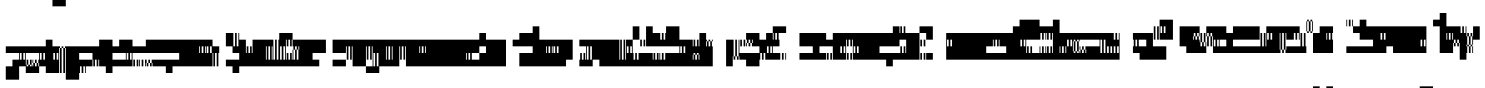

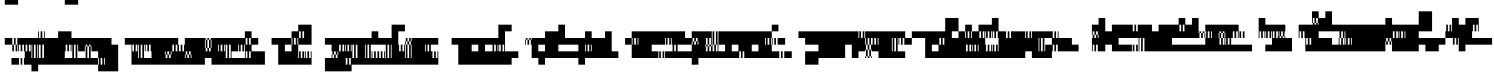

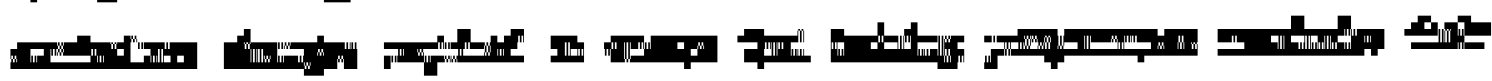

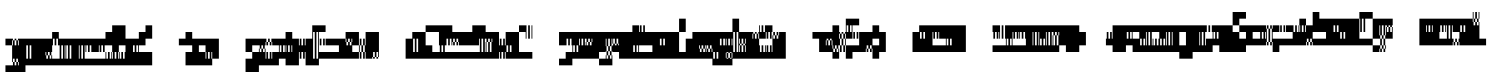
ty

ב

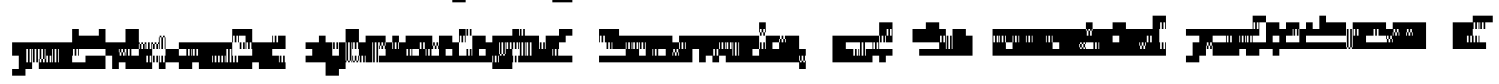

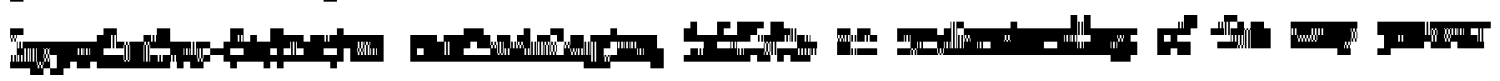
=

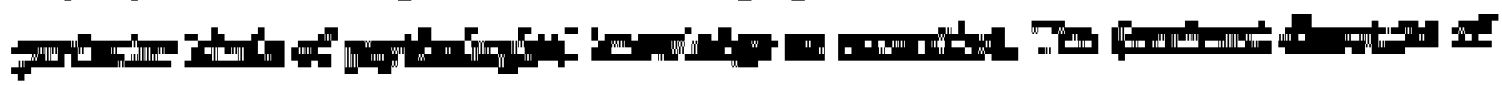

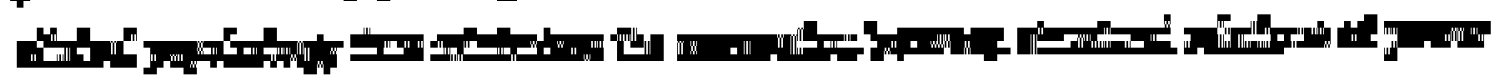

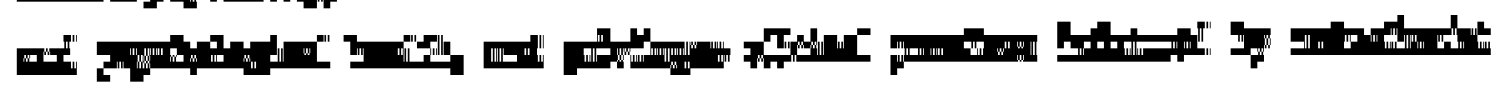
:

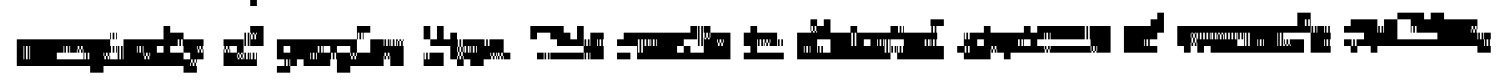

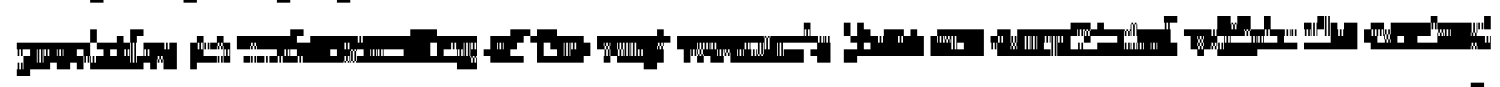
A

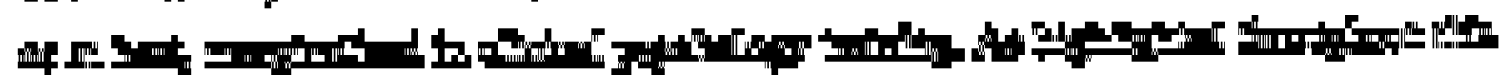

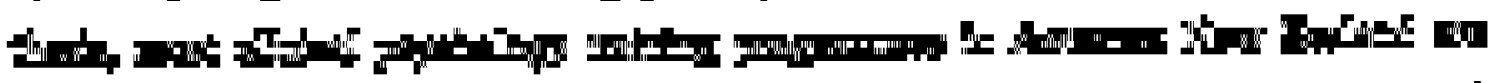

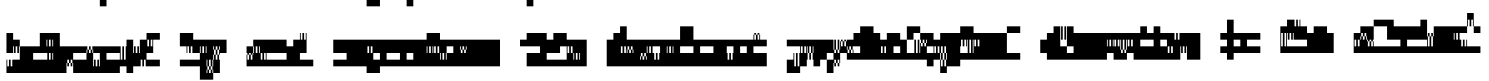

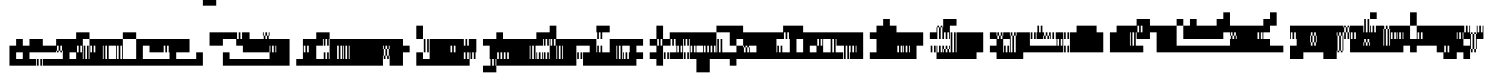

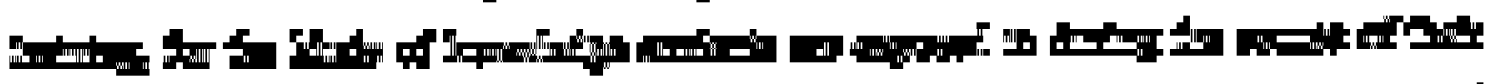

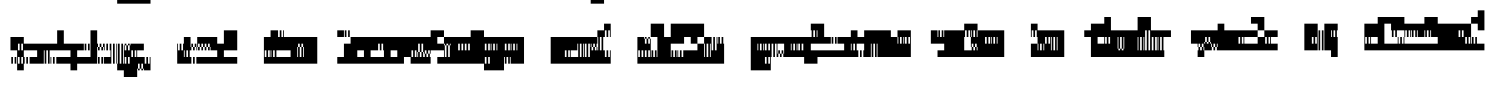

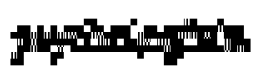


The general inadequacies and limitations in the way clinical psychology training programmes incorporate an analysis of gender and other relations of power, and convey an understanding of the relationship between women's sociopolitical positions and psychological health have been identified in this research. Overall, the majority of students and pro/feminist staff who participated in this research regarded the inclusion of gender education as inadequate and feminist clinical psychologists identified many gaps in the inclusion of gender education in clinical training. A common theme amongst student participants was that gender education was limited, infrequent, added on, often reliant on students, was not part of the core curriculum and not integrated throughout clinical training. Students in most programmes reported that there was little if any attention to diversity and that education incorporating an analysis of power relating to diverse social groups was almost non-existent. When included, education about gender was largely confined to the generic woman, included only in the context of women's health, was descriptive and not located within a broader analysis of gender or other relations of power. Williams and Watson (1991b) noted similar findings, although participants in my research reported a somewhat broader array of topics within which gender was addressed. However, curriculum content reported to be about gender in some programmes, such as sexual dysfunction and male violence, was not presented in the context of an analysis of gender, assumed a male perspective, only focused on men, and did not include education relating to women's experiences. As discussed in Chapter Seven, these examples reflect limitations in the way some participants understood an analysis of gender, and like Williams and Watson's (1991b) research, suggest some confusion about meanings of gender.

A key finding of this research is that when gender education was included in clinical training it frequently depended on pro/feminist students, and the few pro/feminist staff or visiting lecturers who taught clinical psychology. Again, Williams and Watson (1991b) noted similar findings in their research suggesting that there have been few changes in the way gender education is endorsed or delivered in clinical training in over a decade. Likewise, more recent research by Nathan (1999) is indicative of a similar reliance on Māori staff and students as cultural educators and the continued limited inclusion of tikanga Maori content in most clinical programmes. 
In this research, both staff and students rated the inclusion of gender education as important for the training of clinical psychologists and identified a range of topics central to understanding women's lives. Despite this, students also reported that the priorities placed on the selection of topics and prerequisite courses did not reflect the importance that they placed on gender education as part of the core clinical curriculum. Thus, despite the relevance and importance of gender education to all aspects of clinical psychology, it was positioned as less important than other topics such as criminal justice, behaviour modification, and neuropsychology, which some participants regarded as non-essential to clinical practice but which were compulsory courses in some clinical training programmes. In comparable research examining the inclusion of diversity education in clinical psychology training in Canada, Hertzsprung and Dobson (2000) found that there was considerable variation amongst training directors in their perceptions of the importance of gender and diversity education in clinical psychology training and practice. Indeed, some directors did not regard any diversity education as essential to effective clinical practice.

Participants' comments throughout this research suggest that the lack of inclusion of gender and other analyses of power primarily reflect the attitudes, knowledge and priorities of academic staff. This finding is consistent with discussions by other feminist psychologists concerning the limited way gender education is included in clinical psychology (Bekker, 1991; Boyle, 1997; Hare-Mustin and Marecek, 1997; Ussher, 1992, 2000a; Williams and Watson, 1991b, 1991c). Feminist research indicates that the exclusion of gender education in clinical psychology has little to do with resources, although many trainers claim that a lack of resources accounts for the lack of inclusion of gender content (Bekker, 1991; Williams and Watson, 1991b). Given the ample body of feminist, Maori and other critical literature available to inform the clinical curricula, and the availability of a diverse array of people whose expertise could be utilised in training programmes in Aotearoa New Zealand, claims by clinical trainers that there is a lack of resources seem unfounded.

In my research, most staff took a conventional positivist science approach to clinical training reflecting the conceptual frameworks of clinical psychology's dominant 
discourse. Some staff appeared to lack understanding of the relevance of a gender analysis to clinical training. Others were reported to lack interest or resist the inclusion of feminist knowledges, and feminist literature or research. Indeed, there were staff who had not seriously considered the connection between gender and an understanding of the way power shapes women's lives and realities, and the construction of psychological knowledge. This lack of awareness or interest, and instances of resistance amongst some staff meant that feminist staff and students reported that their knowledge and expertise, and experiences as women, were not valued or legitimated. In some situations, students use of feminist knowledges and perspectives in clinical course work was dismissed as 'unscientific' or was only regarded as valid if located within the dominant CBT model of training. Adcock and Newbigging (1990) have discussed similar experiences of clinical training. They refer to the 'emotional disquiet' of clinical training noting that the "model was decontextualized and floated free from the constraints and forces which shape our everyday experiences... [e]verything in our training told us that this disquiet was unscientific, therefore wrong, therefore devalued' (Adcock and Newbigging, 1990: 173). In sum, although overtly negative attitudes amongst staff were uncommon in my research, the lack of inclusion of gender education seemed to reflect a lack of understanding and/or active commitment by most clinical trainers. This had the effect of inadequately representing women's diverse experiences, realities and material worlds and uncritically reproducing the dominant disciplinary discourse.

This research also identified the predominance of a CBT theoretical model (located within a scientist dominant, scientist-practitioner model of training) as particularly problematic in terms of marginalising gender and the effects of other dimensions of power, and justifying the exclusion of feminist knowledges. Feminist clinical psychologists, and critically oriented academic staff and students, addressed the importance of broadening the scope of clinical inquiry and practice beyond CBTs focus on the problematisation of individuals, the conceptualisation of singular, discretely defined "disorders", and the use of reductionist and mechanistic frameworks focussed on symptom reduction. The narrow ontological, epistemological and theoretical approach taken in most clinical programmes meant students had little exposure to knowledges other than those legitimated by mainstream clinical psychology and published in its academic journals and texts. The widespread endorsement of CBT, in 
conjunction with the limited inclusion of analyses of gender, meant that many students reported being inadequately prepared to work competently, ethically and responsibly with women and other marginalised groups for whom an individualist, rationalist, and reductionist ontological standpoint can be alien, alienating and potentially harmful. However, where academic staff took a critical-realist or social constructionist epistemological position, adopted an eclectic theoretical approach to training, and encouraged methodological pluralism, the curriculum was reported by students, staff and FCPs to be more holistic, conveyed a better understanding of diversity, and more successful in positioning gender and other analyses of power as an integral feature of clinical training.

By formally and systematically identifying the lack of analysis of gender in most clinical psychology training programmes in Aotearoa New Zealand this thesis offers a contribution to an analysis, but more importantly, an ongoing dialogue about the way clinical psychology constructs knowledge about women's experiences and material realities, shapes everyday meanings about women's lives, and responds to women as consumers of psychological services. The findings of this thesis will undoubtedly stimulate debate and perhaps controversy amongst mainstream clinical psychologists. Debate precedes change. As such, this thesis contributes to development of the wider field of clinical psychology. Finally, this research raises many questions about the future of clinical psychology training and how the broader discipline and institutional structure of clinical psychology can encourage and endorse practices that better serve the interests of women.

\section{Future Directions for the Development of Clinical Psychology Training}

The purpose of this section is to propose ideas for the future development of clinical psychology training in Aotearoa New Zealand that address the issues raised by the participants in this research. I also draw upon an array of literature from feminist and Māori knowledges, and work encompassed in the field of critical psychology. This section is included to contribute to ongoing debates around the construction of psychological knowledge and the role clinical psychology training programmes have in 
perpetuating certain kinds of knowledge that are both regulatory and oppressive. On the basis of my research findings, I argue that the formal inclusion of frameworks to enable the integration of analyses of power into the clinical psychology curricula would address many of the issues raised by the participants. If an analysis of power became integral and implicit to all areas of the clinical curricula, then an understanding of gender and other structural relations that shape human experience would offer a knowledge base that more adequately and comprehensively represented the lives of women and other marginalised groups. In this section, I address a range of strategies for locating power at the centre of clinical psychology training and practice. Collectively, these strategies offer a practical means to effect transformative change across the broad spectrum of clinical psychology, its disciplinary frameworks and institutional structure. As a starting point, I outline Jane Ussher's (2000b) critical-realist, feminist standpoint epistemological model which provides a comprehensive framework for psychological analysis and intervention.

Jane Ussher's Material-Discursive-Intrapsychic Model

Feminist psychologists have discussed ontological, epistemological, theoretical and methodological frameworks that can enable clinical psychology to shift beyond its narrow positivist-realist and individualist foundations (Marecek, 2001; Stoppard, 1999, 2000; Ussher, 1997, 2000b). Indeed, feminist writers have drawn attention to the importance of methodological pluralism in expanding the conceptual frameworks of psychology (Crawford and Kimmel, 1999; Stoppard, 2002; Ussher, 1999). On the basis of my research I argue that of particular relevance for the future development of clinical psychology is Ussher's (2002b) utilisation of critical-realist and feminist standpoint epistemologies and methodologies consistent with these approaches, that can provide an avenue through which to conceptualise multiple levels of analysis (Ussher, 2000b). In moving beyond unilinear analyses characteristic of mainstream clinical psychology, a multilevel analysis encompassing the material, discursive and intrapsychic offers a comprehensive framework for conceptualising experience as well as offering multi- 
levelled approaches to intervention that include the micro level of therapy through to macro politics and transformative social change (Ussher, 2000b). ${ }^{172}$

The material-discursive-intrapsychic model proposed by Ussher (2000b: 219) offers a fluid and interrelated approach and means that 'experience can be examined without privileging one level of analysis above the other'. This model therefore provides a route through the impasse presented by the either/or positions of strictly materialist or strictly discursive standpoints, while also incorporating and recognising the importance of the intrapsychic. In Dwight Fee's (2000: 14) words, this model 'fundamentally relies upon the multidimensional relationship between knowledge, structural oppressions and person-centered phenomenology. As such, Ussher's (2000b) model offers analytical frameworks applicable to all aspects of clinical psychology and an opportunity to shift towards a more comprehensive conceptual analysis applicable to diverse experiences, diverse groups of people, and diverse historical, sociopolitical and cultural contexts. In Ussher's (2000b: 219) words 'it is time all three levels together are incorporated into theory and practice'. Ussher's (2000b) model offers an epistemological analysis that could shift clinical psychology beyond its current positivist-realist focus and enable an approach that locates psychological knowledge and practice in the experiences, worldviews and material realities of women and other marginalised groups.

\section{Frameworks for Doing Psychology Critically}

In addition to Ussher's (2002b) model, ideas proposed by Isaac Prilleltensky and Geoffrey Nelson (2002) offer practical strategies that can enable clinical psychology training programmes to put power and the politics of psychological knowledge and practice at the centre of its agenda. They offer conceptual frameworks and practical applications for 'doing psychology critically'. The paradigm shift advanced by these writers has particular relevance for the future development of clinical psychology training. In addition, the critical-practitioner/activist model of training they advocate is consistent with that endorsed by Glen Larner discussed in Chapter One, who states that

\footnotetext{
${ }^{172}$ For diagrammatic representation of Ussher's model see Ussher (2000b: 225).
} 
clinical psychology needs a "broader, more critical application that takes into account qualitative and contextual aspects of practice - meaning, language, culture, spirituality, and relationship' (Larner, 2001: 41).

The critical psychology stance promoted by Prilleltensky and Nelson (2002) is values based, and in accordance with the work of feminist psychologists cited throughout this thesis, is explicitly political, locates power, equity and justice as fundamental to any conceptual frameworks in psychology, and is integrally concerned with emancipation, human rights and welfare. While many of the ideas advanced by Prilleltensky and Nelson (2002) reflect those common to feminist psychology, their publication, Doing Psychology Critically: Making a Difference in Diverse Settings, offers a concise and practical resource for the development and implementation of strategies for critical psychology education and practice which are readily applicable to clinical psychology training. The theoretical and methodological foundations of this approach emphasise values, assumptions and practices in teaching psychology from a critical position. In particular, this includes an emphasis on the holistic, relational, interconnected and contextual nature of well-being and explicit recognition of the historically, sociopolitically and culturally situatedness of knowledge construction processes. Central to their approach is the self-reflexive critique of dominant theories, methodologies and practices in psychology and exploration of the political interests served by dominant discourses. This involves the critique of taxonomies such as the DSM and the way meaning systems of this kind can be oppressive and discriminatory.

Within the frameworks proposed by Prilleltensky and Nelson (2002), macro processes relating to politics and the global environment are interwoven with the micro processes of classroom learning and clinical practice. Students are encouraged to reconceptualise "the personal" in terms of social inequalities and inequities, and to understand the way 'power suffuses our very own actions as psychologists and is 'multifaceted and omnipresent' (Prilleltensky and Nelson, 2002: 5-7). Students in my research identified the need for opportunities to address their own values and personal processes in a safe learning environment. This is consistent with Prilleltensky and Nelson's (2002) critical model of training. Further, differences between students and staff members stated values and behaviour, and the content of the curricula are explored, and both students 
and staff are encouraged to pursue political action. The paradigm shift proposed by Prilleltensky and Nelson (2002), like those endorsed by many feminist and Māori psychologists, requires movement beyond the borders of positivist psychology to engage ontological, epistemological, theoretical and methodological frameworks from interdisciplinary contexts. As Ussher (1992: 59) comments, 'psychology has been too insular as a discipline' and such changes are needed, particularly in clinical psychology, in order for it to 'progress and survive'.

\section{Treaty of Waitangi Frameworks}

While analyses of power relating to gender are limited in most clinical psychology programmes, some writers have identified how other analyses of power, such as those relating to the Treaty of Waitangi are impacting on psychology (Nikora, 2001). While the Treaty and associated bicultural knowledges and practices are still marginal in most clinical programmes (Nathan, 1999), Māori psychologists and others have developed analytical frameworks and protocols for implementation of the Treaty, and have identified a range of structural mechanisms through which the Treaty can be meaningfully incorporated within clinical psychology and the broader discipline in Aotearoa New Zealand (Herbert, 1998a, 1998b; Nikora, 2001; NSCBI, 1994; Pakeha Treaty Action, 1997). The ontological and epistemological positions advanced by Māori writers offer a way forward for clinical psychology by moving beyond narrow conceptions of the "psychological" to offer frameworks of health and well-being that encapsulate the dynamic, interconnectedness of multiple spheres (Durie, 2001). Positive changes made in relation to the Treaty within some clinical programmes are indicative of the ways clinical psychology can change when there is a commitment from Pakeha academic staff, ${ }^{173}$ adequate resourcing and appropriate institutional endorsement. While recognising the legislative status of the Treaty, ongoing consequences of colonial oppression, and significant efforts by Māori and others to ensure the Treaty gains institutional recognition within psychology, this model and the processes of its

\footnotetext{
${ }^{173}$ Including many European academic staff from Britain and North America.
} 
implementation may offer a framework for incorporating other analyses of power throughout clinical psychology.

\section{Strategies for Feminist Curriculum Development}

Drawing on contributions made by members of various working parties at the first National Conference on Education and Training in Feminist Practice in Boston 1993 as discussed in Chapter Three, I now examine possibilities for the future development of clinical psychology based on this body of feminist work. In particular, the recommendations of the feminist curriculum development working group have significance for guiding curriculum transformation in clinical psychology (Worell and Johnson, 1997a). This group identified key principles and values for feminist curriculum development that are explicitly inclusive of all women and grounded in 'women's diverse identities and sociocultural contexts' (Chin and Russo, 1997: 93). Such a curriculum explicitly recognises the shifting nature of experience and contexts in which knowledge is produced, the need for a dynamic and changing curricula, and the importance of political action. Eight principles for curriculum development were identified, each of which require examination of underlying assumptions and values, and the development of curriculum content and skills necessary for feminist practice. These include: diversity; egalitarianism and empowerment; self-determination including recognition of women's agency; acknowledgment of the complexity of peoples' realities and the importance of diverse representations of experience; collaboration and connection as a basis for all interactions and practice; social action and explicit recognition of psychologists as agents of social change as well as the need for critical examination of psychology's knowledge production processes; critical self-reflection and attention to ethical practice; and integrative, interdisciplinary conceptual frameworks and perspectives amenable to an understanding of the interconnectedness of the 'physiological, biological, psychological, sociocultural, spiritual, and situational' (Chin and Russo, 1997: 105). The contributors emphasised the longitudinal and multifaceted approach required to develop and implement feminist curricula which involves intervention from high school through to postgraduate education and 'all 
aspects of the educational experience, including training experiences, educational content, teaching processes and class-room climate' (Chin and Russo, 1997: 95).

Supervision is also an important feature of the curriculum. In particular, issues of power in the supervisor-supervisee relationship and 'reinforcing appropriate boundaries while promoting self-examination, avoiding dogmatic thinking or dualistic positions, and recognizing inherent biases within a power relationship are central (Chin and Russo, 1997: 109). ${ }^{174}$ Likewise, underlying feminist curriculum transformation is the need for feminist pedagogy (Kimmel and Worell, 1997). To this end the Feminist Pedagogy Working Group (Kimmel and Worell, 1997) provide a comprehensive model for implementing feminist principles and practices in teaching feminist psychology. ${ }^{175}$

Central to the development of a feminist and critical psychology curriculum is the - development of a body of readily available resources (Chin and Russo, 1997; Gergen, Chrisler and LoCicero, 1999). Chin and Russo (1997: 111) have discussed the need for texts and other literature and research, collections of course syllabi, bibliographies, and summaries of resources as a means to implement and sustain the ongoing development of feminist curricula. They emphasise the importance of electronic communications and databases as a means to access up-to-date information and facilitate interdisciplinary exchange. ${ }^{176}$ Innovative methods and associated resources for research, publishing and teaching psychology have also been put forward by other feminist psychologists (Gergen, Chrisler and LoCicero, 1999). Academic staff teaching clinical psychology require readily available resources of this kind to effectively incorporate analyses of gender and other relations of power throughout the clinical curriculum and to ensure

\footnotetext{
${ }^{174}$ For an appended version of 'Guiding principles for the education and training of health care professionals: An application of feminist principles of curriculum development' see Chin and Russo (1997: 114).

${ }^{175}$ For diagrammatic representation of this model see Kimmel and Worell (1997: 148-153).

${ }^{176}$ An already established body working for curriculum transformation across disciplines includes the National Center for Curriculum Transformation Resources on Women (Chin and Russo, 1997). This center is responsible for gathering and cataloguing resources and includes 'analyses of central issues in curriculum transformation work; bibliographies; model projects; lists of prior projects and consultants; revised syllabi; disciplinary critiques and contributions; and manuals on how to start projects, locate funding, evaluate projects and deal with resistance' (Chin and Russo, 1997: 112).
} 
adequate representation of this work is included in recommended reading lists distributed to students.

The importance and power of language is also central to the development of a clinical psychology and its movement beyond the positivist-realist, quasi-medical frameworks embodied in the DSM and other diagnostic practices, and the dominant discourses used to talk about women. As evidenced in my research, there were many instances where names, words and the more general language used by some students and staff belied an array of discriminatory and negative assumptions about women and other marginalised groups which effectively perpetuate inequalities. In addition, Boyle (1997: 236) notes "we need an alternative language in which to talk about psychological distress and disturbing behaviour, which avoids the assumptions of diagnostic categories'. To bring about any meaningful change, clinical psychology must take a critical and self-reflexive approach to the way language shapes realities and find a better language for talking about the effects of structural inequities on women's lives (Boyle, 1997; Crawford, 2001; Marecek, 2001; Williams and Watson, 1991c).

Williams and Watson's Workshop - Recommendations for Change

This section draws primarily on recommendations for change arising from Williams and Watson's Sexual Inequality and Clinical Psychology Training in Britain Workshop Report (1991c). Contributors to Williams and Watson's (1991c) workshop provided a range of strategies to enhance knowledge and understanding of the effects of inequalities and to improve the way this knowledge is incorporated in clinical psychology training. Their aim was to identify key factors that would enable graduates to work effectively with the psychological consequences of inequality' and strategies that would 'ensure that sexual inequality training is commonplace in British clinical psychology courses' (Williams and Watson, 1991c: 102). While it is recognised that strategies for change are needed at multiple levels they recommended that a new agenda for training is required. To this end they identified key areas where change could be effectively targeted, offered ideas for curriculum development and ways to effect 
change both amongst clinical educators and within clinical psychology's institutional organisation.

First and foremost, workshop contributors emphasised the need for course organisers to seriously address the importance of integrating teaching about gender inequalities, 'race', class, poverty and other analyses of power throughout clinical training and as a foundational basis of training programmes (Williams and Watson, 1991b). Key issues arising from the workshop include taking a critical stance in relation to dominant psychological theories and practices that 'reproduce the sexual status quo' (Williams and Watson, 1991c: 102). They also stressed the importance of moving beyond the individual to examine the ways the sociopolitical context shape women's lives. Contributors stressed the importance of addressing the knowledge base of clinical psychology which must be grounded in peoples experiences and should regard those experiences as legitimate and valuable sources of knowledge; be informed by feminist theories, methodologies and research, and interdisciplinary knowledges, especially those that take a critical epistemological stance; and recognise the multiple inequalities and inequities associated with gender, class, 'race' and other dimension of power. Contributors also encouraged clinical psychologists to critically examine the ways the dominant discourses and practices of clinical psychology maintain structural inequities that are harmful to women. They recommended that this diverse knowledge base should be central to clinical training as well as to the development of gender education guidelines and the ongoing education of students, staff and supervisors.

Changing the agenda of clinical training requires a shift in epistemological and methodological orientation and the utilisation of literature and research from interdisciplinary contexts. Contributors to Williams and Watson's (1991c) workshop, like Bekker (1991) cited previously, were adamant that there is an ample body of published work and resources available to inform this curricula change.

In addition, the workshop strongly recommended 'cutting across boundaries that typically divide us - service user from service provider; academic from clinical psychologist; trainer from trainee (Williams and Watson, 1991c: 109). Gender education workshops for clinical supervisors and the establishment of a working party 
to monitor gender education and other issues in the selection and teaching of students were also recommended. Further, Williams and Watson's research (1991b, 1991c) addresses the need to incorporate gender education into accreditation guidelines and the requirements of psychology's national professional organisation. Similarly, Chin and Russo (1997) note that feminist principles need to be incorporated into accreditation standards within psychology if curriculum changes are to occur. Williams and Watson (199b: 87) comment that it seems crucial that psychology's professional organisation endorses such initiatives by 'setting agendas for academic and clinical training... [and] by specifying criteria for evaluation'. This issue was raised by some staff in my research as accreditation requirements have yet to be established in Aotearoa New Zealand. However, the National Association of Clinical Psychology Training Programmes recently formed in this country could make significant changes in the clinical curriculum by setting minimum requirements for clinical training, for establishing frameworks for the implementation and evaluation of these requirements, and in working towards the establishment of accreditation criteria.

The recruitment and retention of feminist staff is also required if clinical psychology is to undergo any transformative change in the way it incorporates analyses of gender and represents women's lives. To encourage and promote change of this nature, clinical trainers, along with their colleagues in the broader discipline and profession of psychology, need to address the continued stigmatisation of feminists and feminist knowledges and to recognise how tolerance of discrimination of this kind adversely affects all women. Indeed, it is imperative that feminist knowledges become normative and legitimate forms of knowledge within clinical curricula and throughout graduate and undergraduate psychology. This requires a commitment from all academic staff and a more open and reflexive approach to the epistemological, methodological and theoretical approaches staff adopt in their teaching, research and practice of psychology. In addition, the provision of incentives such as awards and scholarships for feminist scholarship needs to occur as a means to support students in their pursuit of feminist developments in psychology (Chin and Russo, 1997). Chin and Russo (1997) note that curriculum transformation in psychology requires the involvement of feminists at all levels of the institutional hierarchy, including in policy making, as directors of training, in accreditation and registration processes, and as part of regulatory bodies. 
In addition to making analyses of power central to the clinical curriculum change could be facilitated by making gender courses a prerequisite to enrolment in clinical training, and ensuring gender education courses are a dedicated part of the clinical curriculum. While some staff in this research were resistant to the idea of compulsory gender education courses, trainers need to seriously question priorities in the core curriculum and the relevance of other clinical courses which, while having limited application, are themselves mandatory. Furthermore, a multi-faceted approach to the incorporation of gender and other analyses of power is required throughout clinical psychology training, as well as in graduate and undergraduate psychology. It is only by providing a systematic and ongoing approach that students will be able to develop an understanding of the theories and knowledges that provide a framework for understanding analyses of power. This approach would complement work already being undertaken in relation to the implementation of the Treaty of Waitangi in Aotearoa New Zealand and strengthen student and staff understanding of power across multiple dimensions.

\section{Institutional Change}

Feminist psychologists recognise that transformative and sustained change does not occur in a vacuum. Endorsement of feminist knowledges, research and practices, and the inclusion of analyses of gender throughout clinical psychology requires change at the broad institutional level (Bekker, 1991; Hare-Mustin and Marecek, 1997; Williams and Watson, 1991b, 1991c; Wilkinson, 1996). Although this has not been a focus of my research, I am mindful that psychology's professional organisations in the USA, Britain, Canada and Australia have well established feminist or women and psychology divisions. However, the NZPsS has long resisted the establishment of such a grouping (Lapsley and Wilkinson, 2001) which has implications for the integration of feminist knowledges throughout psychology.

Institutional endorsement seems imperative to bring about transformative and lasting change, and as evidenced internationally, gives feminist psychologists a stronger position to consolidate the energy and resources needed to lobby for such changes. Chin 
and Russo (1997) note that the American Psychological Association's Division of Women could be instrumental in establishing a curriculum transformation task force as a 'clearing house for the dissemination of feminist curriculum materials within psychology and across disciplines'. By having an officially sanctioned role within psychology's professional organisations, feminist and other critical psychologists are better able to establish a legitimate forum for discussion and debate at conferences, and contribute to ongoing commentary both via peer review processes and more informal channels. In addition, institutional sanctioning could give feminist psychologists better leverage to lobby for appropriate representation in the executive of psychology's professional organisations and provide a formal mechanism for contributing to the standards of training and education directorates which affect academic psychology courses such as clinical psychology training. As Bekker (1991) concludes, future change in clinical psychology training depends on the continued action of feminist psychologists in positions of influence in the organisational structure of psychology. As the National Association of Clinical Psychology Training Programmes is currently establishing itself, it seems timely and appropriate for this group to enlist the expertise of feminist psychologists to shape the future of clinical psychology training.

\section{Limitations of my Research/Suggestions for Future Research}

While I have focused on women and gender in this research there is a need to address conceptual frameworks for integrating multiple dimensions of power in future research related to clinical psychology training and the broader field of psychology. Various writers have proposed frameworks for conceptualising the integration of gender, 'race' and ethnicity (Ginorio and Martinez, 1998; Madden and Hyde, 1998; Okazaki, 1998), and the integration of race, class, gender and sexuality (Weber, 1998). Work in this area is gaining increasing recognition within feminist psychology, although until recently has often been ignored or marginalised within both feminist and mainstream psychology (Greene and Sanchez-Hucles, 1997). Greene and Sanchez-Hucles (1997: 194) note that 'it is imperative that psychology training programs make diversity a routine and not tangential feature of training'. To this end the recommendations of Greene and SanchezHucles (1997) working group on ways to advance an inclusive feminist psychology by 
embracing diversity are pertinent. Future research needs to focus on the implementation of conceptual frameworks for integrating multiple dimensions of power, rather than has historically been the case, focusing on singular dimensions as if they were separate from and not mediated by, other sites of power.

Although I have focused on women and gender in this research, it is important to note that gender education is not only about women. Boyle (1997: 235) comments that "we must name the effects of sexual inequality on men if we are to avoid a gender-based analysis which is about (weak) women, but not for women'. Further, as Boyle (1997: 235) comments, in 'making gender visible' we need to highlight the negative effects of gender inequalities on men (such as 'macho' behaviour, and male dominance, control and violence) which are currently 'normalised', 'obscured' and 'protected from scrutiny' in clinical psychology. Research to examine these issues would contribute significantly to the development of clinical psychology training and practice.

While I had originally intended including women consumers in my research, this was regarded as too large a project for this particular research. However, I recognise that although there is a significant body of literature addressing women's experiences of psychiatry there has been little attention to women's experiences of clinical psychology (Hare-Mustin and Marecek, 1997). Given that clinical psychology has many parallels with the medical and pathological models of psychiatry (Hare-Mustin and Marecek, 1997; Marecek, 2001) research with women consumers is an important aspect of future research concerning many of the issues raised in this research.

The limited representation of Maori students in clinical psychology programmes, and in my research, leaves gaps in the way issues of 'race', gender and other relations of power are addressed. Future research aimed at investigating the interface of these dimensions, specific to the local context, is another avenue for exploration.

Throughout my research there were discrepancies between what staff and students reported was included in the clinical curriculum. There are many possible explanations for these differences reflecting the different positions and backgrounds that staff and students bring to the clinical arena. However, what seems important is that students in 
this research did not regard their clinical psychology training as adequate in providing an analysis of gender or other power relations, despite this knowledge being regarded as important to understanding women's lives and central to their work as clinical psychologists. It therefore seems imperative to examine this issue in future research about clinical training. In the meantime it is important that staff explore this issue in an ongoing and self-reflexive way and develop better co-ordination of the clinical curriculum to ensure students gain a comprehensive analysis of power and understanding of issues regarded as central to competent, responsible and ethical clinical practice.

Another area that could be usefully investigated is the way gender education is integrated and delivered in clinical training and the effectiveness of various approaches to training. As discussed in this research, many students were dissatisfied with the reliance on students to provide education about gender and thought this was an ineffective way of ensuring gender and diversity education was included. Further, the lack of encouragement and active endorsement of topics and courses that focus on gender and the use of feminist or other critical research methodologies, was regarded as problematic. It would therefore be useful to undertake an analysis of staff ideas and practices relating to knowledges and components of training they think are important for clinical practice, to compare these with what students regard as important to their ability to work with diverse groups of people, and to address the ways these respective content areas are prioritised in the curricula.

The epistemological and methodological position taken in my research constitutes one way of examining issues of gender and power in clinical psychology training. The use of coding schemes used when taking a constant comparative approach rest on 'a "powerful conceptual grid" from which it is difficult to escape' (Denzin and Lincoln, 1994: 825). Similarly, a reliance on the perceptions of students and staff involved in clinical training tells little about the way consumers, especially women and other marginalised groups, experience the practice of clinical psychology. The inclusion of consumers, and the adoption of alternative epistemological and methodological frameworks, might provide different accounts of the way issues of gender and power are understood and conveyed within clinical psychology. 
Limits on word length in this thesis led to the exclusion of a chapter devoted to the analysis of interviews with feminist clinical psychologists. While this exclusion can be regarded as a gap in the thesis, the breadth and depth of the research meant decisions had to be made about priorities for the thesis. As such, I prioritised the inclusion of analyses central to the purpose of the research which centred on the nature and content of gender and power analyses in the clinical curriculum at the present time. My motivations for including the FCP group was not only to add to the picture about the current status of clinical training (as included in the thesis), but also to canvass ideas from 'experts' in the field about how analyses of power can inform clinical training in the future. In hindsight, this latter goal was somewhat ambitious and could constitute a thesis in its own right. Further analysis of data from this group would undoubtedly be beneficial in understanding why and how curriculum content relating to gender and power is constrained in clinical training, and offer insights about the way these participants incorporate critical frameworks in their clinical teaching, research and practice.

There are numerous possibilities for future research in this area. Taking a discourse analytic approach could be useful in highlighting a range of discursive strategies that operate to privilege dominant cultural meanings within the context of clinical psychology training. As an example, such an approach could be utilised to examine the way participants' narratives about the inclusion of analyses of power in clinical training (such as male violence) often draw on dominant cultural stories and stereotypes which operate to perpetuate a lack of understanding of the gendered dynamics of power and the impact of violence in women's lives. Similarly, research involving a textual analysis of clinical psychology curricula based on recorded sessions and written materials used across a range of courses within clinical training could offer useful insights into disciplinary power/knowledge. Further, a comparative study exploring differences in education between programmes in Aotearoa New Zealand and feminist and critical psychology programmes internationally could be beneficial in signalling routes for the future development of clinical training. Finally, taking a poststructural position may offer a more complex analytical approach useful in highlighting multiple meanings and pointing to innovative strategies for change. 


\section{Conclusion}

On the basis of the research undertaken, I argue that clinical psychology training in Aotearoa New Zealand is in need of significant change to better represent the interests and needs of women. As Ussher (2000b: 227) comments, 'if we look outwards from our own ideological and professional boundaries, we may surprise ourselves at what can be achieved'. Echoing comments made by Māori, feminist and other critical writers throughout this thesis, clinical psychology needs to reconsider the nature of its curriculum content, the diversity of literature, resources and research used in clinical training, and the positioning of Māori and feminists as 'deficient' Other within clinical psychology's dominant discourses. The future of clinical psychology depends on politicisation, disruption of the status quo, responsiveness to challenges posed by those from diverse ontological and epistemological standpoints, and in particular, offering a more broadly conceptualised approach to 'psychological' knowledge that adequately captures the way structural relations of power shape the experiences, realities and material conditions of women's lives. 


\section{Bibliography}

Abbott, M.W., \& Durie, M.H. (1987) A whiter shade of pale: Taha Māori and professional psychology training. New Zealand Journal of Psychology, 16: 58-71

Adams, P.J., Towns, A., \& Gavey, N. (1995) Dominance and entitlement: The rhetoric men use to discuss their violence toward women. Discourse and Society, 6: 387-406

Adcock, C., \& Newbigging, K. (1990) Women in the shadows: Women, feminism and clinical psychology. In E. Burman (Ed). Feminists and Psychological Practice (pp. 172-188). London: Sage

Addis, M.E. (2000) Graduate training in the Boulder model clinical psychology programs: The evolving tension between science and art. In S. Soldz \& L. McCullough (Eds). Reconciling Empirical Knowledge and Clinical Experience. The Art and Science of Psychotherapy. (pp. 51-66). Washington DC: American Psychological Association

Albee, G.W. (2000) The Boulder Model's fatal flaw. American Psychologist, 55(2): 247-248

Allen, F. (1995) Feminist theory and cognitive behaviorism. In W. O'Donohue \& L. Krasner (Eds). Theories of Behavior Therapy. Exploring Behavior Change (pp. 495-528) Washington DC: American Psychological Association

Allen, N.B. (1996) Cognitive psychotherapy. In S. Bloch (Ed). An Introduction to the Psychotherapies: Third edition (pp. 167-191). Oxford: Oxford University Press

American Psychiatric Association (1994) Diagnostic and Statistical Manual of Mental Disorders IV. Washington DC: American Psychiatric Association

Andrews, H. (2001) Back to basics: Psychotherapy is an interpersonal process. Australian Psychologist, 36(2): 107-114

Appleby, Y. (1992) Disability and 'compulsory heterosexuality'. Feminism and Psychology, 2(3): 502-505

Arkoff, D.B., \& Glass, C.R. (1992) Cognitive therapy and psychotherapy integration. In D.K. Freedheim (Ed). History of Psychotherapy: A Century of Change (pp. 657694). Washington, DC: American Psychological Association

Afshar, H., \& Maynard, M. (Eds) The Dynamics of 'Race' and Gender: Some Feminist Interventions. London: Taylor and Francis 
Aitken, G. (1996) The present absence/pathologized presence of black women in mental health services. In Burman, E., Aitken, G., Alldred, P., Allwood, R., Billington, T., Goldberg, B., Gordo Lopez, A.J., Heenan, C., Marks, D., \& Warner, S. Psychology Discourse Practice: From Regulation to Resistance (pp. 75-95). London, Gunpowder Square: Taylor \& Francis

Asch, A., \& Fine, M. (1992) Beyond pedestals: Revisiting the lives of women with disabilities. In M. Fine (Ed) Disruptive Voices. The Possibilities of Feminist Research (pp. 139-172). Ann Arbor: The University of Michigan

Atkins, D.C., \& Christensen, A. (2001) Is professional training worth the bother? A review of the impact of psychotherapy training on client outcome. Australian Psychologist, 36(2): 122-130

Awatere, D. (1984) Maori Sovereignty. Auckland: Broadsheet

Bakers Dozen. (1997) Feminist student voices. In J. Worell \& . N. Johnson (Eds) Shaping the Future of Feminist Psychology: Education, Research and Practice (pp. 227-244). Washington DC: American Psychological Society

Bandura, A. (1977) Social Learning Theory. New Jersey, Englewood Cliffs: PrenticeHall

Banister, P., Burman, E., Parker, I., Taylor, M., \& Tindall, C. (1994) Qualitative Methods in Psychology. A Research Guide. Buckingham: Open University Press

Banks, M.E., Ackerman, R.J., \& Corbett, C.A. (1995) Feminist neuropsychology: Issues for physically challenged women. In J. Chrisler \& A. Hemstreet (Eds) Variations on a Theme: Diversity and the Psychology of Women (pp. 29-49). Albany: State University of New York Press

Barrett, M. (1987) The concept of "difference". Feminist Review, 26: 29-41

Basco, M.R., \& Rush, A.J. (1996) Cognitive-Behavioral Therapy for Bipolar Disorder. New York: The Guilford Press

Baydala. A. (2001) The soliloquy of empirical validation in cognitive psychology. Australian Psychologist, 36(1): 44-50

Beck, A.T. (1967) Depression: Clinical, Experimental and Theoretical Aspects. New York: Hoeber Medical Division, Harper \& Row

Beck, A.T. (1985) Cognition and Psychotherapy. New York: Plenum Press

Beck, A.T. (1988) Cognitive approaches to panic disorder: Theory and therapy. In S. Rachman \& J. Maser (Eds). Panic: Psychological Perspectives (pp. 91-109). New Jersey, Hillsdale: Lawrence Erlbaum 
Beck, A.T., Emery, G., \& Greenberg, R.L. (1985) Anxiety Disorders and Phobias: A Cognitive Perspective. New York: Basic Books

Beck, A.T., \& Freeman, A.M. (1990) Cognitive Therapy of Personality Disorders. New York: Guilford Press

Beck, A.T., Rush, A.J., Shaw, B.F., \& Emery, G. (1979) Cognitive Therapy of Depression. New York: Guilford

Beck, A.T., Sokol, L., Clark, D.A., Berchick, R.J., \& Wright, F.D. (1992) A crossover study of focused cognitive therapy for panic disorder. American Journal of Psychiatry, 149(6): 778-783

Beck, J.S. (1995) Cognitive Therapy. Basics and Beyond. New York: The Guilford Press

Bekker, M.H.J. (1991) Sex inequality in the training of Dutch clinical psychologists. Feminism \& Psychology, 1(1): 96-100

Bell, S., \& Gordon, J. (1999) Scholarship - the new dimension to equity issues for academic women. Women's Studies International Forum, 22(6): 157-163

Belle, D., \& Doucet, J. (2003) Poverty, inequality and discrimination as sources of depression amongst U.S. women. Psychology of Women Quarterly, 27:101-113

Benjamin, LT., \& Baker, D.B. (2000) Boulder at 50. American Psychologist, 55(2): 233-237

Bennun, I. (1994) Marital conflict: Treatment. In S.J.E Lindsay \& G.E. Powell (Eds). The Handbook of Clinical Adult Psychology: Second edition (pp. 283-294). London: Routledge

Bergin, A.E \& Garfield, S.L. (Eds) (1994) Handbook of Psychotherapy and Behavior Change: Fourth edition. New York: John Wiley \& Sons

Bhaskar, R. (1989) Reclaiming Reality. A Critical Introduction to Contemporary Philosophy. London: Verso

Bhavnani, K., \& Phoenix, A. (1994) Shifting identities, shifting racisms. Feminism and Psychology, 4(1): 5-18

Bird, L. (1998) Dances with feminism: Sidestepping and sandbagging. In E.Burman (Ed). Deconstructing Feminist Psychology (pp. 90-114). London: Sage

Blackburn, A., \& Davidson, D. (1995) Cognitive Therapy for Depression and Anxiety. Oxford: Blackwell Science

Blackman, L.M. (1996) 'The dangerous classes: Retelling the psychiatric story'. Feminism \& Psychology, 6(30): 361-380 
Bloch, S. (Ed) (1996) An Introduction to the Psychotherapies: Third edition. Oxford: Oxford University Press

Bohan, J.S. (Ed) (1992) Seldom Seen, Rarely Heard: Women's Place in Psychology. Boulder, CO: Westview Press

Booker, M. (2002) Stories of violence: Use of testimony in a support group for Latin American Battered Women. In L.H. Collins., M.R. Dunlap., \& J.C. Chrisler (Eds) Charting a New Course for Feminist Psychology (pp.307-320). Westport, CT: Praeger Publishers

Bostock, J. (1997) Clinical psychology: Research/practice. Knowing our place: Understanding women's experiences and causes of distress. Feminism \& Psychology, 7(2): 239-247

Boyle, M. (1994) Gender, science and sexual dysfunction. In T.R. Sarbin \& J. Kitsuse (Eds) Constructing the Social. London: Sage

Boyle, M. (1997) Clinical psychology: Theory. Making gender visible in clinical psychology. Feminism and Psychology, 7(2): 231-238

Braebeck, M., \& Brown, L. (1997) Feminist theory and psychological practice. In J. Worrell \& N. Johnson (Eds). Shaping the Future of Feminist Psychology. Education, Research, Practice (pp. 15-35). Washington DC: American Psychological Association

Brassington, J.C. (1996) Student opinion on the development of a doctorate of clinical psychology degree in New Zealand. New Zealand Journal of Psychology, 89: 32-36

Brown, L.S. (1991) Plus ca change ... or, who writes the scripts for these guys anyway? Feminism \& Psychology, 1(1):89-92

Brown, L.S. (1994) Subversive Dialogues. Theory in Feminist Therapy. New York: Basic Books.

Brown, L.S. (1995) Cultural diversity in feminist therapy: Theory and practice. In H. Landrine (Ed). Bringing Cultural Diversity to Feminist Psychology (pp. 143-161). Washington DC: American Psychological Association

Brown, L.S. (1997). Ethics in psychology. Cui bono? In D. Fox \& I. Prilleltensky (Eds). Critical Psychology: An Introduction (pp. 51-67). California, Thousand Oaks: Sage

Brown, L.S \& Ballou, M. (Eds) (1992) Personality and Psychopathology. Feminist Reappraisals. New York: The Guilford Press

Bruce, R.J., \& Sanderson, W.C. (1998) Specific Phobias. Clinical Applications of Evidence-Based Psychotherapy. New Jersey: Jason Aronson 
Burman, E. (Ed) (1990b) Feminists and Psychological Practice. London: Sage

Burman, E. (1996a) Introduction: Contexts, contests and interventions. In E. Burman, P. Alldred, C. Bewley, B. Goldberg, C. Heenan, J., D. Marks, Marshall, K. Taylor, R. Ullah \& S. Warner. Challenging Women. Psychology's Exclusions, Feminist Possibilities (pp. 1-16). Buckingham: Open University Press

Burman, E. (1996b) Psychology discourse practice: From regulation to resistance. In E. Burman, G. Aitken, P. Alldred, R. Allwood, T. Billington, B. Goldberg, A.G. Lōpez, C. Heenan, D. Marks \& S. Warner (Eds). Psychology Discourse Practice: From Regulation to Resistance (pp. 1-14). London: Taylor \& Francis

Burman, E. (1997) Differentiating and de-developing critical social psychology. In T. Ibanez \& L. Iniguez (Eds.). Critical Social Psychology (pp. 229-240). London: Routledge

Burman, E. (1998) Deconstructing Feminist Psychology. London: Routledge

Burman, E \& Parker, I. (Eds) (1993) Discourse Analytic Research: Repertoires and Readings of Texts in Action. London and New York: Routledge

Burns, J. Mad or just plain bad? Gender and the work of forensic clinical psychologists. In J.M. Ussher \& Nicolson, P. (Eds) Gender Issues in Clinical Psychology (pp. 106-128). London: Routledge

Burt, S. \& Code, L. (Eds) (1995) Changing Methods. Feminists Transforming Practice. Ontario, Canada: Broadview Press

Busch, R., \& Robertson, N.R. (1993) The gap goes on: An analysis of issues under the Domestic Violence Act 1995. New Zealand Universities Law Review, 17: 337-378

Bushnell, J. (1995) AGM Report. New Zealand Clinical Psychologist, 6(3): 2-5

Butler, G. (1989) Issues in the application of cognitive and behavioral strategies to the treatment of social phobia. Clinical Psychology Review, 9: 91-107

Caplan, P.J. (1995) They Say You're Crazy: How the World's Most Powerful Psychiatrists Decide Who's Normal. Reading, MA: Addison-Wesley

Caplan, P.J., \& Gans, M. (1991) Is there empirical justification for the category of 'Self-defeating Personality Disorder'? Feminism \& Psychology: An International Journal, 1(2): 263-278

Caplan, P.J., McCurdy-Myers, J., \& Gans, M. (1992) Should 'Pre-menstrual Syndrome' be called a psychiatric abnormality? Feminism Psychology: An International Journal, 2(1): 27-44 
Carlson, N.R., Buskit, W., \& Martin, G.N. (2000) Psychology. The Science of Behaviour. European Adaptation. Great Britain: Pearson Education

Chambless, D.L., \& Gillis, M.M. (1993) Cognitive therapy of anxiety disorders. Journal of Consulting and Clinical Psychology, 61: 248-260

Chambless, D.L., Sanderson, W.C., Shoham, V., Johnson, S.B., Pope, K.S., CritsChristoph, P., Baker, M., Johnson, B., Woody, D.R., Sue, S., Beutler, L., Williams, D.A., \& McCurry, S. (1996) An update of empirically validated theories. The Clinical Psychologist, 49(2): 5-18

Chesler, P. (1972) Women and Madness. New York: Avon

Cheung, F.M. (1991) Consciousness-raising of gender issues in clinical psychology training: A community psychology approach. Feminism and Psychology 1(1): 93-95

Chin, J.L., \& Russo, N.F. (1997) Feminist curriculum development: Principles and resources. In J Worell \& N.G. Johnson (Eds). Shaping the Future of Feminist Psychology. Education, Research, and Practice (pp. 93-120) Washington, DC: American Psychological Association

Clark, D.M., Salkovskis, P.M., Hackmann, A., Middleton, H., \& Gelder, M. (1992) A comparison of cognitive therapy, applied relaxation, and imipramine in the treatment of panic disorder. British Journal of Psychiatry, 164, 759-769

Clarke, V. (2000) Lesbian mothers: Sameness and difference. Feminism and Psychology, 10(2): 273-278

Code of Ethics Review Group (2002) Code of Ethics for Psychologists Working in Aotearoa/New Zealand. (Version for confirmation)

Collins, L.H., Dunlap, M.R \& Chrisler, J.C. (Eds) (2002) Charting a New Course for Feminist Psychology. Westport: Praeger Publishers

Collins, P.H. (1991) Learning from the outsider within: The sociological significance of black feminist thought. In M.M Fonow \& J.A. Cook (Eds). Beyond Methodology. Feminist Scholarship as Lived Research (pp. 35-59). Bloomington: Indiana University Press

Collins, P.H. (1997) Comment on Hekman's "Truth and Method: Feminist standpoint theory revisited": Where's the power? Signs: Journal of Women in Culture and Society, 22(2): 375-381

Coney, S. (1988) The Unfortunate Experiment. Auckland: Penguin

Corballis, M.C. (1990) The two profiles of psychology. New Zealand Journal of Psychology 19: 2-8 
Cotterill, P. (1992) Interviewing women: Issues of friendship, vulnerability, and power. Women's Studies International Forum 15(5-6): 593-606

Courchaine, K.E., \& Dowd, E.T. (1994) Groups. In F.M Dattilio \& A. Freeman (Eds). Cognitive-Behavioral Strategies in Crisis Intervention (pp. 221-237). New York: The Guilford Press

Cram, F. (1993) Ethics in Māori research: Working paper. In L.W. Nikora (Ed). Cultural Justice and Ethics (pp. 31-36). Proceedings of a Symposium held at the Annual Conference of the New Zealand Psychological Society, Victoria University of Wellington, 23-24 August 1993

Cram, F. (2001a) Ma Te Wa e Whakaatu Mai: Time will tell. Feminism \& Psychology, 11(3): 401-406

Cram, F. (2001b) Rangahau Māori: Tona tika, tona pono - The validity and integrity of Māori research. In M. Tolich (Ed). Research Ethics in Aotearoa New Zealand (pp. 35-52). Auckland: Pearson

Crawford, M. (2001). Gender and language. In R.K. Unger (Ed) Handbook of the Psychology of Women and Gender (pp.228-244). New York: John Wiley

Crawford., M \& Kimmel, E.B. (1999) Promoting methodological diversity in feminist research. Psychology of Women Quarterly, 23(1):1-6

Crowley, H.., \& Himmelweit, S. (Eds) (1992) Knowing Women: Feminism and Knowledge. Cambridge: The Polity Press

Cumming, G., \& Hyslop, W. (1998) Professional training in psychology and academic staff profiles in Australian universities. Australian Psychologist, 33(1): 62-67

Dattilio, F.M., \& Freeman A. (Eds) (2000) Cognitive-Behavioral Strategies in Crisis Intervention. Second Edition. New York: The Guilford Press

Davar, B.V. (2001) Gender and mental health: Inter-disciplinary perspectives, In B.V. Davar (Ed) Mental Health from a Gender Perspective (pp.13-33). New Delhi: Sage

Davis, K., Leijenaar, M \& Oldersma, J. (Eds) (1991) The Gender of Power. London: Sage

Davdison, G.C., \& Neale, J.M. (2001) Abnormal Psychology: Eighth edition. New York: John Wiley \& Sons

de Groot, J., \& Maynard, M. (Eds) (1993) Women's Studies in the 1990's. Doing Things Differently? New York: Macmillan Press

Denmark, F.L. (1998) Women and psychology. An international perspective. American Psychologist, 53(4): 465-473 
Denzin, N.K., \& Lincoln, Y.S. (Eds) (1994) Handbook of Qualitative Research. California: Sage

Department of Health (2001) Treatment Choice in Psychological Therapies and Counselling. Evidence Based Clinical Guidelines. London, UK: Department of Health

de Vries, H.M., \& Gallegher-Thompson, D. (1994) Older adults. In F.M Dattilio \& A. Freeman (Eds). Cognitive-Behavioral Strategies in Crisis Intervention (pp. 200220). New York: Guilford Press

DiGiuseppe, R. (1993) Comprehensive cognitive-behavior therapy with a socially isolated child. In K.T Kuehlwein \& H.R. Rosen (Eds). Cognitive Therapies in Action. Evolving Innovative Practice (pp. 160-184). California, San Francisco: Jossey-Bass

Dobson, K.S. (1988) The present and future of the cognitive-behavioral therapies. In K.S. Dobson. Handbook of Cognitive-Behavioral Therapies (pp. 387-418). New York: The Guildford Press

Drummond, L. (1996) Behavioural psychotherapy. In S. Bloch (Ed). An Introduction to the Psychotherapies: Third edition (pp. 137-166). Oxford: Oxford University Press

Duelli Klein, R. (1983) How to do what we want to do: Thoughts about feminist methodology. In G. Bowles \& R. Duelli Klein (Eds). Theories of Women's Studies (pp. 88-104). London: Routledge and Kegan Paul

Du Plessis, R., \& Alice, L (Eds) (1998) Feminist Thought in Aotearoa New Zealand: Connections and Differences. Auckland: Oxford University Press

Durie, M. (2001) Mauri Ora: The Dynamics of Māori Health. New Zealand, Auckland: Oxford University Press

Ellis, A. (1962) Reason and Emotion in Psychotherapy. New Jersey, Secaucus: Lyle Stuart and Citadel Press

Epstein, N., \& Schlesinger, S.E. (1994) Couples problems. In F.M Dattilio \& A. Freeman (Eds). Cognitive-Behavioral Strategies in Crisis Intervention (pp. 258277). New York: Guilford Press

Espin, O., \& Gawalek, M. (1992) Women's diversity: Ethnicity, race, clan and gender in theories of feminist psychology. In L. Brown \& M. Ballou (Eds). Personality and Psychopathology: Feminist Reappraisals (pp. 88-107). New York: Guilford Press

Farran, D. (1990) 'Seeking Susan'. Producing statistical information on young people's leisure. In L. Stanley (Ed). Feminist Praxis. Research, Theory and Epistemology in Feminist Sociology (pp. 91-102). London: Routledge 
Fee, D. (Ed) Pathology and the Postmodern. London: Sage

Fine, M. (1993) Introduction. Women with disabilities: Found voices. Women \& Therapy, 14, 3/4: 1-5

Fine, M. (1994) Working the hyphens. Reinventing self and other in qualitative research. In N.K Denzin \& Y.S. Lincoln (Eds). Handbook of Qualitative Research (pp. 70-82). California: Sage

Fine, M., \& Asch, A. (1988) Women with Disabilities: Essays in Psychology, Culture and Politics. Philadelphia: Temple University Press

Fine, M., \& Gordon, S.M. (1991) Effacing the center and the margins: Life at the intersection of psychology and feminism. Feminism and Psychology, 1(1): 19-27

Fine, M., Weis., L., Powell., L.C., \& Wong., L.M. (Eds) Off White: Readings on Race, Power, and Society. New York: Routledge.

Foa, E.B., \& Rothbaum, B.O. (1998) Treating the Trauma of Rape: CognitiveBehavioral Therapy for PTSD. New York: Guilford Press

Fodor, I.G. (1988) Cognitive behaviour therapy: Evaluation of theory and practice for addressing women's issues. In M.A.Dutton-Douglas \& L.E. Walker (Eds). Feminist Psychotherapies. Integration of Feminist Systems (pp. 91-117). New Jersey: Ablex Publishing

Fodor, I.G. (1993) A feminist framework for integrative psychology. In G. Stricker \& J.R. Gold (Eds). Comprehensive Handbook of Psychotherapy Integration (pp. 217235). New York: Plenum

Fonow, M.M., \& Cook, J.A. (1991) Back to the future: A look at the second wave of feminist epistemology and methodology. In M.M Fonow \& J.A. Cook (Eds). Beyond Methodology. Feminist Scholarship as Lived Research (pp. 1-15). Bloomington: Indiana University Press

Fox, D., \& Prilleltensky, I. (Ed) (1997) Critical Psychology: An Introduction. London: Sage

Friedan, B. (1963) The Feminine Mystique. New York: Norton

Frith, H. (2001) Editors' introduction: Young women, feminism and the future: Dialogues and discoveries. Feminism \& Psychology, 11(2): 147-151

Fuss, D. (1997) The 'risk' of essence. In S. Kemp \& J. Squire (Eds). Feminisms (pp. 250-258). Oxford: Oxford University Press

Gauld, R. (2001) Health ethics committees, methodological review and qualitative research. In M. Tolich (Ed). Research Ethics in Aotearoa New Zealand (pp. 113126). Auckland: Pearson 
Gavey, N. (1989) Feminist poststructuralism and discourse analysis: Contributions to feminist psychology. Psychology of Women Quarterly, 13: 459-475

Gavey, N. (1990) Rape and Coercion within Heterosexual Relationships: An Intersection of Psychological, Feminist and Postmodern Inquiries. Unpublished doctoral dissertation, University of Auckland

Gavey, N. (1992) Technologies and effects of heterosexual coercion. Feminism and Psychology: An International Journal, 2(3): 325-51

Gavey, N. (1996) Women's desire and sexual violence discourse. In S. Wilkinson (Ed). Feminist Social Psychologies. International Perspectives (pp. 51-65). Buckingham: Open University Press

Gavriel, A. (1993) Hellenic Views of Mental Health. Paper presented School of Nursing and Midwifery, Victoria University, 2000

Gergen, M., Chrisler, J.C., \& LoCicero, A. (1999) Innovative methods: Resources for research, publishing, and teaching. Psychology of Women Quarterly, 23: 431-456

Ginorio, A.B. (1998) Where are the Latina? Ethno-race and gender in psychology courses. Psychology of Women Quarterly, 22(1): 77-96

Glover, M. (1995) Te puna Roimata. Maori Women's experience of Male Partner Violence: 7 Case Studies. Auckland: Bound to Last

Glucksmann, M. (1994) The work of knowledge and the knowledge of women's work. In M. Maynard \& J. Purvis (Eds). Researching Women's Lives from a Feminist Perspective (pp. 149-165). London: Taylor and Francis

Goldfried, M.R. (1995) From Cognitive-Behavior Therapy to Psychotherapy Integration. An Evolving View. New York: Springer Publishing Company

Gonçalves, Ó.F. (1997) Postmodern cognitive psychotherapy: From the university to the multiversity. Journal of Cognitive Psychotherapy: An International Quarterly, 11(2): 105-112

Gossop, M. (1994) Drug and alcohol problems: Treatment. In S.J.E. Lindsay \& G.E. Powell (Eds). The Handbook of Clinical Adult Psychology: Second edition (pp. 384412). London: Routledge

Gowaty, P.A. (2001) Women, psychology and evolution. In R.K.Unger (Ed). Handbook of the Psychology of Women and Gender (pp. 66-83). New York: John Wiley and Sons

Greaves, L., Wylie, A., \& the staff of the Battered Women's Advocacy Centre: Champagne, C., Karch, L., Lapp, R., Lee, J., \& Osthoff, B. (1995) Women and violence: Feminist practice and quantitative methods. In S. Burt \& L. Code (Eds). 
Changing Methods. Feminists Transforming Practice (pp, 301-325). Ontario: Broadview press

Greene, B., \& Sanchez-Hucles, J. (1997) Diversity: Advancing an inclusive feminist psychology. In J. Worell \& N.G. Johnson. Shaping the Future of Feminist Psychology. Education, Research, and Practice. Washington, DC: American Psychological Association

Gunew, S. (Ed) (1991) A Reader in Feminist Knowledge. London: Routledge

Gunew, S., \& Yeatman, A.(Eds) (1993) Feminism and the Politics of Difference. Australia, Allen and Unwin

Haddock, G., Tarrier, N., Spaulding, W., Yusupoff, L., Kinney, C., \& McCarthy, E. (1998) Individual cognitive-behavior therapy in the treatment of hallucinations and delusions: A review. Clinical Psychology Review, 18(7): 821-838

Hall, R.L., \& Green, B. (1996) Sins of omission and commission: Women, psychotherapy and the psychological literature. Women and Therapy, 18(1): 5-31

Hanmer, J., \& Itzin, C. (Ed) (2001) Home Truths About Domestic Violence: Feminist Influences on Policy and Practice. New York: Routledge

Haraway, D. (1991) Simians, Cyborgs and Women: The Reinvention of Nature. NY: Routledge

Harding, S. (1987a) Introduction: Is there a feminist methodology? In S. Harding (Ed). Feminism and Methodology. Social Science Issues (pp. 1-14). Milton Keynes: Open University Press

Harding, S. (Ed) (1987b) Feminism and Methodology. Social Science Issues. Milton Keynes: Open University Press

Harding, S. (1991a) The instability of the analytical categories of feminist theory. In H. Crowley \& S. Himmelweit. Knowing Women: Feminism and Knowledge. Milton Keynes: Polity Press/The Open University

Harding, S. (1991b) Whose Science? Whose Knowledge?: Thinking from Women's Lives. Ithaca, NY: Cornell University Press

Harding, S. (1993) Rethinking standpoint epistemology: "What is strong objectivity?" In L. Alcoff \& E. Potter (Eds). Feminist Epistemologies (pp. 49-82). New York: Routledge

Harding, S. (1997a) Comment on Hekman's "truth and method: Feminist standpoint theory revisited": Whose standpoint needs the regimes of truth and reality? Signs: Journal of Women in Culture and Society, 22(2): 382-391 
Harding, S., \& Hintikka, M. (Eds) (1983) Discovering Reality: Feminist Perspectives on Epistemology, Metaphysics, Methodology and the Philosophy of Science. Dordrecht: Reidel

Hare-Mustin, R., \& Marecek, J. (Eds) (1990) Making a Difference. Psychology and the Construction of Gender. USA: Yale University

Hare-Mustin, R., \& Marecek, J. (1997) Abnormal and clinical psychology: The politics of madness. In D. Fox \& I. Prilleltensky (Eds). Critical Psychology. An Introduction (pp. 104-120). California, Thousand Oaks: Sage

Hartsock, N. (1983) The feminist standpoint: Developing the ground for a specifically feminist historical materialism. In S. Harding \& M.B. Hintikka (Eds). Discovering Reality. Feminist Perspectives on Epistemology, Metaphysics, Methodology, and Philosophy of Science (pp. 283-310). Boston: D. Reidel

Hartsock, N. (1987) The feminist standpoint. In S. Harding (Ed). Feminism and Methodology (pp. 157-180). Milton Keynes: Open University Press

Hartsock, N. (1987a) "Rethinking modernism: Minority vs. majority theories." Cultural Critique, 7: 187-206

Hartsock, N. (1989-90) "Postmodernism and political change: Issues for feminist theory." Cultural Critique, 14: 15-33

Hartsock, N. (1990) Foucault on power: A theory for women? In L.J. Nicolson (Ed). Feminism/Postmodernism (pp. 157-175). New York: Routledge

Hartsock, N. (1997a) Comment on Hekman's "truth and method: Feminist standpoint theory revisited": Truth or Justice? Signs: Journal of Women in Culture and Society, 22(2): $367-374$

Hartsock, N. (1997b) The feminist standpoint: Developing the ground for a specifically feminist historical materialism. In S. Kemp \& J. Squire (Eds). Feminisms (pp. 152160). Oxford: Oxford University Press

Hawkesworth, M. (1999) Analyzing backlash: Feminist standpoint theory as an analytical tool. Women's Studies International Forum, 22(2): 135-155

Healy, S. (1993) Confronting ageism: A MUST for mental health. Faces of women and aging. Women \& Therapy, 14, 1/2:41-50

Heenan, C. (1996) Women, food and fat: Too many cooks in the kitchen? In E. Burman, P. Alldred, C. Bewley, B. Goldberg, C. Heenan, J., D. Marks, Marshall, K. Taylor, R. Ullah \& S. Warner. Challenging Women. Psychology's Exclusions, Feminist Possibilities. Buckingham: Open University Press

Hekman, S. (1997a) Truth and method: Feminist standpoint theory revisited. Signs: Journal of women in Culture and Society, 22(2): 341-365 
Hekman, S. (1997b) Reply to Hartsock, Collins, Harding, and Smith. Signs: Journal of Women in Culture and Society, 22(2): 399-402

Henriques, J., Hollway, W., Urwin, C., Venn, C., \& Walkerdine, V. (1984) Changing the Subject. Psychology, Social Regulation and Subjectivity. London: Methuen

Henwood, K., Griffin C., \& Phoenix, A. (Eds) (1998) Standpoints and Differences. Essays in the Practice of Feminist Psychology. London: Sage

Henwood, K., \& Pidgeon, N. (1994) Beyond the qualitative paradigm: A framework for introducing diversity within qualitative psychology. Journal of Community and Applied Social Psychology, 4: 225-238

Henwood, K., \& Pidgeon, N. (1995) Remaking the link: Qualitative research and feminist standpoint theory. Feminism \& Psychology, 5(1): 7-30

Herbert, A. (1993) Cultural justice, ethics and practice: Summary of presentation. In L.W. Nikora (Ed) Cultural Justice and Ethics (pp. 34-36). Proceedings of a symposium held at the Annual Conference of the New Zealand Psychological Society, Victoria University of Wellington, 23-24 August, 1993

Herbert, A. (1998a) The Treaty of Waitangi in clinical psychology training at the University of Waikato. The Bulletin of the New Zealand Psychological Society, 93:12-14

Herbert, A. (1998b) The Treaty of Waitangi in clinical psychology training at the University of Waikato. The Bulletin of the New Zealand Psychological Society, 94: 24-26

Hersen, M., Kazdin, A.E., \& Bellack, A.S. (Eds) (1983) The Clinical Psychology Handbook. New York: Pergamon Press

Hertzsprung, E.A.M., \& Dobson, K.S. (2000) Diversity training: Conceptual issues and practices for Canadian clinical psychology programs. Canadian Psychology/Psychologie Canadiene, 41(3): 184-191)

Holdstock, T.L. (2000) Examining Psychology. Critical Perspectives and African Insights. London: Routledge

Hill, M. (1998) We can't afford it: Confusions and silences on the topic of class. In M. Hill \& E.D. Rothblum (Eds) Classism and Feminist Therapy - Counting Costs (pp. 1-5). New York: Harrington Park Press

Hirini, P.R., \& Nairn, R.G. (1996) Psychological practice for the New Zealand context. New Zealand Journal of Psychology, 89: 6-7

Hirsch, M., \& Keller, E.P (Eds) (1990) Conflicts in Feminism. London: Routledge 
Ho, E., Au, S., Bedford C., \& Cooper, J. (2002) Mental Health Issues for Asians in New Zealand. A Literature Review. Wellington; New Zealand: Mental Health Commission

Holland, S. (1991) From private symptoms to public action. Open forum. Feminism and Psychology, 1(1): 58-62

Holland, S. (1992) From social abuse to social action. A neighbourhood psychotherapy and social action project for women. In J.M. Ussher \& P. Nicolson (Eds). Gender Issues in Clinical Psychology (pp. 68-77). Routledge: London and New York

Holland, J., \& Ramazanoğlu, C. (1994) Coming to conclusions: Power and interpretation in researching young women's sexuality. In M.M. Maynard \& J. Purvis (Eds). Researching Women's Lives from a Feminist Perspective (pp. 125148). London: Taylor \& Francis

Hollon, C.R. (1990) Cognitive-Behavioral Interventions with Young Offenders. New York: Pergamon Press

Hollon, C.R. (Ed) (2000) Handbook of Offender Assessment and Treatment. Chichester: Wiley

Hollon, S.D., \& Beck, A. T. (1994) Cognitive and cognitive-behavioral therapies. In A.E. Bergin \& S.L.Garfield (Eds). Handbook of Psychotherapy and Behavior Change: Fourth edition (pp. 428-466). New York: John Wiley \& Sons

Hollon, S.D., Shelton, R.C., \& Loosen, P.T. (1991) Cognitive therapy and pharmacotherapy for depression. Journal of Consulting and Clinical Psychology, 59(1): 88-89

Hollway, W. (2000) Practising critical psychology within a British psychology department. In T. Sloan (Ed) Critical Psychology: Voices for Change (pp. 34-45)

Hollway, W. (1992) Gender difference and the production of subjectivity. In $\mathrm{H}$. Crowley \& S. Himmelweit (Eds). Knowing Women. Feminism and Knowledge (pp. 240-276)

Horvath. A.O. (2001) The therapeutic alliance: Concepts, research and training. Australian Psychologist, 36(2): 170-176

Hurst, S.A., \& Genest, M. (1995) Cognitive-behavioral therapy with a feminist orientation: A perspective for therapy with depressed women. Canadian Psychology Psychologie canadienne, 36(3): 236-257

Irwin, K. (1992) Towards theories of Māori feminisms. In R. Du Plessis (Ed). Feminist Voices. Women's Studies Texts for Aotearoa/New Zealand (pp. 1-21). Auckland: Oxford University Press

Ibàñez, T \& İñiguez, L. (Eds) (1997) Critical Social Psychology. London: Sage 
Jackson, S. (1998) Feminist social theory. In S. Jackson \& J. Jones (Eds). Contemporary Feminist Theories (pp. 12-33). Edinburgh: Edinburgh University Press

Jackson, S. (1997) Using focus groups to explore sexual coercion in teenagers heterosexual relationships. In G. Habermann (Ed). Looking Back and Moving Forward: 50 Years of New Zealand Psychology. Palmerston North: New Zealand Psychological Society

Jackson, S. (2001) Happily never after: Young womens stories of abuse in heterosexual love relationships. Feminism and Psychology, 11(3): 305-322

Jacobson, N.S. (Ed) (1987) Psychotherapists in Clinical Practice. Cognitive and Behavioural Perspectives. New York: Guildford Press

Jaggar, A. (1997) Love and knowledge: Emotion in feminist epistemology. In S. Kemp \& J. Squire (Eds). Feminisms (pp. 188-193). Oxford: Oxford University Press

James, B., \& Saville-Smith, K. (1994) Gender Culture and Power. Challenging New Zealand's Gendered Culture. (Rev. ed) Auckland: Oxford University Press

Jayaratne, T.E., \& Stewart, A.J. (1991) Quantitative and qualitative methods in the social sciences: Current feminist issues and practical strategies. In M.M. Fonow \& J.A. Cook (Eds). Beyond Methodology. Feminist Scholarship as Lived Research (pp. 85-106). Bloomington: Indiana University Press

Jenkins, K., \& Pihama, L. (2001) Matauranga Wahine: Teaching Maori women's knowledge alongside feminism. Feminism \& Psychology, 11(3), 293-303

Jensen, J.P., Bergin, A.E., \& Greaves, D.W. (1990) The meaning of eclecticism: New survey and analysis of components. Professional Psychology, 21: 124-130

John, I. (1998) The scientist-practitioner model: A critical examination. Australian Psychologist, 33(1): 22-30

Kantrowitz, R.E., \& Ballou, M. (1992) A feminist critique of cognitive-behavioral therapy. In L.S Brown \& M. Ballou (Eds). Personality and Psychopathology: Feminist Reappraisals. New York: Guildford

Kaslow, F.W. (Ed) (1996) Handbook of Relational Diagnosis and Dysfunctional Family Patterns. NY: Wiley

Kelly, L., Burton, S., \& Regan, L. (1994) Researching women's lives or studying women's oppression? Reflections on what constitutes feminist research. In $\mathrm{M}$. Maynard \& J. Purvis (Eds). Researching Women's Lives From a Feminist Perspective (pp. 27-100). London: Taylor and Francis 
Kendall, P.C., \& Hollon, S.D. (Eds) (1979) Cognitive-Behavioral Interventions: Theory, Research, and Procedures. New York: Academic Press

Kidder, L.H., \& Fine, M. (1997) Qualitative inquiry in psychology: A radical tradition. In D. Fox \& I. Prilleltensky (Eds). Critical Psychology: An Introduction (pp. 34-50). California, Thousand Oaks: Sage

Kimmel, E., \& Worell, J. (1997) Preaching what we practice: Principles and strategies of feminist pedagogy. In Shaping the Future of Feminist Psychology. Education, Research and Practice (pp. 121-155). Washington, DC: American Psychological Association

King, N., Ollendick, T.H., \& Tonge, B.J. (1997) Children's night-time fears. Clinical Psychology Review, 17(4): 431-443

Kingdon, D.G., \& Turkington, D. (1994) Cognitive-Behavioral Therapy of Schizophrenia. New York: Guilford press

Kirk, S.A. \& Kutchins, H. (1992) The Selling of the DSM: The Rhetoric of Science in Psychiatry. New York: Aldine de Gruyter

Kirkman, A. (2001) Ethics and the politics of research: Where gender and sexuality still matter. In M. Tolich (Ed). Research Ethics in Aotearoa New Zealand (pp. 53-63). Auckland: Pearson

Kitzinger, C. (1987) The Social Construction of Lesbianism. London: Sage

Kitzinger, C. (1989) Deconstructing sex difference: Rhonda Unger's social constructionism. The British Psychological Society: Psychology of Women Newsletter, 4: 9-17

Kitzinger, C. (1990a) The rhetoric of pseudo-science. In I. Parker \& J. Shotter (Eds). Deconstructing Social Psychology. London: Routledge

Kitzinger, C. (1990b) Resisting the discipline. In E. Burman (Ed). Feminists and Psychological Practice. London: Sage

Kitzinger, C. (Ed) (1993) Special Feature: 'Psychology constructs the female: A reappraisal.' Feminism and Psychology: An International Journal, 3(2): 189-245

Kitzinger, C. (1995) Social constructionism: Implications for lesbian and gay psychology. In A. D'Augelli \& C. Patterson (Eds). Lesbian, Gay and Bisexual Identities Over the Lifespan: Psychological Perspectives (pp. 136-161). New York: Oxford University Press

Kitzinger, C. (1996) The token lesbian chapter. In S. Wilkinson (Ed). Feminist Social Psychologies: International Perspectives (pp. 119-144). Buckingham: Open University Press 
Kitzinger, C. (1997) Lesbian and gay psychology: A critical analysis. In D. Fox \& I. Prilleltensky (Eds). Critical Psychology: An Introduction (pp. 212-216). California, Thousand Oaks: Sage

Kitzinger, C. (2000) Women with Androgen Insensitivity Syndrome (AIS). In J.M. Ussher (Ed). Women's Health. Contemporary International Perspectives (pp. 387393

Kitzinger, C. (2001) Sexualities. In R.K. Unger (Ed). Handbook of the Psychology of Women and Gender (pp.272-288). New York: John Wiley and Sons

Kitzinger, C. \& Coyle, A. (2002) Introducing lesbian and gay psychology. In C. Kitzinger \& A. Coyle (Eds). Lesbian \& Gay Psychology. New Perspectives (pp. 129). Oxford: The British Psychological Society and Blackwell Publishers

Kitzinger, C., \& Perkins, R. (1993) Changing Our Minds: Lesbian Feminism and Psychology. New York: New York University Press

Kitzinger, C., Wilkinson, S., \& Perkins, R. (1992) Theorizing heterosexuality (editorial introduction). Feminism and Psychology: An International Journal, 2(3): 293-324

Knight, R. (1990) Scientists and practitioners: On training clinical psychologists. Commentaries. New Zealand Journal of Psychology, 19: 88-89

Koss, M.P., Bailey, J.A., Yuan, N.P., Herrera, V.M., \& Lichter, E.L. (2003) Depression and PTSD in survivors of male violence: Research and training initiatives to facilitate recovery. Psychology of Women Quarterly, 27(12): 130-142

Kuehlewein, K.T., \& Rosen, H. (Eds) (1993) Cognitive Therapies in Action. Evolving Innovative Practice. California, San Francisco: Jossey-Bass

Kvale, S. (Ed) (1992) Psychology and Postmodernism. London, Newbury Park: Sage

Ladouceur, R., \& Walker, M. (1996) A cognitive perspective on gambling. In P.M. Salkovskis (Ed). Trends in Cognitive and Behavioural Therapies (pp. 89-120). England, West Sussex: John Wiley \& Sons

Landrine, H. (Ed) (1995) Bringing Cultural Diversity to Feminist Psychology. Theory, Research, and Practice. Washington DC: American Psychological Association

Lapsley, H. (1994) Suffrage centennial event: Honouring NZ women pioneers in psychology. The Bulletin of the New Zealand Psychological Society, 80: 7-12

Lapsley, H., Gavey, N., \& Cram, F. (2001) Editors Introduction: Feminist Psychology in Aotearoa/New Zealand. Feminism and Psychology, 11(3): 275-298

Lapsley, H., \& Paulin, K. (1994) Lesbians in psychology. The Bulletin of the New Zealand Psychological Society, 80: 24-25 
Lapsley, H., \& Ritchie, J. (1997) Women and psychology in New Zealand: A retrospective and prospective. The Bulletin of the New Zealand Psychological Society, 92: 26-9

Lapsley, H., \& Wilkinson, S. (2001) Organzing feminist psychology in New Zealand. Feminism \& Psychology, 11(3): 386-391

Larner, G. (2001) The critical-practitioner model of therapy. Australian Psychologist, $36(1): 36-43$

Lather, P. (1991) Getting Smart: Feminist Research and Pedagogy With/in the Postmodern. London: Routledge

Lawson-Te Aho, K. (1993) The socially constructed nature of psychology and the abnormalisation of Māori. The Bulletin of the New Zealand Psychological Society, 76: $25-26$

Lazarus, A.A. (1971) Behavior Therapy and Beyond. New York: McGraw-Hill

Lazarus, A.A. (1984) Multimodal therapy. In R.J, Corsini (Ed). Current Psychotherapies: Third edition. Itasca, IL: F.E. Peacock

Lazarus, A.A. (Ed) (1985) Casebook of Multimodal Therapy. New York: Guilford

Lee, D. (1997) Feminist research. Interviewing men: Vulnerabilities and dilemmas. Women's Studies International Forum, 20(4): 553-564

Leibrich, J. (1993) Straight to the point: Angles on giving up crime (Appendix A, pp. 241-285). Wellington: University of Otago Press in association with the Department of Justice

Levy, M. (2002) Barriers and Incentives to Mãori Participation in the Profession of Psychology. A Report for the New Zealand Psychologists'Board. Māori and Psychology Research Unit: University of Waikato

Lindsay, S.J.E., \& Powell, G.E. (Eds) (1994) The Handbook of Clinical Adult Psychology: Second edition. London: Routledge

Linehan, M. (1993) Cognitive-Behavioral Treatment of Borderline Personality disorder. New York: Guilford Press.

Lyddon, W.J. (1997) Postmodern cognitive psychotherapy: Moving beyond modernist dualisms. Journal of Cognitive Psychotherapy: An International Quarterly, 11(2): 119-126

Lyddon, W.J., \& Weill, R. (1997) Cognitive psychotherapy and postmodernism: Emerging themes and challenges. Journal of Cognitive Psychotherapy, 11(2): 75-90 
Mackinnon, C. (1996) From practice to theory, or what is a white woman anyway? In D. Bell \&R. Klein (Eds). Radically Speaking. Feminism Reclaimed. North Melbourne, Australia: Spinifex

Mackinnon, C. (1992) Article 3:1 Sexuality. In H. Crowley \& S. Himmelweit (Eds). Knowing Women. Feminism and Knowledge (pp. 114-116). Cambridge: Polity Press in association with the Open University

Madden M.E., \& Hyde, J.S. (1998) Integrating gender and ethnicity into psychology courses. Psychology of Women Quarterly, 22:1-12

Mahoney, M.J. (1974) Cognition and Behavior Modification. Cambridge: Ballinger

Mahoney, M.J. (1991) Human Change Processes: The Scientific Foundations of Psychotherapy. New York: Basic Books

Mahoney, M.J. (1993) Introduction to the special section: Theoretical developments in the cognitive psychotherapies. Journal of Consulting and Clinical Psychology, 61(2): 187-193

Marecek, J. (2001) Disorderly constructs: Feminist frameworks for clinical psychology. In R.K. Unger (Ed). Handbook of the Psychology of Women and Gender (pp.303316). New York: John Wiley and Sons

Marecek, J., \& Hare-Mustin, R.T. (1991) A short history of the future: Feminism and clinical psychology. Psychology of Women Quarterly, 15: 521-536

Marecek, J., Fine, M., \& Kidder, L. (1997) Working between worlds: Qualitative methods and social psychology. Journal of Social Issues, 53(4): 631-44

Marshall, A. (1994) Sensuous sapphires: A study of the social construction of black female sexuality. In M. Maynard \& J. Purvis (Eds). Researching Women's Lives from a Feminist Perspective (pp. 106-124). London: Taylor and Francis

Mattis, J.S. (2002) Religion and spirituality in the meaning making and coping experiences of African American women: A qualitative analysis. Psychology of Women Quarterly, 26(4): 309-321

Maykut, P., \& Morehouse, R. (1994) Beginning Qualitative Research: A Philosophic and Practical Guide. Washington DC: Falmer Press

Maynard, M. (1994) Methods, practice and epistemology: The debate about feminism and research. In M. Maynard \& J. Purvis (Eds). Researching Women's Lives from a Feminist Perspective (pp. 10-26). London: Taylor and Francis

McGrath, E., Keita, G.P., Strickland, B.R., \& Russo, N.F. (1990) Women and Depression: Risk Factors and Treatment Issues. Washington DC: American Psychological Association 
Meichenbaum, D. (1977) Cognitive-Behavior Modification: An Integrative Approach. New York: Plenum Press

Meichenbaum, D. (1994) A Clinical Handbook/Practical Therapist Manual for Assessing and Treating Adults with Post-Traumatic Stress Disorder (PTSD). Ontario, Waterloo: Institute Press

Mies, M. (1983) Towards a methodology for feminist research. In G. Bowles \& R. Duelli Klein (Eds). Theories of Women's Studies (pp. 117-139). London: Routledge and Kegan Paul

Mies, Maria. (1991) Women's research or feminist research? Debate surrounding feminist science and methodology. In M.M. Fonow \& J.A. Cook (Eds). Beyond Methodology. Feminist Scholarship as Lived Research (pp. 60-84). Bloomington: Indiana University Press

Minister for Disability Issues (2002) The New Zealand Disability Strategy. Making a World of Difference Whakanui Oranga. Wellington; New Zealand: Ministry of Health

Ministerial Advisory Committee (1986) Puao-te-atau: The Report of the Ministerial Advisory Committee on a Mãori Perspective for the Department of Social Welfare. Wellington, New Zealand: Government Printer

Ministry of Health Manatu Hauora (1995) Strategic Directions for the Mental Health Services for Pacific Islands People. Wellington: Ministry of Health

Ministry of Health Manatu Hauora (1997) Making a Pacific Difference. Strategic Initiatives for the Health of Pacific People in New Zealand. Wellingon: Public Health Group, Ministry of Health

Moeke-Maxwell, T. (2003) Bringing Home the Body: Maori Women's Cultural Hybridity in Aotearoa/New Zealand. Unpublished PhD thesis. New Zealand: University of Waikato.

Moeke-Pickering, T.M., Paewai, M.K, Turangi-Joseph, A., \& Herbert, A. (1996) Clinical psychology in Aotearoa/New Zealand: Indigenous perspectives. In A.S Bellack \& M. Herson (Eds) Comprehensive Clinical Psychology. Volume 3: Sociocultural and Individual Differences. Oxford: Elserver

Mooney-Somers, J., \&Ussher, J.M. (2000) Young lesbians and mental health: the closet is a depressing place to be. In J.M. Ussher (2001) (Ed) Women's Health Contemporar International Perspectives (pp. 83-92). London: BPS Books

Moreton-Robinson, A. (2000). Talkin' Up to the White Woman: Indigenous Women and Feminism. Australia: University of Queensland Press. 
Morgan, M., \& Coombes, L. (2001) Subjectivities and silences, mother and woman: Theorizing an experience of silence as speaking subject. Feminism \& Psychology, 11(3): $361-375$

Mulinari, D., \& Sandell, K. (1999) Exploring the notion of experience in feminist thought. ACTA Sociological Journal of the Scandinavian Sociological Association, 42: $287-297$

Muran, E.M., \& DiGiuseppe, R. (1994) Rape. In F.M Dattilio \& A. Freeman (Eds). Cognitive-Behavioral Strategies in Crisis Intervention (pp. 161-176). New York: Guilford Press

Nairn, R., \& the National Standing Committee on Bicultural Issues (1997) Cultural justice and ethics in psychological practice. In H. Love \& W. Whittaker (Eds). Practice Issues for Clinical and Applied Psychologists in New Zealand (pp. 127135). Wellington: The New Zealand Psychological Society

Narayan, U., \& Harding, S. (Eds) (2000) Decentering the Centre. Bloomington, Indiana: Indiana University Press

Nathan, S. (1999) Tikanga Māori in Aotearoa/New Zealand Clinical Psychology Training Programmes: A Follow-up of Abbot and Durie's (1987) Study. Unpublished Master's thesis, Victoria University of Wellington

National Standing Committee on Bicultural Issues (1993) The Treaty of Waitangi and/or bicultural issues facing psychologists in the teaching, research and practice of psychology in Aotearoa. The Bulletin of the New Zealand Psychological Society, 76: 6-48

National Standing Committee on Bicultural Issues (1994) The New Zealand Psychological Society and the Treaty of Waitangi: Proposed implementation plan. The Bulletin of the New Zealand Psychological Society, 82:13-17

Newman, M.G., \& Castonguay, L.G. (1999) Contemporary challenges and new directions in psychotherapy: An introduction. Journal of Clinical Psychology: In Session, 55(11): 1321-1324

New Zealand Council of Christian Social Services (2001). Poverty Indicator Project. Fourth Quarter 2001. Summary Report. Wellington: New Zealand Council of Christian Social Services

New Zealand Psychological Society (1986) The New Zealand Psychological Society Code of Ethics. Wellington, New Zealand

New Zealand Psychological Society (1992, August) Minutes of the 23rd Annual General Meeting. Christchurch

New Zealand Psychological Society (1994) Bulletin of the New Zealand Psychological Society, 82 
New Zealand Psychological Society (1994) Women in psychology. The Bulletin of the New Zealand Psychological Society, 80: 6-38

The New Zealand Psychological Society (1999) The Bulletin of the New Zealand Psychological Society, 95

Nicolson, L.J. (Ed) (1990) Feminism/Postmodernism. New York: Routledge

Nicolson, P. (1992) Gender issues in the organisation of clinical psychology. In J.M. Ussher \& P. Nicolson (Eds). Gender Issues in Clinical Psychology (pp. 8-38). London: Routledge

Nicolson, P. (1995) Feminism and psychology. In J.A. Smith, R., Harre \& L.V. Langenhove (Eds). Rethinking Psychology (pp. 122-142). California, Thousand Oaks: Sage

Nicolson, P. (1997) Social psychology: theory. Feminist social psychology: A ReView. Feminism \& Psychology, 7(2): 248-254

Nicolson, P. (1998) Post-natal Depression. Psychology, Science, and the Transition to Motherhood. London: Routledge

Nicolson, P., \& Ussher, J.M. (1992) The Psychology of Women's Health and Healthcare. Houndmills, Basingstoke, Hampshire: Macmillan

Nikora, L.W. (Ed) (1993, August) Cultural Justice and Ethics. Proceedings of a symposium held at the Annual Conference of the New Zealand Psychological Society, Victoria University of Wellington, 23-24 August, 1993

Nikora, L.W. (2001) Rangatiratanga-Kawanatanga: Dealing with the rhetoric. Feminism and Psychology, 11(3):377-385

Nikora, L.W., \& Evans, I. (1998) A Maori and Psychology Research Unit. Paper presented at the Te Oru Rangahau Conference, Massey University, Palmerston North, July 7-9 (http://130.217.157.10/mpru/pubs/confpapers/nikora-evans.htm (retrieved, 1 February, 2003)

Oakley, A. (1981) Interviewing women: A contradiction in terms. In H. Roberts (Ed). Doing Feminist Research. London: Routledge and Kegan Paul

Oakley, A. (1998) Gender, methodology and people's ways of knowing: Some problems with feminism and the paradigm debate in social science. Sociology, 32(4): 707-731

O'Brien, M. (2001) Doing ethical research legally: Research ethics and the law. In M. Tolich (Ed). Research Ethics in Aotearoa New Zealand (pp. 25-34). Auckland: Pearson 
O'Donovan, A., \& Dyck, M. (2001) Effective training in clinical and counselling psychology: Not as simple as it sounds. Australian Psychologist, 36(2): 149-156

O'Donovan, A., Dyck, M., \& Bain, J.D. (2001) Trainees' experience of postgraduate clinical training. Australian Psychologist, 36(2): 164-169

O'Sullivan, J.J., \& Quevillion, R.P. (1992) Forty years later. Is the Boulder Model still alive? American Psychologist, 47, 67-70

O'Gorman, J.G. (2001) The scientist-practitioner model and it's critics. Australian Psychologist, 36(2): 164-169

Oliver, P., \& Lapsley, H. (1994) Women in psychology special feature: Getting it together: Networking and women psychologists. The Bulletin of the New Zealand Psychological Society, 80: 13-16

O’Neill, B. (1995) The gender gap: Re-evaluating theory and method. In S. Burt \& L. Code (Eds) Changing Methods. Feminists Transforming Practice (pp. 327-356). Ontario, Canada: Broadview Press

Orlinksy, D.E., Botermans, J.F., \& Ronnestad, M.H. Towards an empirically grounded model of psychotherapy training: Four thousand therapists rate influences on their development. Australian Psychologist, 36(2): 139-148

Okazaki, S. (1998) Teaching gender issues in Asian American psychology: A pedagogical framework. Psychology of Women Quarterly, 22(1): 33-52

Padensky, C.A., \& Greenberger, D. (1995) Clinicians Guide to Mind Over Mood. New York: Guilford Press

Pakeha Treaty Action Group (1997) Pakeha clinical psychology and the Treaty of Waitangi. In H.L. Love \& W. Whittaker (Eds). Practice Issues for Clinical Psychologists in New Zealand (pp. 147-157). Wellington: New Zealand Psychological Society

Parker, G. (1997) Case management: An evidence-based review fails to make its case. Current Opinion in Psychiatry, 10: 261-263

Parnell, M., \& Vanderkloot, J. (1994) Poor women: Making a difference. In M.P Mirkin (Ed). Women in Context. Toward a Feminist Reconstruction of Psychotherapy. (pp. 390-407). New York: The Guildford Press

Paterson, K. (1993) Life in a clinical diploma course. In L.W. Nikora (Ed). Cultural Justice and Ethics (pp. 57-61). Proceedings of a symposium held at the Annual Conference of the New Zealand Psychological Society, Victoria University of Wellington, 23-24 August, 1993 
Pearce, S., \& Mays, J. (1994) Chronic pain treatment. In S.J.E. Lindsay \& G.E. Powell (Eds). The Handbook of Clinical Adult Psychology: Second edition (pp. 612-627). London: Routledge

Pence, E., \& Paymar, M. (1993) Education Groups for Men who Batter. The Deluth Model. New York: Springer Publishing

Perkins, R. (1991) Women with long term mental health problems: Issues of power and powerlessness. Feminism and Psychology, 1(1): 131-140

Perkins, R. (1992) Working with socially disabled clients: A feminist perspective. In J.M. Ussher \& P. Nicolson (Eds). Gender Issues in Clinical Psychology (pp.171193). London: Routledge

Perris, C., Ingelsson, U., \& Jonsson, P. (1993) Cognitive therapy as a general framework in the treatment of psychotic patients. In K.T. Kuehlewein \& H. Rosen (Eds). Cognitive Therapies in Action. Evolving Innovative Practice (pp. 379-402). California, San Francisco: Jossey-Bass

Persons, J.B. (1993) Case conceptualization in cognitive-behavior therapy. In K.T. Kuehlwein and H. Rosen (Eds). Cognitive Therapies in Action. Evolving Innovative Practice (pp. 33-53). California, San Francisco: Jossey-Bass

Phoenix, A. (1994) Practicing feminist research: The intersection of gender and 'race' in the research process. In M. Maynard \& J. Purvis (Eds). Researching Women's Lives from a Feminist Perspective (pp. 49-71). London: Taylor and Francis

Phoenix, A., Woollett, A., \& Lloyd, E. (Eds). (1991) Motherhood: Meanings, Practices and Ideologies. London: Sage

Pilgrim, D., \& Treacher, A. (1992) Clinical Psychology Observed. London: Routledge

Potter, J., \& Wetherell, M. (1987) Discourse and Social Psychology: Beyond Attitudes and Behaviour. London: Sage

Prilleltensky, I., \& Fox, D. (1997) Introducing critical psychology: Values, assumptions, and the status quo. In D. Fox \& I. Prilleltensky (Eds). Critical Psychology: An Introduction (pp. 2-20). London: Sage

Prilleltensky, I., \& Nelson, G. (1997) Community psychology: Reclaiming social justice. In D. Fox \& I. Prilleltensky (Eds). Critical Psychology: An Introduction (pp. 166-84). London: Sage

Prilleltensky, I., \& Nelson, G. (2002) Doing Psychology Critically. Making a Difference in Diverse Settings. Hampshire: Palgrave Macmillan

Rabinowitz, V. C., \& Weseen, S. (1997) Elucidating epistemological impasses: Reviewing the qualitative/quantitative debates in psychology. Journal of Social Issues, 53(4): 605-630 
Rachman, S.J. (1996) Trends in cognitive and behavioural therapies. In P.M. Salkovskis (Ed). Trends in Cognitive and Behavioural Therapies (pp. 1-24). England, West Sussex: John Wiley \& Sons

Ramazanoğlu, C., with Holland, J. (2002) Feminist Methodology. Challenges and Choices. London: Sage

Reay, D. (1996) Dealing with difficult differences: Reflexivity and social class in feminist research. Feminism \& Psychology, 6(3): 443-456

Reinharz, S. (1992) Feminist Methods in Social Research. Oxford: Oxford University Press

Reinharz, S. (1993) Neglected voices and excessive demands in feminist research. Sociology, 16(1): 69-75

Rich, A. (1980) Compulsory heterosexuality and lesbian existence. Signs, 5: 631-660

Richards, J. (2001) Rewriting the agenda for training in clinical and counselling psychology. Australian Psychologist, 36(2): 99-106

Richardson, D. (1996) "Misguided, dangerous and wrong": On the maligning of radical feminism. In D. Bell \& R. Klein (Eds). Radically Speaking: Feminism Reclaimed (pp. 143-154). Victoria, Australia: Spinifex Press

Riger, S. (1992) Epistemological debates, feminist voices. Science, social values, and the study of women. American Psychologist, 47(6): 730-740

Riley, D. (1987) Am I that Name? Feminism and the Category of 'Women' in History. London: Macmillan

Ritchie, J. (2001) Mother, grandmother and researcher: Forty years of child rearing studies. Feminism \& Psychology, 11(3): 407-413

Roberson, S.M. (2001) Exploring Discourses in the Ethical Approval Process. Paper presented at the Postgraduate Seminar Series, School of Education, Victoria University of Wellington

Roberson, S.M. (2002) The Challenges and Implications of Researching Youth Violence using a Critical Approach. Paper presented at the Health Policy, Practice and Research in the $21^{\text {st }}$ Century: Making a Difference Conference. Auckland, New Zealand

Robertson, J. (2000) Ethical issues and researching sensitive topics: Mature women and 'bulimia'. Feminism \& Psychology, 10(4): 531-537 
Roffman, E. (1996) A class conscious perspective on the use of self as instrument in graduate clinical training. In M. Hill \& E.D. Rothblum (Eds) Classism and Feminist Therapy. Counting Costs (pp.165-179). New York: Harrington Park Press

Royal Commission on Social Policy Te Kōmihana A Te Karauna Mō Ngā Āhuatanga Ā Iwi (1998) The April Report: Volume II: Future Directions (pp. 1-88). Wellington: The Royal Commison on Social Policy

Ryan, P.M. (1997) The Reed Dictionary of Maori. $2^{\text {nd }}$ ed. New Zealand, Auckland: New Zealand Maori Language Commission

Ryba, K., Pine, T., Mentis, M., \& Bowler, J. (1999) Training educational psychologists for the $21^{\text {st }}$ century: A Massey University perspective. The Bulletin of the New Zealand Psychological Society, 95: 5-13

Safran, J. D. (1996) Emotion in cognitive-behavioral theory and treatment. In P.M. Salkovskis (Ed). Trends in Cognitive and Behavioural Therapies (pp. 121-132). England, West Sussex: John Wiley \& Sons

Safran, J.D. (1998) Widening the Scope of Cognitive Therapy. The Therapeutic Relationship, Emotion and the Process of Change. New Jersey: Jason Aronson

Safran, J.D., \& Muran, J.C. (2000) Negotiating the Therapeutic Alliance: A Relational Treatment Guide. New York: Guildford Press

Safran, J.D., \& Segal, Z.V. (1996) Interpersonal Process in Cognitive Therapy: Second edition. New York: Basic Books

Salkovskis, P. M. (Ed) (1996) Trends in Cognitive and Behavioural Therapies. England, West Sussex: John Wiley \& Sons

Sawrey, R. (1993) A survey of psychologists opinions and behaviours on aspects of Maori mental health. In L.W. Nikora (Ed). Cultural Justice and Ethics (pp. 63-73). Proceedings of a symposium held at the Annual Conference of the New Zealand Psychological Society, Victoria University of Wellington, 23-24 August 1993

Saphira, M.E. (1981) The Sexual Abuse of Children. Auckland, New Zealand: Papers Inc

Saphira, M.E. (1984) Amazon Mothers. Auckland, New Zealand: Papers Inc

Saphira, M.E. (2001) No funds for dirty washing. Feminism \& Psychology, 11(3): 429-432

Saris, R.N., \& Johnston-Robeldo, I. (2000) Poor women are still shut out of mainstream psychology. Psychology of Women Quarterly, 24(3): 233-235

Sayal-Bennet, A. (1991) Equal opportunities - Empty rhetoric. Feminism and Psychology, 1(1): 76-77 
Skeggs, B. (1994) Situating the production of feminist ethnography. In M. Maynard \& J. Purvis (Eds). Researching Women's Lives from a Feminist Perspective (pp. $72-$ 92). London: Taylor \& Francis

Sloan, T (Ed) (2000) Critical Psychology. Voices for Change. London: Macmillan Press

Smith, D.E. (1990) Texts, Facts and Femininity: Exploring the Relations of Ruling. London: Routledge

Smith, D.E. (1997) Comment on Hekman's "truth and method: feminist standpoint theory revisited". Signs: Journal of Women in Culture and Society, 22(2): 392-398

Smith, L.T. (1998) Decolonising Methodologies. Research and Indigenous Peoples. Dunedin, New Zealand: University of Otago Press

Smucker, M.R., \& Dancu, C.V. (1999) Cognitive-Behavioral Treatment for Adult Survivors of Childhood Trauma. Imagery Rescripting and Reprocessing. New Jersey: Jason Aronson

Sobell, M.B., \& Sobell, L.C. (1996) Control as a pathway to recovery from alcohol problems. In P.M. Salkovskis (Ed). Trends in Cognitive and Behavioural Therapies (pp. 77-88). England, West Sussex: John Wiley \& Sons

Soldz, S., \& McCullough, L. (Eds) (2000) Reconciling Empirical Knowledge and Clinical Experience. The Art and Science of Psychotherapy. Washington, DC: American Psychological Association

Spence, S.H. (1994) Interpersonal problems: Treatment. In S.J.E Lindsay \& G.E. Powell (Eds). The Handbook of Clinical Adult Psychology: Second edition (pp.253270). London: Routledge

Sriram, R., \& Mukherjee, S. (2001) The unsafe nest: Analysing and treating the roots and reaches of marital violence. In B.V. Davar (Ed) Mental Health from a Gender Perspective (pp. 219-247). New Delhi: Sage

Stanko, E.A. (1994) Dancing with denial: Researching women and questioning men. In M. Maynard \& J. Purvis (Eds). Researching Women's Lives from a Feminist Perspective (pp. 93-105). London: Taylor and Francis

Stanley, L. (1990) Feminist praxis and the academic mode of production: An editorial introduction. In L. Stanley (Ed). Feminist Praxis. Research, Theory and Epistemology in Feminist Sociology (pp. 3-19). London: Routledge

Stanley, L. (1997) Recovering women in history from feminist deconstructionism. In S. Kemp \& J. Squire (Eds). Feminisms (pp. 274-277). Oxford: Oxford University Press 
Stanley, L. (1999) 'Debating Feminist Theory: More Questions than Answers?' Women's Studies Journal, 15(1), 87-106.

Stanley, L., \& Wise, S. (1983) Breaking Out: Feminist Consciousness and Feminist Research. London: Routledge and Kegan Paul

Stanley, L., \& Wise, S. (1990) Method, methodology and epistemology in feminist research processes. In L. Stanley (Ed). Feminist Praxis. Research, Theory and Epistemology in Feminist Sociology (pp. 20-60). London: Routledge

Stanley, L., \& Wise, S. (1991) Feminist research, feminist consciousness and experiences of sexism. In M.M. Fonow \& J.A. Cook (Eds). Beyond Methodology. Feminist Scholarship as Lived Research (pp. 265-283). Bloomington: Indiana University Press

Stanley, L., \& Wise, S. (1993) Breaking Out Again. Feminist Ontology and Epistemology. London: Routledge

Stewart, T. (1995) Ka pu te ruah, Ka hao te rangatahi. Contributions to 'Indigenous Psychology' in Aoteroa/New Zealand. Unpublished Master's thesis, University of Auckland

Stoppard, J.M. (1989) An evaluation of the adequacy of cognitive/behavioural theories. Canadian Psychology/Psychologie Canadienne, 30(1): 39-45

Stoppard, J.M. (1999) Why new perspectives are needed for understanding depression in women. Canadian Psychology/Psychologie Canadienne, 40(2): 79-90

Stoppard, J.M. (2000) Understanding Depression. Feminist Social Constructionist Approaches. London: Routledge

Stricker, G. (2000) The scientist-practitioner model - Gandhi was right again. American Psychologist, 55(2): 253-254

Stricker, G., \& Gold, J. (Eds) (1993) Comprehensive Handbook of Psychotherapy Integration. New York: Plenum Press

Tamasese, K. (1993) Interface of gender and culture. In L.W. Nikora (Ed). Cultural Justice and Ethics (pp. 9-12). Proceedings of a symposium held at the Annual Conference of the New Zealand Psychological Society Victoria University of Wellington, 23-24 August, 1993

Tamasese, K., \& Waldegrave, C. (1996) Cultural and gender accountability in the 'Just Therapy' approach. Journal of Feminist Family Therapy, 5(2): 29-45

Te Awekotuku, N. (1996) Māori-lesbian-feminist radical. In D. Bell \& R.D. Klein (Eds). Radically Speaking: Feminism Reclaimed (pp. 55-61). Australia: Spinifex 
Te Awekotuku, N., \& Manatu Māori (1991) He Tikanga Whakaaro. Research Ethics in the Māori Community. Wellington: Manatu Māori

Tolich, M. (2001a) Beyond an unfortunate experiment: Ethics for small-town New Zealand. In M. Tolich (Ed). Research Ethics in Aotearoa New Zealand (pp. 2-12) Auckland: Pearson

Tolich, M. (Ed) (2001b) Research Ethics in Aotearoa New Zealand. Auckland: Pearson

Tompkins, J. (1997) Me and my shadow. In S. Kemp \& J. Squire. (Eds). Feminisms (pp. 44-51). Oxford: Oxford University Press

Toner, B.B. (1994) Cognitive-behavioral treatment of functional somatic syndromes: Integrating gender issues. Cognitive and Behavioral Practice, 1: 157-178

Towns, A. (1998) Family violence: Guidelines for providers to develop practice protocols. The Bulletin of the New Zealand Psychological Society, 93, May

Towns, A., \& Adams, P. (2000) "If I really loved him it would be okay": Women's accounts of male partner violence. Violence Against Women, 6: 558-585

Trimble, J.E. The mental health service and training needs of American Indians. In H.G. Myers, P. Wohlford, L.P. Guzman, \& R.J. Echemendia (Eds). Ethnic Minority Perspectives on Clinical Training and Services in Psychology ( $\mathrm{pp}$ 43-48). Washington, DC: American Psychological Association

Tupuola, A.M. (1993) Raising research consciousness the Fa'aSamoa way. New Zealand Annual Review of Education, 3: 175-189

Tupuola, A. (1998) Fa'aSamoa in the 1990s; Young Samoan women speak. In R. Du Plessis \& L. Alice (Eds) Feminist Thought in Aotearoa New Zealand. Connections and Differences. Auckland, New Zealand: Oxford University Press

Tupuola, A. (2002) What's in a name? Western terms and non-western experiences. International Journal of Critical Psychology, 5

Turia, T. (2000) Speech to New Zealand Psychological Society Conference, Waikato University http://www.executive.govt.nz/speech.cfm?speechralph=32299\&SR=1 (retrieved 26 February, 2003)

Turner, R.M., Becker, L., \& DeLoach, C. (1994) Borderline personality. In F.M. Dattilio \& A. Freeman (Eds). Cognitive-Behavioral Strategies in Crisis Intervention (pp. 25-45). New York: The Guilford Press

Unger, R.K. (1992) Will the real sex difference please stand up? Feminism \& Psychology, 2(2): 231-238 
Unger, R. (1996) Using the master's tools: Epistemology and empiricism. In S. Wilkinson (Ed). Feminist Social Psychologies. International Perspectives. Buckingham: Open University Press

Unger, R. (1998) Resisting Gender. Twenty Five Years of Feminist Psychology. California, Thousand Oaks: Sage

Unger, R.K. (2001) Women as subjects, actors, and agents in the history of psychology. In R.K. Unger (Ed). Handbook of the Psychology of Women and Gender (pp.3-16) New York: John Wiley

Unger, R.K., \& Crawford, M. (1996) Women and Gender: A Feminist Psychology: Second edition. New York: McGraw-Hill

Ussher, J.M. (1989) Acknowledging gender issues in clinical psychology: Reevaluating the position of women. Clinical Psychology Forum, 22: 11-14

Ussher, J.M. (1990) Choosing psychology or not throwing the baby out with the bathwater. In E. Burman (Ed). Feminists and Psychological Practice (pp. 47-61). London: Sage

Ussher, J.M. (1991) Women's Madness. Hertfordshire: Harvester Wheatsheaf

Ussher, J.M. (1992) Science sexing psychology: Positivist science and gender bias in clinical psychology. In J.M. Ussher \& P. Nicolson (Eds). Gender Issues in Clinical Psychology (pp. 39-67). London: Routledge

Ussher, J.M. (1997a) Fantasies of Femininity: Reframing the Boundaries of Sex. London: Penguin

Ussher, J.M. (1997b) Body talk: The Material and Discursive Regulation of Sexuality, Madness and Reproduction. London: Routledge

Ussher, J.M. (1999) Eclecticism and methodological pluralism. The way forward for feminist research. Psychology of Women Quarterly, 23(1): 41- 46

Ussher, J.M. (2000a) Critical psychology in the mainstream: A struggle for survival. In T. Sloan (Ed). Critical Psychology: Voices for Change (pp. 6-20). Hampshire: MacMillan Press

Ussher, J.M. (2000b) Women's madness: A Material-discursive-intrapsychic approach. In D. Fee (Ed). Pathology and the Postmodern. Mental Illness as Discourse and Experience (pp. 207-230). London: Sage

Ussher, J.M. (2000c) (Ed) Women's Health. Contemporary International Perspectives. London, BPS Books

Ussher, J.M., \& Nicholson, P. (Eds) (1992) Gender Issues in Clinical Psychology. London: Routledge 
Vazquez, C.I. (1991) A training program for Hispanic psychologists at New York University - Belevue Hospital Center. In H.G. Myers, P. Wohlford, L.P. Guzman, \& R.J. Echemendia (Eds). Ethnic Minority Perspectives on Clinical Training and Services in Psychology (pp.143-148). Washington, DC: American Psychological Association

Vetere, A. Working with families. In J.M. Ussher \& P. Nicolson (Eds). Gender Issues in Clinical Psychology (pp. 129-152). London: Routledge

Vickers, E. (1991) Looking back: Reflections on clinical psychology training. Feminism and Psychology, 1(1): 69-73

Waldegrave, C. (1993) The challenges of culture to psychology and post-modern thinking. In L.W. Nikora (Ed). Cultural Justice and Ethics. Proceedings of a symposium held at the Annual Conference of the New Zealand Psychological Society. Victoria University of Wellington, 23-24 August, 1993

Wagner, I. (1994) Connecting Communities of Practice. Feminism, Science, and Technology. Women's Studies International Forum, 17(2-3): 257-265

Walkerdine, V. (1986) Post-structuralist theoy and everyday social practices: the family and the school. In S. Wilkinson (Ed) Feminist Social Psychology. Developing Theory and Practice (pp. 57-76). Milton Keynes: Open University Press

Walkerdine, V. (Ed) (1996a) Subjectivity and social class: New directions for feminist psychology. Feminism \& Psychology, 6(3): 355-360

Walkerdine, V. (1996b) Working class women: Psychological and social aspects of survival. In S. Wilkinson (Ed). Feminist Social Psychologies. International Perspectives (pp.145-162). Buckingham: Open University Press

Walkerdine, V. (1997) Post-modernity, subjectivity and the media. In T. Ibàñez \& L. İniguez (Eds). Critical Social Psychology (pp. 169-177). London: Sage

Weatherall, A. (2002) Gender, Language and Discourse. London: Routledge

Weber, L. (1998) On conceptual frameworks for understanding race, class, gender and sexuality. Psychology of Women Quarterly, 22: 13-32

West, C.M. (2002) Black battered women: New directions for research and black feminist theory. In L.H. Collins., M.R. Dunlap., \& J.C. Chrisler (Eds) Charting a New Course for Feminist Psychology (pp. 216-237). Westport, CT: Praeger Publishers

Wetherell, M., \& Potter, J. (1992) Mapping the Language of Racism: Discourse and the Legitimation of Exploitation. London: Harvester Wheatsheaf 
Whelehan, I. (1995) Modern Feminist Thought: From Second Wave to 'PostFeminism'. Edinburgh: Edinburgh University Press

Whitbeck, L., McMorris, B.J., Hoyt, D.R., Stubben, J.E., \& Lafromboise, T. (2002) Perceived discrimination, traditional practices, and depressive symptoms among American Indians in the Upper Midwest. Journal of Health \& Social Behavior, 43(4): 4000-420

White, J.W., \& Sorenson, S.B. (1992) Adult sexual assault. Journal of Social Issues, 48(1): $1-8$

Wilkinson, S. (Ed) (1986) Feminist Social Psychology: Developing Theory and Practice. Milton Keynes: Open University Press

Wilkinson, S. (Ed) (1994) Special feature: 'Women and madness: A reappraisal'. Feminism \& Psychology: An International Journal, 4(2): 261-306

Wilkinson, S. (Ed) (1996) Feminist Social Psychologies. International Perspectives. Buckingham: Open University Press

Wilkinson, S. (1997a) Feminism and psychology. In D. Fox \& I. Prilleltensky (Eds). Critical Psychology: An Introduction (pp. 247-264). London: Sage

Wilkinson, S. (1997b) Prioritizing the political: Feminist psychology. In T. Ibanez \& L. Iniguez (Eds). Critical Psychology. An Introduction (pp. 178-194). London: Sage

Wilkinson, S. (1997c) Still seeking transformation: Feminist challenges to psychology. In L. Stanley (Ed). Knowing Feminisms (pp. 97-108). London: Sage

Wilkinson, S. (2001) Theoretical perspectives on women and gender. In R.K. Unger (Ed). Handbook of the Psychology of Women and Gender (pp.17-28). New York: John Wiley

Wilkinson, S., \& Burns, J. (1990) Women organizing within psychology: Two accounts. In E. Burman (Ed). Feminists and Psychological Practice (pp. 140-162). London: Sage

Wilkinson, S., \& Kitzinger, C. (Eds) (1993) Heterosexuality: A Feminism and Psychology Reader. London: Sage

Wilkinson, S., \& Kitzinger, C. (Eds) (1995) Feminism and Discourse. Psychological Perspectives. London: Sage

Wilkinson, S., \& Kitzinger, C. (Eds) (1996) Representing the Other: A Feminism \& Psychology Reader. London: Sage

Williams, J., \& Watson, G. (1991a) Clinical psychology training: Training in oppression? Feminism \& Psychology, 1(1): 55-57 
Williams, J., \& Watson, G. (1991b) Sexual inequality and clinical psychology training in Britain. Survey Report. Feminism \& Psychology, 1(1): 78-88

Williams, J., \& Watson, G. (1991c) Sexual inequality and clinical psychology training in Britain. Workshop Report. Feminism \& Psychology, 1(1): 101-109

Worrell, J. (2000) Feminism and psychology: Revolution or evolution? The Annals of the American Academy of Political Science, 571: 183-196

Worrell, J., \& Etaugh, C. (1994) Transforming theory and research with women. Themes and variations. Psychology of Women Quarterly, 18(4): 443-450

Worell, J., \& N.G. Johnson. (1997a) Introduction. Creating the future: Process and promise in feminist practice. Worell, J. \& Johnson, N.G. (Eds) Shaping the Future of Feminist Psychology. Education, Research and Practice (pp. 1-14). Washington, DC: American Psychological Association

Worell, J., \& Johnson, N.G. (Eds) (1997b) Shaping the Future of Feminist Psychology. Education, Research and Practice. Washington, DC: American Psychological Association

World Health Organisation (1992) The ICD-10 Classification of Mental and Behavioral Disorders. Geneva: World Health Organisation

Yensen, H., \& McCreanor, T. (1993) Pakeha students and a pro-Treaty analysis: Teaching issues in a Diploma of Clinical Psychology Programme. In L.W. Nikora (Ed). Cultural Justice and Ethics (pp. 44-46). Proceedings of a Symposium held at the Annual Conference of the New Zealand Psychological Society, Victoria University of Wellington, 23-24 August, 1993

Young, W., Morris, A., Cameron, N., \& Haslett, S. (1997) New Zealand National Survey of Crime Victims 1996. Wellington: Victimisation Survey Committee from Victoria Link Ltd \& AC Nielsen-McNair

Yusupoff, L., Haddock, G., Sellwood, W., \& Tarrier, N. (1996) Cognitive-behavioural therapy for hallucinations and delusions: current practices and future trends. In P.M. Salkovskis (Ed). Trends in Cognitive and Behavioural Therapies (pp. 133-146). West Sussex: John Wiley \& Sons 


\title{
Appendix A
}

\author{
Heather Barnett \\ Women's Studies Department \\ VICTORIA UNIVERSITY OF WELLINGTON \\ P.O Box 600, WELLINGTON PH: (04) 472-1000 Ext 8933 \\ E-Mail: Heather.Barnett@vuw.ac.nz Fax: (04) 495-5046
}

\section{Research Participant Consent Form}

The purpose of this consent form is to ensure that you agree to participate in this research in accordance with the conditions specified on this form and to give you the opportunity to amend or add conditions if you wish to. Your consent covers thesis publication as well as other written material or oral presentations that may result from it. The research has been approved by the Human Ethics Committee of Victoria University, Wellington, 1996.

This $\mathrm{PhD}$ research aims to provide an analysis of the training of clinical psychologists in Aotearoa (NZ) with specific regard to how issues of gender, power and inequality are understood and applied within clinical psychology. Your views as (student/graduate/academic/practicing) clinical psychologists are therefore important in providing understanding about these issues in the NZ context.

\section{CONFIDENTIALITY}

You are assured complete confidentiality (unless you indicate otherwise, as below). What you write or say in the course of the research will remain entrusted to myself or co-opted interviewers (should you elect an interview). Any transcribing, computer input or other work that may be undertaken by people other than myself will utilise pseudonyms.

\section{ANONYMITY}

To ensure that you are unable to be identified in the thesis report or related publications, you will be allocated a pseudonym at the beginning of the research (unless you state otherwise).

If you elect an interview as well as completing a questionnaire, a second opportunity to consider your position on confidentiality and anonymity will be provided at the end of the interview.

In the thesis report and any related publications it would be useful to report some quotes and refer to issues raised by participants that may have some sensitivity.

\section{Please TICK the relevant box below:}

a) I agree to have quotes reported and to be identified I agree to have quotes reported WITHOUT being identified I do NOT agree to have quotes reported

b) I agree to have issues I raise reported and to be identified I agree to have issues I raise renorted WITHOUT being identified 


\section{INTERVIEWS}

All interviews will be transcribed and tapes wiped after transcriptions have occurred. Would you please select the option you want regarding your transcript by TICKING the relevant box below:

a) please DO NOT send me a copy of my transcript

b) please send me a copy of my transcript for my own interest

c) please send me a copy of my transcript to review, amend and return to the researcher

\section{PARTICIPANT WITHDRAWAL}

I may withdraw from the research at any time up until one month after the final date questionnaires are due back (as noted in the cover letter) or up until one month after my interview. If I withdraw from the research I will notify the researcher. Please tick the relevant box below regarding your questionnaire and/or interview transcript. (Those that aren't returned will be destroyed.)

In the event that I withdraw from the research please:

a) return my questionnaire

b) return my interview transcript

c) do not return either my questionnaire or interview transcript

\section{RESEARCH INFORMATION AND FEEDBACK}

The researcher has provided me with preliminary information about this research and I may seek additional information as long as it does not breach confidentiality nor impinge on the rights of other participants.

A summary of the research report will be sent to me at completion of the thesis.

I WISH TO HAVE THE FOLLOWING CONDITION/S AMENDED OR ADDED TO THE CONSENT FORM:

If any amendments or additions I make are problematic to the research, the researcher will discuss them with me so that some mutually acceptable solution is agreed to. , date .../../96, agree to the conditions specified in this consent form. 


\title{
Appendix B
}

\author{
Heather Barnett \\ Women's Studies Department \\ VICTORIA UNIVERSITY OF WELLINGTON \\ P.O Box 600, WELLINGTON PH: (04)472-1000 Ext 8934 \\ E-mail: Heather.Barnett@vuw.ac.nz Fax: (04) 495-5046 \\ INTERVIEW CONSENT FORM \\ 1997
}

I understand that Heather Barnett is a doctoral student in the Women's Studies

Department at Victoria University, Wellington. She is undertaking research concerning gender and the training of clinical psychologists and is conducting interviews about this topic with clinical psychology students and staff as part of her doctoral research.

NAME (Please print clearly)

\section{UNIVERSITY}

ADDRESS

\section{PHONE CONTACT}

\section{E-MAIL}

I understand that:

a) I have full control of the interview and may withdraw at any time

b) the interview will only be tape-recorded and transcribed if I agree (Otherwise notes will be taken by the interviewer)

c) the interview will only be tape-recorded and transcribed under conditions which I have indicated over the page

d) I have the right to see, revise and amend the transcript (or any notes taken during the interview) as indicated over the page

e) I have read, signed and returned the Research participant Consent Form which was sent to me at the time I received the research questionnaire

\section{CONDITIONS}

Please tick beside the statements you agree with:

1. I agree to the interview being audio-taped

2. I do not agree to the interview being audio-taped (Please go to 7 below) 
3. I agree to the use of my real name during audio-taping the interview (A pseudonym will be used on the transcript)

4. I do not agree to the use of my real name during audio-taping the interview

5. I understand that the interview tape will only be listened to by Heather Barnett or a transcriber who has signed a contract regarding confidentiality and anonymity

6. After the interview, I require that the audio-tape be:

a) returned to me

b) erased by the interviewer

c) archived

7. After the interview, I require that a copy of the transcript/notes be:

a) returned to me for my own interest

b) returned to me to review, amend and return to the researcher

c) destroyed by the interviewer at the completion of the research

\section{SIGNED}

DATE 
Appendix C

\title{
CLINICAL PSYCHOLOGY TRAINING PROGRAMMES
}

\author{
1996
}

\section{GENDER RESEARCH}

\section{QUESTIONNAIRE FOR STUDENTS}

Researcher:

Heather Barnett

Women's Studies Department Victoria University WELLINGTON

Ph: (04) 472-1000 ext 8933

E-MAIL: Heather.Barnett@VUW.AC.NZ 


\section{QUESTIONNAIRE INFORMATION}

The following questions are designed to find out about your views on issues relating to gender in the training of clinical psychologists. What you have to say about these issues is important for the development of clinical psychology.

I hope you will support this study by completing the questionnaire and returning it as soon as you can.

Please skim read the questionnaire before you start answering questions then try to answer as many questions as you can. If you have some ideas that don't quite fit how a question is phrased please jot your ideas down beside the given question. If you don't know or are unsure please say so.

What you write in this questionnaire is confidential and strictly governed by the agreement contained in the attached Research Participant Consent Form. Please remember to complete and sign the Research Participant Consent Form when you return your questionnaire.

I would be grateful if you would fill out this questionnaire and return it to Victoria University by 18 October, 1996. A stamped, addressed envelope is enclosed for your convenience. Thank you for taking the time to participate in this research.

If you have any queries please feel free to contact me:

Name Heather Barnett

Phone (04) $472-1000 \quad$ Ext 8933

(04) 384-9885 Call minder

Messages Janey Bedggood

(Women's Studies Secretary)

E-mail Heather.Barnett@vuw.ac.nz

Fax (04) 495-5046. 


\section{CLARIFICATION OF TERMS USED IN THIS QUESTIONNAIRE}

\section{1. "Gender"}

The concept of "gender" has many meanings. This research is concerned with the ways in which gender is thought about and conceptualised within clinical psychology.

For the purposes of this questionnaire "gender" should be taken to include:

a) the social categories men and women

b) the concepts of masculinity and femininity

c) the social and behavioural aspects associated with being male or female

d) gender relations, which refers to the hierarchical social organisation between the groups men and women and incorporates notions of power status, social position and material resources

e) the interaction of gender with other social categories such as class, race, ethnicity, ability, sexuality age and so on.

Please try and apply this definition of "gender" in answering the Questionnaire.

\section{2. "Training programme" or "Training"}

The term "training programme" or "training" refers to any training you receive through your university's clinical psychology post-graduate training programme. It may include courses, workshops, seminars or other forums in which training is provided but it must be part of, or a directive of, the Diploma/Applied Masters programme.

"Training programme" does not refer to undergraduate university courses or to education you seek independently. 


\section{A. EDUCATION ABOUT GENDER ISSUES IN YOUR CLINICAL PSYCHOLOGY TRAINING PROGRAMME}

1. Does your clinical psychology training programme include any education about gender issues (For example sexual abuse domestic violence why diagnostic rates for depression are higher for women than men).

PLEASE TICK $(\sqrt{ })$ THE BOX WHICH APPLIES:

NO

YES

2. Does your psychology department offer any courses in gender issues and psychology PLEASE TICK $(\sqrt{ })$ THE BOX WHICH APPLIES:

NO

YES

DON'T KNOW

3. If a psychology and gender course (graduate or undergraduate) was available in your psychology department or in association with your psychology department would you take this course?

PLEASE TICK $(\sqrt{ })$ THE BOX WHICH APPLIES:

$\mathrm{NO}$

YES

POSSIBLY

4. Why would/wouldn't you take a course of this kind?

(e.g interested/not interested; have taken similar courses in other depts; cost; time etc)

IF YOU ANSWERED NO TO QUESTION 1 PLEASE GO TO QUESTION $=>\mathbf{1 2}$

IF YOU ANSWERED YES TO QUESTION 1 PLEASE GO TO QUESTION $=>\mathbf{5}$ 
5. How is education about gender included in your training programme?

PLEASE TICK $(\sqrt{ })$ ALL BOXES WHICH APPLY:

Integrated throughout one or more courses

Included as a specific unit within one or more courses

Included as an assignment topic within one or more courses

Mentioned in all courses

Mentioned in some courses

Mentioned in one course only

Compulsory

Optional

Other: (PLEASE SPECIFY BELOW)

6. What proportion of total class time (approx) in your training programme has been allocated to education about gender to date?

PLEASE TICK $(\sqrt{ })$ THE BOX WHICH APPLIES:

Less than $5 \%$

$5-10 \%$

$10-15 \%$

$15-20 \%$

$20-25 \%$

More than 25\%

PLEASE SPECIFY BELOW: 
7. Which areas of your training programme include education about gender issues (For example is it included in adult psychological health, child psychological health, family, sexuality, assessment, aetiology, intervention, therapy, research etc).

PLEASE SPECIFY BELOW:

\section{B. WHAT IS INCLUDED ABOUT GENDER IN YOUR CLINICAL PSYCHOLOGY TRAINING PROGRAMME}

8. Please give some examples of education about gender issues included in your training. (For example sexual inequality, sexism and racism, gender biased assumptions in assessment).

PLEASE SPECIFY BELOW:

9. Does education about gender issues in your training programme include attention to issues primarily relevant to women? (For example rape, postnatal depression, domestic violence, social isolation, "superwoman syndrome")

PLEASE TICK $(\sqrt{ })$ THE BOX WHICH APPLIES:

NO

YES
GO TO QUESTION =;:10

PLEASE SPECIFY BELOW: 
10. Does education about gender issues in your training programme include attention to any power differences between the groups men and women? (e.g. financial inequality following separation; sexual violence; one parent families)

PLEASE TICK $(\sqrt{ })$ THE BOX WHICH APPLIES:

NO

GO TO QUESTION $=>11$

YES

PLEASE SPECIFY BELOW:

The research definition of 'gender' incorporates notions of power relating to different social groups. Education about gender can therefore include education relating to Maori women, Pacific Islands women, lesbians, women with disabilities, economically disadvantaged women, older/younger women and other groups of women.

11. In your training programme's education about gender is attention given to any of the groups of women referred to above?

PLEASE TICK $(\sqrt{ })$ THE BOX WHICH APPLIES:

NO

GO TO QUESTION $=12$

YES

OTHER

PLEASE EXPLAIN: 
12a. How adequately do you consider your training programme provides education about gender issues?

PLEASE CIRCLE THE NUMBER THAT BEST INDICATES YOUR REACTION:

\section{Extremely}

inadequate

1
Extremely

adequate

12b. PLEASE EXPLAIN:

13. Do you think there are any barriers to the inclusion of education about gender in your training programme?

PLEASE TICK $(\sqrt{ })$ THE BOX WHICH APPLIES:

$\mathrm{NO}$

DON'T KNOW

YES
GO TO QUESTION $\Rightarrow 14$

GO TO QUESTION $=>14$

PLEASE SPECIFY BELOW: 


\section{YOUR PERCEPTIONS OF POWER AS AN INTEGRAL COMPONENT OF GENDER}

14. Some people perceive sexual violence as a misuse of power by men over women. What do you think of this view?

PLEASE EXPLAIN:

15. Why do you think some women who have been sexually violated don't disclose this experience?

PLEASE EXPLAIN:

16. Do you think that domestic violence is primarily male violence towards women? PLEASE EXPLAIN:

Please continue - you're doing well! 
17. What factors do you think contribute to domestic violence? PLEASE EXPLAIN:

18. What difficulties sometimes get in the way of women leaving violent relationships?

\section{PLEASE EXPLAIN:}

Some people consider that women's social, economic and political position in this society means women have less power and status than men.

For example women are more likely than men to raise children alone, be poor, to have been sexually abused or violated, to have been subjected to domestic violence and so on.

Equally women are less likely than men to hold positions of power or decision making in political, economic, educational, employment and health arenas.

19. Do you agree/disagree with this view?

\section{PLEASE CIRCLE THE NUMBER BELOW THAT BEST INDICATES YOUR RESPONSE}

Strongly

Agree

1
Strongly

Disagree

5 
20. What bearing do you think women's socio-political position in this society has on women's psychological health?

PLEASE EXPLAIN:

21. How adequately do you think your training programme addresses the impact of women's position in this society on women's well-being?

Extremely

Inadequate

1

2

\author{
Extremely \\ Adequate
}

\section{TOPICS INCLUDED IN YOUR CLINICAL TRAINING PROGRAMME}

22. What specific topics (e.g depression, phobias, addictions, paedophilia) are allocated most time in your clinical psychology training programme? (Please list 5 topics that are allocated most time).

23a. Do you think there are some topics that are central to understanding women's lives that are important in the training of clinical psychologists?

PLEASE TICK $(\sqrt{ })$ THE BOX WHICH APPLIES: 
23b. Why do you think these topics are important?

PLEASE EXPLAIN:

$23 \mathrm{c}$. What priority do you consider these topics, overall, are currently given in your training programme?

PLEASE INDICATE WHAT PRIORITY IS GIVEN TO THESE TOPICS BY CIRCLING THE NUMBER WHICH APPLIES:

$\begin{array}{lllll}\begin{array}{l}\text { Lowest } \\ \text { priority }\end{array} & & & \begin{array}{l}\text { Highest } \\ \text { priority }\end{array} \\ 1 & 2 & 3 & 4 & 5\end{array}$

\section{E. YOUR PERCEPTIONS OF THE IMPORTANCE OF GENDER ISSUES IN CLINICAL PSYCHOLOGY}

24. How would you rate the importance of education about gender in the training of clinical psychologists?

PLEASE CIRCLE THE NUMBER WHICH APPLIES:

\section{Extremely} unimportant 1
2
Extremely important 5

Please continue - you have almost finished 
25. Do you consider that gender issues are political and have little relevance to clinical psychology?

PLEASE TICK $(\sqrt{ })$ THE BOX WHICH APPLIES:

NO

YES

PLEASE EXPLAIN:

26. Are there any other comments you would like to make concerning the place of gender issues in the training of clinical psychologists?

\section{F. DEMOGRAPHICS}

Finally, would you please answer the following questions about yourself.

\section{PLEASE TICK ( . / THE BOX WHICH APPLIES:}

27. Female

Male 
28. Which university are you attending. (You may be enrolled elsewhere).

PLEASE TICK $(\sqrt{ })$ THE BOX WHICH APPLIES:

Auckland

Waikato

Massey

Victoria

Canterbury

Otago

29. In what year of the Diploma in Clinical Psychology/Masters (Applied) are you currently enrolled.

PLEASE TICK $(\sqrt{ })$ THE BOX WHICH APPLIES:

Enrolled year 1

Enrolled year 2

Enrolled year 3

Other

PLEASE EXPLAIN:

30. In what particular area of clinical psychology do you hope to work in the future? PLEASE SPECIFY BELOW:

THAT'S THE END OF THE QUESTIONNAIRE

THANKYOU FOR PERSEVERING! 
NOW JUST COMPLETE THE INTERVIEW PARTICIPATION FORM OVER THE PAGE AND RETURN IT WITH YOUR QUESTIONNAIRE IN THE STAMPED ADDRESSED ENVELOPE PROVIDED

\section{THANK YOU}

FOR PARTICIPATING IN THIS RESEARCH 
Appendix D

\section{CLINICAL PSYCHOLOGY TRAINING PROGRAMMES}

1996

\section{GENDER RESEARCH}

\section{QUESTIONNAIRE FOR STAFF}

Researcher:

Heather Barnett

Women's Studies Department

Victoria University

WELLINGTON

Ph: (04) 472-1000 ext 8933

E-mail: Heather.Barnett@vuw.ac.nz 


\section{QUESTIONNAIRE INFORMATION}

The following questions are designed to find out about your views on issues relating to gender in the training of clinical psychologists. What you have to say about these issues is important for the development of clinical psychology.

WHAT TO DO:

1. READ AND COMPLETE THE QUESTIONNAIRE

Answer as many questions as you can. If you have some ideas that don't quite fit how a question is phrased please jot them down beside the given question. If you don't know or are unsure please say so.

PLEASE REMEMBER TO REFER TO YOUR COURSE AND TEACHING EXPERIENCES IN 1996 WHEN ANSWERING THE QUESTIONNAIRE.

\section{READ AND SIGN THE RESEARCH PARTICIPANT CONSENT FORM} What you write in this questionnaire is confidential and strictly governed by the agreement contained in the attached Research Participant Consent Form.

\section{COMPLETE THE INTERVIEW PARTICIPATION FORM}

At the back of the questionnaire is an Interview Participation form. Please indicate whether you agree to being interviewed. Times for interviews will be arranged to fit in with your timetable.

\section{ENCLOSE COURSE OUTLINES AND READING LISTS}

Would you please also forward a copy of course outlines and reading lists for each of the courses you teach in the Diploma of Clinical Psychology.

5. RETURN THE QUESTIONNAIRE BY APRIL 18, 1997.

I would be grateful if you would fill out the questionnaire and return it to Victoria University by April 18, 1997. A stamped, addressed envelope is enclosed for your convenience.

Thank you for taking the time to participate in this research.

If you have any queries please feel free to contact me:

$\begin{array}{ll}\text { Name } & \text { Heather Barnett } \\ \text { Phone } & \begin{array}{l}\text { (04) 472-1000 Ext 8933 } \\ \text { (04) 387-1728 Callminder }\end{array} \\ \text { Messages } & \begin{array}{l}\text { Janey Bedggood } \\ \text { (Women's Studies Secretary) }\end{array} \\ \text { E-mail } & \begin{array}{l}\text { Heather.Barnett@vuw.ac.nz } \\ \text { Fax }\end{array} \\ & \text { (04) 495-5046 }\end{array}$


6. Are any of the following authors or publications included in reading lists or references used in your clinical psychology training programme?

PLEASE TICK BESIDE THOSE WHICH APPLY:

Feminism and Psychology Journal

Erica Burman

Psychology of Women Quarterly

Mason Durie

Charles Waldegrave

Jeanne Marecek

Linda Waimarie Nikora

Celia Kitzinger

Kum Kum Bhavnani

Paula Nicolson

Linda Nicolson

Sue Wilkinson

David Pilgrim

Jane Ussher

10. Are "experts" or people with specialist knowledge consulted to provide input to the clinical psychology programme at your university? (For example: Local iwi, sexual abuse counsellors, Rape Crisis, Refuge, lesbians, Poverty Action)

13. If students advocate for the inclusion of gender issues in the clinical training programme how do you think lecturers/course co-ordinators respond to such requests?

PLEASE EXPLAIN:

14. Who is responsible for overseeing curriculum development of the clinical psychology training programme at your university?

26. Do you consider that there is a need for a compulsory gender course in the training of clinical psychologists?

PLEASE TICK THE BOX WHICH APPLIES: 
POSSIBLY

PLEASE EXPLAIN BELOW:

27. Do you consider that there is a need to integrate gender analyses throughout all clinical psychology courses?

PLEASE TICK THE BOX WHICH APPLIES:

NO

YES

POSSIBLY

PLEASE EXPLAIN BELOW:

35. What is your staff status in the clinical psychology training programme at your university? (e.g director, professor, lecturer, senior tutor etc).

PLEASE SPECIFY:

36. In what specific areas of clinical psychology have you worked in the past? (e.g Justice, DSW, neuropsychology, acute psychiatric, child and family)

PLEASE SPECIFY BELOW: 
37. How many students are enrolled in each year of the Diploma of Clinical Psychology at your university?

Year 1

Year 2

Year 3

Other $\quad 4 \quad$ PLEASE EXPLAIN: 


\section{QUESTIONNAIRE CHECKLIST}

1. Questionnaire is complete and all relevant questions are answered

2. Research Participant Consent Form is signed

3. Interview participation sheet is signed

4. Clinical Psychology Course outlines are included

5. Questionnaire, Consent Form, Interview form, course outlines and reading lists are clasped together

6. Documents are returned in the envelope provided

\section{THANK YOU FOR PARTICIPATING}

IN THIS RESEARCH 


\title{
Appendix E
}

\author{
INTERVIEW GUIDE \\ Staff and Students
}

1. Background information concerning decision to train as clinical psychologist

2. Definition of gender

How would you define 'gender'? What are 'gender issues'? How is gender contextualised in your clinical psychology training programme?

3. Prioritisation of course content - follow-up discussion about the difference between 


\section{Future Change}

What sorts of changes would you like to see in your course relating to the issues discussed in the research? What sorts of changes would you like to see in the general training of clinical psychologists? How might you improve, reconceptualise, reshape clinical psychology to better represent and respond to the needs of (diverse groups of) women?

8. Research Process

How well has the research process worked for you (e.g first contact, letters, consents, $\mathrm{f} / \mathrm{u}$ information, interviewing)?

9. Comments

Are there any other comments you would like to make?

10. Questionnaire clarification or follow-up on response to specific question 


\section{Appendix F}

\section{INTERVIEW GUIDE \\ 'FEMINIST' CLINICAL PSYCHOLOGISTS}

1. When did you train to be a clinical psychologist?

Where did you train to be a clinical psychologist?

2. What theoretical model (or models) informs your work as a clinical psychologist?

Why do you use this particular model/these models?

3. How do you incorporate feminism(s) or feminist theoretical perspectives in your work as a clinical psychologist? Could you give some examples (e.g re depression, 'domestic' violence, sexual abuse, PTSD).

4. Do you think it is feasible to integrate feminist theoretical perspectives throughout the training of clinical psychologists? How would you go about integrating feminist theoretical perspectives in the training of clinical psychologists?

5. Based on the research survey with staff and student participants, most clinical psychology training in this country is based on a cognitive-behavioural theoretical framework.

a. How adequate or appropriate do you think a cognitive-behavioural theoretical framework is to the work of clinical psychologists?

b. Is there any clinical work for which a cognitive-behavioural model is not appropriate? Why?

c. Are there any particular issues for which this model is not appropriate? Why?

d. Are there any particular groups of people for whom this theoretical model is not appropriate? Why?

6. What theoretical model/s would you like to see incorporated into clinical psychology training? Why?

7. From your knowledge of clinical psychology training programmes and/or recent graduates of clinical psychology, how well do you think gender issues are addressed in current training? What would you like to see happening with regard to these issues?

8. How well do you think biculturalism and the Treaty of Waitangi are addressed/incorporated in current training? What would you like to see happening with regard to these issues?

9. How well do you think other issues of power are addressed e.g race, class, sexual orientation, (dis)ability? What would you like to see happening with regard to these issues?

10. Do you supervise, or have you recently supervised, any clinical psychology students? 
Are there any particular issues relating to gender or other issues of power that students don't have a good understanding of?

11. Are there any topics or issues you would particularly like to see included in the training of clinical psychologists?

12. Are there any ways you think clinical training programmes could better represent and respond to the needs of women?

13. What other changes would you like to see regarding the training of clinical psychologists?

14. Are there any other comments you would like to make?

\section{Demographic Information}

15. Age range

$25-34$

$35-44$

$45-54$

$55-64$

65 and over

16. What ethnic group do you most identify with? 